\title{
Streamlined Total Synthesis of Uncialamycin and Its Application to the Synthesis of Designed Analogues for Biological Investigations
}

K. C. Nicolaou, ${ }^{*}$ Yanping Wang, Min Lu, Debashis Mandal, Manas R. Pattanayak, Ruocheng Yu, Akshay A. Shah, Jason S. Chen, Hongjun Zhang, James J. Crawford, Laxman Pasunoori, Yam B. Poudel, Naidu S. Chowdari, Chin Pan, Ayesha Nazeer, Sanjeev Gangwar, Gregory Vite and Emmanuel N. Pitsinos

\section{TABLE OF CONTENTS}

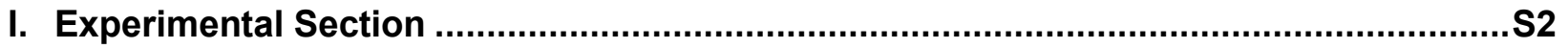

la. Enantioselective, Streamlined and Practical Total Synthesis of (+)-Uncialamycin ....S4

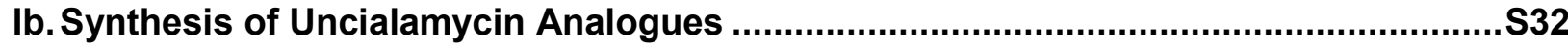

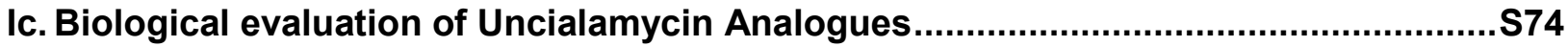

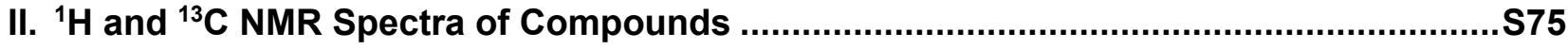

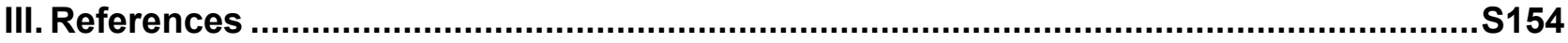




\section{Experimental Section}

General Methods: All reactions were carried out under an argon atmosphere with dry solvents under anhydrous conditions, unless otherwise noted. Dry tetrahydrofuran (THF), toluene, benzene, methanol $(\mathrm{MeOH})$, diethyl ether $\left(\mathrm{Et}_{2} \mathrm{O}\right), N, N^{\prime}$-dimethylformamide (DMF), and methylene chloride $\left(\mathrm{CH}_{2} \mathrm{Cl}_{2}\right)$ were obtained by passing commercially available predried, oxygen-free formulations through activated alumina columns. ${ }^{1}$ Reagents were purchased at the highest commercial quality and used without further purification, unless otherwise stated.

Reactions were monitored by thin-layer chromatography (TLC) carried out on $0.25 \mathrm{~mm} \mathrm{E}$. Merck silica gel plates (60F-254) and visualized under UV light and/or by appropriate staining method (an ethanolic solution of phosphomolybdic acid or cerium sulphate). Flash column chromatography ${ }^{2}$ was performed using E. Merck silica gel (60, particle size $0.04-$ $0.063 \mathrm{~mm}$ ). When stated, silica gel was deactivated by suspending in eluent with $5 \%$ added $\mathrm{H}_{2} \mathrm{O}$ for 12 hours prior to chromatographic purification.

Yields refer to chromatographically and spectroscopically ( ${ }^{1} \mathrm{H}$ NMR) homogeneous materials, unless otherwise stated. NMR spectra were recorded on Bruker DRX-500 or DRX-600 instruments and calibrated using residual undeuterated solvent $\left(\mathrm{CDCl}_{3}: \delta_{\mathrm{H}}=\right.$ 7.26 ppm, $\delta_{c}=77.0$ ppm; $\mathrm{CD}_{3} \mathrm{CN}: \delta_{H}=1.94 \mathrm{ppm}, \delta_{c}=118.3$ ppm; $d_{6}-\mathrm{DMSO}: \delta_{H}=2.50$ ppm, $\delta_{c}=39.5 \mathrm{ppm}$ ) as an internal reference. Alloc-protected compounds show ${ }^{1} \mathrm{H}$ NMR spectra for two rotamers. The chemical shifts of the peaks of the major rotamer are reported and coupling constants are given in $\mathrm{Hz}$ only for the major rotamer. In ${ }^{13} \mathrm{C}$ NMR spectra, peaks listed together in parentheses are assigned to rotamers. The following abbreviations were used to designate multiplicities: $s=$ singlet, $d=$ doublet, $t=$ triplet, $q=$ quartet, $\mathrm{m}=$ multiplet, $\mathrm{br}=$ broad .

Infrared (IR) spectra were recorded on a Perkin-Elmer 100 FT-IR spectrometer. Highresolution mass spectra (HRMS) were obtained on an Agilent ESI-TOF (time of flight) 
mass spectrometer using ESI (electrospray ionization). Optical rotations were recorded on

a Perkin-Elmer Model 343 polarimeter at $589 \mathrm{~nm}$, and are reported in units of $10^{-1}\left(\operatorname{deg} \mathrm{cm}^{2} \mathrm{~g}^{-1}\right)$. 


\section{la. Enantioselective, Streamlined and Practical Total Synthesis of (+)-Uncialamycin}

5-Hydroxy isatin (18). To a stirred solution of 5-methoxy isatin (12) $(10.0 \mathrm{~g}, 56.4 \mathrm{mmol}$,

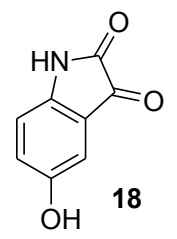

1.0 equiv) in $\mathrm{CH}_{2} \mathrm{Cl}_{2}(40 \mathrm{~mL})$ at $0{ }^{\circ} \mathrm{C}, \mathrm{BBr}_{3}(36.8 \mathrm{~g}, 147 \mathrm{mmol}, 2.6$ equiv) was added dropwise over $2 \mathrm{~h}$ under vigorous stirring at $0{ }^{\circ} \mathrm{C}$. Upon completion of addition, the ice bath was removed and the reaction mixture was stirred for another $1 \mathrm{~h}$ at room temperature, and was then diluted with $\mathrm{CH}_{2} \mathrm{Cl}_{2}(500 \mathrm{~mL})$, cooled to $0{ }^{\circ} \mathrm{C}$, quenched by careful sequential addition of solid $\mathrm{NaOH}(17.6 \mathrm{~g})$ and cold $\left(0-5{ }^{\circ} \mathrm{C}\right)$ $\mathrm{H}_{2} \mathrm{O}(60 \mathrm{~mL})$ (CAUTION, $\mathrm{HBr}$ gas evolution). The resulting mixture was washed with brine (50 $\mathrm{mL})$, and the combined aqueous phases were extracted with $\mathrm{CH}_{2} \mathrm{Cl}_{2}(50 \mathrm{~mL})$. The combined organic phases were concentrated and the residue was recrystallized from glacial acetic acid to yield isatin 18 as a dark red solid ( $8.8 \mathrm{~g}, 54 \mathrm{mmol}, 96 \%$ yield).

18: $\mathrm{R}_{f}=0.31$ (silica gel, $\mathrm{CH}_{2} \mathrm{Cl}_{2} /$ EtOAc 1:1); IR (film) $v_{\max }=3278,1720,1614,1477,1291$, 1194, 881, 822, $800 \mathrm{~cm}^{-1}$; ${ }^{1} \mathrm{H}$ NMR (400 MHz, DMSO-d 6 ): $\delta=10.75(\mathrm{~s}, 1 \mathrm{H}), 9.55(\mathrm{~s}, 1 \mathrm{H})$, 7.00 (dd, $J=8.4,2.4 \mathrm{~Hz}, 1 \mathrm{H}), 6.84(\mathrm{~d}, J=2.4 \mathrm{~Hz}, 1 \mathrm{H}), 6.74(\mathrm{~d}, J=8.4 \mathrm{~Hz}, 1 \mathrm{H}) \mathrm{ppm} ;{ }^{13} \mathrm{C}$ NMR $\left(151 \mathrm{MHz}, \mathrm{DMSO}-d_{6}\right): \delta=184.8,159.4,153.1,143.0,125.0,118.1,113.0,110.4$ ppm; HRMS (ESI-TOF): calcd for $\mathrm{C}_{8} \mathrm{H}_{6} \mathrm{NO}_{3}{ }^{+}\left[\mathrm{M}+\mathrm{H}^{+}\right]$: 164.0342 , found 164.0344 .

Ketoacid 16. Isatin 18 (6.7 g, $41 \mathrm{mmol}, 1.0$ equiv) was dissolved in aqueous $2 \mathrm{~N} \mathrm{NaOH}$

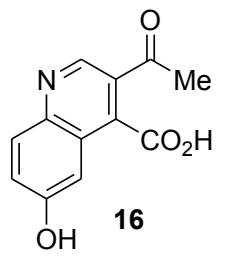

(41 mL, $82 \mathrm{mmol}, 2.0$ equiv) at room temperature, and trans-4-methoxy-3buten-2-one (17, 90\% purity, $9.1 \mathrm{~g}, 82 \mathrm{mmol}, 2.0$ equiv) was added in one portion under vigorous stirring. The reaction mixture was stirred for $15 \mathrm{~min}$, cooled to $0{ }^{\circ} \mathrm{C}$, and acidified with conc. $\mathrm{HCl}$ to $\mathrm{pH} 1$. The resulting green solid was collected by filtration, washed with ice water $(\mathrm{pH}$ of filtrate after each wash was tested, and washing continued until $\mathrm{pH} 5 \sim 6$ ), and dried under vacuum to yield ketoacid 46 as a greenish solid $(8.6 \mathrm{~g}, 37 \mathrm{mmol}, 91 \%$ yield). The crude material was used directly for the next step without further purification (crude ${ }^{1} \mathrm{H} N M R$ and ${ }^{13} \mathrm{C} N M R$ are provided). 
${ }^{1} \mathrm{H}$ NMR (600 MHz, DMSO- $\left.d_{6}\right): \delta=10.7(\mathrm{~s}, 1 \mathrm{H}), 9.04(\mathrm{~s}, 1 \mathrm{H}), 8.09(\mathrm{~d}, J=9.0 \mathrm{~Hz}, 1 \mathrm{H})$, $8.01(\mathrm{~s}, 1 \mathrm{H}), 7.98(\mathrm{~d}, J=3.0 \mathrm{~Hz}, 1 \mathrm{H}), 7.46(\mathrm{dd}, J=9.0,3.0 \mathrm{~Hz}, 1 \mathrm{H}), 1.89(\mathrm{~s}, 3 \mathrm{H}) \mathrm{ppm}$; ${ }^{13} \mathrm{C}$ NMR $\left(151 \mathrm{MHz}\right.$, DMSO-d $\left.d_{6}\right): \delta=167.5,158.5,144.1,143.8,141.0,131.4,125.8,123.5$, 123.2, 106.0, 103.9, $25.4 \mathrm{ppm}$.

Bis-DMB ketoester 20. To a stirred solution of ketoacid $16(7.7 \mathrm{~g}, 33 \mathrm{mmol}, 1.0$ equiv $)$ in

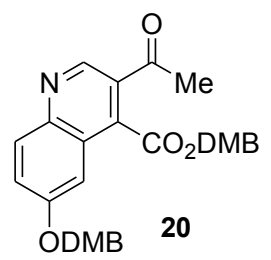
DMF (50 mL) at room temperature, was sequentially added solid $\mathrm{Cs}_{2} \mathrm{CO}_{3}$ (53.8 g, $165 \mathrm{mmol}, 5.0$ equiv), $n$-Bu4NI (1.8 g, $5.0 \mathrm{mmol}, 0.15$ equiv), followed by a solution of 3,4-dimethoxybenzyl bromide (DMBBr, $30.5 \mathrm{~g}$, $132 \mathrm{mmol}, 4.0$ equiv) in DMF (15 mL). The reaction mixture was stirred at the same temperature for $5 \mathrm{~h}$, and then partitioned between EtOAc $(300 \mathrm{~mL})$ and $\mathrm{H}_{2} \mathrm{O}(300 \mathrm{~mL})$. The aqueous layer was extracted with EtOAc $(3 \times 150 \mathrm{~mL})$, and the combined organic layers were washed with $\mathrm{H}_{2} \mathrm{O}(3 \times 150 \mathrm{~mL})$ and brine $(150 \mathrm{~mL})$, dried over $\mathrm{MgSO}_{4}$ and concentrated. The residue was passed through a short pad of Celite and eluted with hexanes/EtOAc $(v / v=1 / 2)$, concentrated and co-evaporated with toluene $(3 \times 25)$ to yield crude bis-DMB ketoester $\mathbf{2 0}$ as a dark oil. For the purpose of characterization, a small amount of material was purified to result in pure bis-DMB ketoester $\mathbf{2 0}$ as a white solid.

20: $R_{f}=0.26$ (silica gel, hexanes/EtOAc 3:7); mp $147-148{ }^{\circ} \mathrm{C}$ (hexanes/EtOAc); IR (film) $\nu_{\max }=3001,2938,2837,1731,1689,1619,1593,1562,1518,1443,1421,1369,1336$, $1264,1209,1161,1137,1027,916,833,809,766,749,732,701,680 \mathrm{~cm}^{-1} ;{ }^{1} \mathrm{H}$ NMR $(600$ $\left.\mathrm{MHz}, \mathrm{CDCl}_{3}\right): \delta=9.20(\mathrm{~s}, 1 \mathrm{H}), 8.06(\mathrm{~d}, J=9.6 \mathrm{~Hz}, 1 \mathrm{H}), 7.51(\mathrm{dd}, J=9.0,3.0 \mathrm{~Hz}, 1 \mathrm{H})$, 7.11-7.09 (m, 2 H), $7.02(\mathrm{~d}, J=3.0 \mathrm{~Hz}, 1 \mathrm{H}), 6.97-6.94(\mathrm{~m}, 2 \mathrm{H}), 6.89(\mathrm{~d}, J=7.8 \mathrm{~Hz}, 1 \mathrm{H})$, 6.79 (d, J = $7.8 \mathrm{~Hz}, 1 \mathrm{H}), 5.49$ (s, $2 \mathrm{H}), 4.71(\mathrm{~s}, 2 \mathrm{H}), 3.93(\mathrm{~s}, 3 \mathrm{H}), 3.90(\mathrm{~s}, 3 \mathrm{H}), 3.89$ (s, 3 $\mathrm{H}), 3.67$ (s, $3 \mathrm{H}), 2.74$ (s, $3 \mathrm{H}) \mathrm{ppm} ;{ }^{13} \mathrm{C}$ NMR $\left(151 \mathrm{MHz}, \mathrm{CDCl}_{3}\right): \delta=196.4,167.6,158.3$, $149.4,149.3,149.2,149.1,146.4,146.2,138.5,131.0,128.0,127.7,126.4,126.0,125.0$ 
122.2, 121.0, 112.7, 111.5, 111.1, 110.8, 103.8, 70.8, 68.1, 55.95, 55.94, 55.92, 55.6, 28.0 ppm; HRMS (ESI-TOF): calcd for $\mathrm{C}_{30} \mathrm{H}_{30} \mathrm{NO}_{8}{ }^{+}\left[\mathrm{M}+\mathrm{H}^{+}\right]$]: 532.1966, found 532.1973.

Lactone (+)-22. The crude bis-DMB ketoester 20 was dissolved in $\mathrm{CH}_{2} \mathrm{Cl}_{2}(150 \mathrm{~mL})$ and $\mathrm{Me}$ cooled to $0{ }^{\circ} \mathrm{C}$. To the stirred solution were sequentially added $(\mathrm{S}, \mathrm{S})$-Noyori
catalyst $21\left(1.3 \mathrm{~g}, 1.7 \mathrm{mmol}, 0.05\right.$ equiv) and a premixed cold $\left(0-5{ }^{\circ} \mathrm{C}\right)$ mmol, 4.3 equiv). The resulting mixture was stirred at $0{ }^{\circ} \mathrm{C}$ for $24 \mathrm{~h}$, then quenched with saturated aqueous $\mathrm{NaHCO}_{3}(150 \mathrm{~mL})$, the aqueous layer was separated and extracted with $\mathrm{CH}_{2} \mathrm{Cl}_{2}(3 \times 150 \mathrm{~mL})$, and the combined organic layers were washed with saturated aqueous $\mathrm{NaHCO}_{3}(150 \mathrm{~mL})$ and brine $(150 \mathrm{~mL})$, dried over $\mathrm{MgSO}_{4}$, and concentrated. Flash column chromatography (silica gel, $\mathrm{CH}_{2} \mathrm{Cl}_{2} / \mathrm{EtOAc} 15: 1$ to $10: 1$ ) gave a dark brown solid, which was recrystallized from EtOAc to yield lactone (+)-22 as an off-white solid (6.1 g, $27 \mathrm{mmol}, 82 \%$ yield over the two steps, $>99 \%$ ee by HPLC analysis of bis-TES ether derivative 22 derived from DIBAL-H reduction and TES protection; chiral OD-H $5 \mu$ column, $4.6 \times 250 \mathrm{~mm}$, hexanes: $i-\mathrm{PrOH} 98: 2,1 \mathrm{~mL} \mathrm{~min}^{-1}$; major enantiomer retention time $=14.37$ min, minor enantiomer retention time $=16.88 \mathrm{~min}$ ). All characterization data were in agreement with the ones previously reported for this compound. ${ }^{3 b}$

Enediyne 10: To a stirred solution of allylic alcohol $23^{4}(8.57 \mathrm{~g}, 55.5 \mathrm{mmol})$ in $\mathrm{CH}_{2} \mathrm{Cl}_{2}(300$ $\mathrm{mL})$ at $0{ }^{\circ} \mathrm{C}$ were added $4 \AA$ molecular sieves $(10 \mathrm{~g}), \mathrm{N}$-methyl-
$\mathrm{H} 10$ TMS morpholine- $\mathrm{N}$-oxide $(9.76 \mathrm{~g}, 83.3 \mathrm{mmol}, 1.5$ equiv), TPAP $(1.95 \mathrm{~g}, 5.5$ mmol, 0.1 equiv) and the resulting reaction mixture was stirred for $5 \mathrm{~min}$ at the same temperature. Following completion of the reaction, crude reaction mixture was adsorbed onto Celite ${ }^{\circledR}$ and filtered through a short pad of silica gel using hexanes as eluent. The filtrates were evaporated in vacuo to afford crude aldehyde $\mathbf{2 4}$ which was used in the next step without further purification. 
To a freshly prepared solution of LDA (66.6 mmol, 1.2 equiv) in THF $(150 \mathrm{~mL})$ at $-78{ }^{\circ} \mathrm{C}$ was added trimethylsilyldiazomethane $\left(2.0 \mathrm{M}\right.$ in $\mathrm{Et}_{2} \mathrm{O}, 33.3 \mathrm{~mL}, 66.6 \mathrm{mmol}, 1.2$ equiv $)$ and the resulting solution was stirred for $20 \mathrm{~min}$ at the same temperature. To the resulting bright yellow solution was added dropwise via cannula a pre-cooled $\left(-78^{\circ} \mathrm{C}\right)$ solution of crude aldehyde 24 in THF (100 mL). The resulting mixture was allowed to warm to $25{ }^{\circ} \mathrm{C}$ over the course of $1 \mathrm{~h}$, and then partitioned between pentane $(500 \mathrm{~mL})$ and $\mathrm{H}_{2} \mathrm{O}(500 \mathrm{~mL})$. The organic layer was washed with $\mathrm{H}_{2} \mathrm{O}(3 \times 500 \mathrm{~mL})$ and brine $(500 \mathrm{~mL})$, dried over $\mathrm{MgSO}_{4}$, and concentrated in vacuo at $0{ }^{\circ} \mathrm{C}$. The resulting crude product was purified by flash column chromatography (silica gel, pentane) to provide pure enediyne $\mathbf{1 0}$ as a solution in THF and pentane. The solution was not evaporated to dryness because of the volatility of the product. The yield was determined to be about $30 \%$ (over two steps) by ${ }^{1} \mathrm{H}$ NMR analysis of a weighed aliquot against an internal standard (a known quantity of EtOAc) to determine the percentage $(\mathrm{w} / \mathrm{w})$ of enediyne 10 present.

Dibromoalkene 25. To a stirred solution of allylic alcohol $23^{4}(857 \mathrm{mg}, 5.6 \mathrm{mmol}, 1.0$ $\underset{\mathrm{Br}}{\mathrm{Br}}=\underbrace{\text { equiv }) \text { in } \mathrm{CH}_{2} \mathrm{Cl}_{2}(30 \mathrm{~mL}) \text { at } 0{ }^{\circ} \mathrm{C} \text { was added activated } \mathrm{MnO}_{2}(4.88 \mathrm{~g}, 56.0}_{\text {TMS }}$ $25{ }^{\circ} \mathrm{C}$. Following completion of the reaction, the crude mixture was adsorbed onto Celite ${ }^{\circledR}$ and filtered through a short pad of silica gel using $\mathrm{CH}_{2} \mathrm{Cl}_{2}(3 \times 10 \mathrm{~mL})$ as an eluent to afford crude aldehyde 24 (solution in $\mathrm{CH}_{2} \mathrm{Cl}_{2}$ ) which was used in the next step without further purification.

To a stirred solution of $\mathrm{CBr}_{4}\left(2.78 \mathrm{~g}, 8.4 \mathrm{mmol}, 1.5\right.$ equiv) in $\mathrm{CH}_{2} \mathrm{Cl}_{2}$ at $0{ }^{\circ} \mathrm{C}$ was added $\mathrm{PPh}_{3}(4.43 \mathrm{~g}, 16.8 \mathrm{mmol}, 3.0$ equiv) in small portions and the so obtained solution of crude aldehyde 24 dropwise over $5 \mathrm{~min}$. The resulting reaction mixture was stirred at $0{ }^{\circ} \mathrm{C}$ for $1 \mathrm{~h}$, adsorbed onto Celite ${ }^{\circledR}$ and filtered through a short pad of silica gel using hexanes $(10 \times 3$ $\mathrm{mL})$ as an eluent. The filtrates were washed with saturated aqueous solution of $\mathrm{NaHCO}_{3}(3$ 
$\times 15 \mathrm{~mL}$ ) and brine $(15 \mathrm{~mL})$, dried over $\mathrm{MgSO}_{4}$ and concentrated in vacuo at $0{ }^{\circ} \mathrm{C}$. The crude product was purified by flash column chromatography (silica gel, pentane) providing pure dibromoalkene $25(1.28 \mathrm{~g}, 4.2 \mathrm{mmol}, 75 \%$ yield over the two steps) as a white solid.

25: $R_{f}=0.67$ (silica gel, pentane); IR (film) $v_{\max }=2935,2836,2254,1756,1605,1509$, 1460, 1263, $1213 \mathrm{~cm}^{-1} ;{ }^{1} \mathrm{H}$ NMR $\left(600 \mathrm{MHz}, \mathrm{CDCl}_{3}\right): \delta=7.46(\mathrm{~d}, J=10.7 \mathrm{~Hz}, 1 \mathrm{H}), 6.42(\mathrm{t}$, $J=10.7 \mathrm{~Hz}, 1 \mathrm{H}), 5.64(\mathrm{~d}, J=10.7 \mathrm{~Hz}, 1 \mathrm{H}), 0.22(\mathrm{~s}, 9 \mathrm{H}) \mathrm{ppm} ;{ }^{13} \mathrm{C}$ NMR $(151 \mathrm{MHz}$, $\left.\mathrm{CDCl}_{3}\right): \delta=136.5,134.6,112.7,104.3,101.5,96.1,-0.03$ ppm; HRMS (ESI-TOF): calcd for $\mathrm{C}_{9} \mathrm{H}_{13} \mathrm{Br}_{2} \mathrm{Si}^{+}\left[\mathrm{M}+\mathrm{H}^{+}\right]:$308.9127, found 308.9122.

Generation of enediyne Grignard reagent 10 a from 10 or 25 , and trapping with p-tertbutylbenzaldehyde.

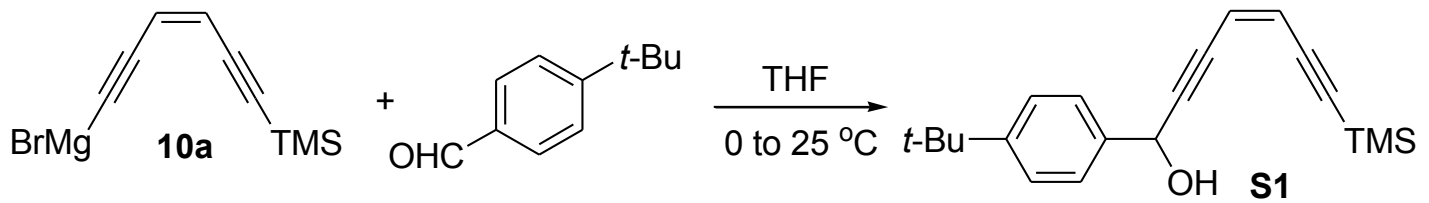

From enediyne 10. To a stirred solution of enediyne $10 \mathrm{in} \mathrm{THF}$ and pentane (ca $1.0 \mathrm{mmol}$ based on ${ }^{1} \mathrm{H}$ NMR analysis; see above) at $25{ }^{\circ} \mathrm{C}$ was added ethylmagnesium bromide (3.0 $\mathrm{M}$ in $\mathrm{Et}_{2} \mathrm{O}, 0.36 \mathrm{~mL}, 1.1 \mathrm{mmol}, 1.1$ equiv) and the resulting reaction mixture was stirred for $40 \mathrm{~min}$ at the same temperature. To the so obtained solution was added $p$-tertbutylbenzaldehyde (178 $\mathrm{mg}, 1.1 \mathrm{mmol}, 1.1$ equiv) in THF $(1 \mathrm{~mL})$ at $0{ }^{\circ} \mathrm{C}$ and the resulting mixture was stirred at $25^{\circ} \mathrm{C}$ for 15 min before it was quenched by the addition of saturated aqueous $\mathrm{NH}_{4} \mathrm{Cl}(5 \mathrm{~mL})$ and partitioned between EtOAc $(10 \mathrm{~mL})$ and $\mathrm{H}_{2} \mathrm{O}(5 \mathrm{~mL})$. The aqueous layer was extracted with EtOAc $(3 \times 5 \mathrm{~mL})$, and the combined organic layers were washed with saturated aqueous $\mathrm{NH}_{4} \mathrm{Cl}(5 \mathrm{~mL})$, saturated aqueous $\mathrm{NaHCO}_{3}(5 \mathrm{~mL})$, and brine $(5 \mathrm{~mL})$, dried over $\mathrm{MgSO}_{4}$ and concentrated in vacuo. The crude product was purified by flash column chromatography (silica gel, hexanes:EtOAc 5:1) providing 
secondary alcohol S1 (273 mg, 80\% yield of 10 a from 10 based on $100 \%$ yield of trapping) as a yellowish oil.

S1: $\mathrm{R}_{f}=0.21$ (silica gel, hexanes/EtOAc 4:1); ${ }^{1} \mathrm{H}$ NMR $\left(600 \mathrm{MHz}, \mathrm{CDCl}_{3}\right): \delta=7.45(\mathrm{~d}, \mathrm{~J}=$ $8.6 \mathrm{~Hz}, 2 \mathrm{H}), 7.41(\mathrm{~d}, J=8.6 \mathrm{~Hz}, 2 \mathrm{H}), 6.08(\mathrm{dd}, J=16.1,1.9 \mathrm{~Hz}, 1 \mathrm{H}), 6.02(\mathrm{~d}, J=16.1 \mathrm{~Hz}$, $1 \mathrm{H}), 5.58(\mathrm{~d}, J=5.3 \mathrm{~Hz}, 1 \mathrm{H}), 2.16(\mathrm{~d}, J=5.9 \mathrm{~Hz}, 1 \mathrm{H}), 1.32(\mathrm{~s}, 9 \mathrm{H}), 0.20(\mathrm{~s}, 9 \mathrm{H}) \mathrm{ppm}$; ${ }^{13} \mathrm{C}$ NMR $\left(151 \mathrm{MHz}, \mathrm{CDCl}_{3}\right): \delta=151.9,137.4,126.6,125.8,121.7,121.2,102.9,99.7$, 94.4, 84.7, 65.1, 34.8, 31.5, -0.1 ppm; HRMS (ESI-TOF): calcd for $\mathrm{C}_{20} \mathrm{H}_{27} \mathrm{OSi}^{+}\left[\mathrm{M}+\mathrm{H}^{+}\right]$: 311.1826, found 311.1823 .

From dibromoalkene 25. To a stirred solution of dibromoalkene 25 (308 mg, $1.0 \mathrm{mmol}$, 1.0 equiv) in THF (10 mL) at $-78{ }^{\circ} \mathrm{C}$ was added dropwise NaHMDS (1.0 $\mathrm{M}$ in THF, $1.0 \mathrm{~mL}$, $1.0 \mathrm{mmol}, 1.0$ equiv) and the resulting reaction mixture was allowed to warm to $-50{ }^{\circ} \mathrm{C}$ over $3 \mathrm{~h}$. The dry-ice/acetone bath was then switched to an ice bath and ethylmagnesium bromide (3.0 M in $\mathrm{Et}_{2} \mathrm{O}, 0.73 \mathrm{~mL}, 2.2 \mathrm{mmol}, 2.2$ equiv) was added dropwise to the above reaction mixture. The resulting mixture was then allowed to warm to $25{ }^{\circ} \mathrm{C}$ and stirred for additional 30 min. A solution of p-tert-butylbenzaldehyde (356 mg, $2.2 \mathrm{mmol}, 2.2$ equiv) in THF $(1 \mathrm{~mL})$ was then added to the so obtained reaction mixture at $0{ }^{\circ} \mathrm{C}$ and the resulting solution was stirred for $30 \mathrm{~min}$ at $25{ }^{\circ} \mathrm{C}$ before it was quenched by the addition of saturated aqueous $\mathrm{NH}_{4} \mathrm{Cl}(5 \mathrm{~mL})$ and partitioned between EtOAc $(10 \mathrm{~mL})$ and $\mathrm{H}_{2} \mathrm{O}(5 \mathrm{~mL})$. The aqueous layer was extracted with EtOAc $(3 \times 5 \mathrm{~mL})$, and the combined organic layers were washed with saturated aqueous $\mathrm{NH}_{4} \mathrm{Cl}(5 \mathrm{~mL})$, saturated aqueous $\mathrm{NaHCO}_{3}(5 \mathrm{~mL})$, and brine $(5 \mathrm{~mL})$, then dried over $\mathrm{MgSO}_{4}$ and concentrated in vacuo. The crude product was purified by flash column chromatography (silica gel, hexanes/EtOAc 5:1) providing pure secondary alcohol S1 (246 mg, 72\% yield of 10a over the two steps from 25 based on $100 \%$ yield of trapping) as a yellowish oil.

Eneyne 28. ${ }^{5}$ To a stirred suspension of $\mathrm{Pd}\left(\mathrm{PPh}_{3}\right)_{4}(347 \mathrm{mg}, 0.3 \mathrm{mmol}, 3 \mathrm{~mol} \%)$ and $\mathrm{Cul}$ (57 mg, $0.3 \mathrm{mmol}, 3 \mathrm{~mol} \%)$ in $\mathrm{Et}_{2} \mathrm{O}(50 \mathrm{~mL})$ at room temperature was added sequentially 
$n$-BuNH $2(1.61 \mathrm{~g}, 2.20 \mathrm{~mL}, 22.0 \mathrm{mmol}, 2.0$ equiv), (Z)-1,2-dichloroethylene (26, $2.03 \mathrm{~g}$, $1.74 \mathrm{~mL}, 21.0 \mathrm{mmol}, 1.9$ equiv), and triisopropylsilyl acetylene $(27,2.00 \mathrm{~g}, 2.55 \mathrm{~mL}, 11.0$ mmol, 1.0 equiv), and the reaction mixture was stirred at ambient temperature for $10 \mathrm{~h}$ (volatile materials: leave as little gas phase as possible in a sealed flask). After evaporation of the solvent, the residue was taken up with hexanes and filtered through a short pad of Celite, eluted with hexanes, and the filtrate was concentrated. Flash column chromatography (silica gel, hexanes) yielded chloro-eneyne 28 as a colourless oil (2.48 g, $10.2 \mathrm{mmol}, 93 \%$ yield).

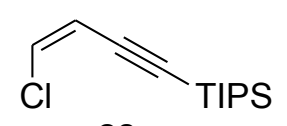

28

28: $R_{f}=0.77$ (hexanes); IR (film) $v_{\max }=2945,2154,1463,882,671 \mathrm{~cm}^{-1}$;

${ }^{1} \mathrm{H}$ NMR $\left(400 \mathrm{MHz}, \mathrm{CDCl}_{3}\right): \delta=6.40(\mathrm{~d}, J=7.6 \mathrm{~Hz}, 1 \mathrm{H}), 5.91(\mathrm{~d}, J=7.6$

$\mathrm{Hz}, 1 \mathrm{H}), 1.11$ (s, $18 \mathrm{H}), 1.09$ (s, $3 \mathrm{H}) \mathrm{ppm} ;{ }^{13} \mathrm{C} \mathrm{NMR}\left(100 \mathrm{MHz}, \mathrm{CDCl}_{3}\right): \delta=129.2,112.4$, 100.4, 100.1, 18.6, 11.2 ppm; HRMS (EI): calcd for $\mathrm{C}_{13} \mathrm{H}_{23} \mathrm{SiCl}^{+}\left[\mathrm{M}^{+}\right]$: 242.1257, found 242.1285 .

Enediyne $30 .{ }^{5}$ To a stirred suspension of $\mathrm{Pd}\left(\mathrm{PPh}_{3}\right)_{4}(142 \mathrm{mg}, 0.12 \mathrm{mmol}, 2.5 \mathrm{~mol} \%$ ) and Cul (23 mg, $0.12 \mathrm{mmol}, 2.5 \mathrm{~mol} \%)$ in $\mathrm{Et}_{2} \mathrm{O}(25 \mathrm{~mL})$ at room temperature was added sequentially $n-\mathrm{BuNH}_{2}(717 \mathrm{mg}, 1.0 \mathrm{~mL}, 9.8 \mathrm{mmol}, 2.0$ equiv), eneyne 28 (1.19 g, $4.9 \mathrm{mmol}$, 1.0 equiv), and trimethylsilyl acetylene $(29,963 \mathrm{mg}, 1.40 \mathrm{~mL}, 9.8 \mathrm{mmol}, 2.0$ equiv). The reaction mixture was stirred at ambient temperature for $12 \mathrm{~h}$ (volatile materials: leave as little gas phase as possible in a sealed flask). After evaporation of the solvent, the residue was taken up with hexanes and filtered through a short pad of Celite, eluted with hexanes, and the filtrate was concentrated. Flash column chromatography (silica gel, hexanes) yielded enediyne 30 as a colourless oil $(1.44 \mathrm{~g}, 4.7 \mathrm{mmol}, 96 \%$ yield).

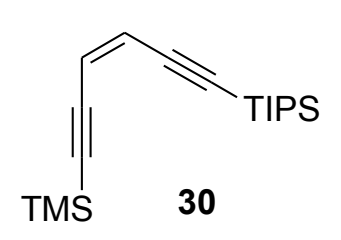

30: $R_{f}=0.48$ (hexanes); IR (film) $v_{\max }=2943,2893,2865,2154,2121$, $1571,1463,1386,1366,1250,1069,996,971,919,882,839,772,759$, 745, 699, 658, $675 \mathrm{~cm}^{-1} ;{ }^{1} \mathrm{H} \mathrm{NMR}\left(600 \mathrm{MHz}, \mathrm{CDCl}_{3}\right): \delta=5.68$ (d, $\mathrm{J}=$ $9.0 \mathrm{~Hz}, 1 \mathrm{H}), 5.66(\mathrm{~d}, J=9.0 \mathrm{~Hz}, 1 \mathrm{H}), 1.11-1.09(\mathrm{~m}, 21 \mathrm{H}), 0.19(\mathrm{~s}, 9 \mathrm{H}) \mathrm{ppm} ;{ }^{13} \mathrm{C}$ NMR 
$\left(151 \mathrm{MHz}, \mathrm{CDCl}_{3}\right): \delta=120.5,120.0,103.5,103.0,101.8,99.9,18.7,11.1,-0.2 \mathrm{ppm} ;$ HRMS (El): calcd for $\mathrm{C}_{18} \mathrm{H}_{32} \mathrm{Si}_{2}{ }^{+}\left[\mathrm{M}^{+}\right]: 304.2043$, found 304.2032 .

Enediyne $15 .{ }^{5}$ To a stirred solution of enediyne $30(1.38 \mathrm{~g}, 4.5 \mathrm{mmol}, 1.0$ equiv) in TIPS benzene/methanol $(1: 1,70 \mathrm{~mL})$ at room temperature was added $\mathrm{K}_{2} \mathrm{CO}_{3}$ (0.69 $\mathrm{g}, 5.0 \mathrm{mmol}, 1.1$ equiv), and the reaction mixture was stirred at ambient temperature for $2 \mathrm{~h}$. Water $(50 \mathrm{~mL})$ was added and the aqueous phase was extracted with hexanes $(3 \times 50 \mathrm{~mL})$. The organic phases were washed with brine (50 mL), dried over anhydrous $\mathrm{MgSO}_{4}$ and evaporated to leave enediyne 15 as a yellowish oil (1.01 g, $4.3 \mathrm{mmol}, 96 \%)$ (CAUTION: 15 slowly turned black during storage, which led to diminished yields for following steps: use freshly prepared for best yields).

15: $R_{f}=0.52$ (hexanes); IR (film) $v_{\max }=3304,2943,2891,2865,2150,1681,1569,1463$, 1385, 1366, 1241, 1049, 1017, 996, 920, 882, 745, 675, $658 \mathrm{~cm}^{-1} ;{ }^{1} \mathrm{H}$ NMR $(600 \mathrm{MHz}$, $\left.\mathrm{CDCl}_{3}\right): \delta=5.95(\mathrm{dd}, J=10.8,1.2 \mathrm{~Hz}, 1 \mathrm{H}), 5.82(\mathrm{dd}, J=10.8,2.4 \mathrm{~Hz}, 1 \mathrm{H}), 3.32(\mathrm{dd}, J=$ 2.4, $1.2 \mathrm{~Hz}, 1 \mathrm{H}), 1.10(\mathrm{~s}, 18 \mathrm{H}), 1.09(\mathrm{~s}, 3 \mathrm{H}) \mathrm{ppm} ;{ }^{13} \mathrm{C} \mathrm{NMR}\left(151 \mathrm{MHz}, \mathrm{CDCl}_{3}\right): \delta=122.0$, $119.3,103.3,100.2,84.8,80.9,18.6,11.2 \mathrm{ppm}$.

TES lactol 11. To a stirred solution of lactone $(+)-22(3.80 \mathrm{~g}, 10.4 \mathrm{mmol}, 1.0$ equiv) in

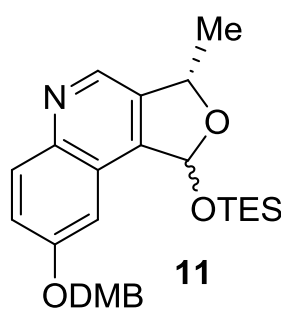
$\mathrm{CH}_{2} \mathrm{Cl}_{2}(100 \mathrm{~mL})$ at $-78{ }^{\circ} \mathrm{C}$ was slowly added DIBAL-H (1.5 $\mathrm{M}$ in toluene, $7.60 \mathrm{~mL}, 11.4 \mathrm{mmol}, 1.1$ equiv). The reaction mixture was stirred at $-78{ }^{\circ} \mathrm{C}$ for $20 \mathrm{~min}$ and then warmed to $25{ }^{\circ} \mathrm{C}$ over $40 \mathrm{~min}$. The reaction mixture was diluted with $\mathrm{CH}_{2} \mathrm{Cl}_{2}(400 \mathrm{~mL})$ and slowly poured into a saturated aqueous solution of sodium potassium tartrate $(200 \mathrm{~mL})$. The resulting mixture was vigorously stirred at $25{ }^{\circ} \mathrm{C}$ for $1 \mathrm{~h}$, then the organic layer was separated and the aqueous layer was extracted with $\mathrm{CH}_{2} \mathrm{Cl}_{2}(3 \times 200 \mathrm{~mL})$. The combined organic extracts were dried over $\mathrm{MgSO}_{4}$ and concentrated. The resultant pale yellow residue (mixture of diastereoisomeric lactols) was taken up in DMF $(120 \mathrm{~mL})$. To this mixture was added 
imidazole (1.84 g, $27.0 \mathrm{mmol}, 2.6$ equiv) and then TESCl (2.26 mL, $13.5 \mathrm{mmol}, 1.3$ equiv). The reaction mixture was stirred at $25{ }^{\circ} \mathrm{C}$ for 20 min, then partitioned between $\mathrm{Et}_{2} \mathrm{O}$ (150 $\mathrm{mL}$ ) and saturated aqueous $\mathrm{NaHCO}_{3}(150 \mathrm{~mL})$. The aqueous layer was extracted with $\mathrm{Et}_{2} \mathrm{O}(2 \times 150 \mathrm{~mL})$, and the combined organic layers were washed with $\mathrm{H}_{2} \mathrm{O}(3 \times 150 \mathrm{~mL})$ and brine $(150 \mathrm{~mL})$, dried over $\mathrm{MgSO}_{4}$, and concentrated. Flash column chromatography (silica gel, hexanes/EtOAc 2:1 to 3:2) yielded TES lactol 11 as a pale yellow oil. Although the bulk of the material thus obtained $(4.30 \mathrm{~g}, 86 \%$ yield over the two steps) was an inconsequential mixture of diastereoisomers (ca. 1:1), small amounts of pure diastereoisomers could be isolated and their characterization data are reported below.

$(-)-11$ (less polar isomer): $R_{f}=0.27$ (silica gel, hexanes/EtOAc 3:2); $[\alpha]_{D^{25}}=-82(c=0.66$, $\mathrm{CH}_{2} \mathrm{Cl}_{2}$ ); IR (film) $v_{\max }=2954,2875,1625,1604,1517,1462,1420,1373,1329,1261$, $1213,1141,1098,1077,1059,1028,995,911,856,830,788,764,749 \mathrm{~cm}^{-1} ;{ }^{1} \mathrm{H}$ NMR $\left(600 \mathrm{MHz}, \mathrm{CDCl}_{3}\right): \delta=8.69(\mathrm{~s}, 1 \mathrm{H}), 8.10(\mathrm{~d}, J=9.0 \mathrm{~Hz}, 1 \mathrm{H}), 7.45(\mathrm{dd}, J=9.0,3.0 \mathrm{~Hz}, 1$ H), $7.27(\mathrm{~d}, J=3.0 \mathrm{~Hz}, 1 \mathrm{H}), 7.03-7.01(\mathrm{~m}, 2 \mathrm{H}), 6.91-6.90(\mathrm{~m}, 2 \mathrm{H}), 5.68$ (qd, J = 6.6, 2.4 $\mathrm{Hz}, 1 \mathrm{H}), 5.11(\mathrm{~d}, J=11.4 \mathrm{~Hz}, 1 \mathrm{H}), 5.08(\mathrm{~d}, J=11.4 \mathrm{~Hz}, 1 \mathrm{H}), 3.92(\mathrm{~s}, 3 \mathrm{H}), 3.91(\mathrm{~s}, 3 \mathrm{H})$, $1.59(\mathrm{~d}, J=6.6 \mathrm{~Hz}, 3 \mathrm{H}), 1.02(\mathrm{t}, J=7.8 \mathrm{~Hz}, 9 \mathrm{H}), 0.74(\mathrm{q}, J=7.8 \mathrm{~Hz}, 6 \mathrm{H}) \mathrm{ppm} ;{ }^{13} \mathrm{C} \mathrm{NMR}$ $\left(151 \mathrm{MHz}, \mathrm{CDCl}_{3}\right) \delta=157.6,149.3,149.1,144.2,143.5,141.6,136.7,131.2,128.7,124.1$, $122.5,120.4,111.1,111.0,102.7,100.1,78.5,70.4,56.0,55.9,21.4,6.8,5.1$ ppm; HRMS (ESI-TOF): calcd for $\mathrm{C}_{27} \mathrm{H}_{36} \mathrm{NO}_{5} \mathrm{Si}^{+}\left[\mathrm{M}+\mathrm{H}^{+}\right]$: 482.2357, found 482.2367 .

$(+)-11$ (more polar isomer): $R_{f}=0.24$ (silica gel, hexanes/EtOAc 3:2); $[\alpha]_{D^{25}}=+97(c=0.37$, $\mathrm{CH}_{2} \mathrm{Cl}_{2}$ ); IR (film) $v_{\max }=2955,2876,1625,1605,1517,1462,1420,1377,1328,1266$, $1215,1160,1141,1093,1054,1027,989,910,854,829,729 \mathrm{~cm}^{-1} ;{ }^{1} \mathrm{H}$ NMR $(600 \mathrm{MHz}$, $\left.\mathrm{CDCl}_{3}\right): \delta=8.69(\mathrm{~s}, 1 \mathrm{H}), 8.11(\mathrm{~d}, J=9.0 \mathrm{~Hz}, 1 \mathrm{H}), 7.45(\mathrm{dd}, J=9.0,3.0 \mathrm{~Hz}, 1 \mathrm{H}), 7.32(\mathrm{~d}$, $J=3.0 \mathrm{~Hz}, 1 \mathrm{H}), 7.02-7.00(\mathrm{~m}, 2 \mathrm{H}), 6.90(\mathrm{~d}, J=8.4 \mathrm{~Hz}, 1 \mathrm{H}), 6.84(\mathrm{~s}, 1 \mathrm{H}), 5.46(\mathrm{q}, J=$ $6.6 \mathrm{~Hz}, 1 \mathrm{H}), 5.10(\mathrm{~d}, J=10.8 \mathrm{~Hz}, 1 \mathrm{H}), 5.07(\mathrm{~d}, J=10.8 \mathrm{~Hz}, 1 \mathrm{H}), 3.92(\mathrm{~s}, 3 \mathrm{H}), 3.91(\mathrm{~s}, 3$ 
H), $1.67(\mathrm{~d}, J=6.6 \mathrm{~Hz}, 3 \mathrm{H}), 1.06(\mathrm{t}, J=7.8 \mathrm{~Hz}, 9 \mathrm{H}), 0.79(\mathrm{q}, J=7.8 \mathrm{~Hz}, 6 \mathrm{H}) \mathrm{ppm} ;{ }^{13} \mathrm{C}$ NMR $\left(151 \mathrm{MHz}, \mathrm{CDCl}_{3}\right): \delta=157.6,149.3,149.2,143.8,143.0,141.6,136.8,131.1,128.7$, $124.3,122.6,120.4,111.1,111.0,102.6,100.6,79.5,70.3,56.0,55.9,23.6,6.9,5.1$ ppm; HRMS (ESI-TOF): calcd for $\mathrm{C}_{27} \mathrm{H}_{36} \mathrm{NO}_{5} \mathrm{Si}^{+}\left[\mathrm{M}+\mathrm{H}^{+}\right]: 482.2357$, found 482.2367 .

Enediyne (+)-30. To a stirred solution of freshly prepared enediyne 15 (11.56 g, 49.73 ODMB (+)-30 mmol, 2.0 equiv) in THF $(116 \mathrm{~mL})$ at $0{ }^{\circ} \mathrm{C}$ was added isopropylmagnesium chloride $(2.0 \mathrm{M}$ in THF, $24.9 \mathrm{~mL}, 49.8 \mathrm{mmol}, 2.0$ equiv) dropwise. The reaction mixture was stirred at $25^{\circ} \mathrm{C}$ for $2 \mathrm{~h}$. The completion of deprotonation was monitored by ${ }^{1} \mathrm{H}$ NMR after $\mathrm{D}_{2} \mathrm{O}$ quenching of an aliquot of reaction mixture. The reaction mixture was then cooled to $0{ }^{\circ} \mathrm{C}$, followed by the addition of a solution of TES-lactol 11 (1:1 diastereoisomeric mixture; $12.0 \mathrm{~g}, 24.9 \mathrm{mmol}, 1.0$ equiv) in THF (54 mL) via cannula. The resulting mixture was stirred at $0{ }^{\circ} \mathrm{C}$, followed by allyl chloroformate $\left(5.29 \mathrm{~mL}, 49.8 \mathrm{mmol}, 2.0\right.$ equiv) at $0{ }^{\circ} \mathrm{C}$. The reaction mixture was stirred at $25{ }^{\circ} \mathrm{C}$ for $30 \mathrm{~min}$, until TLC showed full consumption of 11 (silica gel, hexanes/EtOAc 3:2). The reaction mixture was then partitioned between EtOAc $(150 \mathrm{~mL})$ and $\mathrm{H}_{2} \mathrm{O}(150 \mathrm{~mL})$. The aqueous layer was extracted with EtOAc $(3 \times 150 \mathrm{~mL})$, and the combined organic layers were washed with saturated aqueous $\mathrm{NH}_{4} \mathrm{Cl}(150 \mathrm{~mL})$, saturated aqueous $\mathrm{NaHCO}_{3}(150 \mathrm{~mL})$, and brine $(150 \mathrm{~mL})$, then dried over $\mathrm{MgSO}_{4}$ and concentrated. Flash column chromatography (silica gel, hexanes/EtOAc 10:1 to 4:1) yielded enediyne (+)-30 (mixture of diastereomeric lactols, $17.8 \mathrm{~g}, 22.4 \mathrm{mmol}, 90 \%$ yield) as a pale yellow oil.

(+)-30: $\mathrm{R}_{f}=0.34$ (silica gel, hexanes/EtOAc 4:1); $[\alpha] \mathrm{D}^{25}=+95\left(c=0.58, \mathrm{CH}_{2} \mathrm{Cl}_{2}\right) ; \mathrm{IR}($ film) $V_{\max }=2944,2866,2142,1707,1608,1575,1517,1498,1463,1419,1381,1319,1299$. $1262,1238,1204,1159,1139,1108,1028,992,883,808,745,678,660 \mathrm{~cm}^{-1} ;{ }^{1} \mathrm{H}$ NMR (600 MHz, CD $\left.{ }_{3} \mathrm{CN}\right): \delta=7.53(\mathrm{br} \mathrm{s}, 1), 7.07-6.80(\mathrm{~m}, 5 \mathrm{H}), 6.52-6.39(\mathrm{~m}, 1 \mathrm{H}), 6.23-6.02$ (m, 1 H), 6.02-5.78 (m, 3 H), 5.33-4.89 (m, 5 H), 4.74-4.60 (m, 2 H), $3.80(2 \mathrm{~s}, 6 \mathrm{H}), 1.42$ 
and $1.34(2 \mathrm{~d}, J=6.6 \mathrm{~Hz}, 3 \mathrm{H}), 1.10-0.92(\mathrm{~m}, 30 \mathrm{H}), 0.77-0.62(\mathrm{~m}, 6 \mathrm{H}) \mathrm{ppm} ;{ }^{13} \mathrm{C} \mathrm{NMR}$ $\left(151 \mathrm{MHz}, \mathrm{CD}_{3} \mathrm{CN}\right): \delta=156.9,156.8,154.4,150.29,150.27,150.13,150.11,140.7,140.4$, $133.5,132.4,132.2,130.49,130.46,127.7,127.6,127.3,127.2,124.9,124.8,121.6$, $121.4,121.30,121.27,120.11,120.07,115.30,115.27,112.59,112.55,110.7,110.50$ $104.52,104.46,102.29,101.34,101.1,101.0,100.9,93.0,92.8,82.7,82.3,81.3,80.2$, $80.1,71.0,70.96,67.96,67.92,56.4,56.3,44.9,44.5,22.0,20.6,19.1,19.0,12.0,11.96$ $7.3,7.1,6.0,5.6 \mathrm{ppm}$ (Note: there are more peaks than theoretically expected due to Alloc-group rotamers as well as the presence of lactol diastereoisomers); HRMS (ESITOF): calcd for $\mathrm{C}_{46} \mathrm{H}_{64} \mathrm{NO}_{7} \mathrm{Si}_{2}{ }^{+}\left[\mathrm{M}+\mathrm{H}^{+}\right]$: 798.4216 , found 798.4217 .

Lactol (+)-31. To a stirred solution of TES-ether enediyne (+)-30 (16.7 g, $20.9 \mathrm{mmol})$ in $\mathrm{CH}_{3} \mathrm{CN}(84 \mathrm{~mL})$ and $\mathrm{H}_{2} \mathrm{O}(21 \mathrm{~mL})$ at ambient temperature was added $\mathrm{AcOH}(42 \mathrm{~mL})$. The reaction mixture was stirred at $25{ }^{\circ} \mathrm{C}$ for $2 \mathrm{~h}$, diluted with EtOAc $(100 \mathrm{~mL})$ and quenched with saturated aqueous $\mathrm{NaHCO}_{3}(100 \mathrm{~mL})$. The organic layer was separated, and the aqueous layer was extracted with EtOAc $(2 \times 100 \mathrm{~mL})$, aqueous $\mathrm{NaHCO}_{3}(150 \mathrm{~mL})$ and brine (150 mL), dried over $\mathrm{MgSO}_{4}$, and concentrated. Flash column chromatography (silica gel, hexanes/EtOAc 4:1 to 2:1) yielded lactol (+)-31 (13.0 g, $19.0 \mathrm{mmol}, 91 \%$ yield) as a yellow oil.

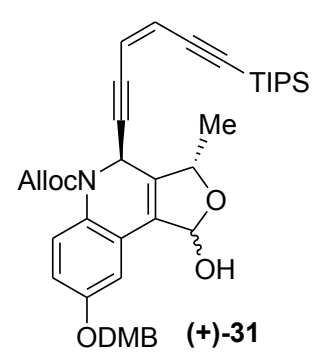

$(+)-31: R_{f}=0.37\left(\right.$ silica gel, hexanes/EtOAc 3:2); $[\alpha]_{D^{25}}=+151(c=0.76$, $\mathrm{CH}_{2} \mathrm{Cl}_{2}$ ); IR (film) $v_{\max }=3451,2942,2865,2143,1706,1608,1575$, $1517,1498,1463,1420,1381,1296,1261,1236,1204,1158,1139$, 1105, 1022, 883, 855, 809, 762, 678, $660 \mathrm{~cm}^{-1} ;{ }^{1} \mathrm{H}$ NMR $(600 \mathrm{MHz}$, $\left.\mathrm{CD}_{3} \mathrm{CN}\right): \delta=7.53(\mathrm{br} \mathrm{s}, 1 \mathrm{H}), 7.09-6.88(\mathrm{~m}, 5 \mathrm{H}), 6.26-6.15(\mathrm{~m}, 2 \mathrm{H}), 6.02-5.81(\mathrm{~m}, 3 \mathrm{H})$, 5.33-5.28 (m, $1 \mathrm{H}), 5.24-5.21(\mathrm{~m}, 1 \mathrm{H}), 5.16-4.88(\mathrm{~m}, 3 \mathrm{H}), 4.75-4.45(\mathrm{~m}, 3 \mathrm{H}), 3.804(\mathrm{~s}$, $3 \mathrm{H}), 3.798(\mathrm{~s}, 3 \mathrm{H}), 1.41$ and $1.32(2 \mathrm{~d}, J=6.6 \mathrm{~Hz}, 3 \mathrm{H}), 1.10-1.07(\mathrm{~m}, 21 \mathrm{H}) \mathrm{ppm} ;{ }^{13} \mathrm{C}$ NMR $\left(151 \mathrm{MHz}, \mathrm{CD}_{3} \mathrm{CN}\right): \delta=170.88,156.89,156.75,154.46,154.38,150.24,150.23$, $150.11,150.09,141.21,140.95,133.52,133.50,131.96,131.56,130.54,130.52,127.67$ 
$127.52,127.25,127.17,124.97,121.58,121.56,121.42,120.26,120.13,115.09,115.08$ $112.87,112.86,112.55,110.75,110.67,104.51,104.45,101.32,101.12,100.98,100.96$ $92.97,82.45,82.31,79.50,79.45,70.99,70.88,67.90,56.36,44.93,44.47,21.91,20.49$, 19.05, 19.01, 12.00, $11.95 \mathrm{ppm}$ (Note: there are more peaks than theoretically expected due to Alloc-group rotamers as well as the presence of lactol diastereoisomers); HRMS (ESI-TOF): calcd for $\mathrm{C}_{40} \mathrm{H}_{50} \mathrm{NO}_{7} \mathrm{Si}^{+}\left[\mathrm{M}+\mathrm{H}^{+}\right]$: 684.3351, found 684.3348 .

Epoxide diol (+)-32. To a stirred solution of lactol (+)-31 (12.00 g, $17.55 \mathrm{mmol}, 1.0$ equiv) in $\mathrm{MeOH}(117 \mathrm{~mL})$ at $0{ }^{\circ} \mathrm{C}$ was added portionwise $\mathrm{NaBH}_{4}(863 \mathrm{mg}, 22.8 \mathrm{mmol}, 1.3$ equiv) (CAUTION: gas evolution). The reaction mixture was stirred at $0{ }^{\circ} \mathrm{C}$ for $20 \mathrm{~min}$, at which time TLC showed full consumption of (+)-31 (silica gel, hexanes/EtOAc 1:1), then diluted with brine $(200 \mathrm{~mL})$ and extracted with $\mathrm{CH}_{2} \mathrm{Cl}_{2}(3 \times 200 \mathrm{~mL})$. The combined organic extracts were dried over $\mathrm{MgSO}_{4}$ and concentrated. A small portion of the residue thus obtained was purified by flash column chromatography (silica gel, hexanes/EtOAc 3:2 to 3:7) to allow characterization of diol (+)-31a. Otherwise, for synthetic purposes the crude residue was taken up in $\mathrm{CH}_{2} \mathrm{Cl}_{2}(100 \mathrm{~mL})$ and to the resulting solution at $0{ }^{\circ} \mathrm{C}$ was added powdered $\mathrm{NaHCO}_{3}(2.94 \mathrm{~g}, 35.0 \mathrm{mmol}, 2.0$ equiv), followed by dropwise addition of a cold $\left(0{ }^{\circ} \mathrm{C}\right.$ ) solution of $m$-CPBA ( $90 \%$ purity, $3.47 \mathrm{~g}, 18.1 \mathrm{mmol}, 1.03$ equiv) in $\mathrm{CH}_{2} \mathrm{Cl}_{2}(17 \mathrm{~mL})$ via cannula. The reaction mixture was stirred at $0{ }^{\circ} \mathrm{C}$ for $4 \mathrm{~h}(\mathrm{CAUTION}$ : at temperatures over $0{ }^{\circ} \mathrm{C}$, allyl carbamate epoxidation was observed), then quenched with saturated aqueous $\mathrm{NaHCO}_{3}(50 \mathrm{~mL})$ and saturated aqueous $\mathrm{Na}_{2} \mathrm{~S}_{2} \mathrm{O}_{3}(50 \mathrm{~mL})$. The organic layer was separated, and the aqueous layer was extracted with $\mathrm{CH}_{2} \mathrm{Cl}_{2}(2 \times 200 \mathrm{~mL})$. The combined organic layers were dried over $\mathrm{MgSO}_{4}$ and concentrated. Flash column chromatography (silica gel, hexanes/EtOAc 3:2 to 1:1) yielded epoxide diol (+)-32 (10.0 g, $14.3 \mathrm{mmol}, 81 \%$ yield over two steps) as a yellow oil. 


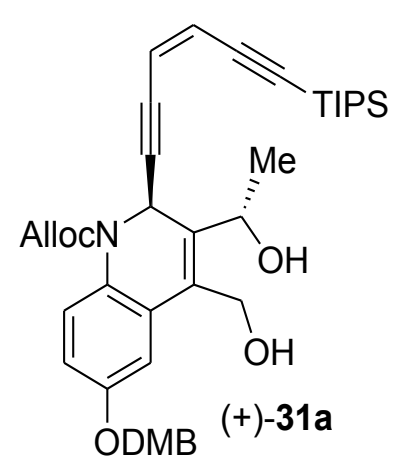

(+)-31a: $R_{f}=0.37$ (silica gel, hexanes:EtOAc 3:7); $[\alpha]_{D} 25=+83(c=$ $0.32, \mathrm{CH}_{2} \mathrm{Cl}_{2}$ ); IR (film) $v_{\max }=3421,2942,2865,2139,1707,1649$, $1608,1575,1517,1499,1463,1420,1393,1321,1284,1264,1245$, $1203,1158,1139,1059,1019,933,883,854,811,760,678,660$ $\mathrm{cm}^{-1} ;{ }^{1} \mathrm{H}$ NMR $\left(600 \mathrm{MHz}, \mathrm{CD}_{3} \mathrm{CN}\right): \delta=7.43(\mathrm{br} \mathrm{s}, 1 \mathrm{H}), 7.19(\mathrm{~d}, J=$ 3.0 Hz, $1 \mathrm{H}$ ), 7.60 (d, J = 1.8 Hz, $1 \mathrm{H}), 7.00(\mathrm{dd}, J=8.4,2.4 \mathrm{~Hz}, 1 \mathrm{H}), 6.93(\mathrm{~d}, J=8.4 \mathrm{~Hz}, 1$ H), $6.91(\mathrm{dd}, J=9.0,3.0 \mathrm{~Hz}, 1 \mathrm{H}), 6.39(\mathrm{~d}, J=1.8 \mathrm{~Hz}, 1 \mathrm{H}), 6.00-5.94(\mathrm{~m}, 1 \mathrm{H}), 5.84(\mathrm{~d}, J$ $=10.8 \mathrm{~Hz}, 1 \mathrm{H}), 5.73(\mathrm{dd}, J=10.8,1.8 \mathrm{~Hz}, 1 \mathrm{H}), 5.35-5.30(\mathrm{br} m, 1 \mathrm{H}), 5.22(\mathrm{~d}, J=10.2$ $\mathrm{Hz}, 1 \mathrm{H}), 5.03(\mathrm{~s}, 2 \mathrm{H}), 5.00$ (q, J = 6.6 Hz, $1 \mathrm{H}), 4.70(\mathrm{dd}, J=7.8,5.4 \mathrm{~Hz}, 1 \mathrm{H}), 4.61(\mathrm{dd}, J$ = 7.8, $5.4 \mathrm{~Hz}, 1 \mathrm{H}), 4.55(\mathrm{~d}, J=12.0 \mathrm{~Hz}, 1 \mathrm{H}), 4.46(\mathrm{~d}, J=12.0 \mathrm{~Hz}, 1 \mathrm{H}), 3.81(\mathrm{~s}, 3 \mathrm{H})$, $3.80(\mathrm{~s}, 3 \mathrm{H}), 3.35(\mathrm{br} \mathrm{s}, 1 \mathrm{H}), 3.01(\mathrm{br} \mathrm{s}, 1 \mathrm{H}), 1.39(\mathrm{~d}, J=6.6 \mathrm{~Hz}, 3 \mathrm{H}), 1.10(\mathrm{~s}, 21 \mathrm{H}) \mathrm{ppm}$; ${ }^{13} \mathrm{C}$ NMR $\left(151 \mathrm{MHz}, \mathrm{CD}_{3} \mathrm{CN}\right): \delta=156.8,153.6,150.2,150.1,141.7,133.6,130.72,130.69$, $129.8,128.9,126.5,121.6,120.9,120.5,114.7,112.9,112.6,112.0,104.6,100.5,96.3$ 80.8, 70.9, 67.5, 64.6, 57.0, 56.4, 44.1, 22.9, 19.1, 12.0 ppm; HRMS (ESI-TOF): calcd for $\mathrm{C}_{40} \mathrm{H}_{51} \mathrm{NO}_{7} \mathrm{SiNa}^{+}\left[\mathrm{M}+\mathrm{Na}^{+}\right]:$708.3327, found 708.3330 .

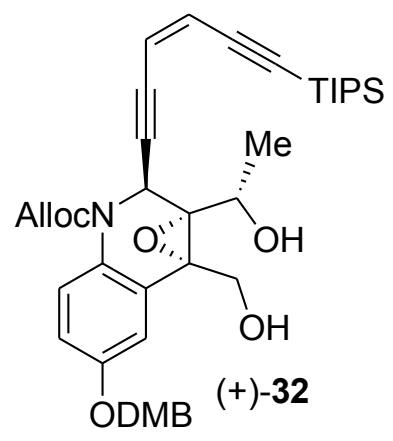

(+)-32: $R_{f}=0.29$ (silica gel, hexanes/EtOAc 4:6); $[\alpha]_{D}{ }^{25}=+200(c=$ 1.00, $\mathrm{CH}_{2} \mathrm{Cl}_{2}$ ); IR (film) $v_{\max }=3474,2942,2865,2139,1706,1611$, $1593,1505,1463,1389,1303,1284,1263,1195,1159,1139,1063$, 1026, 935, 882, 856, 817, 764, 677, $660 \mathrm{~cm}^{-1} ;{ }^{1} \mathrm{H}$ NMR $(600 \mathrm{MHz}$, $\left.\mathrm{CD}_{3} \mathrm{CN}\right): \delta=7.38(\mathrm{~d}, J=2.4 \mathrm{~Hz}, 1 \mathrm{H}), 7.20(\mathrm{br} \mathrm{s}, 1 \mathrm{H}), 7.06(\mathrm{~d}, J=$ $2.4 \mathrm{~Hz}, 1 \mathrm{H}), 7.01(\mathrm{dd}, J=7.8,1.8 \mathrm{~Hz}, 1 \mathrm{H}), 6.96(\mathrm{dd}, J=9.0,3.0 \mathrm{~Hz}, 1 \mathrm{H}), 6.93(\mathrm{~d}, J=7.8$ $\mathrm{Hz}, 1 \mathrm{H}), 6.02$ (br s, $1 \mathrm{H}), 5.88(\mathrm{br} \mathrm{s}, 1 \mathrm{H}), 5.87$ (d, J = 10.8 Hz, 1 H), $5.73(\mathrm{dd}, J=10.8,1.8$ $\mathrm{Hz}, 1 \mathrm{H}), 5.38-5.16(\mathrm{~m}, 2 \mathrm{H}), 5.03(\mathrm{~s}, 2 \mathrm{H}), 4.69-4.52(\mathrm{~m}, 2 \mathrm{H}), 4.24(\mathrm{qd}, J=7.2,4.8 \mathrm{~Hz}, 1$ H), 4.20 (dd, $J=12.6,5.4 \mathrm{~Hz}, 1 \mathrm{H}), 4.05$ (dd, $J=12.6,6.0 \mathrm{~Hz}, 1 \mathrm{H}), 3.81$ (s, $3 \mathrm{H}$ ), 3.80 (s, $3 \mathrm{H}), 3.61(\mathrm{~d}, J=4.2 \mathrm{~Hz}, 1 \mathrm{H}), 3.32(\mathrm{t}, J=5.4 \mathrm{~Hz}, 1 \mathrm{H}), 1.43(\mathrm{~d}, J=6.6 \mathrm{~Hz}, 3 \mathrm{H}), 1.10(\mathrm{~s}$, $21 \mathrm{H}) \mathrm{ppm} ;{ }^{13} \mathrm{C}$ NMR $\left(151 \mathrm{MHz}, \mathrm{CD}_{3} \mathrm{CN}\right): \delta=157.2,155.6,150.2,150.1,133.6,130.5$, 
$130.3,129.8,129.3,121.7,121.5,120.3,115.9,115.2,113.0,112.6,104.6,100.9,100.8$ 94.2, 83.0, 78.0, 71.0, 68.3, 67.5, 62.5, 60.6, 56.4, 45.3, 21.4, 19.1, 12.0 ppm; HRMS (ESI-TOF): calcd for $\mathrm{C}_{40} \mathrm{H}_{52} \mathrm{NO}_{8} \mathrm{Si}^{+}\left[\mathrm{M}+\mathrm{H}^{+}\right]:$702.3457, found 702.3460 .

Hydroxy acetate (-)-33. To a stirred solution of epoxide diol (+)-32 (11.0 g, $15.67 \mathrm{mmol}$, 1.0 equiv) in $\mathrm{CH}_{2} \mathrm{Cl}_{2}(261 \mathrm{~mL})$ at $-78{ }^{\circ} \mathrm{C}$ was added $N, N^{\prime}$-diisopropylethylamine $(5.45 \mathrm{~mL}$, $31.32 \mathrm{mmol}, 2.0$ equiv) and $\mathrm{AcCl}(1.12 \mathrm{~mL}, 15.67 \mathrm{mmol}, 1.0$ equiv). The resulting mixture was stirred at $-78{ }^{\circ} \mathrm{C}$ for $12 \mathrm{~h}$. The reaction was then quenched with saturated aqueous $\mathrm{NaHCO}_{3}(150 \mathrm{~mL})$ and extracted with $\mathrm{CH}_{2} \mathrm{Cl}_{2}(2 \times 200 \mathrm{~mL})$. The combined organic layers were dried over $\mathrm{MgSO}_{4}$ and concentrated. Flash column chromatography (silica gel, hexanes/EtOAc $3: 2$ to $1: 1)$ yielded acetate $(-)-33(10.0 \mathrm{~g}, 13.5 \mathrm{mmol}, 86 \%$ yield) as a yellow foam.

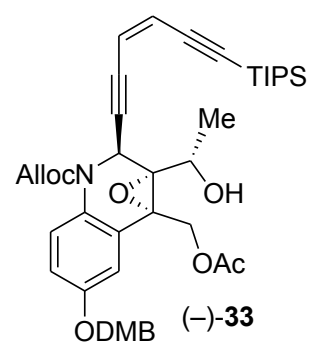

$(-)-33: R_{f}=0.35$ (silica gel, hexanes/EtOAc 1:1); $[\alpha]_{D}^{25}=-50.5(c=1.00$, $\mathrm{CH}_{2} \mathrm{Cl}_{2}$ ); IR (film) $v_{\max }=3490,2943,2865,2138,1742,1712,1649$, $1611,1593,1506,1464,1420,1384,1262,1239,1203,1159,1139$, 1070, 1028, 922, 883, 856, 813, 764, 678, $658 \mathrm{~cm}^{-1} ;{ }^{1} \mathrm{H}$ NMR $(600 \mathrm{MHz}$, $\left.\mathrm{CD}_{3} \mathrm{CN}\right): \delta=7.24(\mathrm{br} \mathrm{s}, 1 \mathrm{H}), 7.09(\mathrm{~d}, J=3.0 \mathrm{~Hz}, 1 \mathrm{H}), 7.01(\mathrm{~d}, J=2.4 \mathrm{~Hz}, 1 \mathrm{H}), 7.00-6.98$ (m, $2 \mathrm{H}), 6.93(\mathrm{~d}, J=8.4 \mathrm{~Hz}, 1 \mathrm{H}), 6.07(\mathrm{~s}, 1 \mathrm{H}), 5.89(\mathrm{br} \mathrm{s}, 1 \mathrm{H}), 5.88(\mathrm{~d}, J=10.8 \mathrm{~Hz}, 1 \mathrm{H})$, $5.73(\mathrm{dd}, J=10.8,1.8 \mathrm{~Hz}, 1 \mathrm{H}), 5.39-5.17(\mathrm{~m}, 2 \mathrm{H}), 5.02(\mathrm{~s}, 2 \mathrm{H}), 4.69-4.61(\mathrm{~m}, 3 \mathrm{H})$, 4.57-4.51 (m, $1 \mathrm{H}), 4.17$ (qd, J = 6.6, $4.2 \mathrm{~Hz}, 1 \mathrm{H}), 3.804(\mathrm{~s}, 3 \mathrm{H}), 3.800(\mathrm{~s}, 3 \mathrm{H}), 3.61(\mathrm{~d}, J$ $=5.4 \mathrm{~Hz}, 1 \mathrm{H}), 2.04(\mathrm{~s}, 3 \mathrm{H}), 1.42(\mathrm{~d}, J=7.2 \mathrm{~Hz}, 3 \mathrm{H}), 1.11(\mathrm{~s}, 21 \mathrm{H}) \mathrm{ppm} ;{ }^{13} \mathrm{C}$ NMR $(151$ $\left.\mathrm{MHz}, \mathrm{CD}_{3} \mathrm{CN}\right): \delta=171.1,157.4,155.4,150.3,150.1,133.5,130.4,130.1,129.6,128.8$ 121.6, 121.4, 120.2, 115.9, 115.0, 112.8, 112.6, 104.5, 101.0, 100.9, 93.8, 83.4, 78.4, 71.1, 68.1, 67.6, 62.3, 60.8, 56.4, 44.9, 21.5, 21.0, 19.1, 12.0 ppm; HRMS (ESI-TOF): calcd for $\mathrm{C}_{42} \mathrm{H}_{54} \mathrm{NO}_{9} \mathrm{Si}^{+}\left[\mathrm{M}+\mathrm{H}^{+}\right]:$744.3562, found 744.3556 .

Under the conditions shown in Table1, entry 1 (see manuscript) diacetate (-)-33a was obtained. 


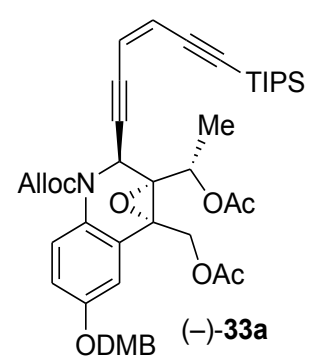

(-)-33a: $R_{f}=0.50$ (silica gel, hexanes/EtOAc 1:1); $[\alpha]_{D}{ }^{25}=-60.8(c=$ 1.00, $\mathrm{CH}_{2} \mathrm{Cl}_{2}$ ); IR (film) $\nu_{\max }=2943,2865,2139,1747,1713,1648,1611$, $1593,1506,1464,1420,1382,1283,1263,1235,1159,1139,1065$, $1027,942,883,855,817,763,709,678,659 \mathrm{~cm}^{-1} ;{ }^{1} \mathrm{H}$ NMR $(600 \mathrm{MHz}$, $\left.\mathrm{CD}_{3} \mathrm{CN}\right): \delta=7.26(\mathrm{br} \mathrm{s}, 1 \mathrm{H}), 7.13(\mathrm{~d}, J=2.4 \mathrm{~Hz}, 1 \mathrm{H}), 7.05(\mathrm{~s}, 1 \mathrm{H}), 7.02(\mathrm{dd}, J=9.0,3.0$ $\mathrm{Hz}, 1 \mathrm{H}), 6.99(\mathrm{~d}, J=7.8 \mathrm{~Hz}, 1 \mathrm{H}), 6.93(\mathrm{~d}, J=7.8 \mathrm{~Hz}, 1 \mathrm{H}), 6.05-5.84(\mathrm{br} \mathrm{m}, 2 \mathrm{H}), 5.91(\mathrm{~d}$, $J=10.8 \mathrm{~Hz}, 1 \mathrm{H}), 5.72(\mathrm{dd}, J=10.8,1.8 \mathrm{~Hz}, 1 \mathrm{H}), 5.35(\mathrm{q}, J=7.2 \mathrm{~Hz}, 1 \mathrm{H}), 5.32-5.13(\mathrm{~m}$, $2 \mathrm{H}), 5.03(\mathrm{~s}, 2 \mathrm{H}), 4.78-4.53(\mathrm{~m}, 4 \mathrm{H}), 3.81(\mathrm{~s}, 3 \mathrm{H}), 3.80(\mathrm{~s}, 3 \mathrm{H}), 2.08(\mathrm{~s}, 3 \mathrm{H}), 2.05(\mathrm{~s}, 3$ $\mathrm{H}), 1.52(\mathrm{~d}, J=6.6 \mathrm{~Hz}, 3 \mathrm{H}), 1.20(\mathrm{~s}, 21 \mathrm{H}) \mathrm{ppm} ;{ }^{13} \mathrm{C} \mathrm{NMR}\left(151 \mathrm{MHz}, \mathrm{CD}_{3} \mathrm{CN}\right): \delta=171.0$, $170.4,157.6,155.5,154.7,150.3,150.2,133.4,130.4,130.0,129.8,129.4,128.1,122.2$ $121.5,120.0,116.2,115.2,112.8,112.6,104.5,101.1,98.9,92.8,83.8,76.1,71.1,70.7$ $67.8,62.0,60.8,56.4,45.5,21.3,21.0,19.1,12.0$ ppm; HRMS (ESI-TOF): calcd for $\mathrm{C}_{44} \mathrm{H}_{55} \mathrm{NO}_{10} \mathrm{SiNa}^{+}\left[\mathrm{M}+\mathrm{Na}^{+}\right]: 808.3487$, found 808.3480 .

Ketone (-)-34. To a stirred solution of hydroxy acetate (-)-33 (9.0 g, $12 \mathrm{mmol}, 1.0$ equiv) ODMB (-)-34 in $\mathrm{CH}_{2} \mathrm{Cl}_{2}(128 \mathrm{~mL})$ was added powdered $\mathrm{NaHCO}_{3}(4.06 \mathrm{~g}, 48.3 \mathrm{mmol}$, 4.0 equiv), and Dess-Martin periodinane (10.26 g, $24.18 \mathrm{mmol}, 2.0$ equiv) at $0{ }^{\circ} \mathrm{C}$. The resulting mixture was stirred at $25^{\circ} \mathrm{C}$ for $2 \mathrm{~h}$, then quenched with saturated aqueous $\mathrm{Na}_{2} \mathrm{~S}_{2} \mathrm{O}_{3}(150 \mathrm{~mL})$. The organic layer was separated, and the aqueous layer was extracted with $\mathrm{CH}_{2} \mathrm{Cl}_{2}(2 \times 200 \mathrm{~mL})$. The combined organic extracts were washed with saturated aqueous $\mathrm{NaHCO}_{3}(150 \mathrm{~mL})$ and brine (150 mL), dried over $\mathrm{MgSO}_{4}$, and filtered through a short plug of Celite (washed with EtOAc prior to use). The solids were rinsed with EtOAc, and the combined filtrates were concentrated to ca. $5 \mathrm{~mL}$ in volume. Flash column chromatography (silica gel, hexanes/EtOAc 2:1) yielded ketone (-)-34 (8.35 g, $11.25 \mathrm{mmol}, 94 \%$ yield) as a yellow oil. (-)-34: $\mathrm{R}_{f}=0.35$ (silica gel, hexanes/EtOAc 3:2); $[\alpha]_{\mathrm{D}^{25}}=-73.7\left(c=1.00, \mathrm{CH}_{2} \mathrm{Cl}_{2}\right) ; \mathrm{IR}($ film) $V_{\max }=2943,2865,2142,1748,1717,1648,1611,1593,1506,1464,1420,1383,1308$, 
1262, 1236, 1159, 1139, 1071, 1027, 920, 883, 855, 820, 763, 678, $661 \mathrm{~cm}^{-1} ;{ }^{1} \mathrm{H}$ NMR $\left(600 \mathrm{MHz}, \mathrm{CD}_{3} \mathrm{CN}\right): \delta=7.28(\mathrm{br} d, J=8.4 \mathrm{~Hz}, 1 \mathrm{H}), 7.15(\mathrm{~d}, J=3.0 \mathrm{~Hz}, 1 \mathrm{H}), 7.06(\mathrm{dd}, J=$ 8.4, 3.0 Hz, $1 \mathrm{H}), 7.05(\mathrm{~s}, 1 \mathrm{H}), 6.99(\mathrm{dd}, J=7.8,2.4 \mathrm{~Hz}, 1 \mathrm{H}), 6.93(\mathrm{~d}, J=7.8 \mathrm{~Hz}, 1 \mathrm{H})$, 6.04-5.86 (m, 2 H), 5.93 (d, J = 10.8 Hz, 1 H), 5.77 (dd, $J=10.8,2.4$ Hz, 1 H), 5.23-5.16 (m, 2 H), 5.04 (s, 2 H), 4.77-4.52 (m, 2 H), $4.70(\mathrm{~d}, J=13.2 \mathrm{~Hz}, 1 \mathrm{H}), 4.54(\mathrm{~d}, J=13.2 \mathrm{~Hz}$, $1 \mathrm{H}), 3.806$ (s, $3 \mathrm{H}), 3.802$ (s, $3 \mathrm{H}), 2.44$ (s, $3 \mathrm{H}), 2.00$ (s, $3 \mathrm{H}), 1.10(\mathrm{~s}, 21 \mathrm{H}) \mathrm{ppm} ;{ }^{13} \mathrm{C}$ NMR $\left(151 \mathrm{MHz}, \mathrm{CD}_{3} \mathrm{CN}\right): \delta=200.3,170.7,157.8,155.7,150.3,150.2,133.4,130.3$, 129.6, 130.0, 126.9, 122.4, 122.2, 121.5, 119.9, 116.6, 115.0, 112.8, 112.6, 104.4, 101.3, 91.4, 84.2, 76.7, 71.2, 70.7, 67.9, 61.5, 61.2, 56.4, 46.3, 29.7, 20.8, 19.0, 12.0 ppm; HRMS (ESI-TOF): calcd for $\mathrm{C}_{42} \mathrm{H}_{52} \mathrm{NO}_{9} \mathrm{Si}^{+}\left[\mathrm{M}+\mathrm{H}^{+}\right]:$742.3406, found 742.3400 .

C26 Inverted alcohol (+)-35. To a stirred solution of ketone (-)-34 (1.94 g, $2.61 \mathrm{mmol}, 1.0$

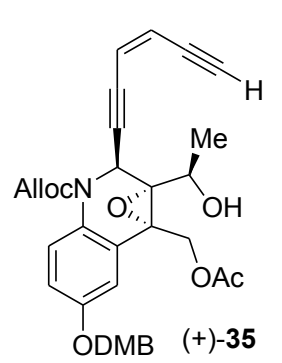
equiv) in THF (20 mL) was added a premixed solution of AcOH/TBAF in THF (AcOH: 394 mg, 6.55 mmol, 2.5 equiv; TBAF: $6.55 \mathrm{~mL}, 1.0 \mathrm{M}$ in THF, $6.55 \mathrm{mmol}, 2.5$ equiv) at $0{ }^{\circ} \mathrm{C}$, the reaction mixture was stirred at $15^{\circ} \mathrm{C}$ for $1 \mathrm{~h}$, and then $\mathrm{MeOH}(25 \mathrm{~mL})$ was added at $0{ }^{\circ} \mathrm{C}$, followed by portionwise addition of $\mathrm{NaBH}_{4}$ (200 mg, $5.29 \mathrm{mmol}, 2.0$ equiv) (CAUTION: gas evolution; if added too fast, the d.r. diminishes). The resulting mixture was stirred at $0{ }^{\circ} \mathrm{C}$ for $30 \mathrm{~min}$, then quenched with $\mathrm{H}_{2} \mathrm{O}(10 \mathrm{~mL})$. The reaction mixture was carefully evaporated to ca. $20 \mathrm{~mL}$ in volume, then partitioned between EtOAc $(100 \mathrm{~mL})$ and $\mathrm{H}_{2} \mathrm{O}(60 \mathrm{~mL})$. The aqueous layer was extracted with EtOAc $(3 \times 100 \mathrm{~mL})$, and the combined organic layers were dried over $\mathrm{MgSO}_{4}$ and concentrated to yield secondary inverted alcohol (+)-35 (1.43 g, $2.43 \mathrm{mmol}$, 93\% yield over the two steps, $\geq 25: 1 \mathrm{dr}$ ) as a yellow oil [CAUTION: (+)-35 slowly turned black during storage, which led to diminished yields for following steps; use fresh for optimal yields].

(+)-35: $\mathrm{R}_{f}=0.24$ (silica gel, hexanes/EtOAc 1:1); $[\alpha]_{D}{ }^{25}=+123\left(c=0.23, \mathrm{CH}_{2} \mathrm{Cl}_{2}\right) ; \mathrm{IR}$ (film) $\nu_{\max }=3490,3281,2926,2853,2093,1738,1704,1648,1611,1593,1506,1464,1420$, 
$1384,1311,1262,1237,1203,1159,1139,1071,1027,977,937,843,764,736 \mathrm{~cm}^{-1} ;{ }^{1} \mathrm{H}$ NMR $\left(600 \mathrm{MHz}, \mathrm{CD}_{3} \mathrm{CN}\right): \delta=7.27(\mathrm{~d}, J=8.4 \mathrm{~Hz}, 1 \mathrm{H}), 7.15(\mathrm{~d}, J=3.0 \mathrm{~Hz}, 1 \mathrm{H}), 7.05(\mathrm{~d}, J$ $=1.8 \mathrm{~Hz}, 1 \mathrm{H}), 7.01(\mathrm{dd}, J=9.0,3.0 \mathrm{~Hz}, 1 \mathrm{H}), 6.99(\mathrm{dd}, J=7.8,1.8 \mathrm{~Hz}, 1 \mathrm{H}), 6.93(\mathrm{~d}, J=$ 7.8 Hz, 1 H), 5.94-5.84 (br m, 2 H), 5.81 (s, 2 H), 5.23-5.17 (m, 2 H), 5.04 (s, 2 H), 4.79$4.73(\mathrm{~m}, 2 \mathrm{H}), 4.65-4.54(\mathrm{~m}, 2 \mathrm{H}), 4.23(\mathrm{qd}, J=6.6,4.8 \mathrm{~Hz}, 1 \mathrm{H}), 3.81(\mathrm{~s}, 3 \mathrm{H}), 3.80(\mathrm{~s}, 3$ H), $3.46(\mathrm{~s}, 1 \mathrm{H}), 3.14(\mathrm{~d}, J=4.8 \mathrm{~Hz}, 1 \mathrm{H}), 2.04(\mathrm{~s}, 3 \mathrm{H}), 1.44(\mathrm{~d}, J=6.0 \mathrm{~Hz}, 3 \mathrm{H}) \mathrm{ppm} ;{ }^{13} \mathrm{C}$ NMR $\left(151 \mathrm{MHz}, \mathrm{CD}_{3} \mathrm{CN}\right): \delta=171.3,157.5,155.8,150.3,150.1,133.5,130.5,129.9$, $128.9,121.42,121.37,120.8,116.0,115.2,112.7,112.6,101.0,98.8,93.4,86.9,82.8$ 81.1, 77.2, 71.1, 67.7, 67.2, 62.1, 61.3, 56.4, 45.9, 21.1, 20.2 ppm; HRMS (ESI-TOF): calcd for $\mathrm{C}_{33} \mathrm{H}_{34} \mathrm{NO}_{9}{ }^{+}\left[\mathrm{M}+\mathrm{H}^{+}\right]: 588.2228$, found 588.2224.

Terminal acetylene primary alcohol (+)-36. To a stirred solution of inverted alcohol

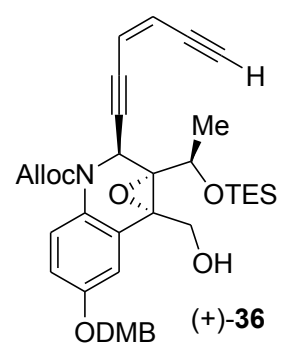
(+)-35 (1.43 g, $2.44 \mathrm{mmol}, 1.0$ equiv) in DMF $(15 \mathrm{~mL})$ at $0{ }^{\circ} \mathrm{C}$ was added imidazole (332 mg, $4.88 \mathrm{mmol}, 2.0$ equiv) and TESCl (551 mg, $3.66 \mathrm{mmol}$, 1.5 equiv). The reaction mixture was stirred at $0{ }^{\circ} \mathrm{C}$ for $15 \mathrm{~min}$, and at $25^{\circ} \mathrm{C}$ for $5 \mathrm{~min}$, then quenched with saturated aqueous $\mathrm{NaHCO}_{3}(50 \mathrm{~mL})$, and extracted with $\mathrm{Et}_{2} \mathrm{O}(3 \times 50 \mathrm{~mL})$. The combined organic extracts were washed with $\mathrm{H}_{2} \mathrm{O}(3 \times 50 \mathrm{~mL})$ and brine $(50 \mathrm{~mL})$, dried over $\mathrm{MgSO}_{4}$, and concentrated. A small portion of the residue thus obtained was purified by flash column chromatography (silica gel, hexanes/EtOAc $9: 1$ to $3: 7)$ to allow characterization of fully protected diol (+)-35a. Otherwise, for synthetic purposes the crude residue was taken up in THF $(20 \mathrm{~mL})$ and cooled to $0{ }^{\circ} \mathrm{C}$. To the stirred solution was added a cold $\left(0-5{ }^{\circ} \mathrm{C}\right)$ saturated solution of $\mathrm{K}_{2} \mathrm{CO}_{3}$ in $\mathrm{MeOH}(2.5 \mathrm{~mL})$, and the reaction mixture was stirred at $-10{ }^{\circ} \mathrm{C}$ for 20 min [CAUTION: (+)-36 slowly underwent deprotection of TES at this temperature, thus the reaction should be carefully monitored at 2 min intervals]. The resulting mixture was then partitioned between EtOAc $(50 \mathrm{~mL})$ and $\mathrm{pH} 6.8$ buffer $(50 \mathrm{~mL})$. The aqueous layer was extracted with EtOAc $(2 \times 50 \mathrm{~mL})$, then the combined organic layers were washed with 
brine (50 mL), dried over $\mathrm{MgSO}_{4}$, and concentrated to ca. $5 \mathrm{~mL}$ in volume. Flash column chromatography (silica gel, hexanes/EtOAc $3: 1$ to $2: 1)$ yielded primary alcohol (+)-36 (1.36 g, $2.07 \mathrm{mmol}, 85 \%$ yield over two steps) as a yellow solid. [CAUTION: (+)-36 slowly turned black during storage, which led to diminished yields for following steps; use fresh for optimal yields].

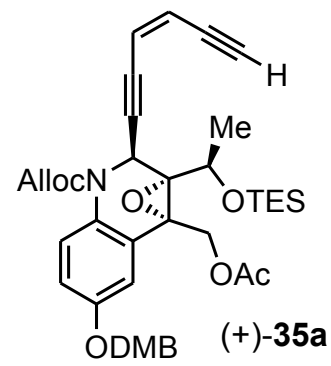

(+)-35a: $R_{f}=0.30$ (silica gel, hexanes/EtOAc 7:3); $[\alpha]_{D^{25}}=+39(c=$ 0.86, $\mathrm{CH}_{2} \mathrm{Cl}_{2}$ ); IR (film) $v_{\max }=3283,2955,2877,2094,1741,1708$, $1648,1611,1593,1506,1464,1419,1384,1309,1283,1263,1239$, $1204,1159,1138,1072,1029,976,911,841,811,782,731 \mathrm{~cm}^{-1} ;{ }^{1} \mathrm{H}$ NMR $\left(600 \mathrm{MHz}, \mathrm{CD}_{3} \mathrm{CN}\right): \delta=7.26(\mathrm{br} \mathrm{d}, J=9.0 \mathrm{~Hz}, 1 \mathrm{H}), 7.10(\mathrm{~d}, J=3.0 \mathrm{~Hz}, 1 \mathrm{H}), 7.04(\mathrm{~d}$, $J=1.8 \mathrm{~Hz}, 1 \mathrm{H}), 7.01-6.98(\mathrm{~m}, 2 \mathrm{H}), 6.93(\mathrm{~d}, J=8.4 \mathrm{~Hz}, 1 \mathrm{H}), 6.02-5.79(\mathrm{~m}, 2 \mathrm{H}), 5.78(\mathrm{~s}$, 2 H), 5.39-5.16 (m, $2 \mathrm{H}), 5.04(\mathrm{~d}, J=12.0 \mathrm{~Hz}, 1 \mathrm{H}), 5.02(\mathrm{~d}, J=12.0 \mathrm{~Hz}, 1 \mathrm{H}), 4.78(\mathrm{~d}, J=$ 12.6 Hz, $1 \mathrm{H}), 4.69(\mathrm{~d}, J=12.6 \mathrm{~Hz}, 1 \mathrm{H}), 4.65-4.53(\mathrm{~m}, 2 \mathrm{H}), 4.38(\mathrm{q}, J=6.0 \mathrm{~Hz}, 1 \mathrm{H})$, $3.81(\mathrm{~s}, 3 \mathrm{H}), 3.80(\mathrm{~s}, 3 \mathrm{H}), 3.41(\mathrm{~s}, 1 \mathrm{H}), 2.04(\mathrm{~s}, 3 \mathrm{H}), 1.44(\mathrm{~d}, J=6.6 \mathrm{~Hz}, 3 \mathrm{H}), 0.95(\mathrm{t}, J=$ $7.8 \mathrm{~Hz}, 9 \mathrm{H}), 0.63(\mathrm{t}, J=7.8 \mathrm{~Hz}, 6 \mathrm{H}) \mathrm{ppm} ;{ }^{13} \mathrm{C} \mathrm{NMR}\left(151 \mathrm{MHz}, \mathrm{CD}_{3} \mathrm{CN}\right): \delta=171.2,157.5$, $155.7,150.3,150.1,133.6,130.5,130.2,129.9,129.1,121.5,121.4,120.6,115.9,115.1$ $112.7,112.6,93.9,86.8,82.2,81.1,77.4,71.0,67.8,67.7,67.6,62.1,61.3,56.4,46.3$, 22.0, 21.0, 7.2, 5.5 ppm; HRMS (ESI-TOF): calcd for $\mathrm{C}_{39} \mathrm{H}_{47} \mathrm{NO}_{9} \mathrm{SiNa}^{+}\left[\mathrm{M}+\mathrm{Na}^{+}\right]:$724.2912, found 724.2913 .

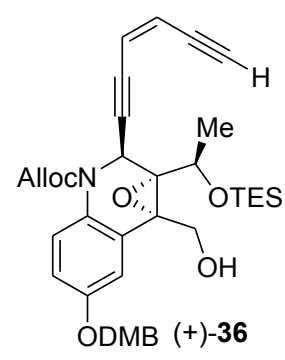

(+)-36: $R_{f}=0.42\left(\right.$ silica gel, hexanes/EtOAc 3:2); $[\alpha]_{D^{25}}=+47.2(c=1.00$,

$\mathrm{CH}_{2} \mathrm{Cl}_{2}$ ); IR (film) $\nu_{\max }=3493,3286,2955,2876,1701,1504,1387,1261$, $1237 \mathrm{~cm}^{-1} ;{ }^{1} \mathrm{H}$ NMR $\left(600 \mathrm{MHz}, \mathrm{CD}_{3} \mathrm{CN}\right): \delta=7.39(\mathrm{~d}, J=2.8 \mathrm{~Hz}, 1 \mathrm{H})$, $7.23(\mathrm{br} \mathrm{d}, J=7.5 \mathrm{~Hz}, 1 \mathrm{H}), 7.06(\mathrm{~d}, J=1.9 \mathrm{~Hz}, 1 \mathrm{H}), 7.01$ (dd, $J=8.2$, $1.9 \mathrm{~Hz}, 1 \mathrm{H}), 6.96(\mathrm{dd}, J=8.8,2.8 \mathrm{~Hz}, 1 \mathrm{H}), 6.93(\mathrm{~d}, J=8.2 \mathrm{~Hz}, 1 \mathrm{H}), 6.0-5.8(\mathrm{br}, 2 \mathrm{H})$, 5.76 (AB doublet, 2 H), 5.4-5.1 (br, 2 H), 5.03 (s, 2 H), 4.7-4.5 (br, 2 H), 4.39 (q, J = 6.3 $\mathrm{Hz}, 1 \mathrm{H}), 4.24(\mathrm{dd}, J=12.5,5.8 \mathrm{~Hz}, 1 \mathrm{H}), 4.18(\mathrm{dd}, J=12.5,5.1 \mathrm{~Hz}, 1 \mathrm{H}), 3.81(\mathrm{~s}, 3 \mathrm{H})$, 
$3.80(\mathrm{~s}, 3 \mathrm{H}), 3.40(\mathrm{~s}, 1 \mathrm{H}), 3.14(\mathrm{t}, J=5.4 \mathrm{~Hz}, 1 \mathrm{H}), 1.43(\mathrm{~d}, J=6.2 \mathrm{~Hz}, 3 \mathrm{H}), 0.96(\mathrm{t}, J=$ $8.0 \mathrm{~Hz}, 9 \mathrm{H}), 0.64$ (q, J = 8.0 Hz, $6 \mathrm{H}) \mathrm{ppm} ;{ }^{13} \mathrm{C} \mathrm{NMR}\left(151 \mathrm{MHz}, \mathrm{CD}_{3} \mathrm{CN}\right): \delta=157.2,155.7$, $150.1,150.0,133.5,130.4,130.3,129.8,129.5,128.9,121.6,120.2,117.9,116.0,115.1$, $112.8,112.5,94.4,86.6,81.6,81.0,76.8,70.9,67.9,67.4,63.4,60.1,56.3,45.9,21.4,7.2$, 5.5 ppm; HRMS (ESI-TOF): calcd for $\mathrm{C}_{37} \mathrm{H}_{46} \mathrm{NO}_{8} \mathrm{Si}^{+}\left[\mathrm{M}+\mathrm{H}^{+}\right]$: 660.2987, found 660.2989.

Aldehyde (+)-14. To a stirred solution of primary alcohol (+)-36 (1.25 g, $1.89 \mathrm{mmol}, 1.0$

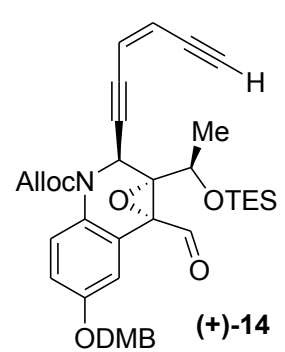
equiv) in $\mathrm{CH}_{2} \mathrm{Cl}_{2}(20 \mathrm{~mL})$ at $0{ }^{\circ} \mathrm{C}$ was added powdered $\mathrm{NaHCO}_{3}(639 \mathrm{mg}$, $7.60 \mathrm{mmol}, 4.0$ equiv), and Dess-Martin periodinane $(1.60 \mathrm{~g}, 3.77 \mathrm{mmol}$, 2.0 equiv). The reaction mixture was stirred at $25{ }^{\circ} \mathrm{C}$ for $1.5 \mathrm{~h}$, then partitioned between $\mathrm{CH}_{2} \mathrm{Cl}_{2}(30 \mathrm{~mL})$ and saturated aqueous $\mathrm{Na}_{2} \mathrm{~S}_{2} \mathrm{O}_{3}(30$ $\mathrm{mL})$. The aqueous layer was extracted with $\mathrm{CH}_{2} \mathrm{Cl}_{2}(2 \times 30 \mathrm{~mL})$, and the combined organic layers were washed with brine $(30 \mathrm{~mL})$, dried over $\mathrm{MgSO}_{4}$, and filtered through a short plug of Celite (washed with EtOAc prior to use). The solids were rinsed with EtOAc, and the combined filtrates were concentrated to ca. $5 \mathrm{~mL}$ in volume. Flash column chromatography (silica gel, hexanes/EtOAc 4:1) yielded aldehyde (+)-14 (1.12 g, 1.70 mmol, 90\% yield) as a yellow oil [CAUTION: (+)-14 slowly turned black during storage, which led to diminished yields for following steps; use fresh for optimal yields].

$(+)-14: \mathrm{R}_{f}=0.31$ (silica gel, hexanes/EtOAc 7:3); $[\alpha]_{D^{25}}=+49\left(\mathrm{c}=0.43, \mathrm{CH}_{2} \mathrm{Cl}_{2}\right) ; \mathrm{IR}($ film) $\nu_{\max }=3286,2955,2934,2876,2095,1709,1648,1610,1593,1516,1503,1463,1442$, $1420,1384,1301,1262,1239,1203,1159,1138,1027,1009,979,924,856,809,762$ 746, $729 \mathrm{~cm}^{-1} ;{ }^{1} \mathrm{H}$ NMR $\left(600 \mathrm{MHz}, \mathrm{CD}_{3} \mathrm{CN}\right): \delta=9.83(\mathrm{~s}, 1 \mathrm{H}), 7.31(\mathrm{br} \mathrm{d}, J=9.0 \mathrm{~Hz}, 1 \mathrm{H})$, $7.20(\mathrm{~d}, J=3.0 \mathrm{~Hz}, 1 \mathrm{H}), 7.04(\mathrm{~d}, J=1.8 \mathrm{~Hz}, 1 \mathrm{H}), 7.02(\mathrm{dd}, J=9.0,3.0 \mathrm{~Hz}, 1 \mathrm{H}), 6.99(\mathrm{dd}$, $J=8.4,1.8 \mathrm{~Hz}, 1 \mathrm{H}), 6.93(\mathrm{~d}, J=7.8 \mathrm{~Hz}, 1 \mathrm{H}), 5.94-5.85(\mathrm{br} \mathrm{m}, 2 \mathrm{H}), 5.83-5.77(\mathrm{~m}, 2 \mathrm{H})$, 5.26-5.14 (br m, $2 \mathrm{H}), 5.02$ (d, J = 11.4 Hz, $1 \mathrm{H}), 4.99$ (d, J = 11.4 Hz, $1 \mathrm{H}), 4.67-4.54(\mathrm{~m}$, $2 \mathrm{H}), 4.37$ (q, J = $6.6 \mathrm{~Hz}, 1 \mathrm{H}), 3.81(\mathrm{~s}, 3 \mathrm{H}), 3.80(\mathrm{~s}, 3 \mathrm{H}), 3,43(\mathrm{~s}, 1 \mathrm{H}), 1.42(\mathrm{~d}, J=6.6 \mathrm{~Hz}$, $3 \mathrm{H}), 0.95(\mathrm{t}, J=7.8 \mathrm{~Hz}, 9 \mathrm{H}), 0.63(\mathrm{q}, J=7.8 \mathrm{~Hz}, 6 \mathrm{H}) \mathrm{ppm} ;{ }^{13} \mathrm{C} \mathrm{NMR}\left(151 \mathrm{MHz}, \mathrm{CD}_{3} \mathrm{CN}\right)$ : 
$\delta=196.4,157.1,155.7,150.2,150.1,133.5,130.3,130.1,125.2,121.6,121.19,121.16$

$118.0,116.3,115.1,112.9,112.6,92.8,87.1,83.2,80.9,80.6,71.0,67.8,67.6,64.7$, 56.37, 56.36, 22.3, 7.1, 5.6 ppm; HRMS (ESI-TOF): calcd for $\mathrm{C}_{37} \mathrm{H}_{44} \mathrm{NO}_{8} \mathrm{Si}^{+}\left[\mathrm{M}+\mathrm{H}^{+}\right]$: 658.2831 , found 658.2846 .

Phenolic aldehyde (+)-37. To a stirred solution of DMB-protected aldehyde (+)-14 (1.12 g,

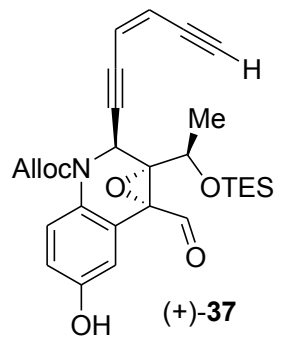
1.70 mmol, 1.0 equiv) in $\mathrm{CH}_{2} \mathrm{Cl}_{2}(50 \mathrm{~mL})$ at ambient temperature was added $\mathrm{pH} 6.8$ buffer $(5.0 \mathrm{~mL})$ and $\mathrm{DDQ}(1.16 \mathrm{~g}, 5.11 \mathrm{mmol}, 3.0$ equiv). The reaction flask was wrapped with aluminium foil and the resulting mixture was stirred at ambient temperature for $12 \mathrm{~h}$, until TLC showed full consumption of $(+)-14\left(4 \%\right.$ EtOAc in $\mathrm{CH}_{2} \mathrm{Cl}_{2}$ ). The reaction mixture was then partitioned between $\mathrm{CH}_{2} \mathrm{Cl}_{2}(100 \mathrm{~mL})$ and $\mathrm{pH} 6.8$ buffer $(100 \mathrm{~mL})$. The aqueous layer was extracted with $\mathrm{CH}_{2} \mathrm{Cl}_{2}(2 \times 100 \mathrm{~mL})$, and the combined organic layers were washed with $\mathrm{pH} 6.8$ buffer $(50 \mathrm{~mL}), \mathrm{H}_{2} \mathrm{O}(50 \mathrm{~mL})$, and brine $(50 \mathrm{~mL})$, dried over $\mathrm{MgSO}_{4}$, and filtered through a short plug of Celite (washed with EtOAc prior to use). The solids were rinsed with $5 \%$ EtOAc in $\mathrm{CH}_{2} \mathrm{Cl}_{2}$, and the combined filtrates were concentrated to ca. $5 \mathrm{~mL}$ in volume. Flash column chromatography $\left(\mathrm{CH}_{2} \mathrm{Cl}_{2} / \mathrm{EtOAc} 1: 0\right.$ to $30: 1$, then hexanes/EtOAc 4:1 after 3,4-dimethoxy-benzaldehyde was fully eluted) yielded phenol (+)-37 [CAUTION: (+)-37 was sensitive to trace amounts of $\mathrm{HCl}$ in $\mathrm{CH}_{2} \mathrm{Cl}_{2}$ : concentration of fractions to ca. $20 \mathrm{~mL}$, then diluted with $20 \mathrm{~mL}$ toluene; repeat the same operations three times and then concentrate to dryness] (810 mg, $1.60 \mathrm{mmol}, 94 \%$ yield) as a yellow oil [CAUTION: (+)-37 slowly turned black during storage, which led to diminished yields for following steps; use fresh for optimal yields].

$(+)-37: \mathrm{R}_{f}=0.31$ (silica gel, hexanes:EtOAc 7:3); $[\alpha]_{\mathrm{D}^{25}}=+71\left(c=0.68, \mathrm{CH}_{2} \mathrm{Cl}_{2}\right) ; \mathrm{IR}($ film$)$ $\nu_{\max }=3383,3297,2956,2915,2878,2095,1705,1649,1614,1589,1505,1457,1392$ $1315,1284,1259,1240,1205,1161,1129,1056,1035,1010,979,937,911,876,831$, 746, 673, $656 \mathrm{~cm}^{-1}$; ${ }^{1} \mathrm{H}$ NMR $\left(500 \mathrm{MHz}, \mathrm{CD}_{3} \mathrm{CN}\right): \delta=9.79(\mathrm{~s}, 1 \mathrm{H}), 7.22(\mathrm{br} \mathrm{d}, J=7.8 \mathrm{~Hz}$, 
$1 \mathrm{H}), 7.13(\mathrm{br} \mathrm{s}, 1 \mathrm{H}), 7.06(\mathrm{~d}, J=3.0 \mathrm{~Hz}, 1 \mathrm{H}), 6.84(\mathrm{dd}, J=9.0,2.4 \mathrm{~Hz}, 1 \mathrm{H}), 5.98-5.85$

(br m, 2 H), 5.81 (s, 2 H), 5.38-5.13 (br m, 2 H), 4.69-4.54 (br m, 2 H), 4.38 (q, J = 6.6 Hz, $1 \mathrm{H}), 3.49(\mathrm{~s}, 1 \mathrm{H}), 1.42(\mathrm{~d}, J=6.0 \mathrm{~Hz}, 3 \mathrm{H}), 0.96(\mathrm{t}, J=7.8 \mathrm{~Hz}, 9 \mathrm{H}), 0.63(\mathrm{q}, J=7.8 \mathrm{~Hz}, 6$ H) ppm; ${ }^{13} \mathrm{C}$ NMR $\left(125 \mathrm{MHz}, \mathrm{CD}_{3} \mathrm{CN}\right): \delta=196.5,155.8,155.4,133.5,130.2,129.1,125.3$, $121.2,121.1,118.0,116.7,115.2,92.9,87.0,83.2,81.0,80.5,67.7,67.5,64.7,46.4,22.3$, 7.1, 5.4 pm; HRMS (ESI-TOF): calcd for $\mathrm{C}_{28} \mathrm{H}_{34} \mathrm{NO}_{6} \mathrm{Si}^{+}\left[\mathrm{M}+\mathrm{H}^{+}\right]$: 508.2150, found 508.2140. Cyclic enediynes (+)-38 and (+)-17-epi-38. A $250 \mathrm{~mL}$ round bottom flask containing
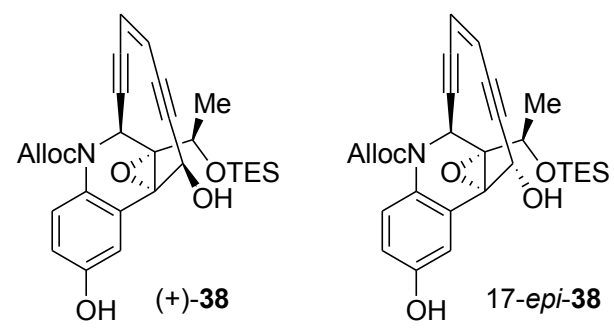
commercially available anhydrous $\mathrm{CeCl}_{3}$ (beads, -10 mesh, $1.57 \mathrm{~g}, 6.37 \mathrm{mmol}, 4.0$ equiv) was heated to $110{ }^{\circ} \mathrm{C}$ (oil bath temperature) under high vaccum with vigorous stirring for $16 \mathrm{~h}$ to afford a white powder. The flask was flushed with $\mathrm{Ar}$ and THF (50 mL) was added to form a cloudy suspension, which was sonicated for $2 \mathrm{~h}$ to afford a milky suspension. A solution of phenol (+)-37 (810 $\mathrm{mg}$, $1.60 \mathrm{mmol}, 1.0$ equiv) in THF (50 mL) was added to the preformed $\mathrm{CeCl}_{3}$ suspension via cannula under sonication over $20 \mathrm{~min}$ at ambient temperature. The resulting mixture was stirred at ambient temperature for $30 \mathrm{~min}$, and then cooled to $-78{ }^{\circ} \mathrm{C}$, followed by dropwise addition of KHMDS (1.0 M in THF, $9.60 \mathrm{~mL}, 9.60 \mathrm{mmol}, 6.0$ equiv), during which time the color of the reaction mixture turned from light yellow to brown, then dark brown. The reaction mixture was stirred at $-78{ }^{\circ} \mathrm{C}$ for $1 \mathrm{~h}$, then slowly warmed up to $-40{ }^{\circ} \mathrm{C}$ over $2 \mathrm{~h}$, and was then quenched by the addition of $\mathrm{AcOH}(1.0 \mathrm{M}$ in THF, $19.1 \mathrm{~mL}, 19.1 \mathrm{mmol}, 12.0$ equiv) at the same temperature. Upon completion of addition, the reaction mixture was allowed to warm to ambient temperature, carefully concentrated to ca. $40 \mathrm{~mL}$ in volume and then partitioned between EtOAc $(100 \mathrm{~mL})$ and $\mathrm{pH} 6.8$ buffer $(100 \mathrm{~mL})$. The aqueous layer was extracted with EtOAc $(2 \times 100 \mathrm{~mL})$, and the combined organic layers were washed with $\mathrm{H}_{2} \mathrm{O}(50 \mathrm{~mL})$ and brine $(50 \mathrm{~mL})$, dried over $\mathrm{MgSO}_{4}$, and filtered through a short plug of Celite (washed with EtOAc prior to use). The solids were rinsed with EtOAc, 
and the combined filtrates were concentrated to ca. $5 \mathrm{~mL}$ in volume. Flash column chromatography (silica gel, hexanes/EtOAc $4: 1$ to $3: 1$ ) yielded cyclic enediyne $(+)-38$ (640 mg, $1.26 \mathrm{mmol}, 79 \%$ yield) and its C17-epimer, (+)-17-epi-38 (112 mg, $0.22 \mathrm{mmol}$, $13 \%$ yield) as a yellowish solid.

(+)-38: $\mathrm{R}_{f}=0.36$ (silica gel, hexanes/EtOAc 3:2); $[\alpha]^{25}=+213\left(c=0.35, \mathrm{CH}_{2} \mathrm{Cl}_{2}\right) ; \mathrm{IR}$ (film) $v_{\max }=3397,2955,2933,2877,2201,1687,1648,1613,1590,1504,1459,1392,1316$, $1297,1284,1239,1197,1124,1101,1070,1040,1016,961,928,869,826,807,783,733$ $\mathrm{cm}^{-1} ;{ }^{1} \mathrm{H}$ NMR $\left(600 \mathrm{MHz}, \mathrm{CD}_{3} \mathrm{CN}\right): \delta=7.94(\mathrm{~d}, \mathrm{~J}=2.4 \mathrm{~Hz}, 1 \mathrm{H}), 7.14(\mathrm{br} \mathrm{s}, 1 \mathrm{H}), 6.93(\mathrm{~s}, 1$ H), $6.73(\mathrm{dd}, J=9.0,3.0 \mathrm{~Hz}, 1 \mathrm{H}), 5.96-5.88(\mathrm{br} \mathrm{m}, 1 \mathrm{H}), 5.90(\mathrm{~d}, J=9.6 \mathrm{~Hz}, 1 \mathrm{H}), 5.83(\mathrm{~d}$, $J=1.2 \mathrm{~Hz}, 1 \mathrm{H}), 5.76(\mathrm{~d}, J=9.6 \mathrm{~Hz}, 1 \mathrm{H}), 5.32-5.16(\mathrm{br} \mathrm{m}, 2 \mathrm{H}), 5.05(\mathrm{~d}, J=4.8 \mathrm{~Hz}, 1 \mathrm{H})$, 4.65-4.55 (m, $2 \mathrm{H}), 4.54(\mathrm{q}, J=6.6 \mathrm{~Hz}, 1 \mathrm{H}), 4.22(\mathrm{~d}, J=4.8 \mathrm{~Hz}, 1 \mathrm{H}), 1.37(\mathrm{~d}, J=6.6 \mathrm{~Hz}$, $3 \mathrm{H}), 0.98$ (t, $J=7.8 \mathrm{~Hz}, 9 \mathrm{H}), 0.67-0.63(\mathrm{~m}, 6 \mathrm{H}) \mathrm{ppm} ;{ }^{13} \mathrm{C} \mathrm{NMR}\left(151 \mathrm{MHz}, \mathrm{CD}_{3} \mathrm{CN}\right): \delta=$ 154.5, 133.7, 130.4, 130.3, 128.4, 124.6, 124.0, 117.8, 115.5, 100.4, 97.2, 91.4, 90.2, 77.3, 67.4, 66.9, 66.1, 65.1, 47.5, 22.4, 7.3, 5.7 ppm; HRMS (ESI-TOF): calcd for $\mathrm{C}_{28} \mathrm{H}_{34} \mathrm{NO}_{6} \mathrm{Si}^{+}$ $\left[\mathrm{M}+\mathrm{H}^{+}\right]: 508.2150$, found 508.2140 .

$(+)$-17-epi-38: $\mathrm{R}_{f}=0.24$ (silica gel, hexanes/EtOAc 3:2); $[\alpha]_{D}{ }^{25}=+243\left(c=0.50, \mathrm{CH}_{2} \mathrm{Cl}_{2}\right)$; IR (film) $v_{\max }=3387,2955,2935,2877,2196,1688,1649,1612,1590,1506,1457,1395$, $1294,1281,1239,1203,1162,1120,1070,1038,1011,977,938,924,851,840,785,764$, 738, $668 \mathrm{~cm}^{-1} ;{ }^{1} \mathrm{H}$ NMR $\left(600 \mathrm{MHz}, \mathrm{CD}_{3} \mathrm{CN}\right): \delta=7.16(\mathrm{br}, 1 \mathrm{H}), 7.01(\mathrm{~d}, J=2.4 \mathrm{~Hz}, 1 \mathrm{H})$, $6.98(\mathrm{~s}, 1 \mathrm{H}), 6.76(\mathrm{dd}, J=8.4,2.4 \mathrm{~Hz}, 1 \mathrm{H}), 5.91(\mathrm{br}, 1 \mathrm{H}), 5.86(\mathrm{dd}, J=10.2,1.8 \mathrm{~Hz}, 1 \mathrm{H})$, $5.82(\mathrm{dd}, J=10.2,1.8 \mathrm{~Hz}, 1 \mathrm{H}), 5.75(\mathrm{~d}, J=1.9 \mathrm{~Hz}, 1 \mathrm{H}), 5.72(\mathrm{~d}, J=4.8 \mathrm{~Hz}, 1 \mathrm{H}), 5.35-$ $5.16(\mathrm{br}, 2 \mathrm{H}), 5.29(\mathrm{q}, J=6.0 \mathrm{~Hz}, 1 \mathrm{H}), 4.68-4.55(\mathrm{br}, 2 \mathrm{H}), 3.86(\mathrm{~d}, J=4.8 \mathrm{~Hz}, 1 \mathrm{H}), 1.34$ $(\mathrm{d}, J=6.0 \mathrm{~Hz}, 3 \mathrm{H}), 0.98(\mathrm{t}, J=7.8 \mathrm{~Hz}, 9 \mathrm{H}), 0.64(\mathrm{q}, J=7.8 \mathrm{~Hz}, 6 \mathrm{H}) \mathrm{ppm} ;{ }^{13} \mathrm{C}$ NMR $(151$ $\left.\mathrm{MHz}, \mathrm{CD}_{3} \mathrm{CN}\right): \delta=154.9,133.7,131.9,129.8,129.0,126.0,124.2,117.8,115.8,114.3$ 100.1, 98.8, 90.7, 90.2, 77.2, 67.4, 66.5, 65.9, 60.8, 47.0, 21.6, 7.4, 5.9 ppm; HRMS (ESITOF): calcd for $\mathrm{C}_{28} \mathrm{H}_{34} \mathrm{NO}_{6} \mathrm{Si}^{+}\left[\mathrm{M}+\mathrm{H}^{+}\right]: 508.2150$, found 508.2145 . 
Quinone aminal (+)-13. To a stirred solution of cyclic enediyne (+)-38 (601 mg, $1.18 \mathrm{mmol}$,

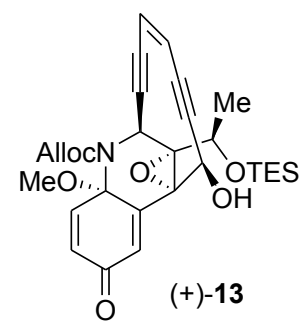

1.0 equiv) in $\mathrm{MeOH}(40 \mathrm{~mL})$ at $0{ }^{\circ} \mathrm{C}$ was added a solution of $\mathrm{Phl}(\mathrm{OAc})_{2}$ (420 mg, $1.30 \mathrm{mmol}, 1.1$ equiv) in $\mathrm{MeOH}(20 \mathrm{~mL}$ ) via cannula. The resulting mixture was stirred at $0{ }^{\circ} \mathrm{C}$ for $10 \mathrm{~min}$ and at $25{ }^{\circ} \mathrm{C}$ for $5 \mathrm{~min}$, then partitioned between EtOAc $(100 \mathrm{~mL})$ and half saturated aqueous $\mathrm{NaHCO}_{3}(100 \mathrm{~mL})$. The aqueous layer was extracted with EtOAc $(2 \times 50 \mathrm{~mL})$, and the combined organic layers were washed with brine $(50 \mathrm{~mL})$, dried over $\mathrm{MgSO}_{4}$, and filtered through a short plug of Celite (washed with EtOAc prior to use). The solids were rinsed with EtOAc, and the combined filtrates were concentrated to ca. $3 \mathrm{~mL}$ in volume. Flash column chromatography (silica gel, hexanes/EtOAc $4: 1$ to $3: 1$ ) yielded quinone aminal (+)-13 (529 mg, $0.984 \mathrm{mmol}, 83 \%$ yield) as a white solid.

(+)-13: $\mathrm{R}_{f}=0.30$ (silica gel, hexanes/EtOAc 3:2); $[\alpha]_{D}^{25}=+592\left(c=0.50, \mathrm{CH}_{2} \mathrm{Cl}_{2}\right) ; \mathrm{IR}($ film$)$ $V_{\max }=3448,2955,2911,2877,1707,1686,1666,1635,1614,1534,1458,1390,1295$, $1281,1255,1210,1194,1122,1094,1059,1020,984,943,896,822,782,766,737 \mathrm{~cm}^{-1}$ ${ }^{1} \mathrm{H}$ NMR $\left(600 \mathrm{MHz}, \mathrm{CD}_{3} \mathrm{CN}\right): \delta=7.52(\mathrm{br} \mathrm{s}, 1 \mathrm{H}), 7.02(\mathrm{~d}, J=1.8 \mathrm{~Hz}, 1 \mathrm{H}), 6.25(\mathrm{dd}, J=$ 10.8, $1.8 \mathrm{~Hz}, 1 \mathrm{H}), 6.00-5.93(\mathrm{~m}, 3 \mathrm{H}), 5.84(\mathrm{dt}, J=10.2,1.2 \mathrm{~Hz}, 1 \mathrm{H}), 5.34(\mathrm{~d}, J=17.4 \mathrm{~Hz}$, $1 \mathrm{H}), 5.23(\mathrm{dd}, J=10.8,1.2 \mathrm{~Hz}, 1 \mathrm{H}), 4.81(\mathrm{~d}, J=4.8 \mathrm{~Hz}, 1 \mathrm{H}), 4.67-4.60(\mathrm{~m}, 2 \mathrm{H}), 4.52(\mathrm{q}$, $J=6.6 \mathrm{~Hz}, 1 \mathrm{H}), 4.18(\mathrm{~d}, J=4.8 \mathrm{~Hz}, 1 \mathrm{H}), 3.02(\mathrm{~s}, 3 \mathrm{H}), 1.33(\mathrm{~d}, J=6.0 \mathrm{~Hz}, 3 \mathrm{H}), 0.94(\mathrm{t}, J$ $=7.8 \mathrm{~Hz}, 9 \mathrm{H}), 0.65-0.58(\mathrm{~m}, 6 \mathrm{H}) \mathrm{ppm} ;{ }^{13} \mathrm{C} \mathrm{NMR}\left(151 \mathrm{MHz}, \mathrm{CD}_{3} \mathrm{CN}\right): \delta=184.9,138.7$, 133.5, 128.8, 124.9, 124.7, 101.0, 99.8, 98.2, 92.4, 89.1, 83.6, 70.1, 68.1, 66.7, 63.9, 51.4, 46.9, 22.5, 7.3, 5.7 ppm; HRMS (ESI-TOF): calcd for $\mathrm{C}_{29} \mathrm{H}_{36} \mathrm{NO}_{7} \mathrm{Si}^{+}\left[\mathrm{M}+\mathrm{H}^{+}\right]: 538.2255$, found 538.2247 .

Iminoquinone (+)-39. To a stirred solution of semiquinone (+)-13 (20 mg, $0.037 \mathrm{mmol}, 1.0$ equiv) in $\mathrm{CH}_{2} \mathrm{Cl}_{2}(1.5 \mathrm{~mL})$ was added $\mathrm{H}_{2} \mathrm{O}\left(3.5 \mu \mathrm{L}, 0.20 \mathrm{mmol}\right.$, 5.4 equiv) and $\mathrm{Pd}\left(\mathrm{PPh}_{3}\right)_{2} \mathrm{Cl}_{2}$ (5.2 mg, $7.4 \mu \mathrm{mol}, 0.2$ equiv), then $n-\mathrm{Bu}_{3} \mathrm{SnH}$ (16 $\mu \mathrm{L}, 0.059 \mathrm{mmol}, 1.6$ equiv). The reaction mixture was stirred at $25{ }^{\circ} \mathrm{C}$ for $20 \mathrm{~min}$, then directly subjected to flash column 
chromatography (silica gel, hexanes/EtOAc 4:1) to yield iminoquinone (+)-39 (6.4 mg, $0.015 \mathrm{mmol}, 63 \%$ yield based on $65 \%$ conversion) as a yellow solid and recovered $(+)-13$ (7.0 mg, $0.013 \mathrm{mmol})$.

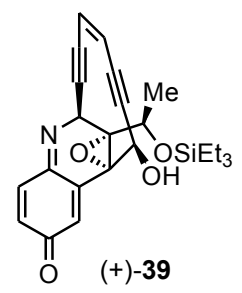

(+)-39: $\mathrm{R}_{f}=0.45$ (silica gel, hexanes/EtOAc 3:2); $[\alpha]_{\mathrm{D}}{ }^{25}=+530(c=0.23$, $\mathrm{CH}_{2} \mathrm{Cl}_{2}$ ); IR (film) $v_{\max }=3366,2956,2924,2876,2854,1722,1648,1591$, $1496,1459,1411,1378,1268,1237,1196,1120,1047,1010,971,906,778$, $732 \mathrm{~cm}^{-1} ;{ }^{1} \mathrm{H}$ NMR $\left(600 \mathrm{MHz}, \mathrm{CD}_{3} \mathrm{CN}\right): \delta=7.38(\mathrm{~d}, J=2.4 \mathrm{~Hz}, 1 \mathrm{H}), 7.16(\mathrm{~d}$, $J=10.2 \mathrm{~Hz}, 1 \mathrm{H}), 6.48(\mathrm{dd}, J=10.2,2.4 \mathrm{~Hz}, 1 \mathrm{H}), 5.99(\mathrm{~d}, J=10.2 \mathrm{~Hz}, 1 \mathrm{H}), 5.95(\mathrm{dt}, J=$ 10.2, $1.2 \mathrm{~Hz}, 1 \mathrm{H}), 5.52(\mathrm{~d}, J=1.8 \mathrm{~Hz}, 1 \mathrm{H}), 5.13(\mathrm{~d}, J=4.8 \mathrm{~Hz}, 1 \mathrm{H}), 4.53(\mathrm{q}, J=6.6 \mathrm{~Hz}, 1$ H), $4.26(\mathrm{~d}, J=4.8 \mathrm{~Hz}, 1 \mathrm{H}), 1.39(\mathrm{~d}, J=6.6 \mathrm{~Hz}, 3 \mathrm{H}), 0.98(\mathrm{t}, J=7.8 \mathrm{~Hz}, 9 \mathrm{H}), 0.65(\mathrm{t}, J=$ $7.8 \mathrm{~Hz}, 6 \mathrm{H}) \mathrm{ppm} ;{ }^{13} \mathrm{C}$ NMR $\left(151 \mathrm{MHz}, \mathrm{CD}_{3} \mathrm{CN}\right): \delta=188.0,163.7,142.6,137.7,132.0$, $131.9,124.8,123.8,100.3,99.2,91.0,87.2,69.9,67.4,64.9,63.6,51.8,22.6,7.3,5.7$ ppm; HRMS (ESI-TOF): calcd for $\mathrm{C}_{24} \mathrm{H}_{28} \mathrm{NO}_{4} \mathrm{Si}^{+}\left[\mathrm{M}+\mathrm{H}^{+}\right]$: 422.1782 , found 422.1785 .

Anthraquinone (+)-42. To a stirred solution of 3-cyano-1(3H)-isobenzofuranone $(7,34 \mathrm{mg}$,

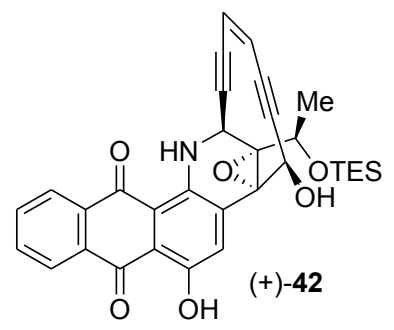
$0.21 \mathrm{mmol}, 3.0$ equiv) in THF $(1.0 \mathrm{~mL})$ at $-78{ }^{\circ} \mathrm{C}$ was added LiHMDS (1.0 M in THF, $0.29 \mathrm{~mL}, 0.29 \mathrm{mmol}, 4.0$ equiv). The resulting mixture was stirred at $-78{ }^{\circ} \mathrm{C}$ for $20 \mathrm{~min}$, and a pre-cooled solution of quinone aminal (+)-13 (39 mg, $72 \mu \mathrm{mol}, 1.0$ equiv) in THF $(1.0 \mathrm{~mL})$ at $-78{ }^{\circ} \mathrm{C}$ was added via cannula. After stirring for $5 \mathrm{~min}$ at $-78{ }^{\circ} \mathrm{C}$, the reaction mixture was allowed to warm up to ambient temperature and stirred for another 50 min during which time the reaction mixture turned dark red and TLC showed full consumption of (+)-13 (silica gel, 8\% EtOAc in $\mathrm{CH}_{2} \mathrm{Cl}_{2}$ ). The reaction mixture was then quenched by the addition of pH 6.8 buffer $(20 \mathrm{~mL})$ and extracted with EtOAc $(3 \times 20 \mathrm{~mL})$. The combined organic extracts were washed with brine $(20 \mathrm{~mL})$, dried over $\mathrm{MgSO}_{4}$, and filtered through a short plug of Celite (washed with EtOAc prior to use). The solids were rinsed with EtOAc, and the combined filtrates were concentrated to yield crude Alloc-anthraquinone $\mathbf{4 3}$ as a 
dark red solid, which was dissolved in degassed THF (1.5 mL) under $\mathrm{Ar}$ and cooled to $0{ }^{\circ} \mathrm{C}$. To this solution was added $\mathrm{Pd}\left(\mathrm{PPh}_{3}\right)_{4}(6 \mathrm{mg}, 5.2 \mu \mathrm{mol}, 0.07$ equiv), followed by dropwise addition of morpholine (16 $\mathrm{mg}, 0.18 \mathrm{mmol}, 2.6$ equiv), the reaction flask was wrapped with aluminium foil, and the resulting mixture was allowed to stir at $0{ }^{\circ} \mathrm{C}$ for $2 \mathrm{~h}$ during which time the reaction mixture turned dark purple. The cooling bath was removed and the reaction mixture was stirred at ambient temperature for $20 \mathrm{~min}$, and then quenched by the addition of $\mathrm{pH} 6.8$ buffer $(20 \mathrm{~mL})$ and extracted with EtOAc $(3 \times 20 \mathrm{~mL})$. The combined organic extracts were washed with saturated aqueous $\mathrm{NaHCO}_{3}(20 \mathrm{~mL})$ and brine $(20 \mathrm{~mL})$, dried over $\mathrm{MgSO}_{4}$, and filtered through a short plug of Celite (washed with EtOAc prior to use). The solids were rinsed with EtOAc, and the combined filtrates were concentrated to ca. $1 \mathrm{~mL}$ in volume. Flash column chromatography [deactivated silica gel (see General Methods), hexanes/EtOAc 2:1 to 1:1] yielded anthraquinone (+)-42 (29 mg, $52 \mu \mathrm{mol}, 73 \%$ yield over the two steps) as a purple solid.

$(+)-42: R_{f}=0.58$ (silica gel, hexanes/EtOAc 3:2); $[\alpha]_{D}{ }^{25}=+2600(c=0.002$, EtOAc); IR (film) $V_{\max }=3429,2955,2876,1788,1620,1587,1487,1277,1234 \mathrm{~cm}^{-1} ;{ }^{1} \mathrm{H}$ NMR $(600$ $\left.\mathrm{MHz}, \mathrm{CD}_{3} \mathrm{CN}\right): \delta=13.18(\mathrm{~s}, 1 \mathrm{H}), 9.98(\mathrm{~d}, J=4.8 \mathrm{~Hz}, 1 \mathrm{H}), 8.48(\mathrm{~s}, 1 \mathrm{H}), 8.29(\mathrm{dd}, J=7.8$, $1.2 \mathrm{~Hz}, 1 \mathrm{H}), 8.28(\mathrm{dd}, J=7.8,1.2 \mathrm{~Hz}, 1 \mathrm{H}), 7.87(\mathrm{td}, J=7.8,1.8 \mathrm{~Hz}, 1 \mathrm{H}), 7.82(\mathrm{td}, J=7.8$, $1.2 \mathrm{~Hz}, 1 \mathrm{H}), 5.96(\mathrm{~d}, J=10.2 \mathrm{~Hz}, 1 \mathrm{H}), 5.88(\mathrm{dt}, J=10.2,1.2 \mathrm{~Hz}, 1 \mathrm{H}), 5.12(\mathrm{~d}, J=4.8 \mathrm{~Hz}$, $1 \mathrm{H}), 4.99(\mathrm{dd}, J=4.2,1.8 \mathrm{~Hz}, 1 \mathrm{H}), 4.56(\mathrm{q}, J=6.0 \mathrm{~Hz}, 1 \mathrm{H}), 4.42(\mathrm{~d}, J=4.8 \mathrm{~Hz}, 1 \mathrm{H})$, $1.39(\mathrm{~d}, J=6.0 \mathrm{~Hz}, 3 \mathrm{H}), 0.99(\mathrm{t}, J=7.8 \mathrm{~Hz}, 9 \mathrm{H}), 0.67$ (q, $J=7.8 \mathrm{~Hz}, 6 \mathrm{H}) \mathrm{ppm} ;{ }^{13} \mathrm{C} \mathrm{NMR}$ $\left(151 \mathrm{MHz}, \mathrm{CD}_{3} \mathrm{CN}\right): \delta=188.7,184.3,156.7,144.8,136.3,135.9,135.6,134.4,133.7$, 131.0, 127.8, 127.1, 124.9, 123.9, 114.3, 112.4, 100.3, 99.8, 91.4, 88.5, 77.4, 66.9, 65.0, 64.9, 44.4, 22.7, 7.3, 5.7 ppm; HRMS (ESI-TOF): calcd for $\mathrm{C}_{32} \mathrm{H}_{32} \mathrm{NO}_{6} \mathrm{Si}^{+}\left[\mathrm{M}+\mathrm{H}^{+}\right]$: 554.1993, found 554.1992. 
Uncialamycin [(+)-1]. To a stirred solution of anthraquinone (+)-42 (29 mg, $52 \mu \mathrm{mol}, 1.0$

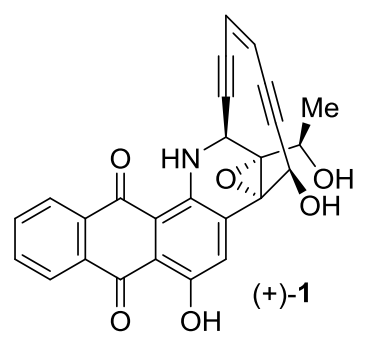
equiv) in degassed THF $(9.0 \mathrm{~mL})$ at room temperature was added a solution of $1: 13 \mathrm{HF} \cdot E t_{3} \mathrm{~N} / \mathrm{THF}(3.0 \mathrm{~mL})$. The sealed reaction flask was wrapped with aluminium foil, and the reaction mixture was stirred at room temperature for $1.5 \mathrm{~h}$, then partitioned between EtOAc $(30 \mathrm{~mL})$ and saturated aqueous $\mathrm{NaHCO}_{3}(30 \mathrm{~mL})$. The organic layer was washed with brine (30 $\mathrm{mL}$ ), dried over $\mathrm{Na}_{2} \mathrm{SO}_{4}$, and concentrated to ca. $1 \mathrm{~mL}$ in volume. Flash column chromatography [deactivated silica gel (see General Methods), hexanes/EtOAc 1:1 to 1:2] yielded uncialamycin [(+)-1] (23 mg, $52 \mu \mathrm{mol}, 99 \%$ yield) as a purple solid.

(+)-1: $\mathrm{mp} 175{ }^{\circ} \mathrm{C}$ (decomp.); $\mathrm{R}_{f}=0.14$ (silica gel, hexanes/EtOAc 3:2); $[\alpha]_{\mathrm{D}}^{25}=+2300(c=$ 0.002, EtOAc); IR (film) $v_{\max }=3429,2926,1715,1620,1587,1484,1355,1234 \mathrm{~cm}^{-1} ;{ }^{1} \mathrm{H}$ NMR (600 MHz, CD $\left.{ }_{3} \mathrm{CN}\right): \delta=13.17(\mathrm{~s}, 1 \mathrm{H}), 10.00(\mathrm{~d}, J=4.2 \mathrm{~Hz}, 1 \mathrm{H}), 8.51(\mathrm{~s}, 1 \mathrm{H}), 8.30$ (dd, $J=7.8,1.2 \mathrm{~Hz}, 1 \mathrm{H}), 8.27(\mathrm{dd}, J=7.8,1.8 \mathrm{~Hz}, 1 \mathrm{H}), 7.86(\mathrm{td}, J=7.8,1.2 \mathrm{~Hz}, 1 \mathrm{H})$, $7.82(\mathrm{td}, J=7.8,1.8 \mathrm{~Hz}, 1 \mathrm{H}), 5.97(\mathrm{~d}, J=7.8 \mathrm{~Hz}, 1 \mathrm{H}), 5.89(\mathrm{dt}, J=9.6,1.2 \mathrm{~Hz}, 1 \mathrm{H}), 5.25$ (d, $J=7.2 \mathrm{~Hz}, 1 \mathrm{H}), 4.92(\mathrm{dd}, J=4.2,1.8 \mathrm{~Hz}, 1 \mathrm{H}), 4.45(\mathrm{~d}, J=4.8 \mathrm{~Hz}, 1 \mathrm{H}), 4.39(\mathrm{qd}, J=$ 6.6, $5.4 \mathrm{~Hz}, 1 \mathrm{H}), 3.27(\mathrm{~d}, J=4.8 \mathrm{~Hz}, 1 \mathrm{H}), 1.39(\mathrm{~d}, J=6.6 \mathrm{~Hz}, 3 \mathrm{~Hz}) \mathrm{ppm} ;{ }^{13} \mathrm{C}$ NMR $(151$ $\left.\mathrm{MHz}, \mathrm{CD}_{3} \mathrm{CN}\right): \delta=188.7,184.4,156.7,144.7,136.2,135.9,135.6,134.5,133.7,131.0$ $127.8,127.1,124.6,124.2,114.4,112.5,100.4,99.2,91.4,88.9,77.1,66.0,65.4,64.8$, 44.4, 21.3 ppm; HRMS (ESI-TOF): calcd for $\mathrm{C}_{26} \mathrm{H}_{18} \mathrm{NO}_{6}{ }^{+}\left[\mathrm{M}+\mathrm{H}^{+}\right]$: 440.1129, found 440.1123.

In the table that follows ${ }^{1} \mathrm{H}$ and ${ }^{13} \mathrm{C}$ NMR data recorded for synthetic uncialamycin $[(+)-1]$ in DMSO-d6 (at $600 \mathrm{MHz}$ for ${ }^{1} \mathrm{H}$ and $151 \mathrm{MHz}$ for ${ }^{13} \mathrm{C}$ ) are presented alongside the corresponding data that have been reported for the isolated natural product. ${ }^{6}$ 
Table S1. Comparison of ${ }^{1} \mathrm{H}$ and ${ }^{13} \mathrm{C}$ NMR of natural and synthetic uncialamycin.

\begin{tabular}{|c|c|c|c|c|}
\hline \multirow{2}{*}{ Position } & \multicolumn{2}{|l|}{ Natural $^{a}$} & \multicolumn{2}{|c|}{ Synthetic $^{b}$} \\
\hline & $\delta^{1} \mathrm{H}$ (mult., $\left.J(\mathrm{~Hz})\right)$ & $\delta^{13} \mathrm{C}$ & $\delta^{1} \mathrm{H}$ (mult., $\left.J(\mathrm{~Hz})\right)$ & $\delta^{13} \mathrm{C}$ \\
\hline 1 & $10.0(\mathrm{~d}, 4.6)$ & & $10.00(\mathrm{~d}, 4.5 \mathrm{~Hz})$ & \\
\hline 2 & & 143.6 & & 143.6 \\
\hline 3 & & 110.4 & & 110.4 \\
\hline 4 & & 187.0 & & 186.9 \\
\hline 5 & & 134.4 & & 134.4 \\
\hline 6 & $8.23(\mathrm{dd}, 1.4,7.6)$ & 126.1 & $8.24(\mathrm{dd}, 7.6,1.4)$ & 126.1 \\
\hline 7 & 7.88 (ddd, 1.4, 7.6, 7.6) & 133.6 & $7.90(\mathrm{dd}, 7.6,7.6,1.4)$ & 133.6 \\
\hline 8 & 7.94 (ddd, 1.4, 7.6, 7.6) & 134.9 & 7.95 (ddd, 7.6, 7.6, 1.4) & 134.9 \\
\hline 9 & $8.24(\mathrm{dd}, 1.4,7.6)$ & 126.6 & $8.25(\mathrm{dd}, 7.6,1.4)$ & 126.6 \\
\hline 10 & & 132.2 & & 132.2 \\
\hline 11 & & 182.2 & & 182.2 \\
\hline 12 & & 112.7 & & 112.7 \\
\hline 13 & & 154.9 & & 154.8 \\
\hline 14 & $8.51(\mathrm{~s})$ & 129.9 & $8.53(\mathrm{~s})$ & 129.9 \\
\hline 15 & & 135.6 & & 135.6 \\
\hline 16 & & 63.5 & & $63.5^{c}$ \\
\hline 17 & $5.14(\mathrm{~d}, 3.3)$ & 63.0 & $5.16(d, 4.8)$ & 62.9 \\
\hline 18 & & 100.4 & & 100.3 \\
\hline 19 & & 89.7 & & 89.6 \\
\hline 20 & $6.05(\mathrm{dd}, 0.8,10)$ & 123.4 & $6.05(\mathrm{~d}, 9.9)$ & 123.3 \\
\hline 21 & $5.97(\mathrm{ddd}, 1.4,1.5,10)$ & 124.0 & $5.98(\mathrm{ddd}, 9.9,1.2,1.2)$ & 123.9 \\
\hline 22 & & 87.4 & & 87.4 \\
\hline 23 & & 98.9 & & 98.8 \\
\hline 24 & $5.04(\mathrm{dd}, 1.5,4.6)$ & 43.2 & $5.06(\mathrm{dd}, 4.5,1.5)$ & 43.2 \\
\hline 25 & & 76.0 & & 75.9 \\
\hline 26 & $4.31(\mathrm{qd}, 6.0,6.0)$ & 63.6 & $4.33(\mathrm{qd}, 6.2,6.2)$ & 63.6 \\
\hline 27 & $1.30(\mathrm{~d}, 6.0)$ & 22.1 & $1.31(\mathrm{~d}, 6.2 \mathrm{~Hz})$ & 22.0 \\
\hline $13-\mathrm{OH}$ & 13.2 (brd.s) & & & \\
\hline $17-\mathrm{OH}$ & 6.66 (brd.s) & & $6.68(\mathrm{~d}, 5.0 \mathrm{~Hz})$ & \\
\hline $26-\mathrm{OH}$ & $5.39(\mathrm{~d}, 6.0)$ & & $5.38(\mathrm{~d}, 5.6)$ & \\
\hline
\end{tabular}

a) Internal reference not specified; b) DMSO- $\left.d_{6}\left(\delta_{\mathrm{H}}=2.50 \mathrm{ppm}, \delta_{\mathrm{C}}=39.5 \mathrm{ppm}\right) ; \mathrm{c}\right)$ this signal has previously been reported erroneously as $\delta 59.7 \mathrm{ppm} .{ }^{3 a}$ 
Bergman cycloaromatization product $( \pm)-47$ from ( \pm )-uncialamycin $[( \pm)-1]$. To a stirred

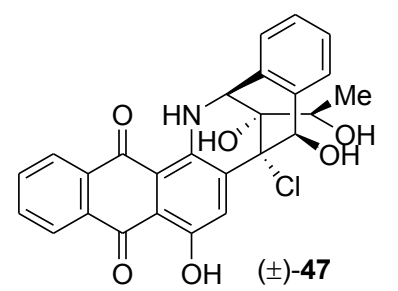

solution of $( \pm)$-uncialamycin $[( \pm)-1](2.0 \mathrm{mg}, 4.6 \mu \mathrm{mol}, 1.0$ equiv $)$ in

$\mathrm{CH}_{2} \mathrm{Cl}_{2}(2 \mathrm{~mL})$ at $25{ }^{\circ} \mathrm{C}$ was added $\mathrm{HCl}\left(0.1 \mathrm{M}\right.$ in $\left.\mathrm{CH}_{2} \mathrm{Cl}_{2}, 0.1 \mathrm{~mL}\right)$. After $5 \mathrm{~min}$, the reaction mixture was diluted with $\mathrm{pH} 6.8$ buffer $(5 \mathrm{~mL})$ and extracted with $\mathrm{CH}_{2} \mathrm{Cl}_{2}(2 \times 5 \mathrm{~mL})$. The organic layer was washed with brine $(5 \mathrm{~mL})$, dried over $\mathrm{MgSO}_{4}$, and concentrated. Flash column chromatography (silica gel, hexanes/EtOAc 2:1 to $1: 1)$ yielded Bergman cycloaromatization product $( \pm)-47$ (2.0 mg, 4.1 $\mu \mathrm{mol}, 90 \%$ yield) as a dark blue solid. Characterization data for $( \pm)-47$ have been reported in reference $3 a$. 


\section{lb. Synthesis of Uncialamycin Analogues}

Protected aminophthalide 62 . To a stirred solution of compound $61(0.50 \mathrm{~g}, 3.4 \mathrm{mmol}$,

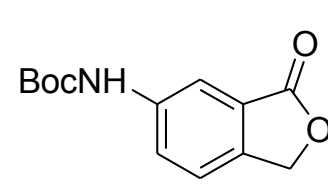

62

1.0 equiv) in THF $(15 \mathrm{~mL})$ at ambient temperature and under an atmosphere of argon was added $\mathrm{Boc}_{2} \mathrm{O}(0.75 \mathrm{~g}, 3.4 \mathrm{mmol}, 1.0$ equiv) and the mixture was heated to reflux for $16 \mathrm{~h}$. It was then allowed to cool to ambient temperature and subsequently concentrated under reduced pressure. The residue was purified by flash column chromatography (silica gel, 20 to $50 \%$ EtOAc in hexanes) to afford in order of elution the Boc protected phthalide $62(0.71 \mathrm{~g}, 2.8 \mathrm{mmol}$, $100 \%$ yield based on $88 \%$ conversion) and unreacted compound 61 (0.06 g, $0.4 \mathrm{mmol})$.

62: white solid, $\mathrm{mp} 166-167^{\circ} \mathrm{C}$ (EtOAc/hexanes); $\mathrm{R}_{f}=0.7$ (silica gel, $50 \%$ EtOAc in hexanes); FT-IR (thin film) $v_{\max }=3321,2979,2936,2881,1772,1746,1722,1630,1604$, $1533,1504,1457,1427,1392,1366,1325,1285,1234,1153,1126,1045,1026,1001$, 940, $914 \mathrm{~cm}^{-1} ;{ }^{1} \mathrm{H}$ NMR $\left(600 \mathrm{MHz}, \mathrm{CDCl}_{3}\right): \delta=7.84(\mathrm{~d}, \mathrm{~J}=2.4 \mathrm{~Hz}, 1 \mathrm{H}), 7.82-7.75(\mathrm{br} \mathrm{s}, 1$ H), $7.39(\mathrm{~d}, J=8.2 \mathrm{~Hz}, 1 \mathrm{H}), 6.90-6.74(\mathrm{br} \mathrm{m}, 1 \mathrm{H}), 5.26(\mathrm{~s}, 2 \mathrm{H}), 1.53$ and $1.52(2 \mathrm{~s}, 9 \mathrm{H})$ ppm; ${ }^{13} \mathrm{C}$ NMR $\left(151 \mathrm{MHz}, \mathrm{CDCl}_{3}\right): \delta=170.8,152.5,140.7,139.7,126.6,124.8,122.6$, 114.7, 81.3, 69.5, 28.3; HRMS (ESI-TOF) calcd for $\mathrm{C}_{13} \mathrm{H}_{15} \mathrm{NO}_{4} \mathrm{Na}^{+}\left[\mathrm{M}+\mathrm{Na}^{+}\right] 222.0893$, found 272.0888 .

Benzamide 63. To a stirred ice-cooled suspension of aluminum chloride (1.10 g,

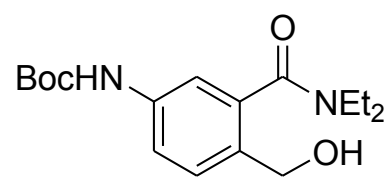

63 $8.25 \mathrm{mmol}, 1.3$ equiv) in $\mathrm{CH}_{2} \mathrm{Cl}_{2}(10.0 \mathrm{~mL})$ was added diethylamine (1.17 g, $16.0 \mathrm{mmol}, 2.5$ equiv) slowly and then the mixture was allowed to stir at the same temperature for $30 \mathrm{~min}$ before a solution of Boc protected phthalide $62(1.60 \mathrm{~g}, 6.42 \mathrm{mmol})$ in $\mathrm{CH}_{2} \mathrm{Cl}_{2}(20.0 \mathrm{~mL})$ was added dropwise over $10 \mathrm{~min}$. The reaction mixture was then heated to $23{ }^{\circ} \mathrm{C}$ and after $15 \mathrm{~min}$ it was cooled back to $0{ }^{\circ} \mathrm{C}$ and quenched with aq. $\mathrm{NH}_{4} \mathrm{Cl}$ solution. The layers were separated, and the aqueous layer was extracted with EtOAc $(3 \times 40 \mathrm{~mL})$. The combined 
organic layers were washed with $\mathrm{H}_{2} \mathrm{O}(50 \mathrm{~mL})$ and brine $(35 \mathrm{~mL})$, dried over $\mathrm{MgSO}_{4}$, and concentrated. The obtained residue was purified by flash column chromatography (silica gel, 50 to $70 \%$ EtOAc in hexanes) to give benzamide alcohol 63 as a white solid (1.70 g, $5.27 \mathrm{mmol}, 82 \%$ yield).

63: $\mathrm{mp} 63-65{ }^{\circ} \mathrm{C}$ (EtOAc/hexanes); $\mathrm{R}_{f}=0.18$ (silica gel, $70 \%$ EtOAc in hexanes); $\mathrm{FT}-\mathrm{IR}$ (neat) $v_{\max }=3312,3062,2984,2940,2909,2877,1794,1736,1622,1542,1499,1478$, $1463,1393,1373,1336,1299,1237,1158,1097,1044 \mathrm{~cm}^{-1} ;{ }^{1} \mathrm{H}$ NMR $\left(600 \mathrm{MHz}, \mathrm{CDCl}_{3}\right)$ : $\delta=7.45(\mathrm{~s}, 1 \mathrm{H}), 7.34(\mathrm{~d}, J=8.4 \mathrm{~Hz}, 1 \mathrm{H}), 7.22(\mathrm{dd}, J=8.4,2.4 \mathrm{~Hz}, 1 \mathrm{H}), 6.52(\mathrm{~s}, 1 \mathrm{H})$, $4.46(\mathrm{~d}, J=6.6 \mathrm{~Hz}, 2 \mathrm{H}), 3.57(\mathrm{q}, J=7.2 \mathrm{~Hz}, 2 \mathrm{H}), 3.39(\mathrm{t}, J=6.6 \mathrm{~Hz}, 1 \mathrm{H}), 3.28(\mathrm{q}, J=7.2$ $\mathrm{Hz}, 2 \mathrm{H}), 1.52(\mathrm{~s}, 9 \mathrm{H}), 1.27$ (t, $J=7.2 \mathrm{~Hz}, 3 \mathrm{H}), 1.12(\mathrm{t}, J=7.2 \mathrm{~Hz}, 3 \mathrm{H}) \mathrm{ppm} ;{ }^{13} \mathrm{C} \mathrm{NMR}$ $\left(151 \mathrm{MHz}, \mathrm{CDCl}_{3}\right): \delta=170.9,152.4,137.7,137.1,133.3,130.7,119.0,115.8,80.9,63.6$, 43.6, 39.5, 28.3, 14.1, 12.8; HRMS (ESI-TOF) calcd for $\mathrm{C}_{17} \mathrm{H}_{26} \mathrm{~N}_{2} \mathrm{O}_{4} \mathrm{Na}^{+}\left[\mathrm{M}+\mathrm{Na}^{+}\right] 345.1785$ found 345.1776 .

Formyl benzamide 64 . To a stirred solution of benzamide alcohol $63(1.20 \mathrm{~g}, 3.72 \mathrm{mmol}$, 64 1.0 equiv) in $\mathrm{CH}_{2} \mathrm{Cl}_{2}(25 \mathrm{~mL})$ at $23{ }^{\circ} \mathrm{C}$ was added $3 \AA \mathrm{MS}(0.6 \mathrm{~g})$ followed by pyridinium dichromate $(2.10 \mathrm{~g}, 5.58 \mathrm{mmol}, 1.5$ equiv). The resulting mixture was stirred at same temperature for $2 \mathrm{~h}$, and filtered through silica gel. The filtrate was concentrated and the obtained residue was purified by flash column chromatography (silica gel, 40 to $60 \%$ EtOAc in hexanes) to give formylbenzamide 64 as an off white solid $(0.74 \mathrm{~g}, 2.31 \mathrm{mmol}, 62 \%$ yield).

64: $\mathrm{mp} 83-84{ }^{\circ} \mathrm{C}$ (EtOAc/hexanes); $\mathrm{R}_{f}=0.35$ (silica gel, $70 \%$ EtOAc in hexanes); $\mathrm{FT}-\mathrm{IR}$ (neat) $v_{\max }=3253,3097,3053,1978,2937,2876,2837,1728,1693,1618,1598,1578$, 1532, 1477, 1460, 1442, 1414, 1393, 1366, 1325, 1292, 1274, 1234, 1154, 1085, 1054 , $1028 \mathrm{~cm}^{-1} ;{ }^{1} \mathrm{H}$ NMR $\left(600 \mathrm{MHz}, \mathrm{CDCl}_{3}\right): \delta=9.91(\mathrm{~s}, 1 \mathrm{H}), 7.87-7.84(\mathrm{~m}, 1 \mathrm{H}), 7.49-7.47(\mathrm{~m}$, $1 \mathrm{H}), 7.41-7.39(\mathrm{~m}, 1 \mathrm{H}), 6.95-6.84(\mathrm{~m}, 1 \mathrm{H}), 3.60(\mathrm{br} \mathrm{s}, 2 \mathrm{H}), 3.14(\mathrm{q}, J=7.2 \mathrm{~Hz}, 2 \mathrm{H})$, 
$1.52(\mathrm{~s}, 9 \mathrm{H}), 1.30$ (t, $J=7.2 \mathrm{~Hz}, 3 \mathrm{H}), 1.05$ (t, $J=7.2 \mathrm{~Hz}, 3 \mathrm{H}) \mathrm{ppm} ;{ }^{13} \mathrm{C}$ NMR $(151 \mathrm{MHz}$, $\left.\mathrm{CDCl}_{3}\right): \delta=189.1,168.3,151.8,143.9,141.2,131.4,127.2,117.7,115.5,81.7,43.0,39.1$, 28.2, 13.9, 12.6 ppm; HRMS (ESI-TOF) calcd for $\mathrm{C}_{17} \mathrm{H}_{24} \mathrm{~N}_{2} \mathrm{O}_{4} \mathrm{Na}^{+}\left[\mathrm{M}+\mathrm{Na}^{+}\right] 343.1628$ found 343.1617.

Cyanophthalide $60 \mathrm{~b}$. To a stirred solution of formylbenzamide $64(0.310 \mathrm{~g}, 0.968 \mathrm{mmol}$,<smiles>CC(C)(C)OC(=O)Nc1ccc2c(c1)C(=O)OC2C#N</smiles>
1.0 equiv.) in $\mathrm{CH}_{2} \mathrm{Cl}_{2}(7 \mathrm{~mL})$ at $0{ }^{\circ} \mathrm{C}$, was added TMSCN $(0.14 \mathrm{~g}, 0.18$ $\mathrm{mL}, 1.4 \mathrm{mmol}, 1.4$ equiv), and a solution of $\mathrm{KCN}(1.6 \mathrm{mg}, 0.02 \mathrm{mmol}$, 0.021 equiv) and 18-crown-6 (5.5 mg, $0.02 \mathrm{mmol}, 0.02$ equiv) in THF $(0.5 \mathrm{~mL})$. The reaction mixture was stirred at the same temperature in a sealed flask for $1.5 \mathrm{~h}$, and for $30 \mathrm{~min}$ at ambient temperature. The reaction mixture was then concentrated under $\mathrm{N}_{2}$ and the residue was co-evaporated with toluene $(2 \times 15 \mathrm{~mL})$ to remove all traces of TMSCN. The resulting brown oil was dissolved in $\mathrm{AcOH}(2 \mathrm{~mL})$ and stirred for $24 \mathrm{~h}$ at room temperature until TLC showed full conversion. The reaction was quenched by careful addition of $1 \mathrm{~N} \mathrm{NaOH}(10 \mathrm{~mL})$, and the resulting mixture was partitioned between EtOAc $(10 \mathrm{~mL})$ and $1 \mathrm{~N} \mathrm{NaOH}(10 \mathrm{~mL})$. The aqueous layer was extracted with EtOAc $(3 \times 20 \mathrm{~mL})$, and the combined organic layers were washed with $\mathrm{H}_{2} \mathrm{O}(30 \mathrm{~mL})$ and brine $(30 \mathrm{~mL})$, dried over $\mathrm{MgSO}_{4}$ and concentrated. The obtained residue was purified by flash column chromatography (silica gel, 15 to $30 \%$ EtOAc in hexanaes) gave cyanophthalide $\mathbf{8 2 b}$ as a slight yellowish solid. (0.22 g, $0.80 \mathrm{mmol}, 83 \%$ yield).

60b: $\mathrm{mp} 159-162{ }^{\circ} \mathrm{C}$ (EtOAc/hexanes); $\mathrm{R}_{f}=0.55$ (silica gel, 50\% EtOAc in hexanes); $\mathrm{FT}-$ $I R$ (neat) $v_{\max }=3354,2981,2845,2299,1785,1710,1626,1609,1540,1501,1432$, $1394,1369,1337,1284,1238,1157,1043,1018 \mathrm{~cm}^{-1} ;{ }^{1} \mathrm{H}$ NMR $\left(600 \mathrm{MHz}, \mathrm{CDCl}_{3}\right): \delta=$ $8.01(\mathrm{~d}, J=1.8 \mathrm{~Hz}, 1 \mathrm{H}), 7.85-7.83(\mathrm{~m}, 1 \mathrm{H}), 7.59(\mathrm{~d}, J=8.4 \mathrm{~Hz}, 1 \mathrm{H}), 6.90(\mathrm{~s}, 1 \mathrm{H}), 6.03$ (s, $1 \mathrm{H}), 1.53(\mathrm{~s}, 9 \mathrm{H}) \mathrm{ppm} ;{ }^{13} \mathrm{C}$ NMR $\left(151 \mathrm{MHz}, \mathrm{CDCl}_{3}\right): \delta=167.2,152.1,141.8,135.3$, 
125.5, 125.4, 123.2, 114.9, 113.9, 81.9, 65.5, 28.2 ppm; HRMS (ESI-TOF) calcd for $\mathrm{C}_{14} \mathrm{H}_{14} \mathrm{~N}_{2} \mathrm{O}_{4} \mathrm{Na}^{+}\left[\mathrm{M}+\mathrm{Na}^{+}\right] 297.0846$ found 297.0853.

Aminocyanophtalide $60 \mathrm{c}$. To a stirred solution of compound $60 \mathrm{~b}(83.3 \mathrm{mg}, 0.30 \mathrm{mmol})$ in<smiles>N#CC1OC(=O)c2cc(N)ccc21</smiles>
1,2-dichloroethane $(25 \mathrm{~mL})$ at ambient temperature and under an atmosphere of argon was added montmorillonite $\mathrm{K} 10(17 \mathrm{mg})$ and the mixture was heated to reflux for $4 \mathrm{~h}$. It was then allowed to cool to ambient temperature and then filtered through a short pad of Celite ${ }^{\mathrm{TM}} 545$. The filtrates were concentrated under reduced pressure to yield pure aminocyanophthalide 60c (51.1 $\mathrm{mg}, 0.29 \mathrm{mmol}, 96 \%)$ as off-white powder.

60c: $\mathrm{mp} 205-206{ }^{\circ} \mathrm{C}$ (EtOAc/hexanes); $\mathrm{R}_{f}=0.2$ (silica gel, 50\% EtOAc in hexanes); FT-IR (thin film) $v_{\max }=3468,3380,3234,1777,1632,1503,1462,1325,1287,1249,1175$, 1041, 1017. 957, $911 \mathrm{~cm}^{-1} ;{ }^{1} \mathrm{H}$ NMR $\left(600 \mathrm{MHz}, \mathrm{CD}_{3} \mathrm{CN}\right): \delta=7.45$ (dd, $\left.J=7.9,6.1 \mathrm{~Hz}, 1 \mathrm{H}\right)$, 7.13-7.05 (m, $1 \mathrm{H}), 7.02(\mathrm{dd}, J=6.2,1.8 \mathrm{~Hz}, 1 \mathrm{H}), 6.14(\mathrm{~d}, J=5.8 \mathrm{~Hz}, 1 \mathrm{H}), 4.74(\mathrm{~s}, 2 \mathrm{H})$ ppm; ${ }^{13} \mathrm{C}$ NMR $\left(151 \mathrm{MHz}, \mathrm{CD}_{3} \mathrm{CN}\right): \delta=169.5,151.9,131.3,126.5,124.5,122.9,116.3$, 109.2, 67.1 ppm; HRMS (ESI-TOF) calcd for $\mathrm{C}_{9} \mathrm{H}_{7} \mathrm{~N}_{2} \mathrm{O}_{2}{ }^{+}\left[\mathrm{M}+\mathrm{H}^{+}\right]$175.0502, found 175.0501.

Methyl ester 66. To a stirred solution of 2,5-dimethyl benzoic acid $(65,5.00 \mathrm{~g}, 33.3 \mathrm{mmol}$,<smiles>COC(=O)c1cc(C)ccc1[N+](=O)[O-]</smiles>

66

1.0 equiv) in methanol $(10 \mathrm{~mL})$ at room temperature was added sulfuric acid $(0.18 \mathrm{~mL}, 3.33 \mathrm{mmol}, 0.1$ equiv). The resulting mixture was heated to reflux for $4 \mathrm{~h}$. The mixture was cooled to room temperature, diluted with EtOAc $(150 \mathrm{~mL})$, washed with water $(50 \mathrm{~mL}), 1 \mathrm{M} \mathrm{NaOH}$ solution $(40 \mathrm{~mL})$ and brine, dried over anhydrous sodium sulfate and concentrated under reduced pressure. The obtained residue was purified by flash column chromatography (silica gel, 1 to $3 \%$ EtOAc in hexanes) to afford pure methyl ester $66^{6}(4.73 \mathrm{~g}, 28.8 \mathrm{mmol}, 86 \%)$ as a colorless oil. 
66: $R_{\mathrm{f}}=0.41$ (silica gel, $5 \%$ ethyl ether in hexanes); FT-IR (neat) $v_{\max }=2951,2927,1719$, $1616,1567,1500,1434,1402,1382,1298,1258,1197,1150,1079,1039,1000,969,897$, 820, 782, 733, 692, $679 \mathrm{~cm}^{-1} ;{ }^{1} \mathrm{H}$ NMR $\left(600 \mathrm{MHz}, \mathrm{CDCl}_{3}\right): \delta=7.72(\mathrm{~d}, J=1.2 \mathrm{~Hz}, 1 \mathrm{H})$, $7.20(\mathrm{~d}, J=7.2,1.2 \mathrm{~Hz}, 1 \mathrm{H}), 7.12(\mathrm{~d}, J=7.2 \mathrm{~Hz}, 1 \mathrm{H}), 3.89(\mathrm{~s}, 3 \mathrm{H}), 2.55(\mathrm{~s}, 3 \mathrm{H}), 2.34(\mathrm{~s}$, $3 \mathrm{H}) \mathrm{ppm} ;{ }^{13} \mathrm{C} \mathrm{NMR}\left(151 \mathrm{MHz}, \mathrm{CDCl}_{3}\right): \delta=168.4,137.2,135.4,132.9,131.8,131.2,129.5$, $51.9,21.4,20.9 \mathrm{ppm}$.

Dibromide $66 \mathrm{a}$. To a stirred solution of methyl ester 66 (4.68 g, $28.5 \mathrm{mmol}, 1.0$ equiv) in

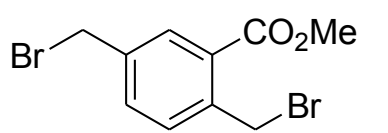

$66 a$ carbon tetrachloride $(20 \mathrm{~mL})$ at room temperature was added $\mathrm{N}$ bromosuccinimide (11.2 g, $62.9 \mathrm{mmol}, 2.2$ equiv). The resulting mixture was heated to reflux for $10 \mathrm{~min}$. Benzoyl peroxide (414 mg,

$1.71 \mathrm{mmol}, 0.06$ equiv) was added in one portion. After $1 \mathrm{~h}$ at the same temperature, the reaction mixture was cooled to room temperature, diluted with EtOAc $(100 \mathrm{~mL})$, washed with saturated aqueous sodium bicarbonate $(30 \mathrm{~mL})$ and brine, dried over anhydrous sodium sulfate and concentrated under reduced pressure. The obtained residue was purified by flash column chromatography (silica gel, 1 to $5 \%$ EtOAc in hexanes) to afford pure dibromide $66 \mathrm{a}^{7}(7.49 \mathrm{~g}, 23.3 \mathrm{mmol}, 82 \%)$ as a white solid.

66a: $\mathrm{mp} 81-82{ }^{\circ} \mathrm{C}$ (EtOAc/hexanes); $R_{\mathrm{f}}=0.31$ (silica gel, $5 \%$ EtOAc in hexanes); FT-IR (neat) $v_{\max }=2953,1721,1611,1572,1500,1434,1412,1312,1278,1218,1203,1156$, 1125, 1107, 1078, 980, 913, 863, 841, 794, 803, 794, 769, $680 \mathrm{~cm}^{-1} ;{ }^{1} \mathrm{H}$ NMR $(600 \mathrm{MHz}$, $\left.\mathrm{CDCl}_{3}\right): \delta=8.00(\mathrm{~d}, J=1.8 \mathrm{~Hz}, 1 \mathrm{H}), 7.52(\mathrm{dd}, J=7.8,1.8 \mathrm{~Hz}, 1 \mathrm{H}), 7.45(\mathrm{~d}, J=7.8 \mathrm{~Hz}, 1$ H), 4.94 (s, $2 \mathrm{H}), 4.48$ (s, $2 \mathrm{H}), 3.96(\mathrm{~s}, 3 \mathrm{H}) \mathrm{ppm} ;{ }^{13} \mathrm{C}$ NMR $\left(151 \mathrm{MHz}, \mathrm{CDCl}_{3}\right): \delta$ = 166.6, 139.6, 138.5, 133.2, 132.5, 132.0, 129.7, 52.6, 32.0, 31.0 ppm.

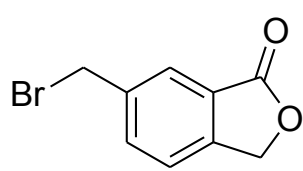

67

Phthalide 67. To a flask was added dibromide 66a $(7.47 \mathrm{~g}, 23.2 \mathrm{mmol}$, 1.0 equiv). The flask was heated to $150{ }^{\circ} \mathrm{C}$ with slightly vacuum for $1.5 \mathrm{~h}$. The resulting compound was purified by flash column chromatography 
(silica gel, 10 to $40 \%$ EtOAc in hexanes) to afford pure phthalide $67^{7}$ (3.60 g, $15.9 \mathrm{mmol}$, $68 \%)$ as a white solid.

67: $\mathrm{mp} 149-150{ }^{\circ} \mathrm{C}$ (EtOAc/hexanes); $R_{\mathrm{f}}=0.21$ (silica gel, 30\% EtOAc in hexanes); FT-IR (neat) $v_{\max }=3043,1758,1625,1588,1490,1456,1434,1364,1314,1287,1236,1223$, 1189, 1151, 1131, 1106, 1052, 998, 922, 912, 837, 773, 733, $694 \mathrm{~cm}^{-1} ;{ }^{1} \mathrm{H}$ NMR $(600 \mathrm{MHz}$, $\left.\mathrm{CDCl}_{3}\right) \delta=7.94(\mathrm{~d}, J=1.8 \mathrm{~Hz}, 1 \mathrm{H}), 7.73(\mathrm{dd}, J=7.8,1.8 \mathrm{~Hz}, 1 \mathrm{H}), 7.49(\mathrm{~d}, J=7.8 \mathrm{~Hz}, 1$ $\mathrm{H}), 5.32(\mathrm{~s}, 2 \mathrm{H}), 4.56(\mathrm{~s}, 2 \mathrm{H}) \mathrm{ppm} ;{ }^{13} \mathrm{C} \mathrm{NMR}\left(151 \mathrm{MHz}, \mathrm{CDCl}_{3}\right) \delta=170.5,146.6,139.6$, 135.1, 126.6, 126.1, 122.9, 69.8, 31.9 ppm; HRMS (ESI) calcd for $\mathrm{C}_{9} \mathrm{H}_{8} \mathrm{O}_{2} \mathrm{Br}^{+}\left[\mathrm{M}+\mathrm{H}^{+}\right]$ 226.9702, found 226.9691 .

Phthalide 68. To a stirred solution of phthalide 67 (1.13 g, $4.98 \mathrm{mmol}, 1.0$ equiv) in dimethylformamide $(5 \mathrm{~mL})$ at room temperature was added
phthalimide $(0.809 \mathrm{~g}, 5.50 \mathrm{mmol}, 1.1$ equiv), potassium carbonate $68 \quad(1.04 \mathrm{~g}, 7.50 \mathrm{mmol}, 1.5$ equiv), tetrabutylammonium iodide $(0.184 \mathrm{~g}$, $0.500 \mathrm{mmol}, 0.1$ equiv). The resulting mixture was heated to $70^{\circ} \mathrm{C}$, and stirred at the same temperature for $1.5 \mathrm{~h}$. The mixture was cooled to room temperature, diluted with dichloromethane $(100 \mathrm{~mL})$, washed with water $(30 \mathrm{~mL})$ and brine, dried over anhydrous sodium sulfate and concentrated under reduced pressure. The obtained residue was purified by flash column chromatography (silica gel, 20 to $50 \%$ EtOAc in hexanes) to afford pure phthalide $68(1.45 \mathrm{~g}, 4.94 \mathrm{mmol}, 99 \%)$ as a white solid.

68: $\mathrm{mp} 187-188{ }^{\circ} \mathrm{C}$ (EtOAc/hexanes); $R_{\mathrm{f}}=0.31$ (silica gel, $50 \%$ EtOAc in hexanes); FT-IR (neat) $v_{\max }=1762,1709,1614,1496,1467,1453,1428,1394,1350,1300,1274,1232$, $1188,1149,1126,1052,1004,947,796,772,747,723,713,700 \mathrm{~cm}^{-1} ;{ }^{1} \mathrm{H}$ NMR $(600 \mathrm{MHz}$, $\left.\mathrm{CDCl}_{3}\right): \delta=7.93(\mathrm{~d}, J=1.8 \mathrm{~Hz}, 1 \mathrm{H}), 7.87(\mathrm{dd}, J=5.4,3.6 \mathrm{~Hz}, 2 \mathrm{H}), 7.76(\mathrm{dd}, J=7.8,1.8$ $\mathrm{Hz}, 1 \mathrm{H}), 7.74(\mathrm{dd}, J=5.4,3.6 \mathrm{~Hz}, 1 \mathrm{H}), 7.46(\mathrm{~d}, J=7.8 \mathrm{~Hz}, 1 \mathrm{H}), 5.28(\mathrm{~s}, 2 \mathrm{H}), 4.96(\mathrm{~s}, 2$ H) $\mathrm{ppm} ;{ }^{13} \mathrm{C} \mathrm{NMR}\left(151 \mathrm{MHz}, \mathrm{CDCl}_{3}\right): \delta=170.8,168.0,146.3,138.1,134.6,134.4(2 \mathrm{C})$, 
132.1, 126.6, 125.5, 123.8 (2C), 122.7, 69.7, 41.1 ppm; HRMS (ESI) calcd for $\mathrm{C}_{17} \mathrm{H}_{12} \mathrm{NO}_{4}$ $\left[\mathrm{M}+\mathrm{H}^{+}\right] 294.0761$, found 294.0751 .

Benzamide 69. To a stirred suspension of aluminum trichloride $(0.574 \mathrm{~g}, 4.31 \mathrm{mmol}, 1.3$ equiv) in dichloromethane $(5 \mathrm{~mL})$ at $0{ }^{\circ} \mathrm{C}$ was added diethylamine $(0.605 \mathrm{~g}, 8.28 \mathrm{mmol}, 2.5$ equiv). The resulting mixture was warmed to room temperature and stirred at the same temperature for $30 \mathrm{~min}$. A solution of phthalide $68(0.972 \mathrm{~g}, 3.31 \mathrm{mmol}, 1.0$ equiv) in dichloromethane $(5 \mathrm{~mL})$ was added to the preformed mixture at $0{ }^{\circ} \mathrm{C}$. After $15 \mathrm{~min}$, the reaction was quenched by adding water $(5 \mathrm{~mL})$. The mixture was stirred for 30 min from $0{ }^{\circ} \mathrm{C}$ to room temperature, and filtered through Celite. The filtrate was extracted with EtOAc $(3 \times 40 \mathrm{~mL})$. The combined organic layers were washed with brine $(30 \mathrm{~mL})$, dried over $\mathrm{Na}_{2} \mathrm{SO}_{4}$ and concentrated. The obtained residue was purified by flash column chromatography (silica gel, 50 to $80 \%$ EtOAc in hexanes) to afford pure hydroxy benzamide 69 (0.942 g, $2.57 \mathrm{mmol}, 78 \%)$ as a viscous oil.

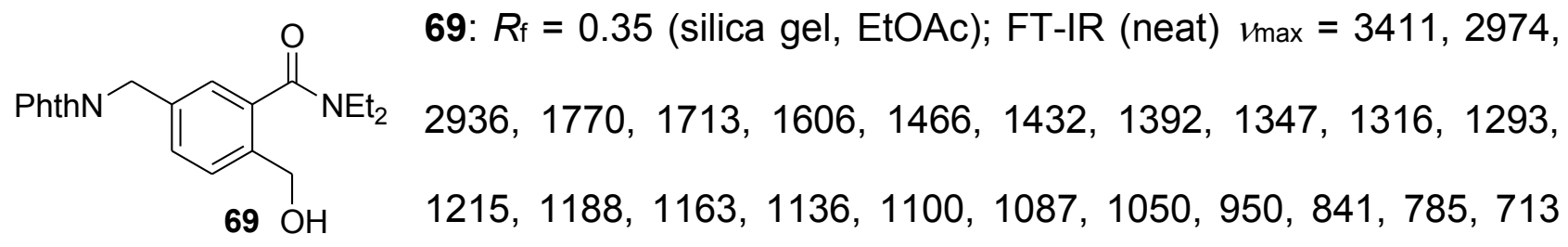
$\mathrm{cm}^{-1} ;{ }^{1} \mathrm{H} \mathrm{NMR}\left(600 \mathrm{MHz}, \mathrm{CDCl}_{3}\right): \delta=7.84(\mathrm{dd}, J=5.4,3.6 \mathrm{~Hz}, 1 \mathrm{H}), 7.72(\mathrm{dd}, J=5.4,3.6$ $\mathrm{Hz}, 1 \mathrm{H}), 7.47(\mathrm{dd}, J=7.8,1.8 \mathrm{~Hz}, 1 \mathrm{H}), 7.39(\mathrm{~d}, J=7.8 \mathrm{~Hz}, 1 \mathrm{H}), 7.33(\mathrm{~d}, J=1.8 \mathrm{~Hz}, 1 \mathrm{H})$, 4.84 (s, 2 H), 4.48 (s, 2 H), 3.55 (q, J = $7.2 \mathrm{~Hz}, 2 \mathrm{H}$ ), 3.20 (q, J = $7.2 \mathrm{~Hz}, 2 \mathrm{H}$ ), 1.63 (br s, 1 $\mathrm{H}), 1.26(\mathrm{t}, J=7.2 \mathrm{~Hz}, 3 \mathrm{H}), 1.08(\mathrm{t}, J=7.2 \mathrm{~Hz}, 3 \mathrm{H}) \mathrm{ppm} ;{ }^{13} \mathrm{C} \mathrm{NMR}\left(151 \mathrm{MHz}, \mathrm{CDCl}_{3}\right): \delta=$ 171.1, 168.1, 138.6, 136.7, 136.0, 134.3 (2C), 132.2, 130.5, 130.2, 126.5, 123.6, 63.9, 43.6, 41.3, 39.6, 14.1, 12.9 ppm; HRMS (ESI) calcd for $\mathrm{C}_{21} \mathrm{H}_{22} \mathrm{~N}_{2} \mathrm{O}_{4} \mathrm{Na}^{+}\left[\mathrm{M}+\mathrm{Na}^{+}\right] 389.1472$, found 389.1473 .

Formyl benzamide 70. To a stirred solution of benzamide alcohol 
room temperature was added $3 \AA$ MS $(0.483 \mathrm{~g})$, followed by pyridinium dichromate $(1.45 \mathrm{~g}$ $3.86 \mathrm{mmol}, 1.5$ equiv). The resulting mixture was stirred at the same temperature $7.5 \mathrm{~h}$, and filtered through silica gel. The filtrate was concentrated, and the obtained residue was purified by flash column chromatography (silica gel, 20 to $70 \%$ EtOAc in hexanes) to afford pure formyl benzamide $70(0.593 \mathrm{~g}, 1.63 \mathrm{mmol}, 63 \%)$ as a viscous oil.

70: $R_{\mathrm{f}}=0.24$ (silica gel, 60\% EtOAc in hexanes); FT-IR (neat) $v_{\max }=2976,2936,2754$, $1771,1711,1627,1605,1575,1494,1467,1433,1389,1348,1316,1282,1206,1189$, 1163, 1099, 1087, 950, 920, 844, 802, 728, $713 \mathrm{~cm}^{-1} ;{ }^{1} \mathrm{H}$ NMR $\left(600 \mathrm{MHz}, \mathrm{CDCl}_{3}\right): \delta=9.99$ (s, $1 \mathrm{H}$ ), 7.88 (d, J = 7.8 Hz, $1 \mathrm{H}$ ), 7.85 (dd, J = 5.4, 3.0 Hz, $2 \mathrm{H}$ ), 7.72 (dd, J = 5.4, 3.0 Hz, $1 \mathrm{H}), 7.57(\mathrm{dd}, J=7.8,1.2 \mathrm{~Hz}, 1 \mathrm{H}), 7.38(\mathrm{~d}, J=1.2 \mathrm{~Hz}, 1 \mathrm{H}), 4.89(\mathrm{~s}, 2 \mathrm{H}), 3.58(\mathrm{q}, J=7.2$ $\mathrm{Hz}, 2 \mathrm{H}$ ), 3.07 (q, J = 7.2 Hz, $2 \mathrm{H}$ ), $1.28(\mathrm{t}, J=7.2 \mathrm{~Hz}, 3 \mathrm{H}), 1.00$ (t, $J=7.2 \mathrm{~Hz}, 3 \mathrm{H}) \mathrm{ppm}$; ${ }^{13} \mathrm{C}$ NMR $\left(151 \mathrm{MHz}, \mathrm{CDCl}_{3}\right): \delta=190.1,168.4,167.9,142.8,140.2,134.4,132.2,132.0$, 130.5, 129.3, 126.9, 123.7, 43.2, 41.2, 39.3, 13.9, 12.8 ppm; HRMS (ESI) calcd for $\mathrm{C}_{21} \mathrm{H}_{20} \mathrm{~N}_{2} \mathrm{O}_{4} \mathrm{Na}\left[\mathrm{M}+\mathrm{Na}^{+}\right] 387.1315$, found 387.1297.

Cyano phthalide 60d. To a stirred solution of formyl benzamide $70(0.490 \mathrm{~g}, 1.34 \mathrm{mmol}$, (c) 1.0 equiv) in $\mathrm{CH}_{2} \mathrm{Cl}_{2} / \mathrm{THF}(1: 1,4 \mathrm{~mL})$ at $0{ }^{\circ} \mathrm{C}$ was added $\mathrm{KCN}(8.8$ mg, $0.14 \mathrm{mmol}, 0.1$ equiv), 18-C-6 (35.7 mg, $0.14 \mathrm{mmol}, 0.1$ equiv), followed by TMSCN $(0.34 \mathrm{~mL}, 2.70 \mathrm{mmol}, 2.0$ equiv). The resulting mixture was warmed to room temperature and stirred at the same temperature for $2.5 \mathrm{~h}$. The solvent was removed under reduced pressure, and the residue was co-evaporated with toluene $(2 \times 2 \mathrm{~mL})$ to remove all traces of TMSCN. The resulting brown oil was dissolved in $\mathrm{AcOH}(2 \mathrm{~mL})$, and $p$-toluenesulfonic acid (12.8 mg, $0.068 \mathrm{mmol}, 0.05$ equiv) was added. The resulting mixture was stirred for $24 \mathrm{~h}$ at $40{ }^{\circ} \mathrm{C}$. The solvent was removed under reduced pressure and the obtained residue was purified by flash column chromatography (silica gel, 10 to $50 \%$ EtOAc in hexanes) to afford pure cyano phthalide 60d (0.390 g, $1.23 \mathrm{mmol}, 92 \%)$ as a white solid. 
60d: $\mathrm{mp} 224-225^{\circ} \mathrm{C}$ (EtOAc/hexanes); $R_{\mathrm{f}}=0.34$ (silica gel, 50\% EtOAc in hexanes); FTIR (neat) $\nu_{\max }=1789,1713,1614,1494,1468,1428,1395,1354,1277,1190,1149,1122$, 1046, 1021, 950, 912, 764, 749, 724, $713 \mathrm{~cm}^{-1} ;{ }^{1} \mathrm{H}$ NMR $\left(600 \mathrm{MHz}, \mathrm{CDCl}_{3}\right): \delta=8.00(\mathrm{~d}, J$ $=1.2 \mathrm{~Hz}, 1 \mathrm{H}), 7.92(\mathrm{dd}, J=7.8,1.2 \mathrm{~Hz}, 1 \mathrm{H}), 7.88(\mathrm{dd}, J=5.4,3.6 \mathrm{~Hz}, 1 \mathrm{H}), 7.75(\mathrm{dd}, J=$ 5.4, 3.6 Hz, $1 \mathrm{H}), 7.67$ (d, J = 7.8 Hz, $1 \mathrm{H}), 6.04$ (s, $1 \mathrm{H}), 4.99$ (s, $2 \mathrm{H}) \mathrm{ppm} ;{ }^{13} \mathrm{C}$ NMR $(151$ $\left.\mathrm{MHz}, \mathrm{CDCl}_{3}\right): \delta=167.9(2 \mathrm{C}), 167.1,141.4,140.9,136.2,134.6(2 \mathrm{C}), 132.0,126.5,125.3$, 123.9 (2C), 123.3, 113.8, 65.7, 41.0 ppm; HRMS (ESI) calcd for $\mathrm{C}_{18} \mathrm{H}_{11} \mathrm{~N}_{2} \mathrm{O}_{4}{ }^{+}\left[\mathrm{M}+\mathrm{Na}^{+}\right]$ 319.0713, found 319.0715 .

\section{Scheme S1. Synthesis of $60 e .^{a}$}

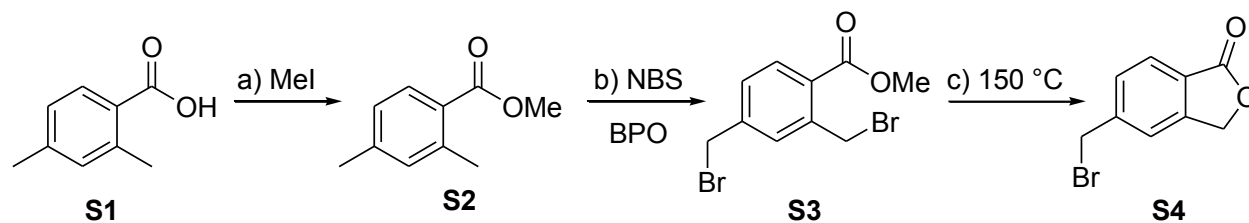

S1

S2

S3

d) PhthNH
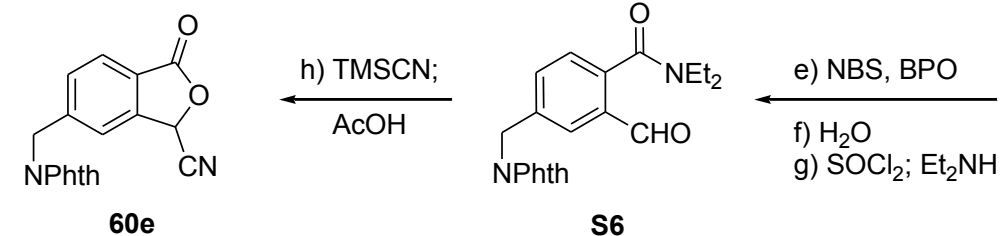

S6

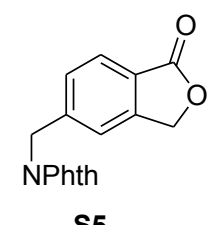

aReagents and Conditions: a) Mel (1.2 equiv), $\mathrm{K}_{2} \mathrm{CO}_{3}$ (1.5 equiv), DMF, rt, $5 \mathrm{~h}, 96 \%$; b) NBS (2.5 equiv), BPO (0.01 equiv), CCl4, reflux, $8 \mathrm{~h}$; c) $150{ }^{\circ} \mathrm{C}, 1.0 \mathrm{~h}, 55 \%$ over the two steps; d) PhthNH (1.1 equiv), $\mathrm{Cs}_{2} \mathrm{CO}_{3}$ (1.5 equiv), $n$-Bu4NI (0.1 equiv), DMF, $40{ }^{\circ} \mathrm{C}, 7.0 \mathrm{~h}$, $65 \%$; e) NBS (1.2 equiv), AIBN (0.2 equiv), $\mathrm{PhH} \mathrm{CCl}_{4}, 85^{\circ} \mathrm{C}, 2 \mathrm{~h}$; f) $\mathrm{H}_{2} \mathrm{O}: \mathrm{THF}(1: 1), 85^{\circ} \mathrm{C}$, 5 h; g) $\mathrm{SOCl}_{2}$, reflux, 2 h; Et $2 \mathrm{NH}$ (1.8 equiv), $\mathrm{CH}_{2} \mathrm{Cl}_{2}$, rt, 2 h, $54 \%$ (3 steps); h) TMSCN (2.0 equiv), $\mathrm{KCN}$ (0.03 equiv), 18-C-6 (0.02 equiv), $\mathrm{CH}_{2} \mathrm{Cl}_{2}, 25^{\circ} \mathrm{C}, 1.5 \mathrm{~h}$; $\mathrm{AcOH}$, rt , $48 \mathrm{~h}, 80 \%$.

Methyl ester S2. To a stirred solution of 2,6-dimethylbenzoic acid (S1, $6.00 \mathrm{~g}, 40.0 \mathrm{mmol}$,<smiles>CC(=O)Oc1cc(C)ccc1C(C)=O</smiles>

1.0 equiv) in DMF $(50 \mathrm{~mL})$ at $0{ }^{\circ} \mathrm{C}$ was added anhydrous $\mathrm{K}_{2} \mathrm{CO}_{3}(8.28 \mathrm{~g}$, $60.0 \mathrm{mmol}, 1.5$ equiv), followed by Mel $(6.82 \mathrm{~g}, 2.99 \mathrm{~mL}, 48 \mathrm{mmol}, 1.2$ equiv) dropwise over 3 min under vigorous stirring. Upon completion of addition, the reaction mixture was stirred for additional $5 \mathrm{~h}$ at room temperature, then poured into $\mathrm{H}_{2} \mathrm{O}(100 \mathrm{~mL})$ and extracted with $\mathrm{Et}_{2} \mathrm{O}(3 \times 100 \mathrm{~mL})$. The combined organic layers were washed with water $(3 \times 50 \mathrm{~mL})$ and brine $(2 \times 50 \mathrm{~mL})$, dried over $\mathrm{MgSO}_{4}$ and 
concentrated under reduced pressure. The obtained residue was purified by flash column chromatography (silica gel, 1 to $4 \%$ EtOAc in hexanes) to yield pure methyl ester S2 6.29 g, $38.4 \mathrm{mmol}, 96 \%)$ as a colorless oil.

S2: $\mathrm{R}_{f}=0.45$ (silica gel, $5 \%$ EtOAc in hexanes); FT-IR (neat) $v_{\max }=2951,2927,1718$, $1614,1571,1499,1434,1289,1258,1236,1189,1152,1084,1039,970 \mathrm{~cm}^{-1} ;{ }^{1} \mathrm{H}$ NMR $\left(600 \mathrm{MHz}, \mathrm{CDCl}_{3}\right): \delta=7.83(\mathrm{~d}, J=7.8 \mathrm{~Hz}, 1 \mathrm{H}), 7.05(\mathrm{~s}, 1 \mathrm{H}), 7.04(\mathrm{~d}, J=7.8 \mathrm{~Hz}, 1 \mathrm{H})$, $3.87(\mathrm{~s}, 3 \mathrm{H}), 2.58(\mathrm{~s}, 3 \mathrm{H}), 2.34(\mathrm{~s}, 3 \mathrm{H}) \mathrm{ppm} ;{ }^{13} \mathrm{C} \mathrm{NMR}\left(151 \mathrm{MHz}, \mathrm{CDCl}_{3}\right): \delta=167.9$, 142.4, 140.3, 132.4, 130.7, 126.5, 126.3, 51.5, 21.7, 21.3 ppm; HRMS (ESI-TOF) calcd for $\mathrm{C}_{10} \mathrm{H}_{13} \mathrm{O}_{2}{ }^{+}[\mathrm{M}+\mathrm{H}]^{+} 165.0910$ found 165.0912.

Dibromo ester S3. To a stirred solution of methyl ester $\mathbf{S} 2(7.00 \mathrm{~g}, 42.7 \mathrm{mmol}, 1.0$ equiv)

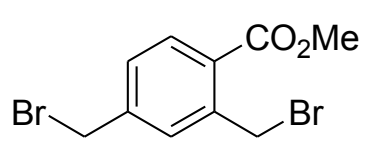

S3

in $\mathrm{CCl}_{4}(50 \mathrm{~mL})$ at room temperature was added $\mathrm{N}$-bromosuccinimide (19.3 g, $107 \mathrm{mmol}, 2.5$ equiv). Then the reaction mixture was heated to $80^{\circ} \mathrm{C}$ and benzoyl peroxide (104 $\mathrm{mg}, 0.427 \mathrm{mmol}, 0.01$ equiv) was added in one portion. Heating was continued for $8 \mathrm{~h}$ and the reaction mixture was then cooled to ambient temperature, and stored at $0{ }^{\circ} \mathrm{C}$ for $3 \mathrm{~h}$. The reaction mixture was then filtered, and the precipitates were rinsed with $\mathrm{CCl}_{4}\left(0-5{ }^{\circ} \mathrm{C}\right)$. The combined filtrates were then washed with saturated aqueous $\mathrm{NaHCO}_{3}(125 \mathrm{~mL})$ and brine $(75 \mathrm{~mL})$, dried over $\mathrm{MgSO}_{4}$, and concentrated under reduced pressure. The obtained residue was purified by flash column chromatography (silica gel, 1 to $5 \%$ EtOAc in hexanes) to give a mixture (ca 3:1) of dibromoester $\mathbf{S} \mathbf{3}^{7}$ and a tribromoester $(11.0 \mathrm{~g})$ as a white solid.

S3: $R_{f}=0.52$ (silica gel, $10 \%$ EtOAc in hexanes); FT-IR (neat mixture) $v_{\max }=3000,2951$, $2841,2309,1718,1610,1572,1498,1433,1373,1268,1219,1191,1118,1078,1046$, $971 \mathrm{~cm}^{-1} ;{ }^{1} \mathrm{H}$ NMR $\left(600 \mathrm{MHz}, \mathrm{CDCl}_{3}\right)$, only signals assigned to $\mathbf{S} 3$ are reported: $\delta=7.94$ $(\mathrm{d}, J=8.4 \mathrm{~Hz}, 1 \mathrm{H}), 7.48(\mathrm{~d}, J=1.8 \mathrm{~Hz}, 1 \mathrm{H}), 7.39(\mathrm{dd}, J=8.4,1.8 \mathrm{~Hz}, 1 \mathrm{H}), 4.93(\mathrm{~s}, 2 \mathrm{H})$, $4.46(\mathrm{~s}, 2 \mathrm{H}), 3.94(\mathrm{~s}, 3 \mathrm{H}) \mathrm{ppm} ;{ }^{13} \mathrm{C} \mathrm{NMR}\left(151 \mathrm{MHz}, \mathrm{CDCl}_{3}\right)$, all signals are reported: $\delta=$ 
166.4, 166.0, 145.5, 142.2, 139.8, 139.8, 132.1, 131.9, 131.8, 130.1, 129.5, 128.9, 128.8, $126.6,52.5,52.4,38.9,31.5,31.0,30.6 \mathrm{ppm}$.

Bromophthalide S4. To a flask was added neat the above mixture $(11 \mathrm{~g})$. The flask was heated to $150{ }^{\circ} \mathrm{C}$ with slight vacuum for $1 \mathrm{~h}$. The reaction mixture was cooled to ambient temperature and the obtained brown residue was purified by flash column chromatography (silica gel, 10 to $30 \%$ EtOAc in hexanes) to afford bromophthalide $\mathbf{S} 4(5.29 \mathrm{~g}, 23.3 \mathrm{mmol}$, $55 \%$ over the two steps) as a white solid.

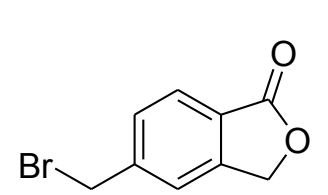

S4

S4: $\mathrm{mp} 156-160{ }^{\circ} \mathrm{C} ; \mathrm{R}_{f}=0.21$ (silica gel, $20 \%$ EtOAc in hexanes); FT-IR (neat) $v_{\max }=3055,3021,1746,1710,1621,1460,1355,1322,1286$, 1217, 1056, $996 \mathrm{~cm}^{-1} ;{ }^{1} \mathrm{H}$ NMR $\left(600 \mathrm{MHz}, \mathrm{CDCl}_{3}\right): \delta=7.90(\mathrm{~d}, J=7.8$ $\mathrm{Hz}, 1 \mathrm{H}), 7.55$ (d, J = $7.8 \mathrm{~Hz}, 1 \mathrm{H}), 7.52(\mathrm{~s}, 1 \mathrm{H}), 5.31$ (s, $2 \mathrm{H}), 4.56(\mathrm{~s}, 2 \mathrm{H}) \mathrm{ppm} ;{ }^{13} \mathrm{C} \mathrm{NMR}$ $\left(151 \mathrm{MHz}, \mathrm{CDCl}_{3}\right): \delta=170.3,147.2,144.3,130.1,126.2,125.8,122.6,69.4,31.8 \mathrm{ppm} ;$ HRMS (ESI-TOF) calcd for $\mathrm{C}_{9} \mathrm{H}_{8} \mathrm{O}_{2} \mathrm{Br}^{+}\left[\mathrm{M}+\mathrm{H}^{+}\right] 226.9702$ found 226.9707.

Phthalide S5. To stirred solution of bromophthalide S4 $(10.0 \mathrm{~g}, 44.3 \mathrm{mmol}, 1.0$ equiv) in DMF $(25 \mathrm{~mL})$ at $25{ }^{\circ} \mathrm{C}$ was added anhydrous $\mathrm{Cs}_{2} \mathrm{CO}_{3}(21.6 \mathrm{~g}, 66.4 \mathrm{mmol}, 1.5$ equiv) and $n$ -

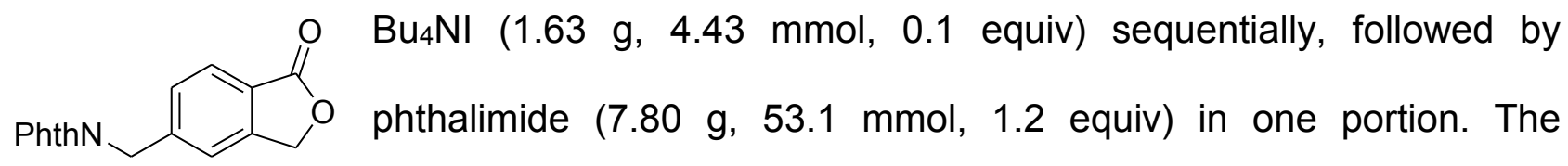
S5 reaction mixture was stirred at $40{ }^{\circ} \mathrm{C}$ for $7 \mathrm{~h}$, then poured into $\mathrm{H}_{2} \mathrm{O}$ $(100 \mathrm{~mL})$ and vigorously stirred for $15 \mathrm{~min}$ and extracted with EtOAc $(3 \times 40 \mathrm{~mL})$. The combined organic layers were washed with water $(3 \times 30 \mathrm{~mL})$ and brine $(2 \times 30 \mathrm{~mL})$, dried over $\mathrm{MgSO}_{4}$ and concentrated under reduced pressure. The obtained residue was purified by flash column chromatography (silica gel, 5 to 10\% EtOAc in dichloromethane) to yield pure phthalide S5 (10.5 g, $28.8 \mathrm{mmol}, 65 \%)$ as a white solid.

S5: $\mathrm{mp} 192-193^{\circ} \mathrm{C} ; \mathrm{R}_{f}=0.3$ (silica gel, $40 \%$ EtOAc in hexanes); FT-IR (neat) $v_{\max }=3040$, $1763,1712,1395,1364,1113,1022,950 \mathrm{~cm}^{-1} ;{ }^{1} \mathrm{H}$ NMR $\left(600 \mathrm{MHz}, \mathrm{CDCl}_{3}\right): \delta=7.88(\mathrm{dd}, J$ 
$=5.4,3.0 \mathrm{~Hz}, 2 \mathrm{H}), 7.87(\mathrm{~d}, J=7.8 \mathrm{~Hz}, 1 \mathrm{H}), 7.75(\mathrm{dd}, J=5.4,3.0 \mathrm{~Hz}, 2 \mathrm{H}), 7.60(\mathrm{~d}, J=$ $7.8 \mathrm{~Hz}, 1 \mathrm{H}), 7.55$ (s, $1 \mathrm{H}), 5.28$ (s, $2 \mathrm{H}), 4.96$ (s, $\left.2 \mathrm{H}) \mathrm{ppm} ;{ }^{13} \mathrm{C} \mathrm{NMR} \mathrm{(151} \mathrm{MHz,} \mathrm{CDCl}_{3}\right): \delta$ $=170.5,167.8,147.2,142.8,134.3,131.9,129.6,126.2,125.4,123.6,122.2,69.5,41.4$ ppm; HRMS (ESI-TOF) calcd for $\mathrm{C}_{17} \mathrm{H}_{11} \mathrm{NO}_{4} \mathrm{Na}^{+}\left[\mathrm{M}+\mathrm{Na}^{+}\right] 316.0580$ found 316.0575.

Formylbenzamide S6. To a stirred suspension of phthalide S5 $(2.00 \mathrm{~g}, 6.81 \mathrm{mmol}, 1.0$ $\underbrace{1}_{\mathrm{S} 6}$ equiv) in $\mathrm{CCl}_{4} /$ benzene $(50 \mathrm{~mL}, 1: 1)$ at ambient temperature, was added $N$-bromosuccinimide (1.47 g, $8.16 \mathrm{mmol}, 1.2$ equiv) in one portion. The reaction mixture was heated to reflux, and azobisisobutyronitrile $(0.23 \mathrm{~g}, 1.36 \mathrm{mmol}, 0.2$ equiv) was added in one portion. The reaction mixture was vigorously stirred at reflux for another $2 \mathrm{~h}$, then cooled to ambient temperature, and stored at $0{ }^{\circ} \mathrm{C}$ for $8 \mathrm{~h}$. The reaction mixture was filtered, and the precipitates were rinsed with $\mathrm{CCl}_{4}\left(0-5{ }^{\circ} \mathrm{C}\right)$. The combined filtrates were then washed with saturated aqueous $\mathrm{NaHCO}_{3}(25 \mathrm{~mL})$ and brine $(25 \mathrm{~mL})$, dried over $\mathrm{Mg}_{2} \mathrm{SO}_{4}$, and concentrated to yield crude product as a yellow foam, which was suspended in $\mathrm{H}_{2} \mathrm{O} / \mathrm{THF}$ (60 mL, 1:1). The suspension was stirred at $85{ }^{\circ} \mathrm{C}$ for $5 \mathrm{~h}$ and cooled to ambient temperature. The reaction mixture was extracted with EtOAc $(5 \times 30 \mathrm{~mL})$, and the combined organic layers were dried over $\mathrm{MgSO}_{4}$ and concentrated to yield crude formylbenzoic acid as a yellow hygroscopic solid, which was dried over $\mathrm{P}_{2} \mathrm{O}_{5}$ for a further 8 h. The crude formylbenzoic acid was suspended in $\mathrm{SOCl}_{2}(12 \mathrm{~mL})$ and the reaction mixture heated at reflux for $2 \mathrm{~h}$. The reaction mixture was concentrated under $\mathrm{N}_{2}$ and the residue was co-evaporated with toluene $(2 \times 15 \mathrm{~mL})$ to remove all traces of $\mathrm{SOCl}_{2}$. The crude product was dissolved in $\mathrm{CH}_{2} \mathrm{Cl}_{2}(15 \mathrm{~mL})$ and the reaction mixture was cooled to $0{ }^{\circ} \mathrm{C}$. A solution of diethylamine $\left(0.89 \mathrm{~g}, 12.2 \mathrm{mmol}, 1.8\right.$ equiv) in $\mathrm{CH}_{2} \mathrm{Cl}_{2}(4 \mathrm{~mL})$ was added dropwise. After ice bath was removed, the reaction mixture was stirred at $25^{\circ} \mathrm{C}$ for $2 \mathrm{~h}$. The reaction was quenched with $1 \mathrm{~N} \mathrm{HCl}(30 \mathrm{~mL})$, and the reaction mixture was extracted with $\mathrm{CH}_{2} \mathrm{Cl}_{2}(2 \times 30 \mathrm{~mL})$. The combined organic layers were washed with brine 
(25 $\mathrm{mL}$ ), dried over $\mathrm{MgSO}_{4}$ and concentrated under reduced pressure. The obtained residue was purified by flash column chromatography (silica gel, 5 to $10 \%$ EtOAc in dichloromethane) to afford formylbenzamide $\mathbf{S} 6$ as a yellowish foam $(1.34 \mathrm{~g}, 3.67 \mathrm{mmol}$, $54 \%$ yield over three steps).

S6: $R_{f}=0.30$ (silica gel, 50\% EtOAc in hexanes); FT-IR (neat) $v_{\max }=3471,2977,2936$, $2874,2754,2252,1772,1712,1626,1567,1501,1467,1429,1392,1437,1318,1288$, 1266, 1155, 1100, 1086, $951 \mathrm{~cm}^{-1} ;{ }^{1} \mathrm{H}$ NMR $\left(600 \mathrm{MHz}, \mathrm{CDCl}_{3}\right): \delta=10.00$ (s, $\left.1 \mathrm{H}\right), 7.95$ (d, $J=1.8 \mathrm{~Hz}, 1 \mathrm{H}), 7.86(\mathrm{dd}, J=5.4,3.0 \mathrm{~Hz}, 2 \mathrm{H}), 7.73(\mathrm{dd}, J=5.6,3.0 \mathrm{~Hz}, 2 \mathrm{H}), 7.69(\mathrm{dd}, J$ $=7.8,1.8 \mathrm{~Hz}, 1 \mathrm{H}), 7.30(\mathrm{~d}, J=7.8 \mathrm{~Hz}, 1 \mathrm{H}), 4.91(\mathrm{~s}, 2 \mathrm{H}), 3.58(\mathrm{q}, J=7.2 \mathrm{~Hz}, 2 \mathrm{H}), 3.08$ (q, $J=7.2 \mathrm{~Hz}, 2 \mathrm{H}), 1.28(\mathrm{t}, J=7.2 \mathrm{~Hz}, 3 \mathrm{H}), 1.00(\mathrm{t}, J=7.2 \mathrm{~Hz}, 3 \mathrm{H}) \mathrm{ppm} ;{ }^{13} \mathrm{C}$ NMR $(151$ $\left.\mathrm{MHz}, \mathrm{CDCl}_{3}\right): \delta=190.2,168.3,167.8,138.9,137.6,134.2,134.1,132.9,131.9,130.0$, 127.3, 123.5, 42.9, 40.8, 39.0, 13.8, 12.5 ppm; HRMS (ESI-TOF) calcd for $\mathrm{C}_{21} \mathrm{H}_{20} \mathrm{~N}_{2} \mathrm{O}_{4} \mathrm{Na}^{+}$ $\left[\mathrm{M}+\mathrm{Na}^{+}\right] 387.1315$ found 387.1320 .

Cyanophthalide $60 \mathrm{e}$. To a stirred solution of formylbenzamide $\mathbf{S 6}(0.24 \mathrm{~g}, 0.66 \mathrm{mmol}, 1.0$ equiv) in $\mathrm{CH}_{2} \mathrm{Cl}_{2}(4 \mathrm{~mL})$ at $0{ }^{\circ} \mathrm{C}$, was added $\mathrm{TMSCN}(130 \mathrm{mg}, 0.17$
$\mathbf{6 0 \mathrm { e }} \mathrm{CN}, 1.31 \mathrm{mmol}, 2.0$ equiv), followed by a solution of $\mathrm{KCN}(1.1 \mathrm{mg}$, $0.02 \mathrm{mmol}, 0.025$ equiv) and 18 -crown-6 $(3.5 \mathrm{mg}, 0.02 \mathrm{mmol}, 0.02$ equiv) in THF $(0.3 \mathrm{~mL})$. The reaction mixture was stirred at $25^{\circ} \mathrm{C}$ in a sealed flask for $1.5 \mathrm{~h}$. The reaction mixture was then concentrated under $\mathrm{N}_{2}$ and the residue was co-evaporated with toluene $(2 \times 25 \mathrm{~mL})$ to remove all traces of TMSCN. The resulting brown oil was dissolved in $\mathrm{AcOH}(3 \mathrm{~mL})$ and stirred for $48 \mathrm{~h}$ at room temperature until TLC showed full conversion. The reaction was quenched by careful addition of $1 \mathrm{~N} \mathrm{NaOH}(10 \mathrm{~mL})$, and the resulting mixture was partitioned between EtOAc $(20 \mathrm{~mL})$ and water. The aqueous layer was extracted with EtOAc $(3 \times 20 \mathrm{~mL})$, and the combined organic layers were washed with $\mathrm{H}_{2} \mathrm{O}(20 \mathrm{~mL})$ and brine $(20 \mathrm{~mL})$, dried over $\mathrm{MgSO}_{4}$ and concentrated under reduced 
pressure. The obtained residue was purified by flash column chromatography (silica gel, 35 to $45 \%$ EtOAc in hexanes) to give cyanophthalide $60 \mathrm{e}$ as a white solid (169 mg, 0.53 $\mathrm{mmol}, 80 \%$ yield).

60e: $\mathrm{mp} 205-208{ }^{\circ} \mathrm{C}$ (EtOAc/hexanes); $\mathrm{R}_{f}=0.55$ (silica gel, 50\% EtOAc in hexanes); FTIR (neat) $v_{\max }=3054,1786,1715,1615,1422,1395,1246,1086,1033,950 \mathrm{~cm}^{-1} ;{ }^{1} \mathrm{H}$ $\operatorname{NMR}\left(600 \mathrm{MHz}, \mathrm{CDCl}_{3}\right): \delta=7.95(\mathrm{~d}, J=7.8 \mathrm{~Hz}, 1 \mathrm{H}), 7.89(\mathrm{dd}, J=5.4,3.0 \mathrm{~Hz}, 2 \mathrm{H}), 7.80$ $7.72(\mathrm{~m}, 4 \mathrm{H}), 6.04(\mathrm{~s}, 1 \mathrm{H}), 5.02(\mathrm{~d}, J=15.0 \mathrm{~Hz}, 1 \mathrm{H}), 4.98(\mathrm{~d}, J=15.0 \mathrm{~Hz}, 1 \mathrm{H}) \mathrm{ppm} ;{ }^{13} \mathrm{C}$ NMR (151 MHz, $\left.\mathrm{CDCl}_{3}\right): \delta=167.7,166.9,144.8,142.4,134.5,132.0,131.8,127.0,124.0$, 123.7, 122.8, 113.6, 65.5, $41.1 \mathrm{ppm}$; HRMS (ESI-TOF) calcd for $\mathrm{C}_{18} \mathrm{H}_{10} \mathrm{~N}_{2} \mathrm{O}_{4} \mathrm{Na}^{+}\left[\mathrm{M}+\mathrm{Na}^{+}\right]$ 341.0533 found 341.0536 .

\section{Scheme S2. Synthesis of 60f. ${ }^{a}$}

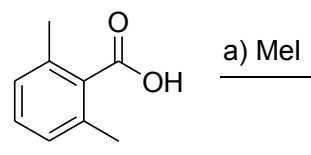

S7

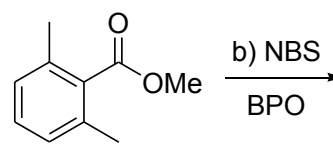

S8

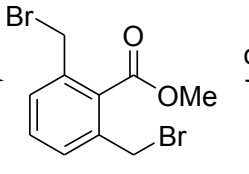

S9

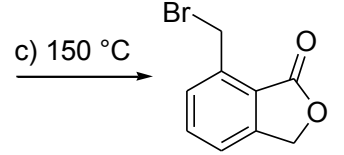

S10

d) PhthNH<smiles>N#CC1OC(=O)c2c(CNc3ccccc3)cccc21</smiles>

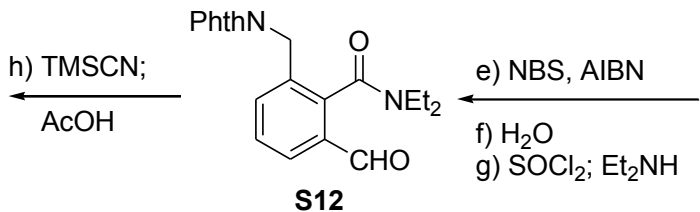<smiles>O=C1OCc2cccc(CNc3ccccc3)c21</smiles>

aReagents and Conditions: a) Mel (1.2 equiv), $\mathrm{K}_{2} \mathrm{CO}_{3}$ (1.5 equiv), DMF, rt, $5 \mathrm{~h}, 95 \%$; b) NBS (2.5 equiv), BPO (0.01 equiv), $\mathrm{CCl}_{4}$, reflux, $8 \mathrm{~h}, 81 \%$; c) $140{ }^{\circ} \mathrm{C}, 1.0 \mathrm{~h}, 85 \%$; d) PhthNH (1.1 equiv), $\mathrm{Cs}_{2} \mathrm{CO}_{3}$ (1.5 equiv), $n$-Bu4NI (0.1 equiv), DMF, $40{ }^{\circ} \mathrm{C}, 7.0 \mathrm{~h}$; e) NBS (1.2 equiv), AIBN ( 0.2 equiv), $\mathrm{PhH} / \mathrm{CCl}_{4}, 85^{\circ} \mathrm{C}, 2 \mathrm{~h}$; f) $\mathrm{H}_{2} \mathrm{O}$ :THF (1:1), $\left.85^{\circ} \mathrm{C}, 5 \mathrm{~h} ; \mathrm{g}\right) \mathrm{SOCl}_{2}$, reflux, 2 h; $\mathrm{Et}_{2} \mathrm{NH}$ (1.8 equiv), $\mathrm{CH}_{2} \mathrm{Cl}_{2}$, rt, $2 \mathrm{~h}, 33 \%$ (4 steps); h) TMSCN (2.0 equiv), $\mathrm{KCN}$ (0.03 equiv), $18-\mathrm{C}-6$ (0.02 equiv), $\mathrm{CH}_{2} \mathrm{Cl}_{2}, 25{ }^{\circ} \mathrm{C}, 1.5 \mathrm{~h}$; $\mathrm{AcOH}$, rt , $48 \mathrm{~h}, 73 \%$.

Methyl ester S8. To a stirred solution of 2,6-dimethylbenzoic acid S7 (6.50 g, $43.3 \mathrm{mmol}$,<smiles>COC(=O)c1c(C)cccc1C</smiles>

S8 1.0 equiv) in DMF $(50 \mathrm{~mL})$ at $0{ }^{\circ} \mathrm{C}$ was added anhydrous $\mathrm{K}_{2} \mathrm{CO}_{3}(8.90 \mathrm{~g}$, $64.9 \mathrm{mmol}, 1.5$ equiv), followed by Mel (7.38 g, $51.9 \mathrm{mmol}, 1.2$ equiv) dropwise. After addition, the reaction mixture was stirred for additional $5 \mathrm{~h}$ at room temperature, then poured into $\mathrm{H}_{2} \mathrm{O}(100 \mathrm{~mL})$ and extracted with $\mathrm{Et}_{2} \mathrm{O}(3 \times 100 \mathrm{~mL})$. 
The combined organic layers were washed with water $(3 \times 50 \mathrm{~mL})$ and brine $(2 \times 50 \mathrm{~mL})$, dried over $\mathrm{MgSO}_{4}$ and concentrated under reduced pressure. The obtained residue was purified by flash column chromatography (silica gel, 1 to $4 \%$ EtOAc in hexanes) to yield pure methyl ester $\mathbf{S} 8(6.75 \mathrm{~g}, 41.2 \mathrm{mmol}, 95 \%)$ as a colorless oil.

S8: $\mathrm{R}_{f}=0.48$ (silica gel, $5 \%$ EtOAc in hexanes); FT-IR (neat) $v_{\max }=2950,1719,1459$, $1435,1293,1267,1248,1202,1147,1050 \mathrm{~cm}^{-1} ;{ }^{1} \mathrm{H}$ NMR $\left(600 \mathrm{MHz}, \mathrm{CDCl}_{3}\right): \delta=7.19(\mathrm{t}, J$ $=7.8 \mathrm{~Hz}, 1 \mathrm{H}), 7.03(\mathrm{~d}, J=7.8 \mathrm{~Hz}, 2 \mathrm{H}), 3.91(\mathrm{~s}, 3 \mathrm{H}), 2.31(\mathrm{~s}, 6 \mathrm{H}) \mathrm{ppm} ;{ }^{13} \mathrm{C}$ NMR $(151$ $\left.\mathrm{MHz}, \mathrm{CDCl}_{3}\right): \delta=170.5,134.9,133.8,129.3,127.5,51.8,19.7$ ppm; HRMS (ESI-TOF) calcd for $\mathrm{C}_{10} \mathrm{H}_{13} \mathrm{O}_{2}{ }^{+}[\mathrm{M}+\mathrm{H}] 165.0910$ found 165.0906 .

Dibromo ester S9. ${ }^{8}$ To a stirred solution of methyl ester $\mathbf{S 8}(7.00 \mathrm{~g}, 42.7 \mathrm{mmol}, 1.0$ equiv)

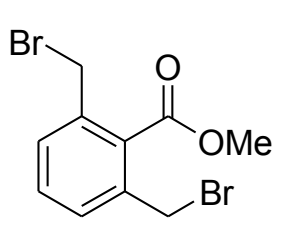

s9 in $\mathrm{CCl}_{4}(50 \mathrm{~mL})$ at room temperature was added $\mathrm{N}$-bromosuccinimide (19.3 g, $107 \mathrm{mmol}, 2.5$ equiv). Then the reaction mixture was heated to $80^{\circ} \mathrm{C}$ and benzoyl peroxide (104 $\mathrm{mg}, 0.427 \mathrm{mmol}, 0.01$ equiv) was added in one portion. Heating was continued for $8 \mathrm{~h}$. The reaction mixture was then cooled to ambient temperature, and stored at $0{ }^{\circ} \mathrm{C}$ for $3 \mathrm{~h}$. The reaction mixture was then filtered, and the precipitates were rinsed with $\mathrm{CCl}_{4}\left(0-5{ }^{\circ} \mathrm{C}\right)$. The combined filtrates were then washed with saturated aqueous $\mathrm{NaHCO}_{3}(125 \mathrm{~mL})$ and brine $(75 \mathrm{~mL})$, dried over $\mathrm{MgSO}_{4}$, and concentrated under reduced pressure. The obtained residue was purified by flash column chromatography (silica gel, 1 to $5 \%$ EtOAc in hexanes) to give dibromoester $\mathbf{S 9}^{8}$ $(11.0 \mathrm{~g}, 34.6 \mathrm{mmol}, 81 \%)$ as a white solid.

S9: $R_{f}=0.52$ (silica gel, 10\% EtOAc in hexanes); FT-IR (neat) $v_{\max }=2985,2950,1723$, 1431, 1280, 1214, 1114, $1063 \mathrm{~cm}^{-1} ;{ }^{1} \mathrm{H}$ NMR $\left(600 \mathrm{MHz}, \mathrm{CDCl}_{3}\right): \delta=7.38-7.37(\mathrm{~m}, 3 \mathrm{H})$, $4.62(\mathrm{~s}, 4 \mathrm{H}), 4.02(\mathrm{~d}, J=1.2 \mathrm{~Hz}, 3 \mathrm{H}) \mathrm{ppm} ;{ }^{13} \mathrm{C} \mathrm{NMR}\left(151 \mathrm{MHz}, \mathrm{CDCl}_{3}\right): \delta=167.7,136.9$, 132.7, 130.7, 130.6, 52.8, 30.4 ppm; HRMS (ESI-TOF) calcd for $\mathrm{C}_{10} \mathrm{H}_{10} \mathrm{O}_{2} \mathrm{Br}_{2} \mathrm{Na}^{+}\left[\mathrm{M}+\mathrm{Na}^{+}\right]$ 342.8940 found 342.8937 . 
Bromophthalide S10. To a flask was added neat dibromoester S9 $(5.80 \mathrm{~g}, 18.2 \mathrm{mmol}, 1.0$ equiv). The flask was heated to $140{ }^{\circ} \mathrm{C}$ with slight vacuum for $1 \mathrm{~h}$. The reaction mixture was cooled to ambient temperature and the obtained brown residue was purified by flash column chromatography (silica gel, 10 to $30 \%$ EtOAc in hexanes) to afford bromophthalide S10 (3.50 g, $15.5 \mathrm{mmol}, 85 \%)$ as a white solid.

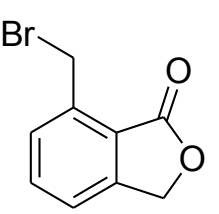

S10

S10: $\mathrm{mp} 159-161{ }^{\circ} \mathrm{C}$ (EtOAc/hexanes); $\mathrm{R}_{f}=0.22$ (silica gel, 30\% EtOAc in hexanes); FT-IR (neat) $v_{\max }=3055,3021,1749,1710,1364,1204,1065$, $1048 \mathrm{~cm}^{-1} ;{ }^{1} \mathrm{H}$ NMR $\left(600 \mathrm{MHz}, \mathrm{CDCl}_{3}\right): \delta=7.66(\mathrm{td}, J=7.2,1.2 \mathrm{~Hz}, 1 \mathrm{H})$, 7.56 (dd, $J=7.8,3.6 \mathrm{~Hz}, 1 \mathrm{H}), 7.42(\mathrm{~d}, J=7.8 \mathrm{~Hz}, 1 \mathrm{H}), 5.30$ (d, J = 2.4 Hz, $2 \mathrm{H}$ ), 5.00 (dd, $J=5.4,2.4 \mathrm{~Hz}, 2 \mathrm{H}) \mathrm{ppm} ;{ }^{13} \mathrm{C}$ NMR $\left(151 \mathrm{MHz}, \mathrm{CDCl}_{3}\right): \delta=170.0,147.4,138.5,134.4$, 130.8, 122.6, 122.1, 69.1, 26.1 ppm; HRMS (ESI-TOF) calcd for $\mathrm{C}_{9} \mathrm{H}_{8} \mathrm{BrO}_{2}{ }^{+}\left[\mathrm{M}+\mathrm{H}^{+}\right]$ 226.9702 found 226.9698 .

Formylbenzamide S12. To stirred solution of bromophthalide $\mathbf{S} 10$ (3.00 g, $13.3 \mathrm{mmol}, 1.0$<smiles>CCNC(=O)c1c(C=O)cccc1CNc1ccccc1</smiles>
equiv) in DMF $(25 \mathrm{~mL})$ at $25^{\circ} \mathrm{C}$ was added anhydrous $\mathrm{Cs}_{2} \mathrm{CO}_{3}(6.50 \mathrm{~g}$, $19.9 \mathrm{mmol}, 1.5$ equiv) and $n$-Bu4NI (0.490 g, $1.33 \mathrm{mmol}, 0.1$ equiv) sequentially, followed by phthalimide $(2.34 \mathrm{~g}, 15.93 \mathrm{mmol}, 1.2$ equiv). The reaction mixture was stirred at $40{ }^{\circ} \mathrm{C}$ for $7 \mathrm{~h}$, then poured into $\mathrm{H}_{2} \mathrm{O}(100 \mathrm{~mL})$ and vigorously stirred for $15 \mathrm{~min}$ and extracted with EtOAc $(3 \times 40 \mathrm{~mL})$. The combined organic layers were washed with water $(3 \times 30 \mathrm{~mL})$ and brine $(2 \times 30 \mathrm{~mL})$, dried over $\mathrm{MgSO}_{4}$ and concentrated under reduced pressure. The obtained residue (crude S11) was used directly in the next step.

To a stirred suspension of phthalide $\mathbf{S} 11$ ( $2.90 \mathrm{~g}, 9.86 \mathrm{mmol}, 1.0$ equiv) in $\mathrm{CCl}_{4} / \mathrm{benzene}$ (60 mL, 1:1) at ambient temperature, was added $\mathrm{N}$-bromosuccinimide $(2.10 \mathrm{~g}, 11.8 \mathrm{mmol}$, 1.2 equiv) in one portion. The reaction mixture was heated to reflux, and azobisisobutyronitrile $(0.330 \mathrm{~g}, 1.97 \mathrm{mmol}, 0.2$ equiv) was then added in one portion. The 
reaction mixture was vigorously stirred at reflux for another $2 \mathrm{~h}$, then cooled to ambient temperature, and stored at $0{ }^{\circ} \mathrm{C}$ for $8 \mathrm{~h}$. The reaction mixture was filtered, and the precipitates were rinsed with $\mathrm{CCl}_{4}\left(0-5{ }^{\circ} \mathrm{C}\right)$. The combined filtrates were then washed with saturated aqueous $\mathrm{NaHCO}_{3}(25 \mathrm{~mL})$ and brine $(25 \mathrm{~mL})$, dried over $\mathrm{Mg}_{2} \mathrm{SO}_{4}$, and concentrated to yield crude bromo compound as a yellow foam, which was suspended in $\mathrm{H}_{2} \mathrm{O} / \mathrm{THF}(60 \mathrm{~mL}, 1: 1)$. The suspension was stirred at $85^{\circ} \mathrm{C}$ for $5 \mathrm{~h}$ and cooled to ambient temperature. The reaction mixture was extracted with EtOAc $(5 \times 30 \mathrm{~mL})$, and the combined organic layers were dried over $\mathrm{MgSO}_{4}$ and concentrated to yield crude hydroxyl compound as a yellow hygroscopic solid, which was dried over $\mathrm{P}_{2} \mathrm{O}_{5}$ for $8 \mathrm{~h}$. The crude hydroxyl compound was suspended in $\mathrm{SOCl}_{2}(15 \mathrm{~mL})$ and the reaction mixture heated to reflux for $2 \mathrm{~h}$. The reaction mixture was concentrated under $\mathrm{N}_{2}$ and the residue was coevaporated with toluene $(2 \times 15 \mathrm{~mL})$ to remove all traces of $\mathrm{SOCl}_{2}$. The crude product was dissolved in $\mathrm{CH}_{2} \mathrm{Cl}_{2}(15 \mathrm{~mL})$ and the reaction mixture was cooled to $0{ }^{\circ} \mathrm{C}$. A solution of diethylamine (1.3 g, $1.85 \mathrm{~mL}, 17.75 \mathrm{mmol}, 1.8$ equiv) in $\mathrm{CH}_{2} \mathrm{Cl}_{2}(4 \mathrm{~mL})$ was added dropwise. Ice bath was removed, and the reaction mixture was stirred at $25^{\circ} \mathrm{C}$ for $2 \mathrm{~h}$. The reaction was quenched with $1 \mathrm{~N} \mathrm{HCl}(30 \mathrm{~mL})$, and the reaction mixture was extracted with $\mathrm{CH}_{2} \mathrm{Cl}_{2}(2 \times 30 \mathrm{~mL})$. The combined organic layers were washed with brine $(25 \mathrm{~mL})$, dried over $\mathrm{MgSO}_{4}$ and concentrated under reduced pressure. The obtained residue was purified by flash column chromatography (silica gel, 5 to $10 \%$ EtOAc in dichloromethane) to afford formylbenzamide $\mathbf{S} 12$ as a yellowish foam (1.58 g, $4.32 \mathrm{mmol}, 33 \%$ over four steps).

S12: $R_{f}=0.30$ (silica gel, 50\% EtOAc in hexanes); FT-IR (neat) $v_{\max }=2977,2936,2874$, $2250,1773,1711,1624,1422,1390,1281 \mathrm{~cm}^{-1} ;{ }^{1} \mathrm{H}$ NMR $\left(600 \mathrm{MHz}, \mathrm{CDCl}_{3}\right): \delta=9.83(\mathrm{~s}, 1$ H), $7.66(\mathrm{dd}, J=6.0,3.0 \mathrm{~Hz}, 2 \mathrm{H}), 7.64(\mathrm{~d}, J=7.2 \mathrm{~Hz}, 1 \mathrm{H}), 7.55(\mathrm{dd}, J=6.0,3.0 \mathrm{~Hz}, 2 \mathrm{H}$ ), $7.29(\mathrm{~d}, J=7.8 \mathrm{~Hz}, 1 \mathrm{H}), 7.24(\mathrm{~d}, J=7.8 \mathrm{~Hz}, 1 \mathrm{H}), 4.87(\mathrm{~d}, J=16.2 \mathrm{~Hz}, 1 \mathrm{H}), 4.48(\mathrm{~d}, J=$ 16.2 Hz, $1 \mathrm{H}), 3.53-3.44(\mathrm{~m}, 2 \mathrm{H}), 3.08-2.95(\mathrm{~m}, 2 \mathrm{H}), 1.15(\mathrm{t}, J=7.2 \mathrm{~Hz}, 3 \mathrm{H}), 0.88(\mathrm{t}, J=$ 
$7.2 \mathrm{~Hz}, 3 \mathrm{H}) \mathrm{ppm} ;{ }^{13} \mathrm{C} \mathrm{NMR}\left(151 \mathrm{MHz}, \mathrm{CDCl}_{3}\right): \delta=190.3,167.8,166.7,137.9,134.2$, 133.7, 133.0, 132.4, 131.8, 129.0, 128.8, 123.4, 43.1, 39.0, 38.3, 13.4, 12.5 ppm; HRMS (ESI-TOF) calcd for $\mathrm{C}_{21} \mathrm{H}_{20} \mathrm{~N}_{2} \mathrm{O}_{4} \mathrm{Na}^{+}\left[\mathrm{M}+\mathrm{Na}^{+}\right] 387.1315$ found 387.1306 .

Cyanophthalide $60 f$. To a stirred solution of formylbenzamide $\mathbf{S 1 2}(1.10 \mathrm{~g}, 3.01 \mathrm{mmol}, 1.0$<smiles>N#CC1OC(=O)c2c(CNc3ccccc3)cccc21</smiles>
equiv) in $\mathrm{CH}_{2} \mathrm{Cl}_{2}(6 \mathrm{~mL})$ at $0{ }^{\circ} \mathrm{C}$ was added TMSCN (597 mg, $6.03 \mathrm{mmol}$, 2.0 equiv), and a solution of $\mathrm{KCN}(4.9 \mathrm{mg}, 0.07 \mathrm{mmol}, 0.025$ equiv) and 18-crown-6 (15.9 mg, $0.06 \mathrm{mmol}, 0.02$ equiv) in THF $(0.5 \mathrm{~mL})$. The reaction mixture was stirred at $25^{\circ} \mathrm{C}$ in a sealed flask for $1.5 \mathrm{~h}$. The reaction mixture was then concentrated under $\mathrm{N}_{2}$ and the residue was co-evaporated with toluene $(2 \times 25 \mathrm{~mL})$ to remove all traces of TMSCN. The resulting brown oil was dissolved in $\mathrm{AcOH}(3 \mathrm{~mL})$ and stirred for $48 \mathrm{~h}$ at room temperature until TLC showed full conversion. The reaction was quenched by careful addition of $1 \mathrm{~N} \mathrm{NaOH}(10 \mathrm{~mL})$, and the resulting mixture was partitioned between EtOAc $(20 \mathrm{~mL})$ and $1 \mathrm{~N} \mathrm{NaOH}(10 \mathrm{~mL})$. The aqueous layer was extracted with EtOAc $(3 \times 20 \mathrm{~mL})$, and the combined organic layers were washed with $\mathrm{H}_{2} \mathrm{O}$ $(20 \mathrm{~mL})$ and brine $(20 \mathrm{~mL})$, dried over $\mathrm{MgSO}_{4}$ and concentrated under reduced pressure. The obtained residue was purified by flash column chromatography (silica gel, 35 to $45 \%$ EtOAc in hexanes) to give cyanophthalide $60 \mathrm{f}$ as a white solid (702 mg, $2.20 \mathrm{mmol}, 73 \%$ yield).

60f: $\mathrm{mp} 185-186^{\circ} \mathrm{C}$ (EtOAc/hexanes); $\mathrm{R}_{f}=0.55$ (silica gel, 50\% EtOAc in hexanes); FT-IR (neat) $v_{\max }=2937,1775,1715,1418,1394,1352,1281,1196,1072,1028,997 \mathrm{~cm}^{-1} ;{ }^{1} \mathrm{H}$ $\operatorname{NMR}\left(600 \mathrm{MHz}, \mathrm{CDCl}_{3}\right): \delta=7.91(\mathrm{dd}, J=6.0,3.0 \mathrm{~Hz}, 2 \mathrm{H}), 7.78(\mathrm{dd}, J=6.0,3.0 \mathrm{~Hz}, 2 \mathrm{H})$, $7.73(\mathrm{t}, J=7.2 \mathrm{~Hz}, 1 \mathrm{H}), 7.59$ (d, J = 7.2 Hz, $1 \mathrm{H}), 7.39$ (d, J = $7.2 \mathrm{~Hz}, 1 \mathrm{H}), 6.09(\mathrm{~s}, 1 \mathrm{H})$, $5.46(\mathrm{~d}, J=16.8 \mathrm{~Hz}, 1 \mathrm{H}), 5.42(\mathrm{~d}, J=16.8 \mathrm{~Hz}, 1 \mathrm{H}),{ }^{13} \mathrm{C} \mathrm{NMR}\left(151 \mathrm{MHz}, \mathrm{CDCl}_{3}\right): \delta=$ $167.8,167.0,142.4,138.4,135.8,134.4,131.9,129.1$, 123.7, 121.7, 121.5, 113.7, 65.4, 36.5 ppm; HRMS (ESI-TOF) calcd for $\mathrm{C}_{18} \mathrm{H}_{10} \mathrm{~N}_{2} \mathrm{O}_{4} \mathrm{Na}^{+}\left[\mathrm{M}+\mathrm{Na}^{+}\right] 341.0533$ found 341.0526 . 
Methyl ester 72. To a stirred solution of 2,4-dihydroxy-3-methylbenzoate $(\mathbf{7 1} ; 5.00 \mathrm{~g}, 27.4$<smiles>COc1ccc(C(C)=O)c(OC)c1OC</smiles>

72 mmol, 1.0 equiv) in DMF $(50 \mathrm{~mL})$ at $0{ }^{\circ} \mathrm{C}$ was sequentially added anhydrous $\mathrm{K}_{2} \mathrm{CO}_{3}(5.69 \mathrm{~g}, 41.2 \mathrm{mmol}, 1.5$ equiv), and Mel (4.68 g, $2.1 \mathrm{~mL}, 33.0 \mathrm{mmol}, 1.2$ equiv) dropwise over $3 \mathrm{~min}$ under vigorous stirring. Upon completion of addition, the reaction mixture was stirred for additional $5 \mathrm{~h}$ at room temperature, then poured into $\mathrm{H}_{2} \mathrm{O}(100 \mathrm{~mL})$ and extracted with $\mathrm{Et}_{2} \mathrm{O}(3 \times 100 \mathrm{~mL})$. The combined organic layers were washed with water $(3 \times 50 \mathrm{~mL})$ and brine $(2 \times 50 \mathrm{~mL})$, dried over $\mathrm{MgSO}_{4}$ and concentrated under reduced pressure. The obtained residue was purified by flash column chromatography (silica gel, 10 to $15 \%$ EtOAc in hexanes) to yield pure methyl ester 72 (5.36 g, $25.5 \mathrm{mmol}, 93 \%)$ as a colorless oil.

72: $\mathrm{R}_{f}=0.65$ (silica gel, 30\% EtOAc in hexanes); FT-IR (neat) $v_{\max }=2970,2937,2837$, 1623, 1598, 1491, 1457, 1426, 1407, 1379, 1364, 1314, 1291, 1269, 1234, 1222, 1167, 1106, 1020, $999 \mathrm{~cm}^{-1} ;{ }^{1} \mathrm{H}$ NMR (600 MHz, $\left.\mathrm{CDCl}_{3}\right): \delta=7.75$ (d, J = 9.0 Hz, $\left.1 \mathrm{H}\right), 6.65$ (d, J $=9.0 \mathrm{~Hz}, 1 \mathrm{H}), 3.88(\mathrm{~s}, 3 \mathrm{H}), 3.86(\mathrm{~s}, 3 \mathrm{H}), 3.80(\mathrm{~s}, 3 \mathrm{H}), 2.15(\mathrm{~s}, 3 \mathrm{H}) \mathrm{ppm} ;{ }^{13} \mathrm{C}$ NMR $(151$ $\left.\mathrm{MHz}_{\mathrm{CDCl}}\right): \delta=166.3,162.0,159.7,130.2,121.0,116.6,105.5,61.5,55.7,51.8,8.7$ ppm; HRMS (ESI-TOF) calcd for $\mathrm{C}_{11} \mathrm{H}_{14} \mathrm{O}_{4} \mathrm{Na}^{+}\left[\mathrm{M}+\mathrm{Na}^{+}\right] 233.0784$ found 233.0792.

Benzamide 73. To a stirred ice-cooled solution of diethylamine $(7.92 \mathrm{~g}, 109 \mathrm{mmol}, 3.8$<smiles>CCOC(=O)c1ccc(OC)c(OC)c1OC</smiles>

73 equiv) in toluene $(40.0 \mathrm{~mL})$ was added trimethylaluminum $(2.0 \mathrm{M}$ solution in hexanes, $30.0 \mathrm{~mL}, 60.0 \mathrm{mmol}, 2.1$ equiv) slowly. After 10 min, the cooling bath was removed and the reaction flask was allowed to warm to ambient temperature. A solution of methyl ether $72(6.00 \mathrm{~g}, 28.5 \mathrm{mmol})$ in toluene $(30.0 \mathrm{~mL})$ was added dropwise to the reaction mixture over $10 \mathrm{~min}$. The reaction mixture was then heated at reflux in an oil bath at $120^{\circ} \mathrm{C}$. After $7 \mathrm{~h}$, the heating bath was removed and the reaction flask was allowed to cool to ambient temperature. The reaction mixture was poured carefully into a mixture of ice water $(75 \mathrm{~mL})$ and concentrated $\mathrm{HCl}(5.5$ 
$\mathrm{mL})$. The layers were separated, and the aqueous layer was extracted with EtOAc $(3 \times 55$ $\mathrm{mL})$. The combined organic layers were washed with $\mathrm{H}_{2} \mathrm{O}(50 \mathrm{~mL})$, and brine $(75 \mathrm{~mL})$, dried over $\mathrm{MgSO}_{4}$, and concentrated. The obtained residue was purified by Flash column chromatography (silica gel, 10 to $20 \%$ EtOAc in hexanes) gave benzamide 73 as a yellowish oil $(6.10 \mathrm{~g}, 24.3 \mathrm{mmol}, 85 \%$ yield).

73: $R_{f}=0.45$ (silica gel, 30\% EtOAc in hexanes); FT-IR (neat) $v_{\max }=2973,2938,2872$, $2849,1693,1625,1590,1574,1485,1455,1431,1390,1379,1363,1347,1317,1285$ 1222, 1202, 1134, 1116, 1080, $1005 \mathrm{~cm}^{-1} ;{ }^{1} \mathrm{H}$ NMR $\left(600 \mathrm{MHz}, \mathrm{CDCl}_{3}\right): \delta=7.02(\mathrm{~d}, J=8.4$ $\mathrm{Hz}, 1 \mathrm{H}), 6.61(\mathrm{~d}, J=8.4 \mathrm{~Hz}, 1 \mathrm{H}), 3.80(\mathrm{~s}, 3 \mathrm{H}), 3.75(\mathrm{br} \mathrm{s}, 1 \mathrm{H}), 3.73(\mathrm{~s}, 3 \mathrm{H}), 3.30(\mathrm{br} \mathrm{s}, 1$ H), 3.13 (br s, 2 H), 2.11 (s, 3 H), 1.22 (t, J = $7.2 \mathrm{~Hz}, 3 \mathrm{H}), 0.99$ (t, J = 7.2 Hz, $3 \mathrm{H}$ ) ppm; ${ }^{13} \mathrm{C}$ NMR $\left(151 \mathrm{MHz}, \mathrm{CDCl}_{3}\right): \delta=169.2,159.0,154.9,124.9,124.0,119.8,105.9,61.5$, 55.6, 42.9, 38.8, 13.9, 12.7, 8.7 ppm; HRMS (ESI-TOF) calcd for $\mathrm{C}_{14} \mathrm{H}_{21} \mathrm{NO}_{3} \mathrm{Na}^{+}\left[\mathrm{M}+\mathrm{Na}^{+}\right]$ 274.1414 found 274.1405 .

Formylbenzamide 74. To a stirred solution of benzamide $73(6.00 \mathrm{~g}, 23.9 \mathrm{mmol})$ in THF<smiles>CCOC(=O)c1c(C=O)cc(OC)c(OC)c1OC</smiles>

74

$(80 \mathrm{~mL})$ at $-78{ }^{\circ} \mathrm{C}$, was added $N, N, N, N$-tetramethylethylenediamine (7.10 mL, $5.54 \mathrm{~g}, 47.8 \mathrm{mmol}, 2.0$ equiv), followed by dropwise addition of $t$-BuLi (1.7 M, $28.1 \mathrm{~mL}, 47.8 \mathrm{mmol}, 2.0$ equiv) at $-78{ }^{\circ} \mathrm{C}$.

After $50 \mathrm{~min}$, DMF (22.0 mL, $287 \mathrm{mmol}, 12$ equiv) was added, and after further $50 \mathrm{~min}$, the cooling bath was removed and the mixture was allowed to warm to ambient temperature over $2 \mathrm{~h}$. The reaction mixture was diluted with $\mathrm{H}_{2} \mathrm{O}(75 \mathrm{~mL})$, and after 20 min of stirring, the diluted solution was partially concentrated to remove the volatile organic solvents. To the aqueous residue was added EtOAc $(150 \mathrm{~mL})$, and the two layers were separated. The aqueous layer was extracted with EtOAc $(150 \mathrm{~mL})$. The combined organic layers were washed with $\mathrm{H}_{2} \mathrm{O}(100 \mathrm{~mL})$ and brine $(3 \times 75 \mathrm{~mL})$, dried over $\mathrm{MgSO}_{4}$, and concentrated. The obtained residue was purified by flash column chromatography (silica gel, 15 to $25 \%$ 
EtOAc in hexanaes) gave formylbenzamide $74(6.40 \mathrm{~g}, 22.9 \mathrm{mmol}, 96 \%$ yield) as a pale yellow solid.

74: $\mathrm{mp} 68-70{ }^{\circ} \mathrm{C}$ (EtOAc/hexanes); $\mathrm{R}_{f}=0.35$ (silica gel, 30\% EtOAc in hexanes); FT-IR (neat) $V_{\max }=2978,2940,2874,2851,1773,1713,1698,1625,1594,1573,1457,1434$, 1389, 1348, 1309, 1287, 1241, 1222, 1202, 1136, 1096, 1049, $991 \mathrm{~cm}^{-1} ;{ }^{1} \mathrm{H}$ NMR $(600$ $\left.\mathrm{MHz}, \mathrm{CDCl}_{3}\right): \delta=9.92(\mathrm{t}, J=1.8 \mathrm{~Hz}, 1 \mathrm{H}), 7.19-7.18(\mathrm{~m}, 1 \mathrm{H}), 3.89(\mathrm{~s}, 3 \mathrm{H}), 3.79(\mathrm{~s}, 3 \mathrm{H})$, 3.75-3.68 (m, $1 \mathrm{H}), 3.54-3.48(\mathrm{~m}, 1 \mathrm{H}), 3.16-3.06(\mathrm{~m}, 2 \mathrm{H}), 2.20(\mathrm{~s}, 3 \mathrm{H}), 1.28(\mathrm{t}, J=6.6$ $\mathrm{Hz}, 3 \mathrm{H}), 0.99$ (t, $J=6.6 \mathrm{~Hz}, 3 \mathrm{H}) \mathrm{ppm} ;{ }^{13} \mathrm{C} \mathrm{NMR}\left(151 \mathrm{MHz}, \mathrm{CDCl}_{3}\right): \delta=189.8,166.1$, $159.0,155.1,131.3,128.3,128.0,104.3,62.0,55.9,43.1,39.2,13.8,12.7,9.7$ ppm; HRMS (ESI-TOF) calcd for $\mathrm{C}_{15} \mathrm{H}_{21} \mathrm{NO}_{4} \mathrm{Na}^{+}\left[\mathrm{M}+\mathrm{Na}^{+}\right] 302.1363$ found 302.1354 .

Phthalimide 76. To a stirred solution of formylbenzamide $74(3.20 \mathrm{~g}, 11.5 \mathrm{mmol}, 1.0$<smiles>CCOC(=O)c1c(C=O)cc(OC)c(CNc2ccccc2)c1OC</smiles>

76 equiv.) in $\mathrm{CCl}_{4}(25 \mathrm{~mL})$ was added $\mathrm{N}$-bromosuccinimide $(2.48 \mathrm{~g}$, $13.8 \mathrm{mmol}, 1.2$ equiv) at ambient temperature under $\mathrm{N}_{2}$, the reaction mixture was heated to $80^{\circ} \mathrm{C}$ and benzoyl peroxide $(167 \mathrm{mg}$, $0.69 \mathrm{mmol}, 0.06$ equiv) was added in one portion. Heating continued for $2 \mathrm{~h}$ and the reaction mixture was allowed to cool to ambient temperature, washed with saturated aqueous $\mathrm{NaHCO}_{3}(25 \mathrm{~mL})$ and brine $(25 \mathrm{~mL})$, dried over $\mathrm{MgSO}_{4}$ and concentrated to give crude benzylbromide $\mathbf{7 5}$ as a light brown solid.

Benzylbromide 75 was then dissolved in DMF (15 mL), $\mathrm{K}_{2} \mathrm{CO}_{3}(2.37 \mathrm{~g}, 17.2 \mathrm{mmol}, 1.5$ equiv) and $n$-Bu4NI (0.420 g, $1.15 \mathrm{mmol}, 0.1$ equiv) were added sequentially, followed by phthalimide ( $1.85 \mathrm{~g}, 12.6 \mathrm{mmol}, 1.1$ equiv) in one portion. The reaction mixture was stirred at $40{ }^{\circ} \mathrm{C}$ for $2 \mathrm{~h}$, then poured into $\mathrm{H}_{2} \mathrm{O}(35 \mathrm{~mL})$ and extracted with EtOAc $(3 \times 50 \mathrm{~mL})$. The combined organic layers were washed with water $(3 \times 40 \mathrm{~mL})$ and brine $(2 \times 50 \mathrm{~mL})$, dried over $\mathrm{MgSO}_{4}$ and concentrated. The obtained residue was purified by flash column chromatography (silica gel, 20 to 45\% EtOAc in hexanes) gave phthalimide $76(1.92 \mathrm{~g}$, $6.90 \mathrm{mmol}, 60 \%$ yield for 2 steps) as a thick oil. 
76: $R_{f}=0.35$ (silica gel, 50\% EtOAc in hexanes); FT-IR (neat) $v_{\max }=2977,2940,2850$, $2757,2349,2327,1773,1715,1627,1594,1573,1457,1436,1390,1348,1310,1288$, 1202, 1137, 1097, $1018 \mathrm{~cm}^{-1} ;{ }^{1} \mathrm{H}$ NMR (600 MHz, $\left.\mathrm{CDCl}_{3}\right): \delta=9.93(\mathrm{~s}, 1 \mathrm{H}), 7.79$ (dd, $J=$ 5.4, 3.0 Hz, 2 H), 7.68 (dd, J = 5.4, 3.0 Hz, 2 H), $7.20(\mathrm{~s}, 1 \mathrm{H}), 5.01(\mathrm{~d}, J=14.4 \mathrm{~Hz}, 1 \mathrm{H}$ ), $4.90(\mathrm{~d}, J=14.4 \mathrm{~Hz}, 1 \mathrm{H}), 3.91(\mathrm{~s}, 3 \mathrm{H}), 3.81(\mathrm{~s}, 3 \mathrm{H}), 3.71-3.66(\mathrm{~m}, 1 \mathrm{H}), 3.54-3.48(\mathrm{~m}, 1$ H), 3.17-3.05 (m, $2 \mathrm{H}), 1.27$ (t, $J=7.2 \mathrm{~Hz}, 3 \mathrm{H}), 0.95(\mathrm{t}, J=7.2 \mathrm{~Hz}, 3 \mathrm{H}) \mathrm{ppm} ;{ }^{13} \mathrm{C} \mathrm{NMR}$ $\left(151 \mathrm{MHz}, \mathrm{CDCl}_{3}\right): \delta=189.7,167.6,165.7,159.0,156.1,133.8,133.5,132.0,127.8$, 124.1, 123.1, 105.0, 63.0, 56.1, 43.2, 39.4, 32.2, 13.7, 12.7 ppm; HRMS (ESI-TOF) calcd for $\mathrm{C}_{23} \mathrm{H}_{24} \mathrm{~N}_{2} \mathrm{O}_{6} \mathrm{Na}^{+}\left[\mathrm{M}+\mathrm{Na}^{+}\right] 447.1527$ found 447.1520 .

Cyanophthalide $60 \mathrm{~g}$. To a stirred solution of phthalimide $76(0.440 \mathrm{~g}, 1.58 \mathrm{mmol}, 1.0$ PhthN OMe o equiv) in $\mathrm{CH}_{2} \mathrm{Cl}_{2}(20 \mathrm{~mL})$ at $0{ }^{\circ} \mathrm{C}$, was added TMSCN $(0.31 \mathrm{~g}, 0.40 \mathrm{~mL}$, (20 $3.16 \mathrm{mmol}, 2.0$ equiv), and a solution of $\mathrm{KCN}(2.6 \mathrm{mg}, 0.04 \mathrm{mmol}$, $(0.7 \mathrm{~mL})$. The reaction mixture was stirred at the same temperature in a sealed flask for $1.5 \mathrm{~h}$, and for $30 \mathrm{~min}$ at ambient temperature. The reaction mixture was then concentrated under $\mathrm{N}_{2}$ and the residue was co-evaporated with toluene $(2 \times 15 \mathrm{~mL})$ to remove all traces of TMSCN. The resulting brown oil was dissolved in $\mathrm{AcOH}(2 \mathrm{~mL})$ and stirred for $80 \mathrm{~h}$ at room temperature until TLC showed full conversion (hexanes/EtOAc 1:1). The reaction was quenched by careful addition of $1 \mathrm{~N} \mathrm{NaOH}(15 \mathrm{~mL})$, and the resulting mixture was partitioned between EtOAc $(20 \mathrm{~mL})$ and $1 \mathrm{~N} \mathrm{NaOH}(15 \mathrm{~mL})$. The aqueous layer was extracted with EtOAc $(3 \times 20 \mathrm{~mL})$, and the combined organic layers were washed with $\mathrm{H}_{2} \mathrm{O}$ $(30 \mathrm{~mL})$ and brine $(30 \mathrm{~mL})$, dried over $\mathrm{MgSO}_{4}$ and concentrated. The obtained residue was purified by flash column chromatography (silica gel, 15 to 35\% EtOAc in hexanes) gave cyanophthalide $60 \mathrm{~g}$ as a slight yellowish solid. $(0.297 \mathrm{~g}, 1.28 \mathrm{mmol}, 81 \%$ yield). 
60g: $\mathrm{mp} 224-226{ }^{\circ} \mathrm{C}$ (EtOAc/hexanes); $\mathrm{R}_{f}=0.45$ (silica gel, 50\% EtOAc in hexanes); $\mathrm{FT}$ IR (neat) $v_{\max }=3097,2955,2851,2308,2204,1769,1734,1713,1603,1467,1426,1392$, $1373,1553,1310,1267,1232,1141,1104,1061,1044,1021 \mathrm{~cm}^{-1} ;{ }^{1} \mathrm{H}$ NMR $(600 \mathrm{MHz}$, $\left.\mathrm{CDCl}_{3}\right): \delta=7.81(\mathrm{dd}, J=5.4,3.0 \mathrm{~Hz}, 2 \mathrm{H}), 7.71(\mathrm{dd}, J=5.4,3.0 \mathrm{~Hz}, 2 \mathrm{H}), 6.81(\mathrm{~s}, 1 \mathrm{H})$, $5.92(\mathrm{~s}, 1 \mathrm{H}), 4.97(\mathrm{~s}, 2 \mathrm{H}), 4.24(\mathrm{~s}, 3 \mathrm{H}), 3.94(\mathrm{~s}, 3 \mathrm{H}) \mathrm{ppm} ;{ }^{13} \mathrm{C} \mathrm{NMR}\left(151 \mathrm{MHz}, \mathrm{CDCl}_{3}\right): \delta$ $=167.7,165.3,164.9,159.4,145.5,134.0,132.0,123.2,119.7,114.0,107.8,99.4,64.9$, 63.2, 56.8, 31.4 ppm; HRMS (ESI-TOF) calcd for $\mathrm{C}_{20} \mathrm{H}_{14} \mathrm{~N}_{2} \mathrm{O}_{6} \mathrm{Na}^{+}\left[\mathrm{M}+\mathrm{Na}^{+}\right] 401.0744$ found 401.0734 .

Formylphthalide 77. To a stirred suspension of bromomethylphthalide 67 (12.9 g, 56.8

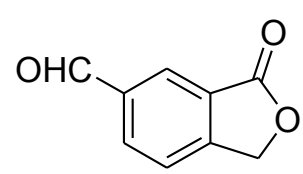

77 mmol, 1.0 equiv) in $80 \%$ acetic acid $(75 \mathrm{~mL})$ at room temperature, was added hexamethylenetetramine (16.0 g, $114 \mathrm{mmol}, 2.0$ equiv) in one portion, followed by $\mathrm{H}_{2} \mathrm{O}(45 \mathrm{~mL})$. The resulting mixture was heated to reflux for $2 \mathrm{~h}$, then cooled to room temperature, and poured into $\mathrm{H}_{2} \mathrm{O}(200 \mathrm{~mL})$. The aqueous phase was extracted with EtOAc $(3 \times 80 \mathrm{~mL})$, and the combined organic phases were washed with saturated aqueous $\mathrm{NaHCO}_{3}(4 \times 100 \mathrm{~mL})$ and brine $(50 \mathrm{~mL})$, dried over $\mathrm{MgSO}_{4}$ and concentrated to give formylphthalide 77 as white crystals $(7.46 \mathrm{~g}, 46.0 \mathrm{mmol}$, $81 \%$ yield).

77: $\mathrm{mp} 138-140{ }^{\circ} \mathrm{C}$ (EtOAc); $\mathrm{R}_{f}=0.41$ (silica gel, 40\% EtOAc in hexanes); FT-IR (neat) $\nu_{\max }=3088,3060,2870,1759,1703,1672,1621,1456,1443,1395,1364,1315,1285$, $1230,1192,1153,1119,1058,997,843,768 \mathrm{~cm}^{-1} ;{ }^{1} \mathrm{H}$ NMR $\left(600 \mathrm{MHz}, \mathrm{CDCl}_{3}\right): \delta=10.13$ (s, $1 \mathrm{H}), 8.41(\mathrm{~s}, 1 \mathrm{H}), 8.24(\mathrm{dd}, J=7.8,1.8 \mathrm{~Hz}, 1 \mathrm{H}), 7.68(\mathrm{~d}, J=7.8 \mathrm{~Hz}, 1 \mathrm{H}), 5.42(\mathrm{~s}, 2 \mathrm{H})$ ppm; ${ }^{13} \mathrm{C}$ NMR $\left(151 \mathrm{MHz}, \mathrm{CDCl}_{3}\right): \delta=190.5,169.7,152.0,137.7,134.1,128.2,127.2$, 123.3, 69.8 ppm; HRMS (ESI) calcd for $\mathrm{C}_{9} \mathrm{H}_{7} \mathrm{O}_{3}{ }^{+}\left[\mathrm{M}+\mathrm{H}^{+}\right]$163.0390, found 163.0388.

N-Alloc-N-methylphthalide 78 . To a stirred solution of formylphthalide 77 (1.10 g, 6.78 mmol, 1.0 equiv) in trifluoroethanol $(15 \mathrm{~mL})$ at room temperature was added a solution of methyl amine in THF ( $2 \mathrm{M}, 3.39 \mathrm{~mL}, 6.78 \mathrm{mmol}, 1.0$ equiv). The resulting mixture was 
stirred at the same temperature $5 \mathrm{~min}$. Sodium borohydride $(0.308 \mathrm{~g}, 8.14 \mathrm{mmol}, 1.2$ equiv) was added. After $5 \mathrm{~min}$, the reaction was quenched by adding water $(1.0 \mathrm{~mL})$. The organic solvent was removed under reduced pressure. The residue was dissolved in $\mathrm{THF} / \mathrm{H}_{2} \mathrm{O}(1: 1$, $20 \mathrm{~mL}$ ). To the resulting mixture at room temperature was added sodium bicarbonate (1.14 $\mathrm{g}, 13.6 \mathrm{mmol}, 2.0$ equiv), followed by AllocCl (1.23 g, $10.2 \mathrm{mmol}, 1.5$ equiv). The mixture was stirred at the same temperature for $40 \mathrm{~min}$. The mixture was extracted with EtOAc (2 $\times 50 \mathrm{~mL})$, and the combined organic layers were washed with brine $(50 \mathrm{~mL})$, dried over $\mathrm{Na}_{2} \mathrm{SO}_{4}$ and concentrated. The obtained residue was purified by flash column chromatography (silica gel, 20 to $60 \%$ EtOAc in hexanes) to afford $\mathrm{N}$-Alloc- $\mathrm{N}$ methylphthalide $78(1.39 \mathrm{~g}, 5.32 \mathrm{mmol}, 78 \%)$ as a colorless oil.

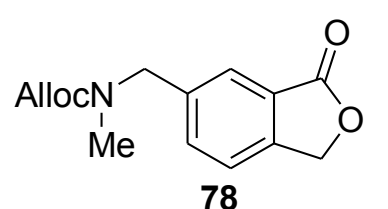

78

78: $R_{f}=0.28$ (silica gel, $50 \%$ EtOAc in hexanes); FT-IR (neat) $v_{\max }=$ $2939,1759,1693,1648,1594,1482,1455,1421,1400,1362,1308$ $1290,1231,1146,1120,1050,1002,948,833,769,743,707 \mathrm{~cm}^{-1}$;

${ }^{1} \mathrm{H}$ NMR $\left(600 \mathrm{MHz}, \mathrm{CDCl}_{3}\right): \delta=7.77(\mathrm{~s}, 1 \mathrm{H}), 7.62-7.54(\mathrm{~m}, 1 \mathrm{H}), 7.47-7.46(\mathrm{~m}, 1 \mathrm{H})$, 5.99-5.87 (m, $1 \mathrm{H}), 5.33-5.19(\mathrm{~m}, 2 \mathrm{H}), 5.30(\mathrm{~s}, 2 \mathrm{H}), 4.64-4.62(\mathrm{~m}, 2 \mathrm{H}), 4.57(\mathrm{~s}, 2 \mathrm{H})$, $2.89(\mathrm{~s}, 3 \mathrm{H}) \mathrm{ppm} ;{ }^{13} \mathrm{C}$ NMR $\left(151 \mathrm{MHz}, \mathrm{CDCl}_{3}\right): \delta=170.8,156.5,145.8,139.3,133.8$, 132.8, 126.2, 124.4, 122.4, 117.5, 69.5, 66.3, 52.2, 33.9 ppm (major rotamer); HRMS (ESITOF): calcd for $\mathrm{C}_{14} \mathrm{H}_{15} \mathrm{NO}_{4} \mathrm{Na}^{+}\left[\mathrm{M}+\mathrm{Na}^{+}\right]$: 284.0893 , found 284.0898 .

Hydroxy benzamide 79 . To a stirred suspension of aluminum trichloride $(0.988 \mathrm{~g}, 7.41$

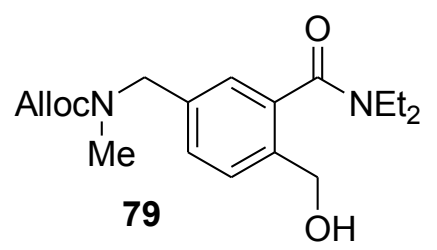
mmol, 1.5 equiv) in dichloromethane $(15 \mathrm{~mL})$ at $0{ }^{\circ} \mathrm{C}$ was added diethylamine (1.53 mL, $14.8 \mathrm{mmol}, 3.0$ equiv). The resulting mixture was warmed to room temperature and stirred at the same temperature for $30 \mathrm{~min}$. A solution of phthalide $78(1.29 \mathrm{~g}, 4.94 \mathrm{mmol}, 1.0$ equiv) in dichloromethane $(10 \mathrm{~mL})$ was added to the preformed mixture at $0{ }^{\circ} \mathrm{C}$. After $15 \mathrm{~min}$, the reaction was quenched by adding water $(25 \mathrm{~mL})$. The mixture was stirred for $30 \mathrm{~min}$ from $0{ }^{\circ} \mathrm{C}$ to room temperature, and filtered through Celite. The filtrate was extracted with 
EtOAc $(3 \times 50 \mathrm{~mL})$. The combined organic layers were washed with brine $(30 \mathrm{~mL})$, dried over $\mathrm{Na}_{2} \mathrm{SO}_{4}$ and concentrated. The obtained residue was purified by flash column chromatography (silica gel, 70 to $100 \%$ EtOAc in hexanes) to afford pure hydroxy benzamide 79 ( $1.57 \mathrm{~g}, 4.69 \mathrm{mmol}, 95 \%)$ as a colorless oil.

79: $R_{f}=0.28$ (silica gel, EtOAc ); FT-IR (neat) $v_{\max }=3405,2975,2936,2876,1689,1604$, $1476,1459,1437,1400,1383,1364,1348,1291,1212,1144,1099,1085,1049,1016$ 986, 913, 842, 824, 769, $727 \mathrm{~cm}^{-1} ;{ }^{1} \mathrm{H}$ NMR $\left(600 \mathrm{MHz}, \mathrm{CDCl}_{3}\right): \delta=7.38-7.37(\mathrm{~m}, 1 \mathrm{H})$, 7.26-7.15 (m, $1 \mathrm{H}), 7.13-7.03(\mathrm{~m}, 1 \mathrm{H}), 5.94-5.85(\mathrm{~m}, 1 \mathrm{H}), 5.29-5.13(\mathrm{~m}, 2 \mathrm{H}), 4.59-4.57$ (m, 2 H), 4.45-4.43 (m, 2 H), 4.44 (s, 2 H), 3.55-3.49 (m, 2 H), 3.16-3.13 (m, 2 H), 2.85$2.81(\mathrm{~m}, 3 \mathrm{H}), 1.22(\mathrm{t}, J=7.2 \mathrm{~Hz}, 3 \mathrm{H}), 1.02(\mathrm{~m}, J=7.2 \mathrm{~Hz}, 3 \mathrm{H}) \mathrm{ppm} ;{ }^{13} \mathrm{C}$ NMR $(151 \mathrm{MHz}$, $\left.\mathrm{CDCl}_{3}\right): \delta=170.9,156.4,138.8,137.6,136.7,136.2,132.8,129.7,128.7,126.9,124.9$, 117.2, 66.1, 63.0, 52.0, 43.2, 39.2, 12.6 ppm (major rotamer); HRMS (ESI-TOF): calcd for $\mathrm{C}_{18} \mathrm{H}_{26} \mathrm{~N}_{2} \mathrm{O}_{4} \mathrm{Na}^{+}\left[\mathrm{M}+\mathrm{Na}^{+}\right]: 357.1785$, found 357.1788 .

Formyl benzamide 80 . To a stirred solution of hydroxy benzamide $79(1.51 \mathrm{~g}, 4.52 \mathrm{mmol}$,<smiles>CCNC(=O)c1cc(CN(C)O)ccc1C=O</smiles>
1.0 equiv) in $\mathrm{CH}_{2} \mathrm{Cl}_{2}(10 \mathrm{~mL})$ was added PDC $(3.40 \mathrm{~g}, 9.03 \mathrm{mmol}$, 2.0 equiv) and $3 \AA$ molecular sieves $(1.13 \mathrm{~g})$ at room temperature. The suspension was stirred for $1 \mathrm{~h}$ at room temperature, then filtered through a short pad of silica gel, rinsed with $\mathrm{CH}_{2} \mathrm{Cl}_{2}$ and concentrated. The residue was purified by flash column chromatography (silica gel, 40 to $80 \%$ EtOAc in hexanes) to afford formyl benzamide 80 (1.19 $\mathrm{mg}, 3.58 \mathrm{mmol}, 79 \%$ yield) as a colorless oil.

80: $R_{f}=0.30$ (silica gel, 80\% EtOAc in hexanes); FT-IR (neat) $v_{\max }=2977,2936,1694$, 1626, 1584, 1473, 1459, 1437, 1394, 1363, 1348, 1276, 1205, 1143, 1100, 1084, 1053 , 987, 947, 920, 844, 831, 800, 766, 749, $729 \mathrm{~cm}^{-1} ;{ }^{1} \mathrm{H} \mathrm{NMR}\left(600 \mathrm{MHz}, \mathrm{CDCl}_{3}\right): \delta=9.99$ (s, $1 \mathrm{H}), 7.88(\mathrm{~d}, J=6.6 \mathrm{~Hz}, 1 \mathrm{H}), 7.39-7.34(\mathrm{~m}, 1 \mathrm{H}), 7.21-7.16(\mathrm{~m}, 1 \mathrm{H}), 5.96-5.82(\mathrm{~m}, 1 \mathrm{H})$, 5.31-5.14 (m, 2 H), 4.60 (br s, 2 H), 4.55 (s, 2 H), 3.58 (q, J = 6.6 Hz, 2 H), 3.07 (q, J = 6.6 $\mathrm{Hz}, 2 \mathrm{H}), 2.91-2.87(\mathrm{~m}, 3 \mathrm{H}), 1.28(\mathrm{t}, J=7.2 \mathrm{~Hz}, 3 \mathrm{H}), 0.99$ (t, $J=7.2 \mathrm{~Hz}, 3 \mathrm{H}) \mathrm{ppm} ;{ }^{13} \mathrm{C}$ 
$\operatorname{NMR}\left(151 \mathrm{MHz}, \mathrm{CDCl}_{3}\right): \delta=189.9,168.4,156.5,144.5,139.9,132.7,131.7,130.3,128.1$ 125.7, 117.5, 66.3, 52.3, 42.9, 39.1, 34.0, 12.5 ppm; HRMS (ESI-TOF): calcd for $\mathrm{C}_{18} \mathrm{H}_{24} \mathrm{~N}_{2} \mathrm{O}_{4} \mathrm{Na}^{+}\left[\mathrm{M}+\mathrm{Na}^{+}\right]: 355.1628$, found 355.1626.

Cyano phthalide $60 \mathrm{~h}$. To a stirred solution of formyl benzamide $80(1.10 \mathrm{~g}, 3.31 \mathrm{mmol}$,<smiles>N#CC1OC(=O)c2cc(C[N+](=O)[O-])ccc21</smiles>
1.0 equiv) in $\mathrm{CH}_{2} \mathrm{Cl}_{2} / \mathrm{THF}(10: 1,11 \mathrm{~mL})$ at $0{ }^{\circ} \mathrm{C}$ was added $\mathrm{KCN}(21.6$ $\mathrm{mg}, 0.332 \mathrm{mmol}, 0.1$ equiv), $18-\mathrm{C}-6(87.5 \mathrm{mg}, 0.331 \mathrm{mmol}, 0.1$ equiv), followed by TMSCN $(0.830 \mathrm{~mL}, 6.63 \mathrm{mmol}, 2.0$ equiv). The resulting mixture was warmed to room temperature and stirred at the same temperature for $2.0 \mathrm{~h}$. The solvent was removed under reduced pressure, and the residue was co-evaporated with toluene $(2 \times 2 \mathrm{~mL})$ to remove all traces of TMSCN. The resulting brown oil was dissolved in $\mathrm{AcOH}(2 \mathrm{~mL})$, and $p$-toluenesulfonic acid $(31.5 \mathrm{mg}, 0.166 \mathrm{mmol}, 0.05$ equiv) was added. The resulting mixture was stirred for $24 \mathrm{~h}$ at $40^{\circ} \mathrm{C}$. The solvent was removed under reduced pressure and the obtained residue was purified by flash column chromatography (silica gel, 20 to $50 \%$ EtOAc in hexanes) to afford pure cyano phthalide $60 \mathrm{~h}(0.830 \mathrm{~g}, 2.90 \mathrm{mmol}, 88 \%)$ as a colorless oil.

60h: $R_{f}=0.29$ (silica gel, 50\% EtOAc in hexanes); FT-IR (neat) $v_{\max }=2939,1785,1689$, $1648,1600,1481,1438,1421,1362,1326,1277,1224,1212,1145,1116,1043,1018$ 988, 951, 913, 815, 765, 749, $730 \mathrm{~cm}^{-1} ;{ }^{1} \mathrm{H}$ NMR (600 MHz, $\left.\mathrm{CDCl}_{3}\right): \delta=7.82$ (br s, $\left.1 \mathrm{H}\right)$, 7.75-7.41 (m, $1 \mathrm{H}), 7.68-7.66(\mathrm{~m}, 1 \mathrm{H}), 6.10(\mathrm{~s}, 1 \mathrm{H}), 5.97-5.86(\mathrm{~m}, 1 \mathrm{H}), 5.32-6.16(\mathrm{~m}, 2$ H), 4.62-4.60 (m, $4 \mathrm{H}), 2.92(\mathrm{~s}, 3 \mathrm{H}) \mathrm{ppm} ;{ }^{13} \mathrm{C} \mathrm{NMR}\left(151 \mathrm{MHz}, \mathrm{CDCl}_{3}\right): \delta=167.2,156.5$, $146.9,142.2,140.9,135.1,134.6,132.6,125.0,123.0,113.8,66.4,65.6,52.1,34.1 \mathrm{ppm}$ (major rotamer); HRMS (ESI-TOF): calcd for $\mathrm{C}_{15} \mathrm{H}_{15} \mathrm{~N}_{2} \mathrm{O}_{4}{ }^{+}\left[\mathrm{M}+\mathrm{H}^{+}\right]$: 287.1026 , found 287.1031. 


\section{General Procedure A.}

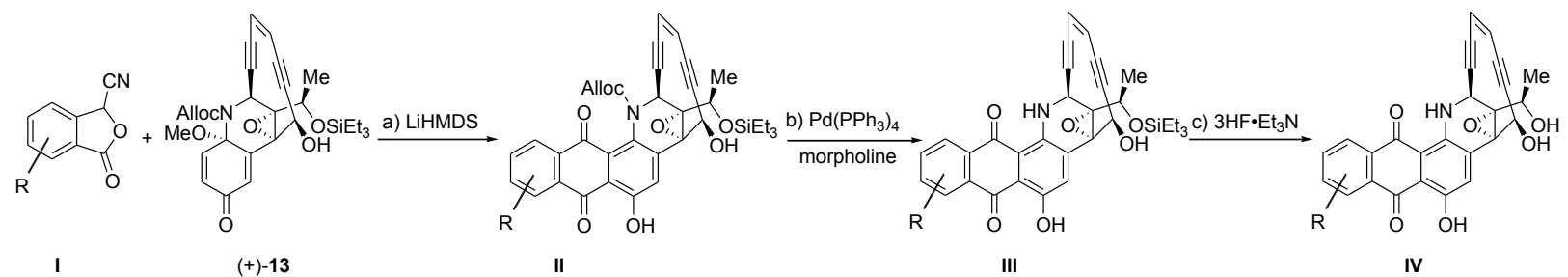

(a) To a stirred solution of cyanophthalide I (2.0-3.0 equiv) in $\operatorname{THF}(0.2 \mathrm{M})$ at $-78{ }^{\circ} \mathrm{C}$ was added LiHMDS (1.0 M in THF, 4.0 equiv). The resulting mixture was stirred at the same temperature for $20 \mathrm{~min}$. Quinone aminal (+)-13 (1.0 equiv) was added at $-78{ }^{\circ} \mathrm{C}$. After 5 min, the resulting mixture was warmed slowly to room temperature. The reaction was monitored by TLC until quinone aminal (+)-13 was completely consumed. The reaction was quenched by addition of $\mathrm{pH} 6.8$ buffer $(10 \mathrm{~mL})$ and extracted with EtOAC $(3 \times 15 \mathrm{~mL})$. The combined organic layers were washed with brine $(20 \mathrm{~mL})$, dried over $\mathrm{Na}_{2} \mathrm{SO}_{4}$, filtered and concentrated to give crude Alloc-anthraquinone II as a dark red or dark yellow solid.

(b) To a stirred solution of Alloc-anthraquinone II in $\operatorname{THF}(0.2 \mathrm{M})$ at $0{ }^{\circ} \mathrm{C}$ was added $\mathrm{Pd}\left(\mathrm{PPh}_{3}\right)_{4}$ (0.1 equiv), followed by morpholine (2.4 equiv). The resulting mixture, covered with aluminum foil, was stirred at the same temperature for $2 \mathrm{~h}$. After additional 20 min at room temperature, the reaction was quenched by addition of $\mathrm{pH} 6.8$ buffer $(10 \mathrm{~mL})$ and extracted with EtOAc $(3 \times 15 \mathrm{~mL})$. The combined organic layers were washed with brine (20 mL), dried over $\mathrm{Na}_{2} \mathrm{SO}_{4}$, filtered through a pad of silica gel and concentrated to give crude anthraquinone III as a purple solid.

(c) To a stirred solution of anthraquinone III in degassed THF $(0.2 \mathrm{~mL})$ at $0{ }^{\circ} \mathrm{C}$ was added slowly $3 \mathrm{HF} \cdot \mathrm{Et}_{3} \mathrm{~N}$ (150 equiv). The resulting mixture, covered with aluminum foil, was warmed to room temperature and stirred at the same temperature for $1.5 \mathrm{~h}$. The reaction was quenched by adding saturated aqueous $\mathrm{NaHCO}_{3}$, and extracted by EtOAc $(3 \times 15$ $\mathrm{mL})$. The combined organic layers were washed with brine $(20 \mathrm{~mL})$, dried over $\mathrm{Na}_{2} \mathrm{SO}_{4}$, 
filtered and concentrated. The obtained residue was purified by flash column chromatography (silica gel, EtOAc in hexanes) to afford pure uncialamycin analogue IV.

Naphthalene-Uncialamycin Analogue (+)-48. Prepared according to general procedure

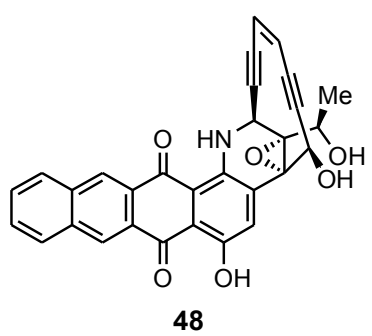

A from cyanophthalide $60 \mathrm{a}(60 \mathrm{mg}, 0.28 \mathrm{mmol}, 3.0$ equiv) and quinone aminal $(+)-13(51 \mathrm{mg}, 95 \mu \mathrm{mol}, 1.0$ equiv). DMF was employed as solvent instead of THF in the anthraquinone fusion (i.e. step a). Naphthalene-uncialamycin analogue (+)-48 (10 mg, $20 \mu \mathrm{mol}$, $21 \%$ for 3 steps) was obtained as a purple solid.

$(+)$-48: $R_{\mathrm{f}}=0.33$ (silica gel, $60 \%$ EtOAc in hexanes); $[\alpha]_{\mathrm{D}^{20}}=+900(\mathrm{c}=0.01$, EtOAc); FTIR (neat) $v_{\max }=3364,2955,2925,2854,1709,1636,1610,1582,1557,1484,1458,1396$, $1313,1259,1237,1218,1186,1100,1018,966,911,815,772,740,678 \mathrm{~cm}^{-1} ;{ }^{1} \mathrm{H}$ NMR (600 MHz, $\left.\mathrm{CD}_{3} \mathrm{CN}\right): \delta=13.27(\mathrm{~s}, 1 \mathrm{H}), 10.06(\mathrm{~d}, J=4.2 \mathrm{~Hz}, 1 \mathrm{H}), 8.87(\mathrm{~s}, 1 \mathrm{H}), 8.85(\mathrm{~s}, 1$ H), $8.52(\mathrm{~s}, 1 \mathrm{H}), 8.21-8.18(\mathrm{~m}, 2 \mathrm{H}), 7.77-7.73(\mathrm{~m}, 2 \mathrm{H}), 5.98(\mathrm{~d}, J=9.6 \mathrm{~Hz}, 1 \mathrm{H}), 5.90(\mathrm{~d}$, $J=9.6 \mathrm{~Hz}, 1 \mathrm{H}), 5.27(\mathrm{~d}, J=4.2 \mathrm{~Hz}, 1 \mathrm{H}), 4.94(\mathrm{dd}, J=4.2,1.8 \mathrm{~Hz}, 1 \mathrm{H}), 4.47(\mathrm{~d}, J=4.8$ $\mathrm{Hz}, 1 \mathrm{H}), 4.40$ (qd, J = 6.6, $5.4 \mathrm{~Hz}, 1 \mathrm{H}), 3.27(\mathrm{~d}, J=4.8 \mathrm{~Hz}, 1 \mathrm{H}), 1.40(\mathrm{~d}, J=6.6 \mathrm{~Hz}, 3 \mathrm{H})$ ppm; ${ }^{13} \mathrm{C}$ NMR $\left(151 \mathrm{MHz}, \mathrm{CD}_{3} \mathrm{CN}\right): \delta=188.8,184.6,156.6,144.7,136.4,136.0,135.6$, $131.9,131.0,130.90,130.85,130.84,130.5,130.3,129.8,129.6,124.6,124.2,115.3$, 113.6, 100.5, 99.3, 91.4, 89.0, 77.3, 66.0, 65.5, 64.9, 44.4, 21.3 ppm; HRMS (ESI) calcd for $\mathrm{C}_{30} \mathrm{H}_{20} \mathrm{NO}_{6}{ }^{+}\left[\mathrm{M}+\mathrm{H}^{+}\right] 490.1285$, found 490.1288 .

Analogue (+)-49a. Prepared according to general procedure A from cyanophthalide $60 \mathrm{~b}$

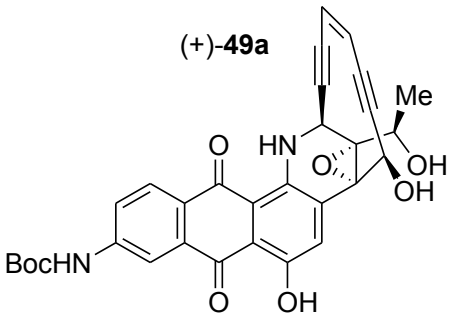

(9.0 mg, $33 \mu \mathrm{mol}, 1.8$ equiv) and quinone aminal (+)-13 (9.5 $\mathrm{mg}, 18 \mu \mathrm{mol}, 1.0$ equiv). Analogue (+)-49a (3.5 mg, $6.3 \mu \mathrm{mol}$, $35 \%$ for 3 steps) was obtained as a purple solid.

$(+)-49 a: R_{\mathrm{f}}=0.17$ (silica gel, $50 \%$ EtOAc in hexanes); $[\alpha]_{\mathrm{D}}^{20}=$ $+3600\left(c=0.001\right.$, EtOAc); FT-IR (neat) $v_{\max }=3342,2980,2936,1711,1625,1590,1529$, $1483,1432,1393,1369,1355,1332,1230,1153,10096,1059,998,964,936,905,856$, 
830, 793, 772, 740, 692, $655 \mathrm{~cm}^{-1}$; ${ }^{1} \mathrm{H}$ NMR $\left(600 \mathrm{MHz}, \mathrm{CD}_{3} \mathrm{CN}\right): \delta=13.12(\mathrm{~s}, 1 \mathrm{H}), 9.98(\mathrm{~d}$, $J=4.8 \mathrm{~Hz}, 1 \mathrm{H}), 8.48(\mathrm{~s}, 1 \mathrm{H}), 8.34(\mathrm{~d}, J=2.4 \mathrm{~Hz}, 1 \mathrm{H}), 8.20(\mathrm{~d}, J=8.4 \mathrm{~Hz}, 1 \mathrm{H}), 8.07(\mathrm{br}$ s, $1 \mathrm{H}), 7.81(\mathrm{dd}, J=8.4,1.8 \mathrm{~Hz}, 1 \mathrm{H}), 5.97(\mathrm{dd}, J=9.6,1.2 \mathrm{~Hz}, 1 \mathrm{H}), 5.88(\mathrm{dt}, J=9.6,1.2$ $\mathrm{Hz}, 1 \mathrm{H}), 5.25(\mathrm{~d}, J=4.8 \mathrm{~Hz}, 1 \mathrm{H}), 4.90(\mathrm{dd}, J=4.2,1.8 \mathrm{~Hz}, 1 \mathrm{H}), 4.43(\mathrm{~d}, J=4.8 \mathrm{~Hz}, 1 \mathrm{H})$, $4.38(q d, J=6.6,4.8 \mathrm{~Hz}, 1 \mathrm{H}), 3.24(\mathrm{~d}, J=4.8 \mathrm{~Hz}, 1 \mathrm{H}), 1.53(\mathrm{~s}, 9 \mathrm{H}), 1.39(\mathrm{~d}, J=6.6 \mathrm{~Hz}$, $3 \mathrm{H}) \mathrm{ppm} ;{ }^{13} \mathrm{C}$ NMR $\left(151 \mathrm{MHz}, \mathrm{CD}_{3} \mathrm{CN}\right): \delta=188.6,183.8,156.7,153.6,145.4,144.5$, $136.3,134.8,130.6,130.2,129.4,124.6,124.3,124.1,114.9,114.7,112.5,100.5,99.3$, 91.4, 88.9, 81.7, 77.0, 66.0, 65.5, 64.8, 44.3, 28.4, 21.3 ppm; HRMS (ESI) calcd for $\mathrm{C}_{31} \mathrm{H}_{26} \mathrm{~N}_{2} \mathrm{O}_{8} \mathrm{Na}^{+}\left[\mathrm{M}+\mathrm{Na}^{+}\right] 577.1581$, found 577.1579 .

8-Amino-Uncialamycin (+)-49b. Prepared according to general procedure A from

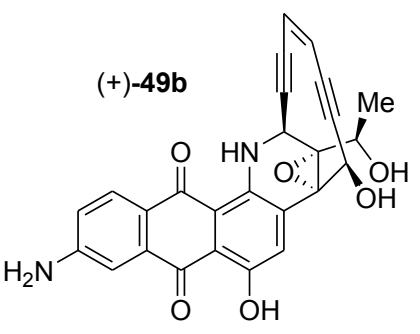
cyanophthalide $60 \mathrm{c}$ (38 mg, $0.22 \mathrm{mmol}, 3.0$ equiv) and quinone aminal (+)-13 (39 mg, $73 \mu \mathrm{mol}, 1.0$ equiv). 8-Amino-uncialamycin (+)-49b (22 mg, $48 \mu \mathrm{mol}, 66 \%$ for 3 steps) was obtained as a purple solid.

(+)-49b: $R_{f}=0.13$ (silica gel, $70 \%$ EtOAc in hexanes); $[\alpha]_{D}{ }^{25}=+870(c=0.02$, EtOAc); IR (film) $V_{\max }=3375,3239,2934,1626,1581,1480,1357,1326,1258,1233 \mathrm{~cm}^{-1} ;{ }^{1} \mathrm{H}$ NMR $\left(600 \mathrm{MHz}, \mathrm{CD}_{3} \mathrm{CN}\right): \delta=13.10(\mathrm{~s}, 1 \mathrm{H}), 9.96(\mathrm{~s}, 1 \mathrm{H}), 8.41(\mathrm{~s}, 1 \mathrm{H}), 8.00(\mathrm{~d}, J=8.4 \mathrm{~Hz}, 1 \mathrm{H})$, $7.34(\mathrm{~s}, 1 \mathrm{H}), 6.98(\mathrm{~d}, J=8.4,1 \mathrm{H}), 5.95(\mathrm{~d}, J=9.6 \mathrm{~Hz}, 1 \mathrm{H}), 5.87(\mathrm{~d}, J=9.6 \mathrm{~Hz}, 1 \mathrm{H}), 5.24$ (d, J = 4.8 Hz, $1 \mathrm{H}), 5.17(\mathrm{br} \mathrm{s}, 2 \mathrm{H}), 4.86(\mathrm{~s}, 1 \mathrm{H}), 4.55-4.50(\mathrm{br} \mathrm{m}, 1 \mathrm{H}), 4.40-4.33(\mathrm{~m}, 1$ $\mathrm{H}), 3.27(\mathrm{~m}, 1 \mathrm{H}), 1.38(\mathrm{~d}, J=6.6 \mathrm{~Hz}, 3 \mathrm{H}) \mathrm{ppm} ;{ }^{13} \mathrm{C} \mathrm{NMR}\left(151 \mathrm{MHz}, \mathrm{CD}_{3} \mathrm{CN}\right): \delta=189.3$, $183.9,156.4,124.1,143.9,136.0,135.4,130.2,129.8,125.3,124.5,124.0,120.3,114.8$, 112.8, 109.9, 100.5, 99.5, 91.3, 88.8, 77.0, 66.0, 65.5, 64.8, 44.3, 21.2 ppm; HRMS (ESITOF): calcd for $\mathrm{C}_{26} \mathrm{H}_{19} \mathrm{~N}_{2} \mathrm{O}_{6}{ }^{+}\left[\mathrm{M}+\mathrm{H}^{+}\right]$: 455.1238 , found 455.1239 .

8-Phthalimidomethyl-uncialamycin (+)-50a. Prepared according to general procedure A from cyanophthalide 60d (86 mg, $0.27 \mathrm{mmol}, 1.4$ equiv) and quinone aminal (+)-13 (102 
mg, 0.19 mmol, 1.0 equiv). 8-Phthalimidomethyl-uncialamycin (+)-50a (83 mg, $0.14 \mathrm{mmol}$, $73 \%$ for 3 steps) as a purple solid.

(+)-50a: $R_{f}=0.24$ (silica gel, $70 \%$ EtOAc in hexanes); $[\alpha]_{D^{20}}=+1200(c=0.001$, EtOAc); IR (film) $V_{\max }=3467,3059,2979,2936,1771,1715,1626,1597,1567,1486,1468,1429$,

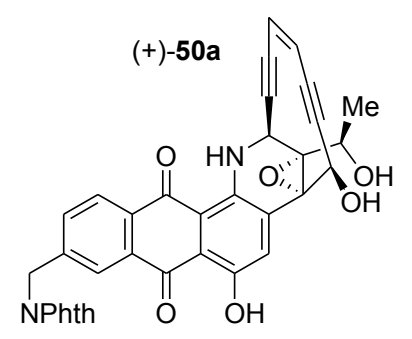
$1394,1373,1346,1321,1269,1241,1205,1149,1098,1052$, 1002, 952, 908, 795, 727, 713, 693, $671 \mathrm{~cm}^{-1} ;{ }^{1} \mathrm{H}$ NMR $(600 \mathrm{MHz}$, $\left.\mathrm{CD}_{3} \mathrm{CN}\right): \delta=13.10(\mathrm{~s}, 1 \mathrm{H}), 9.99(\mathrm{~d}, J=4.8 \mathrm{~Hz}, 1 \mathrm{H}), 8.49(\mathrm{~s}, 1 \mathrm{H})$, $8.25(\mathrm{~d}, J=7.8 \mathrm{~Hz}, 1 \mathrm{H}), 8.22(\mathrm{~d}, J=1.8 \mathrm{~Hz}, 1 \mathrm{H}), 7.87$ (dd, $J=5.4$, $3.0 \mathrm{~Hz}, 2 \mathrm{H}), 7.82(\mathrm{dd}, J=7.8,1.8 \mathrm{~Hz}, 1 \mathrm{H}), 7.81(\mathrm{dd}, J=5.4,3.0 \mathrm{~Hz}, 2 \mathrm{H}), 5.96(\mathrm{dd}, J=$ 10.2, $1.2 \mathrm{~Hz}, 1 \mathrm{H}), 5.88(\mathrm{dt}, J=10.2,1.2 \mathrm{~Hz}, 1 \mathrm{H}), 5.24(\mathrm{~d}, J=4.2 \mathrm{~Hz}, 1 \mathrm{H}), 4.98(\mathrm{~s}, 2 \mathrm{H})$, $4.91(\mathrm{dd}, J=4.2,1.8 \mathrm{~Hz}, 1 \mathrm{H}), 4.41(\mathrm{~d}, J=4.8 \mathrm{~Hz}, 1 \mathrm{H}), 4.38(\mathrm{dq}, J=6.6,4.8 \mathrm{~Hz}, 1 \mathrm{H})$, $3.24(\mathrm{~d}, J=4.8 \mathrm{~Hz}, 1 \mathrm{H}), 1.38(\mathrm{~d}, J=6.6 \mathrm{~Hz}, 3 \mathrm{H}) \mathrm{ppm} ;{ }^{13} \mathrm{C} \operatorname{NMR}\left(151 \mathrm{MHz}, \mathrm{CD}_{3} \mathrm{CN}\right): \delta=$ 188.3, 184.0, 169.1, 156.8, 144.8, 143.7, 136.3, 135.4, 135.2, 134.8, 134.0, 133.1, 131.0, $128.4,126.2,124.6,124.19,124.17,114.4,112.4,100.4,99.2,91.4,88.9,77.1,65.9,65.4$, 64.8, 44.3, 41.8, 21.3 ppm; HRMS (ESI-TOF): calcd for $\mathrm{C}_{35} \mathrm{H}_{23} \mathrm{~N}_{2} \mathrm{O}_{8}{ }^{+}\left[\mathrm{M}+\mathrm{H}^{+}\right]$: 599.1449, found 599.1447 .

\section{General Procedure B.}
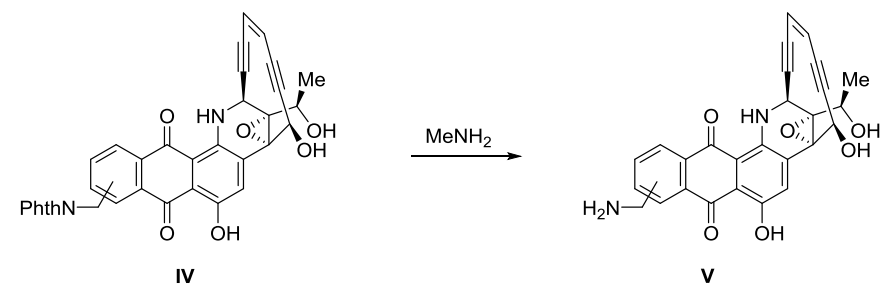

To a solution of phthalimidomethyl-uncialamycin IV (1.0 equiv) in degassed THF/MeOH (2:10, $0.05 \mathrm{M})$ at $0{ }^{\circ} \mathrm{C}$ was added $\mathrm{MeNH}_{2}\left(40 \%\right.$ wt in $\mathrm{H}_{2} \mathrm{O}, 100$ equiv) dropwise. The resulting mixture, covered with aluminum foil, was stirred at $10{ }^{\circ} \mathrm{C}$. The reaction was monitored by LCMS and HPLC. Once judged complete, the mixture was concentrated at $8{ }^{\circ} \mathrm{C}$. The residue was either used directly for subsequent chemical step or purified on 
HPLC using X Bridge prep C18 column $(30 \times 250 \mathrm{~mm}, 5 \mathrm{~mm}$ OBD) with $5-95 \%$ water/acetonitrile $(0.05 \%$ formic acid $)$. The product aminomethyl-uncialamycin was collected as a formic acid salt, which was immediately used for biological experiments. (CAUTION: aminomethyl-uncialamycins are labile, slowly decomposing at $-78^{\circ} \mathrm{C}$ ).

8-Aminomethyl-Uncialamycin (+)-50b. Prepared according to general procedure $B$, from

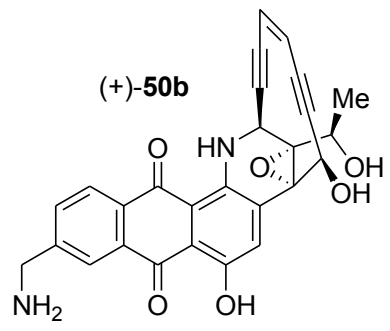
8-phthalimidomethyl-uncialamycin (+)-50a. Purified on R-HPLC using X Bridge prep C18 column ( $30 \times 250 \mathrm{~mm}, 5 \mu \mathrm{m}$ OBD) with 5$95 \%$ water/acetonitrile $(0.05 \%$ formic acid $)$ over $40 \mathrm{~min}$. A fraction collected at 11.5 min was lyophilized to obtain (+)-50b as a purple solid. $\mathrm{R}_{f}=0.24$ (silica gel, $30 \% \mathrm{MeOH}$ in EtOAc); $[\alpha]_{D^{20}}=+2700$ (c $=0.001$, EtOAc); FT-IR (neat) $v_{\max }=3359,3311,3197,2957,2921,2851,1660,1632,1596,1562,1487,1468$, $1424,1410,1376,1343,1317,1259,1206,1084,1028,968,908,870,799,720,703 \mathrm{~cm}^{-1}$; ${ }^{1} \mathrm{H}$ NMR $\left(600 \mathrm{MHz}, \mathrm{CD}_{3} \mathrm{CN}\right): \delta=9.99(\mathrm{~d}, J=3.6 \mathrm{~Hz}, 1 \mathrm{H}), 8.50(\mathrm{~s}, 1 \mathrm{H}), 8.25(\mathrm{~s}, 1 \mathrm{H}), 8.24$ $(\mathrm{d}, J=7.8 \mathrm{~Hz}, 1 \mathrm{H}), 7.83(\mathrm{~d}, J=7.8 \mathrm{~Hz}, 1 \mathrm{H}), 5.97(\mathrm{~d}, J=10.2 \mathrm{~Hz}, 1 \mathrm{H}), 5.89(\mathrm{dt}, J=10.2$, $1.2 \mathrm{~Hz}, 1 \mathrm{H}), 5.25(\mathrm{~s}, 1 \mathrm{H}), 4.91$ (dd, J = 4.2, $1.8 \mathrm{~Hz}, 1 \mathrm{H}), 4.40-4.37(\mathrm{~m}, 1 \mathrm{H}), 3.98(\mathrm{~s}, 2 \mathrm{H})$, 3.27 (br s, $1 \mathrm{H}$ ), 2.57 (br s, $1 \mathrm{H}), 1.39$ (d, J = 6.6 Hz, $3 \mathrm{H}$ ), ppm; ${ }^{13} \mathrm{C}$ NMR (151 MHz, $\left.\mathrm{CD}_{3} \mathrm{CN}\right): \delta=188.9,184.5,156.7,151.7,144.6,136.1,134.39,134.36,133.7,130.8,128.0$ $125.2,124.6,124.1,114.5,112.6,100.5,99.3,91.3,88.9,77.1,66.0,65.5,64.8,46.4$, 44.3, 21.3 ppm; HRMS (ESI-TOF): calcd for $\mathrm{C}_{27} \mathrm{H}_{21} \mathrm{~N}_{2} \mathrm{O}_{6}{ }^{+}\left[\mathrm{M}+\mathrm{H}^{+}\right]$: 469.1394, found 469.1397.

8-tert-Butylcarbamoylmethyl-Uncialamycin (+)-50c. To a stirred solution of crude 8aminomethyl-uncialamycin $(+)-50 b$ that was obtained according to general procedure $\mathrm{B}$ from 8-phthalimidomethyl-uncialamycin (+)-50a $(4.0 \mathrm{mg}, 6.7 \mu \mathrm{mol}, 1.0$ equiv) in degassed THF $(1.0 \mathrm{~mL})$ at $0{ }^{\circ} \mathrm{C}$ was added saturated aqueous $\mathrm{NaHCO}_{3}(1.0 \mathrm{~mL})$ and $\mathrm{Boc}_{2} \mathrm{O}(1.3 \mathrm{mg}$, $8.0 \mu \mathrm{mol}, 1.2$ equiv). The resulting mixture, covered with aluminum foil, was stirred at the same temperature for $1.5 \mathrm{~h}$. The mixture was extracted with EtOAc $(3 \times 10 \mathrm{~mL})$. The 
combined organic layers were washed with brine $(10 \mathrm{~mL})$, dried over $\mathrm{Na}_{2} \mathrm{SO}_{4}$, filtered and concentrated. The obtained residue was purified by flash column chromatography (silica gel, 50 to $70 \%$ EtOAc in hexanes) to afford pure 8-tert-butylcarbamoylmethyl-uncialamycin (+)-50c (2.7 mg, $4.7 \mu \mathrm{mol}, 70 \%$ yield over two steps) as a purple solid.

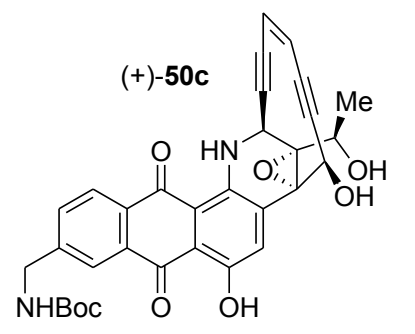

(+)-50c: $R_{f}=0.27$ (silica gel, EtOAc in hexanes $70 \%$ ); $[\alpha]_{D}{ }^{20}=$ $+3300\left(\mathrm{c}=0.001\right.$, EtOAc); FT-IR (neat) $v_{\max }=3380,2981,2934$, $1694,1626,1596,1560,1487,1391,1367,1343,1319,1275,1260$, $1204,1166,1098,1053,908,864,794,764,750,698 \mathrm{~cm}^{-1} ;{ }^{1} \mathrm{H}$ NMR (600 MHz, CD $\left.{ }_{3} \mathrm{CN}\right): \delta=13.16(\mathrm{~s}, 1 \mathrm{H}), 10.00(\mathrm{~d}, J=4.8 \mathrm{~Hz}, 1 \mathrm{H}), 8.50(\mathrm{~s}, 1 \mathrm{H}), 8.26$ (d, $J=8.4 \mathrm{~Hz}, 1 \mathrm{H}), 8.16(\mathrm{~s}, 1 \mathrm{H}), 7.75(\mathrm{dd}, J=8.4,1.8 \mathrm{~Hz}, 1 \mathrm{H}), 5.97(\mathrm{~d}, J=9.6 \mathrm{~Hz}, 1 \mathrm{H})$, $6.96(\mathrm{br} \mathrm{s}, 1 \mathrm{H}), 5.89(\mathrm{dt}, J=9.6,1.2 \mathrm{~Hz}, 1 \mathrm{H}), 5.25(\mathrm{~d}, J=4.8 \mathrm{~Hz}, 1 \mathrm{H}), 4.92(\mathrm{dd}, J=4.8$, $1.8 \mathrm{~Hz}, 1 \mathrm{H}), 4.42-4.37(\mathrm{~m}, 4 \mathrm{H}), 3.25(\mathrm{~d}, J=4.8 \mathrm{~Hz}, 1 \mathrm{H}), 1.44(\mathrm{~s}, 9 \mathrm{H}), 1.39(\mathrm{~d}, J=6.6$ $\mathrm{Hz}, 3 \mathrm{H}) \mathrm{ppm} ;{ }^{13} \mathrm{C}$ NMR $\left(151 \mathrm{MHz}, \mathrm{CD}_{3} \mathrm{CN}\right): \delta=188.7,184.3,157.1,156.7,147.5,144.7$, $136.2,134.8,134.1,133.8,130.9,128.2,125.2,124.6,124.2,114.5,112.5,100.4,99.3$, 91.4, 88.9, 79.9, 77.1, 66.0, 65.5, 64.8, 44.4, 44.3, 28.6, 21.3 ppm; HRMS (ESI-TOF): calcd for $\mathrm{C}_{32} \mathrm{H}_{29} \mathrm{~N}_{2} \mathrm{O}_{8}{ }^{+}\left[\mathrm{M}+\mathrm{H}^{+}\right]: 569.1918$, found 569.1918 .

7-Phthalimidomethyl-Uncialamycin (+)-51a. Prepared according to the general

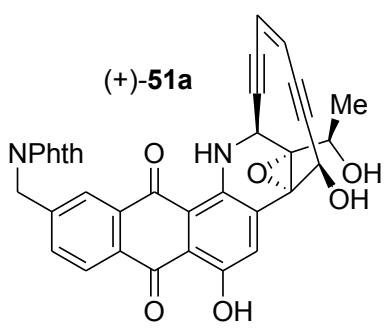
procedure A from cyanophthalide $60 \mathrm{e}(22 \mathrm{mg}, 69 \mu \mathrm{mol}, 1.3$ equiv) and quinone aminal (+)-13 (29 mg, $54 \mu \mathrm{mol}, 1.0$ equiv). 7Phthalimidomethyl-uncialamycin (+)-51a (20 mg, $33 \mu \mathrm{mol}, 61 \%$ for 3 steps) was obtained as a purple solid.

$\mathrm{R}_{f}=0.33$ (silica gel, 70\% EtOAc in hexanes); $[\alpha]_{D}^{20}=+520(\mathrm{c}=0.01$, EtOAc); FT-IR (neat) $\nu_{\max }=3462,2921,2851,1770,1715,1655,1627,1594,1561,1484,1428,1394,1352$, $1318,1262,1239,1195,1154,1098,1057,953,899,798,729,713 \mathrm{~cm}^{-1} ;{ }^{1} \mathrm{H}$ NMR $(600$ $\left.\mathrm{MHz}, \mathrm{CD}_{3} \mathrm{CN}\right): \delta=13.15(\mathrm{~s}, 1 \mathrm{H}), 9.98(\mathrm{~d}, J=4.8 \mathrm{~Hz}, 1 \mathrm{H}), 8.50(\mathrm{~s}, 1 \mathrm{H}), 8.230(\mathrm{~d}, J=7.8$ $\mathrm{Hz}, 1 \mathrm{H}), 8.227(\mathrm{~d}, J=1.8 \mathrm{~Hz}, 1 \mathrm{H}), 7.88(\mathrm{dd}, J=5.4,3.0 \mathrm{~Hz}, 1 \mathrm{H}), 7.82$ (dd, $J=5.4,3.0$ 
$\mathrm{Hz}, 1 \mathrm{H}), 7.78(\mathrm{dd}, J=7.8,1.8 \mathrm{~Hz}, 1 \mathrm{H}), 5.96(\mathrm{~d}, J=9.6 \mathrm{~Hz}, 1 \mathrm{H}), 5.88(\mathrm{dt}, J=9.6,1.2 \mathrm{~Hz}$, $1 \mathrm{H}), 5.24(\mathrm{~d}, J=4.8 \mathrm{~Hz}, 1 \mathrm{H}), 4.99(\mathrm{~s}, 2 \mathrm{H}), 4.90(\mathrm{dd}, J=4.2,1.8 \mathrm{~Hz}, 1 \mathrm{H}), 4.43(\mathrm{~d}, J=4.8$ $\mathrm{Hz}, 1 \mathrm{H}), 4.38(\mathrm{qd}, J=6.6,4.8 \mathrm{~Hz}, 1 \mathrm{H}), 3.26(\mathrm{~d}, J=4.8 \mathrm{~Hz}, 1 \mathrm{H}), 1.38(\mathrm{~d}, J=6.6 \mathrm{~Hz}, 3 \mathrm{H})$ ppm; ${ }^{13} \mathrm{C}$ NMR $\left(151 \mathrm{MHz}, \mathrm{CD}_{3} \mathrm{CN}\right): \delta=188.2,184.0,169.1,156.7,144.9,144.8,136.2$, $136.1,135.4,133.6,133.1,133.0,131.1,127.8,126.8,124.6,124.19,124.16,114.3$, 112.5, 100.4, 99.2, 91.3, 88.9, 77.1, 65.9, 65.4, 64.8, 44.3, 42.0, 21.3 ppm; HRMS (ESITOF): calcd for $\mathrm{C}_{35} \mathrm{H}_{23} \mathrm{~N}_{2} \mathrm{O}_{8}{ }^{+}\left[\mathrm{M}+\mathrm{H}^{+}\right]$: 599.1449, found 599.1449.

7-Aminomethyl-Uncialamycin (+)-51b. Prepared according to general procedure $B$, from

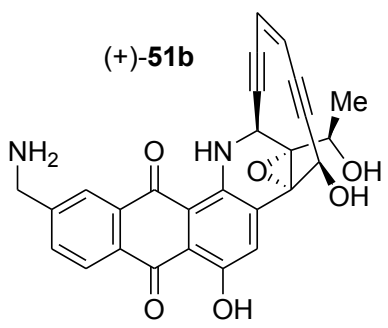
7-phthalimidomethyl-uncialamycin. Purified on Waters Delta Prep 4000 with X Bridge prep C18 column (19x150 mm, $5 \mu \mathrm{m}$ OBD) using $5-95 \%$ water/acetonitrile $(0.05 \%$ formic acid $)$ over $30 \mathrm{~min}$. A fraction collected at 11.5 min was lyophilized to obtain $(+)-51 \mathbf{b}$ as a purple solid, which was immediately used for the biological experiment.

(+)-51b: $R_{f}=0.18$ (silica gel, 30\% MeOH in EtOAc); $[\alpha]_{D^{20}}=+2300(c=0.001$, EtOAc); FT$I R$ (neat) $v_{\max }=3359,3312,3200,2955,2922,2852,1660,1632,1593,1559,1468,1411$, 1362, 1260, 1237, 1200, 1110, 1059, 1008, 937, 882, 802, $721 \mathrm{~cm}^{-1} ;{ }^{1} \mathrm{H}$ NMR $(600 \mathrm{MHz}$, $\left.\mathrm{CD}_{3} \mathrm{CN}\right): \delta=13.22(\mathrm{br} \mathrm{s}, 1 \mathrm{H}), 9.99(\mathrm{~d}, J=3.6 \mathrm{~Hz}, 1 \mathrm{H}), 8.48(\mathrm{~s}, 1 \mathrm{H}), 8.26(\mathrm{~s}, 1 \mathrm{H}), 8.23(\mathrm{~d}$, $J=7.8 \mathrm{~Hz}, 1 \mathrm{H}), 7.79(\mathrm{~d}, J=7.8 \mathrm{~Hz}, 1 \mathrm{H}), 5.96(\mathrm{~d}, J=9.6 \mathrm{~Hz}, 1 \mathrm{H}), 5.89(\mathrm{~d}, J=9.6 \mathrm{~Hz}, 1$ H), $5.25(\mathrm{~s}, 1 \mathrm{H}), 4.92(\mathrm{dd}, J=4.2,1.2 \mathrm{~Hz}, 1 \mathrm{H}), 4.39(\mathrm{q}, J=6.6 \mathrm{~Hz}, 1 \mathrm{H}), 4.00(\mathrm{~s}, 2 \mathrm{H})$, 3.27 (br s, $1 \mathrm{H}), 1.39$ (d, $J=6.6 \mathrm{~Hz}, 3 \mathrm{H}) \mathrm{ppm} ;{ }^{13} \mathrm{C} \mathrm{NMR}\left(151 \mathrm{MHz}, \mathrm{CD}_{3} \mathrm{CN}\right): \delta=188.5$, 184.6, 156.6, 144.7, 136.0, 135.9, 133.2, 132.2, 131.0, 127.4, 126.1, 124.6, 124.2, 114.4, 112.7, 100.5, 99.2, 91.3, 88.9, 77.1, 66.0, 65.4, 64.8, 46.5, 44.4, 21.3 ppm; HRMS (ESITOF): calcd for $\mathrm{C}_{27} \mathrm{H}_{21} \mathrm{~N}_{2} \mathrm{O}_{6}{ }^{+}\left[\mathrm{M}+\mathrm{H}^{+}\right]$: 469.1394 , found 469.1396 .

7-tert-Butylcarbamoylmethyl-Uncialamycin (+)-51c. To a stirred solution of crude 7aminomethyl-uncialamycin (+)-51b that was obtained according to general procedure B from 7-phthalimidomethyl-uncialamycin (+)-51a (1.6 mg, $2.7 \mu \mathrm{mol}, 1.0$ equiv) in degassed 
THF $(0.5 \mathrm{~mL})$ at $0{ }^{\circ} \mathrm{C}$ was added saturated aqueous $\mathrm{NaHCO}_{3}(0.5 \mathrm{~mL})$ and $\mathrm{Boc}_{2} \mathrm{O}(0.8 \mathrm{mg}$, $3.5 \mu \mathrm{mol}, 1.3$ equiv). The resulting mixture, covered with aluminum foil, was stirred at the same temperature for $1.5 \mathrm{~h}$. The mixture was extracted with EtOAc $(3 \times 10 \mathrm{~mL})$. The combined organic layers were washed with brine $(10 \mathrm{~mL})$, dried over $\mathrm{Na}_{2} \mathrm{SO}_{4}$, filtered and concentrated. The obtained residue was purified by flash column chromatography (silica gel, 50 to $70 \%$ EtOAc in hexanes) to afford pure 7-tert-butylcarbamoylmethyl-uncialamycin $(+)-51 \mathrm{c}(1.0 \mathrm{mg}, 1.8 \mu \mathrm{mol}, 66 \%$ yield over two steps) as a purple solid.

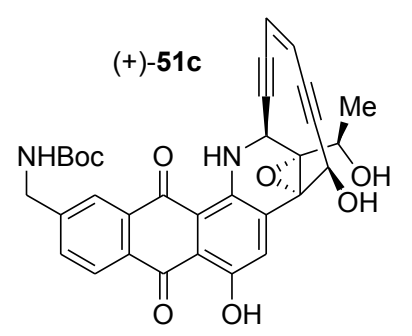

$\mathrm{R}_{f}=0.38$ (silica gel, $70 \%$ EtOAc in hexanes); $[\alpha]_{\mathrm{D}}^{20}=+920(\mathrm{c}=$ 0.003, EtOAc); FT-IR (neat) $v_{\max }=3366,3057,2926,2854,1688$, $1627,1594,1551,1482,1456,1367,1319,1253,1239,1192,1165$, $1100,1055,1018,982,964,945,910,867,814,795,762,742 \mathrm{~cm}^{-}$

1; ${ }^{1} \mathrm{H}$ NMR (600 MHz, $\left.\mathrm{CD}_{3} \mathrm{CN}\right): \delta=13.19(\mathrm{~s}, 1 \mathrm{H}), 9.99(\mathrm{~d}, J=4.2 \mathrm{~Hz}, 1 \mathrm{H}), 8.50(\mathrm{~s}, 1 \mathrm{H})$, $8.24(\mathrm{~d}, J=7.8 \mathrm{~Hz}, 1 \mathrm{H}), 8.18(\mathrm{~s}, 1 \mathrm{H}), 7.71(\mathrm{~d}, J=7.8 \mathrm{~Hz}, 1 \mathrm{H}), 5.97(\mathrm{~d}, J=10.2,1 \mathrm{H})$, $5.96(\mathrm{br} \mathrm{s}, 1 \mathrm{H}), 5.89(\mathrm{dt}, J=10.2,1.2 \mathrm{~Hz}, 1 \mathrm{H}), 5.25(\mathrm{~d}, J=4.8 \mathrm{~Hz}, 1 \mathrm{H}), 4.92(\mathrm{dd}, J=4.2$, $1.2 \mathrm{~Hz}, 1 \mathrm{H}), 4.45(\mathrm{~d}, J=5.4 \mathrm{~Hz}, 1 \mathrm{H}), 4.41-4.36(\mathrm{~m}, 3 \mathrm{H}), 3.26(\mathrm{~d}, J=4.8 \mathrm{~Hz}, 1 \mathrm{H}), 1.44$ (s, $9 \mathrm{H}), 1.39(\mathrm{~d}, J=6.6 \mathrm{~Hz}, 3 \mathrm{H}) \mathrm{ppm} ;{ }^{13} \mathrm{C}$ NMR $\left(151 \mathrm{MHz}, \mathrm{CD}_{3} \mathrm{CN}\right): \delta=188.4,184.4$, 157.1, 156.6, 148.8, 144.7, 136.1, 136.0, 132.9, 132.6, 131.0, 127.6, 125.9, 124.6, 124.2, 114.4, 112.6, 100.4, 99.2, 91.4, 88.9, 79.8, 77.1, 66.0, 65.5, 64.8, 44.6, 44.4, 28.6, 21.3 ppm; HRMS (ESI-TOF): calcd for $\mathrm{C}_{32} \mathrm{H}_{28} \mathrm{~N}_{2} \mathrm{O}_{8} \mathrm{Na}^{+}$[M+Na+]: 591.1738, found 591.1744.

9-Phthalimidomethyl-uncialamycin (+)-52. Prepared according to general procedure $A$ from cyanophthalide $60 f(59 \mathrm{mg}, 0.19 \mathrm{mmol}, 3.0$ equiv) and
steps) was obtained as a purple solid.

$(+)$-52: $R_{f}=0.28$ (silica gel, EtOAc in hexanes $\left.70 \%\right) ;[\alpha]_{D}{ }^{20}=+1250(c=0.002$, EtOAc); IR (film) $V_{\max }=3362,2959,2923,2852,1771,1716,1660,1632,1615,1578,1488,1467$, 
1407, 1390, 1349, 1322, 1260, 1227, 1205, 1096, 1060, 1019, 957, 865, 800, 735, 714, $661 \mathrm{~cm}^{-1} ;{ }^{1} \mathrm{H}$ NMR $\left(600 \mathrm{MHz}, \mathrm{CD}_{3} \mathrm{CN}\right): \delta=13.18(\mathrm{~s}, 1 \mathrm{H}), 9.95(\mathrm{~d}, J=4.2 \mathrm{~Hz}, 1 \mathrm{H}), 8.52(\mathrm{~s}$, $1 \mathrm{H}), 8.33(\mathrm{~d}, J=7.8 \mathrm{~Hz}, 1 \mathrm{H}), 7.92(\mathrm{dd}, J=5.4,3.0 \mathrm{~Hz}, 1 \mathrm{H}), 7.86(\mathrm{dd}, J=5.4,3.0 \mathrm{~Hz}, 1$ H), $7.73(\mathrm{t}, J=7.8 \mathrm{~Hz}, 1 \mathrm{H}), 7.52(\mathrm{dd}, J=7.8,1.2 \mathrm{~Hz}, 1 \mathrm{H}), 5.98(\mathrm{~d}, J=9.6 \mathrm{~Hz}, 1 \mathrm{H}), 5.90$ (dt, $J=9.6,1.2 \mathrm{~Hz}, 1 \mathrm{H}$ ), $5.49(\mathrm{~s}, 2 \mathrm{H}), 5.26(\mathrm{~d}, J=4.8 \mathrm{~Hz}, 1 \mathrm{H}), 4.93(\mathrm{dd}, J=4.2,1.2 \mathrm{~Hz}$, $1 \mathrm{H}), 4.44(\mathrm{~d}, J=4.8 \mathrm{~Hz}, 1 \mathrm{H}), 4.40(\mathrm{qd}, J=6.6,4.8 \mathrm{~Hz}, 1 \mathrm{H}), 3.26(\mathrm{~d}, J=5.4 \mathrm{~Hz}, 1 \mathrm{H})$, $1.40(\mathrm{~d}, J=6.6 \mathrm{~Hz}, 3 \mathrm{H})$ ppm; HRMS (ESI-TOF): calcd for $\mathrm{C}_{35} \mathrm{H}_{23} \mathrm{~N}_{2} \mathrm{O}_{8}{ }^{+}\left[\mathrm{M}+\mathrm{H}^{+}\right]$: 599.1449, found 599.1445 .

8-Phthalimidomethyl-7,9-Dimethoxy-Uncialamycin (+)-53a. Prepared according to

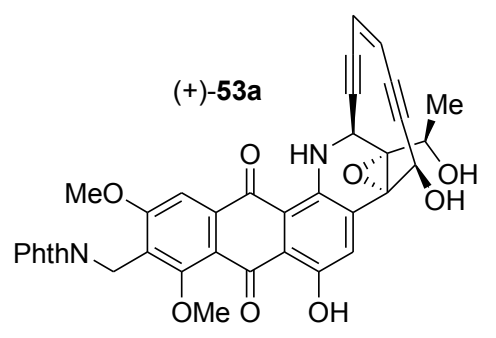
general procedure A from cyanophthalide $60 \mathrm{~g}(72 \mathrm{mg}, 0.19$ mmol, 3.0 equiv) and quinone aminal (+)-13 (34 mg, $63 \mu \mathrm{mol}$, 1.0 equiv). $t$-BuOLi (20 mg, $0.25 \mathrm{mmol}, 4.0$ equiv) was employed as the base in the anthraquinone fusion step (i.e. step a). 8-Phthalimidomethyl-7,9-dimethoxy-uncialamycin (+)-53a (5 mg, $7.6 \mu \mathrm{mol}, 12 \%$ for 3 steps) was obtained as a purple solid.

$\mathrm{R}_{f}=0.19$ (silica gel, $70 \%$ EtOAc in hexanes); $[\alpha]_{D}^{20}=+1300(c=0.002$, EtOAc); FT-IR (neat) $v_{\max }=3365,2961,2925,2853,1772,1714,1662,1619,1572,1487,1466,1394$, $1373,1322,1258,1205,1131,1087,1016,903,796,720,672,663 \mathrm{~cm}^{-1} ;{ }^{1} \mathrm{H}$ NMR $(600$ $\left.\mathrm{MHz}, \mathrm{CD}_{3} \mathrm{CN}\right): \delta=13.58(\mathrm{~s}, 1 \mathrm{H}), 9.88(\mathrm{~d}, J=4.2 \mathrm{~Hz}, 1 \mathrm{H}), 8.47(\mathrm{~s}, 1 \mathrm{H}), 7.80(\mathrm{dd}, J=5.4$, $3.0 \mathrm{~Hz}, 2 \mathrm{H}$ ), 7.77 (dd, $J=5.4,3.0 \mathrm{~Hz}, 2 \mathrm{H}), 7.67$ (s, $1 \mathrm{H}), 5.96$ (d, J = $9.6 \mathrm{~Hz}, 1 \mathrm{H}), 5.89$ (dt, $J=9.6,1.2 \mathrm{~Hz}, 1 \mathrm{H}), 5.23(\mathrm{~d}, J=4.8 \mathrm{~Hz}, 1 \mathrm{H}), 4.98(\mathrm{~s}, 2 \mathrm{H}), 4.91(\mathrm{dd}, J=4.2,1.2 \mathrm{~Hz}$, $1 \mathrm{H}), 4.40(\mathrm{~d}, J=5.4 \mathrm{~Hz}, 1 \mathrm{H}), 4.37(\mathrm{dq}, J=6.0,4.8 \mathrm{~Hz}, 1 \mathrm{H}), 3.934(\mathrm{~s}, 3 \mathrm{H}), 3.925(\mathrm{~s}, 3 \mathrm{H})$, $3.23(\mathrm{~d}, J=4.8 \mathrm{~Hz}, 1 \mathrm{H}), 1.38(\mathrm{~d}, J=6.6 \mathrm{~Hz}, 3 \mathrm{H}) \mathrm{ppm} ;{ }^{13} \mathrm{C} \mathrm{NMR}\left(151 \mathrm{MHz}, \mathrm{CD}_{3} \mathrm{CN}\right): \delta=$ 187.2, 183.5, 168.7, 164.4, 162.3, 156.3, 144.3, 139.0, 135.4, 135.1, 134.6, 133.1, 131.6, $125.3,124.6,124.2,123.8,115.0,112.3,105.8,101.0,100.5,99.2,91.3,88.9,77.1,66.0$, 
65.4, 64.8, 62.8, 57.2, 44.4, 21.3 ppm; HRMS (ESI-TOF): calcd for $\mathrm{C}_{37} \mathrm{H}_{27} \mathrm{~N}_{2} \mathrm{O}_{10}{ }^{+}\left[\mathrm{M}+\mathrm{H}^{+}\right]$: 659.1660 , found 659.1664 .

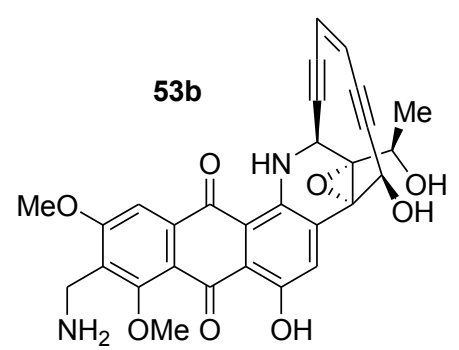

8-Aminomethyl-7,9-Dimethoxy-Uncialamycin 53b. Prepared according to general procedure B from 8-phthalimidomethyl-7,9dimethoxy-uncialamycin $(4.7 \mathrm{mg}, 7.14 \mu \mathrm{mol})$. 8-Aminomethyl7,9-dimethoxy-uncialamycin 53b $(0.529 \mathrm{mg}, 1.00 \mu \mathrm{mol}, 14 \%)$ was obtained as a purple solid. ${ }^{1} \mathrm{H}$ NMR $\left(600 \mathrm{MHz}\right.$, DMSO- $\left.d_{6}\right): \delta=9.91(\mathrm{~d}, J=4.4 \mathrm{~Hz}, 1$ H), $8.51(\mathrm{~s}, 1 \mathrm{H}), 8.32(\mathrm{~s}, 2 \mathrm{H}), 7.66(\mathrm{~s}, 1 \mathrm{H}), 6.07(\mathrm{~d}, J=10.0 \mathrm{~Hz}, 1 \mathrm{H}), 5.99(\mathrm{~d}, J=10.4$ Hz, $1 \mathrm{H}), 5.39$ (s, $1 \mathrm{H}), 5.14$ (s, 1H), $5.06(\mathrm{dd}, J=4.5,1.2 \mathrm{~Hz}, 1 \mathrm{H}), 4.34(\mathrm{~m}, 1 \mathrm{H}), 4.05(\mathrm{~s}$, $3 \mathrm{H}$ ), 3.87 (s, $3 \mathrm{H}$ ), 3.84 (s, $2 \mathrm{H}$ ), 1.31 (d, J = $6.4 \mathrm{~Hz}, 3 \mathrm{H}$ ), ppm; MS (ESI-TOF): calcd for $\mathrm{C}_{29} \mathrm{H}_{25} \mathrm{~N}_{2} \mathrm{O}_{8}{ }^{+}\left[\mathrm{M}+\mathrm{H}^{+}\right]: 529.16$, found 529.2 .

Uncialamycin Analogue (+)-54. Intermediate 83 was prepared from cyanophthalide $60 \mathrm{~h}$

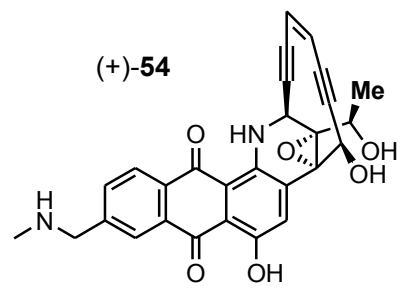

(68 mg, $0.24 \mathrm{mmol}, 2.0$ equiv) and quinone aminal (+)-13 (63 mg,

$0.118 \mathrm{mmol}, 1.0$ equiv) according to general procedure A (step a).

To a solution of the thus obtained crude bis-Alloc-derivative 83 in DMF $(1 \mathrm{~mL})$ at $0{ }^{\circ} \mathrm{C}$ was added triethylamine trihydrofluoride $(95$ $\mathrm{mg}, 0.588 \mathrm{mmol}, 5$ equiv) and stirred for $1 \mathrm{~h}$. The reaction was quenched by the addition of aqueous $\mathrm{NaHCO}_{3}$ solution $(10 \mathrm{~mL})$ and was then extracted with EtOAc $(2 \times 10 \mathrm{~mL})$ and dried over $\mathrm{Na}_{2} \mathrm{SO}_{4}$. The solvent was evaporated and the residue was dissolved in DMF (1 $\mathrm{mL})$ at $0{ }^{\circ} \mathrm{C}$. Morpholine $(0.021 \mathrm{~mL}, 0.24 \mathrm{mmol}, 2.0$ equiv) was added, followed by $\mathrm{Pd}\left(\mathrm{PPh}_{3}\right)_{4}$ (14 $\mathrm{mg}, 0.012 \mathrm{mmol}, 0.1$ equiv) and the reaction was allowed to proceed for $1 \mathrm{~h}$. It was then diluted with DMSO $(2 \mathrm{~mL})$ and purified on a Shimadzu preparative HPLC using X Bridge Prep C18 5um OBD 10x150 mm column eluting with 0-95\% $\mathrm{H}_{2} \mathrm{O} / \mathrm{MeCN}(0.05 \%$ formic acid) to give analogue (+)-54 as a purple solid $(23.4 \mathrm{mg}, 0.048 \mathrm{mmol}, 41 \%$ yield over three steps). 
$(+)-54: R_{f}=0.25$ (silica gel, $20 \% \mathrm{MeOH}$ in acetone); $[\alpha]_{D^{20}}=+3000(\mathrm{c}=0.001$, EtOAc); FTIR (neat) $\nu_{\max }=3359,3309,3187,2957,2921,2851,1659,1632,1598,1562,1486,1469$, $1410,1375,1344,1261,1240,1207,1138,1099,1056,1015,964,908,799,767,702$, $655 \mathrm{~cm}^{-1} ;{ }^{1} \mathrm{H}$ NMR $\left(600 \mathrm{MHz}, \mathrm{CD}_{3} \mathrm{CN}\right): \delta=13.25(\mathrm{~s}, 1 \mathrm{H}), 9.99(\mathrm{~d}, J=4.8 \mathrm{~Hz}, 1 \mathrm{H}), 8.50(\mathrm{~s}$, $1 \mathrm{H}), 8.24(\mathrm{~d}, J=7.8 \mathrm{~Hz}, 1 \mathrm{H}), 8.22(\mathrm{~d}, J=1.2 \mathrm{~Hz}, 1 \mathrm{H}), 7.82(\mathrm{dd}, J=7.8,1.2 \mathrm{~Hz}, 1 \mathrm{H})$, $5.97(\mathrm{~d}, J=10.2 \mathrm{~Hz}, 1 \mathrm{H}), 5.89(\mathrm{dt}, J=10.2,1.2 \mathrm{~Hz}, 1 \mathrm{H}), 5.25(\mathrm{~s}, 1 \mathrm{H}), 4.91(\mathrm{dd}, J=4.8$, $1.8 \mathrm{~Hz}, 1 \mathrm{H}), 4.39(\mathrm{q}, J=6.0 \mathrm{~Hz}, 1 \mathrm{H}), 3.88(\mathrm{~s}, 2 \mathrm{H}), 3.28(\mathrm{br} \mathrm{s}, 1 \mathrm{H}), 2.38(\mathrm{~s}, 3 \mathrm{H}), 1.39$ (d, $J=6.6 \mathrm{~Hz}, 3 \mathrm{H}) \mathrm{ppm} ;{ }^{13} \mathrm{C} \mathrm{NMR}\left(151 \mathrm{MHz}, \mathrm{CD}_{3} \mathrm{CN}\right): \delta=188.8,184.4,156.7,144.6,136.1$, 135.2, 134.6, 133.7, 130.9, 127.9, 126.2, 124.6, 124.1, 114.5, 112.6, 101.0, 100.5, 99.3, 91.3, 88.9, 77.1, 66.0, 65.5, 64.8, 55.7, 44.3, 36.2, 21.3 ppm; HRMS (ESI-TOF): calcd for $\mathrm{C}_{28} \mathrm{H}_{23} \mathrm{~N}_{2} \mathrm{O}_{6}{ }^{+}\left[\mathrm{M}+\mathrm{H}^{+}\right]:$483.1551, found 483.1558 .

Analogue (+)-55. Intermediate 83 was prepared from cyanophthalide $60 \mathrm{~h}(31 \mathrm{mg}, 0.11$

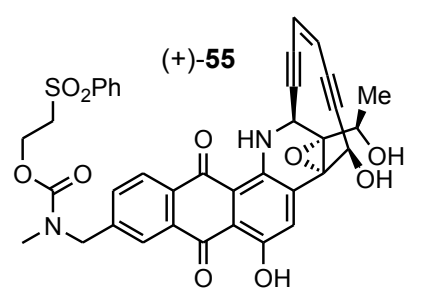

mmol, 2.0 equiv) and quinone aminal (+)-13 (30 mg, $55 \mu \mathrm{mol}, 1.0$ equiv) according to general procedure A (step a). To a stirred solution of the thus obtained crude bis-Alloc-derivative 83 in degassed THF $(1.0 \mathrm{~mL})$ at $0{ }^{\circ} \mathrm{C}$ was added $\mathrm{Pd}\left(\mathrm{PPh}_{3}\right) 4(6.1 \mathrm{mg}, 5.3$ $\mu \mathrm{mol}, 0.1$ equiv) and morpholine (11 $\mathrm{mg}, 0.13 \mathrm{mmol}, 2.4$ equiv). The resulting mixture was warmed to room temperature. After $1 \mathrm{~h}$, the solvent was removed under vacuum. The crude material 84 was used to directly for the next step.

To a stirred solution of crude 84 in $\mathrm{CH}_{2} \mathrm{Cl}_{2}(1.0 \mathrm{~mL})$ at $0{ }^{\circ} \mathrm{C}$ was added a solution of freshly made chloroformate $85^{9}$ (67 mg, $0.27 \mathrm{mmol}, 5$ equiv) in $\mathrm{CH}_{2} \mathrm{Cl}_{2}(0.5 \mathrm{~mL})$ and pyridine (21 $\mathrm{mg}, 0.27 \mathrm{mmol}, 5$ equiv). The resulting mixture was stirred at $0{ }^{\circ} \mathrm{C}$ for $10 \mathrm{~min}$. The reaction was quenched by the addition of water $(5 \mathrm{~mL})$, and extracted with EtOAc $(2 \times 10 \mathrm{~mL})$. The combined organic layers were washed with brine $(10 \mathrm{~mL})$, dried over $\mathrm{Na}_{2} \mathrm{SO}_{4}$ and concentrated. The obtained residue was filtered through a short pad of silica, and the filtrate was concentrated. The crude intermediate $\mathbf{8 6}$ was used directly for the next step. 
The crude intermediate $\mathbf{8 6}$ was converted into phenylsuflonyl analogue (+)-55 according to general procedure A, step c (19 mg, $28 \mu \mathrm{mol}, 51 \%$ from (+)-13).

$(+)-55: R_{\mathrm{f}}=0.26$ (silica gel, 80\% EtOAc in hexanes); $[\alpha]_{\mathrm{D}}{ }^{20}=+5000(\mathrm{c}=0.001$, EtOAc); FT-IR (neat) $v_{\max }=3451,3060,2980,2935,1703,1626,1596,1563,1485,1447,1405$, 1372, 1341, 1319, 1240, 1202, 1142, 1097, 1087, 1049, 999, 962, 908, 874, 847, 797, 767, 732, $689 \mathrm{~cm}^{-1} ;{ }^{1} \mathrm{H}$ NMR $\left(600 \mathrm{MHz}, \mathrm{CD}_{3} \mathrm{CN}\right): \delta=13.16(\mathrm{~s}, 1 \mathrm{H}), 10.01(\mathrm{~d}, J=4.2 \mathrm{~Hz}, 1 \mathrm{H})$, $8.51(\mathrm{~s}, 1 \mathrm{H}), 8.28-8.24(\mathrm{~m}, 1 \mathrm{H}), 8.07-7.99(\mathrm{~m}, 1 \mathrm{H}), 7.94-7.86(\mathrm{~m}, 2 \mathrm{H}), 7.66-7.52(\mathrm{~m}, 4$ H), $5.97(\mathrm{~d}, J=10.2 \mathrm{~Hz}, 1 \mathrm{H}), 5.89(\mathrm{dt}, J=10.2,1.2 \mathrm{~Hz}, 1 \mathrm{H}), 5.25(\mathrm{~d}, J=5.4 \mathrm{~Hz}, 1 \mathrm{H})$, $4.93(\mathrm{dd}, J=4.2,1.8 \mathrm{~Hz}, 1 \mathrm{H}), 4.50(\mathrm{br} \mathrm{s}, 1 \mathrm{H}), 4.44(\mathrm{~d}, J=4.8 \mathrm{~Hz}, 1 \mathrm{H}), 4.42-4.37(\mathrm{~m}, 3$ H), $4.22(\mathrm{br} \mathrm{s}, 1 \mathrm{H}), 3.60-3.51(\mathrm{~m}, 2 \mathrm{H}), 3.26(\mathrm{~d}, J=4.8 \mathrm{~Hz}, 1 \mathrm{H}), 2.80-2.48(\mathrm{~m}, 3 \mathrm{H}), 1.39$ (d, $J=6.6 \mathrm{~Hz}, 3 \mathrm{H}$ ) ppm (exists as rotamers); ${ }^{13} \mathrm{C}$ NMR $\left(151 \mathrm{MHz}, \mathrm{CD}_{3} \mathrm{CN}\right): \delta=188.5$, $184.1,156.8,(156.7+156.1), 145.0,144.7,(141.0+140.8), 136.3,135.0,134.9,134.5$, 134.3, 133.9, 131.0, 130.4, 128.8, 128.3, (125.7+125.6), 124.6, 124.2, 114.4, 112.5, 100.4, $99.2,91.4,88.9,77.1,66.0,65.4,64.8,(60.1+59.8), 56.1,(52.8+52.3), 44.3,(35.1+34.4)$, 21.3 ppm; HRMS (ESI) calcd for $\mathrm{C}_{37} \mathrm{H}_{30} \mathrm{~N}_{2} \mathrm{O}_{10} \mathrm{SNa}^{+}\left[\mathrm{M}+\mathrm{Na}^{+}\right]$717.1513, found 717.1507.

Analogue (+)-56. To a stirred solution of $(+)-81(9.0 \mathrm{mg}, 11 \mu \mathrm{mol}, 1$ equiv) in THF (1 mL)

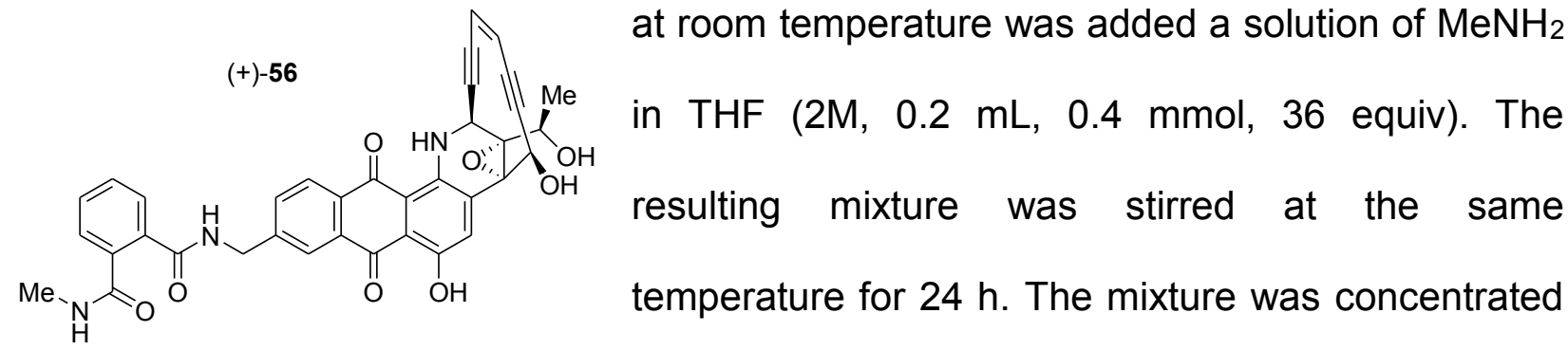
under vacuum, and the residue was filtered through a short pad of silica. The solvent was removed and the residue obtained was converted to analogue (+)-56 (purple solid) in two steps according to general procedure A, steps b and c $(5.5 \mathrm{mg}, 8.7 \mu \mathrm{mol}, 77 \%$ for three steps).

(+)-56: $R_{\mathrm{f}}=0.27$ (silica gel, $20 \%$ acetone in EtOAc); $[\alpha]_{\mathrm{D}}^{20}=+2000(\mathrm{c}=0.002$, EtOAc); FTIR (neat) $\nu_{\max }=3342,2931,1727,1628,1595,1542,1485,1411,1373,1239,1204,1155$, 
1107, 1056, 1005, 963, 938, 908, 795, 738, $694 \mathrm{~cm}^{-1} ;{ }^{1} \mathrm{H}$ NMR $\left(600 \mathrm{MHz}, \mathrm{CD}_{3} \mathrm{CN}\right): \delta=$ $13.17(\mathrm{~s}, 1 \mathrm{H}), 10.00(\mathrm{~d}, J=4.8 \mathrm{~Hz}, 1 \mathrm{H}), 8.50(\mathrm{~s}, 1 \mathrm{H}), 8.28(\mathrm{~d}, J=8.4 \mathrm{~Hz}, 1 \mathrm{H}), 8.24(\mathrm{~d}, J$ $=1.8 \mathrm{~Hz}, 1 \mathrm{H}), 7.89(\mathrm{dd}, J=7.8,1.8 \mathrm{~Hz}, 1 \mathrm{H}), 7.67(\mathrm{t}, J=6.0 \mathrm{~Hz}, 1 \mathrm{H}), 7.62-7.60(\mathrm{~m}, 1 \mathrm{H})$, 7.53-7.51 (m, 3 H), 6.86 (br s, 1 H), 5.97 (d, J = 9.6 Hz, 1 H), 5.89 (dt, J = 9.6, $1.2 \mathrm{~Hz}, 1 \mathrm{H}$ ), $5.25(\mathrm{~d}, J=2.4 \mathrm{~Hz}, 1 \mathrm{H}), 4.92(\mathrm{dd}, J=4.2,1.8 \mathrm{~Hz}, 1 \mathrm{H}), 4.68(\mathrm{~d}, J=6.0 \mathrm{~Hz}, 2 \mathrm{H}), 4.45(\mathrm{~d}$, $J=4.8 \mathrm{~Hz}, 1 \mathrm{H}), 4.39(\mathrm{qd}, J=6.6,4.8 \mathrm{~Hz}, 1 \mathrm{H}), 3.26(\mathrm{~d}, J=4.8 \mathrm{~Hz}, 1 \mathrm{H}), 2.78(\mathrm{~d}, J=4.8$ $\mathrm{Hz}, 3 \mathrm{H}), 1.39$ (d, $J=6.6 \mathrm{~Hz}, 3 \mathrm{H}) \mathrm{ppm} ;{ }^{13} \mathrm{C} \mathrm{NMR}\left(151 \mathrm{MHz}, \mathrm{CD}_{3} \mathrm{CN}\right): \delta=188.6,184.2$, $170.2,169.8,156.7,146.5,144.7,136.9,136.3,136.2,134.8,134.6,133.8,131.1,130.9$, $130.8,129.1,128.7,128.2,125.7,124.6,124.2,114.5,112.5,100.4,99.3,91.3,88.9,77.1$, 66.0, 65.5, 64.8, 44.3, 43.8, 26.8, 21.3 ppm; HRMS (ESI) calcd for $\mathrm{C}_{36} \mathrm{H}_{27} \mathrm{~N}_{3} \mathrm{O}_{8} \mathrm{Na}^{+}\left[\mathrm{M}+\mathrm{Na}^{+}\right]$ 652.1690 found 652.1685 .

Analogue (+)-57. To a stirred solution of (+)-81 (44 mg, $55 \mu \mathrm{mol}, 1.0$ equiv) in MeOH/THF

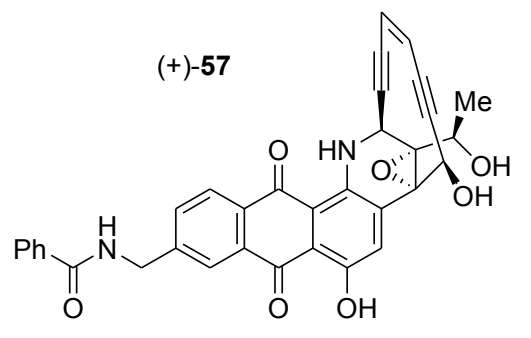

$(5: 1,2.4 \mathrm{~mL})$ at $0{ }^{\circ} \mathrm{C}$ was added a solution of $\mathrm{MeNH}_{2}$ in water $(40 \%, 0.6 \mathrm{~mL}, 6.9 \mathrm{mmol}, 124$ equiv). The resulting mixture was stirred at the same temperature for $1 \mathrm{~h}$, and then warmed to $10{ }^{\circ} \mathrm{C}$. After $5 \mathrm{~h}$, the solvent was removed, and the crude primary amine $\mathbf{8 7}$ was divided in three equal portions. Each portion was used directly for the synthesis of analogues 57-59 (see below).

To a stirred solution of one third of the crude primary amine 87 (ca. $18 \mu \mathrm{mol}, 1.0$ equiv) in DMF $(0.6 \mathrm{~mL})$ at $0{ }^{\circ} \mathrm{C}$ was added $\operatorname{Pr} 2 \mathrm{NEt}(7.2 \mathrm{mg}, 56 \mu \mathrm{mol}, 3.0$ equiv), followed by benzoic acid (3.4 mg, $28 \mu \mathrm{mol}, 1.5$ equiv) and HATU (14 mg, $37 \mu \mathrm{mol}, 2.0$ equiv). The resulting mixture was warmed to room temperature and stirred for $1 \mathrm{~h}$. The reaction was quenched by the addition of water $(5 \mathrm{~mL})$, and extracted with EtOAc $(2 \times 10 \mathrm{~mL})$. The combined organic layers were washed with brine $(10 \mathrm{~mL})$, dried over $\mathrm{Na}_{2} \mathrm{SO}_{4}$ and concentrated. The obtained residue was filtered through a short pad of silica, and the filtrate was 
concentrated. The residue thus obtained was converted into analog (+)-57 (purple solid) according to general procedure $\mathrm{A}$, steps $\mathrm{b}$ and c (3.3 mg, $6.0 \mu \mathrm{mol}, 33 \%, 4$ steps).

$(+)-57: R_{\mathrm{f}}=0.27$ (silica gel, 70\% EtOAc in hexanes); $[\alpha]_{\mathrm{D}^{20}}=+1275(\mathrm{c}=0.004$, EtOAc); FT-IR (neat) $v_{\max }=3365,2953,2901,1627,1596,1536,1489,1422,1261,1238,1203$, 1104, 1039, 1027, 965, 908, 799, 765, 689, $662 \mathrm{~cm}^{-1} ;{ }^{1} \mathrm{H}$ NMR $\left(600 \mathrm{MHz}, \mathrm{CD}_{3} \mathrm{CN}\right): \delta=$ $13.14(\mathrm{~s}, 1 \mathrm{H}), 10.00(\mathrm{~d}, J=4.2 \mathrm{~Hz}, 1 \mathrm{H}), 8.49(\mathrm{~s}, 1 \mathrm{H}), 8.27(\mathrm{~d}, J=7.8 \mathrm{~Hz}, 1 \mathrm{H}), 8.23(\mathrm{~d}, J$ $=1.8 \mathrm{~Hz}, 1 \mathrm{H}), 7.87-7.83(\mathrm{~m}, 3 \mathrm{H}), 7.73(\mathrm{t}, J=6.0 \mathrm{~Hz}, 1 \mathrm{H}), 7.58-7.55(\mathrm{~m}, 1 \mathrm{H}), 7.51-7.48$ $(\mathrm{m}, 2 \mathrm{H}), 5.97(\mathrm{~d}, J=9.6 \mathrm{~Hz}, 1 \mathrm{H}), 5.89(\mathrm{dt}, J=9.6,1.2 \mathrm{~Hz}, 1 \mathrm{H}), 5.24(\mathrm{~d}, J=4.8 \mathrm{~Hz}, 1 \mathrm{H})$, $4.91(\mathrm{dd}, J=4.2,1.8 \mathrm{~Hz}, 1 \mathrm{H}), 4.72(\mathrm{~d}, J=6.0 \mathrm{~Hz}, 2 \mathrm{H}), 4.44(\mathrm{~d}, J=5.4 \mathrm{~Hz}, 1 \mathrm{H}), 4.38$ (qd, $J=6.6,5.4 \mathrm{~Hz}, 1 \mathrm{H}), 3.26(\mathrm{~d}, J=4.8 \mathrm{~Hz}, 1 \mathrm{H}), 1.38(\mathrm{~d}, J=6.6 \mathrm{~Hz}, 3 \mathrm{H}) \mathrm{ppm} ;{ }^{13} \mathrm{C} \mathrm{NMR}$ $\left(151 \mathrm{MHz}, \mathrm{CD}_{3} \mathrm{CN}\right) \delta=188.6,184.2,168.1,156.7,146.8,144.7,136.2,135.2,134.8$ $134.5,133.8,132.6,130.9,129.6,128.2,128.1,125.5,124.6,124.2,114.5,112.5,100.4$, 99.3, 91.3, 88.9, 77.1, 66.0, 65.4, 64.8, 44.3, 43.7, 21.3 ppm; HRMS (ESI) calcd for $\mathrm{C}_{34} \mathrm{H}_{24} \mathrm{~N}_{2} \mathrm{O}_{7} \mathrm{Na}^{+}\left[\mathrm{M}+\mathrm{Na}^{+}\right] 595.1476$, found 595.1473 .

Analogue (+)-58. To a stirred solution of one third of the crude primary amine 87 (ca. 18

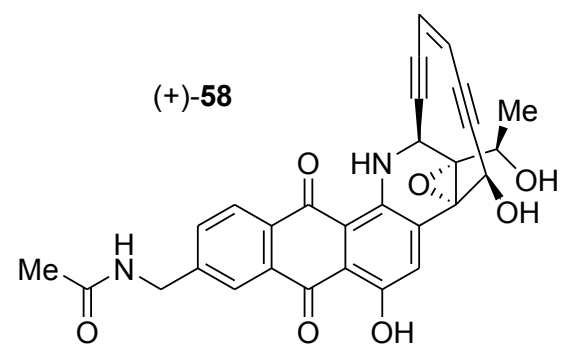
$\mu$ mol, 1.0 equiv) in $\mathrm{CH}_{2} \mathrm{Cl}_{2}(0.6 \mathrm{~mL})$ at $0{ }^{\circ} \mathrm{C}$ was added ${ }_{i} \operatorname{Pr}_{2} \mathrm{NEt}\left(7.2 \mathrm{mg}, 56 \mu \mathrm{mol}, 3.0\right.$ equiv), followed by $\mathrm{Ac}_{2} \mathrm{O}$ (3.8 mg, $37 \mu \mathrm{mol}, 2.0$ equiv). The resulting mixture was warmed to room temperature and stirred for $1 \mathrm{~h}$. The reaction was quenched by the addition of water $(5 \mathrm{~mL})$, and extracted with EtOAc $(2 \times 10$ $\mathrm{mL})$. The combined organic layers were washed with brine $(10 \mathrm{~mL})$, dried over $\mathrm{Na}_{2} \mathrm{SO}_{4}$ and concentrated. The obtained residue was filtered through a short pad of silica, and the filtrate was concentrated. The crude amide thus obtained was converted into analog (+)-58 (purple solid) according to general procedure A, steps b and c (3.2 mg, $6.3 \mu \mathrm{mol}, 35 \%, 4$ steps). 
$(+)$-58: $R_{\mathrm{f}}=0.26$ (silica gel, $20 \%$ Acetone in EtOAc); $[\alpha]_{\mathrm{D}}{ }^{20}=+1500(\mathrm{c}=0.004$, EtOAc);

FT-IR (neat) $v_{\max }=3377,2939,1626,1596,1555,1487,1375,1343,1319,1239,1204$, 1151, 1099, 1055, 963, 908, 792, 739, $689 \mathrm{~cm}^{-1} ;{ }^{1} \mathrm{H}$ NMR $\left(600 \mathrm{MHz}, \mathrm{CD}_{3} \mathrm{CN}\right): \delta=13.16(\mathrm{~s}$, $1 \mathrm{H}), 10.00(\mathrm{~d}, J=4.2 \mathrm{~Hz}, 1 \mathrm{H}), 8.50(\mathrm{~s}, 1 \mathrm{H}), 8.25(\mathrm{~d}, J=7.8 \mathrm{~Hz}, 1 \mathrm{H}), 8.15(\mathrm{~d}, J=1.8 \mathrm{~Hz}$, $1 \mathrm{H}), 7.75(\mathrm{dd}, J=7.8,1.8 \mathrm{~Hz}, 1 \mathrm{H}), 7.00(\mathrm{t}, J=6.0 \mathrm{~Hz}, 1 \mathrm{H}), 5.97(\mathrm{dd}, J=10.2,1.2 \mathrm{~Hz}, 1$ H), $5.89(\mathrm{dt}, J=10.2,1,2 \mathrm{~Hz}, 1 \mathrm{H}), 5.25(\mathrm{~d}, J=4.8 \mathrm{~Hz}, 1 \mathrm{H}), 4.92(\mathrm{dd}, J=4.8,1.8 \mathrm{~Hz}, 1 \mathrm{H})$, $4.49(\mathrm{~d}, J=6.0 \mathrm{~Hz}, 2 \mathrm{H}), 4.46(\mathrm{~d}, J=5.4 \mathrm{~Hz}, 1 \mathrm{H}), 4.38(\mathrm{qd}, J=6.0,4.8 \mathrm{~Hz}, 1 \mathrm{H}), 3.26(\mathrm{~d}$, $J=5.4 \mathrm{~Hz}, 1 \mathrm{H}), 1.96(\mathrm{~s}, 3 \mathrm{H}), 1.39(\mathrm{~d}, J=6.0 \mathrm{~Hz}, 3 \mathrm{H}) \mathrm{ppm} ;{ }^{13} \mathrm{C} \mathrm{NMR}\left(151 \mathrm{MHz}, \mathrm{CD}_{3} \mathrm{CN}\right)$ : $\delta=188.6,184.2,171.0,156.7,147.0,144.7,136.2,134.7,134.4,133.8,130.9,128.2$, $125.4,124.6,124.2,114.5,112.5,100.4,99.3,91.3,88.9,77.1,66.0,65.4,64.8,44.3$, 43.3, 23.0, 21.3 ppm; HRMS (ESI) calcd for $\mathrm{C}_{29} \mathrm{H}_{22} \mathrm{~N}_{2} \mathrm{O}_{7} \mathrm{Na}^{+}\left[\mathrm{M}+\mathrm{Na}^{+}\right] 533.1319$, found 533.1335.

Analogue (+)-59. To a stirred suspension of Fmoc-4-Abz-OH 88 (13 mg, $36 \mu \mathrm{mol}, 2.0$

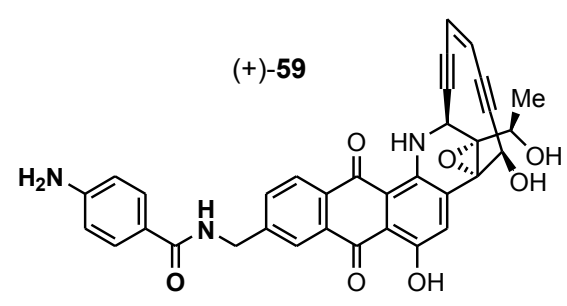
equiv) in $\mathrm{MeCN}(0.5 \mathrm{~mL})$ at room temperature was added HATU (10 mg, $27 \mu \mathrm{mol}, 1.5$ equiv), followed by $\operatorname{Pr}_{2} \mathrm{NEt}(7$ $\mathrm{mg}, 54 \mu \mathrm{mol}, 3.0$ equiv). The resulting mixture was stirred at the same temperature for $30 \mathrm{~min}$, and added to a stirred solution of one third of the crude primary amine 87 (ca. $18 \mu \mathrm{mol}, 1.0$ equiv) in MeCN (0.5 $\mathrm{mL}$ ). The resulting mixture was stirred at room temperature for $1 \mathrm{~h}$. The reaction was quenched by the addition of water $(5 \mathrm{~mL})$, and extracted with EtOAc $(2 \times 10 \mathrm{~mL})$. The combined organic layers were washed with brine $(10 \mathrm{~mL})$, dried over $\mathrm{Na}_{2} \mathrm{SO}_{4}$ and concentrated. The obtained residue was filtered through a short pad of silica, and the filtrate was concentrated. The thus obtained crude amide was converted into analogue (+)59 (purple solid) according to general procedure A, steps b and c (5.1 mg, $8.7 \mu \mathrm{mol}, 48 \%$, 4 steps). 
$(+)$-59: $R_{\mathrm{f}}=0.27$ (silica gel, EtOAc); $[\alpha]_{\mathrm{D}}^{20}=+630\left(\mathrm{c}=0.004\right.$, EtOAc); FT-IR (neat) $v_{\max }=$ $3359,2960,2922,2852,1727,1631,1597,1557,1488,1468,1379,1290,1260,1204$, 1095, 1058, 1018, 907, 847, 800, 760, 694, $654 \mathrm{~cm}^{-1} ;{ }^{1} \mathrm{H}$ NMR $\left(600 \mathrm{MHz}, \mathrm{CD}_{3} \mathrm{CN}\right): \delta=$ 13.14 (s, $1 \mathrm{H}), 9.99$ (d, J = 4.2 Hz, $1 \mathrm{H}), 8.49$ (s, $1 \mathrm{H}), 8.25$ (d, J = 8.4 Hz, $1 \mathrm{H}), 8.19$ (d, J = $1.8 \mathrm{~Hz}, 1 \mathrm{H}), 7.81(\mathrm{dd}, J=7.8,1.8 \mathrm{~Hz}, 1 \mathrm{H}), 7.64-7.61(\mathrm{~m}, 2 \mathrm{H}), 7.44(\mathrm{t}, J=6.0 \mathrm{~Hz}, 1 \mathrm{H})$, 6.67-6.65 (m, $2 \mathrm{H}), 6.96(\mathrm{dd}, J=9.6,1.2 \mathrm{~Hz}, 1 \mathrm{H}), 5.89$ (dt, J = 9.6, $1.2 \mathrm{~Hz}, 1 \mathrm{H}), 5.25(\mathrm{~d}, J$ $=4.8 \mathrm{~Hz}, 1 \mathrm{H}), 4.91(\mathrm{dd}, J=4.2,1.8 \mathrm{~Hz}, 1 \mathrm{H}), 4.67(\mathrm{~d}, J=6.0 \mathrm{~Hz}, 2 \mathrm{H}), 4.59(\mathrm{br} \mathrm{s}, 2 \mathrm{H})$, $4.41(\mathrm{~d}, J=5.4 \mathrm{~Hz}, 1 \mathrm{H}), 4.38(\mathrm{dq}, J=6.6,5.4 \mathrm{~Hz}, 1 \mathrm{H}), 3.24(\mathrm{~d}, J=4.8 \mathrm{~Hz}, 1 \mathrm{H}), 1.38(\mathrm{~d}$, $J=6.6 \mathrm{~Hz}, 3 \mathrm{H}) \mathrm{ppm} ;{ }^{13} \mathrm{C}$ NMR $\left(151 \mathrm{MHz}, \mathrm{CD}_{3} \mathrm{CN}\right): \delta=188.7,184.3,167.9,156.7,152.4$, $147.5,144.6,136.2,134.7,134.5,133.8,130.9,129.7,128.2,125.4,124.6,124.2,123.2$ 114.5, 114.3, 112.5, 101.0, 100.4, 99.3, 91.3, 88.9, 77.1, 66.0, 65.5, 64.8, 44.3, 43.5, 21.3 ppm; HRMS (ESI) calcd for $\mathrm{C}_{34} \mathrm{H}_{25} \mathrm{~N}_{3} \mathrm{O}_{7} \mathrm{Na}^{+}\left[\mathrm{M}+\mathrm{Na}^{+}\right] 610.1585$, found 610.1599. 


\section{Ic. Biological evaluation of Uncialamycin Analogues}

\section{Cell Viability Assay}

CellTiter-Glo ${ }^{\circledR}$ cell viability kits (Promega, Madison, WI) were used to detect the viability (ATP content) of cells. NCI-N87 human gastric cancer cells (ATCC, Catalog CRL5822), NCl-H226 human mesothelioma cells (ATCC, Catalog CRL-5826) and OVCAR3 human ovarian cancer cells (ATCC, Catalog HTB-161) were cultured following ATCC instruction. NCl/Adr-Res cells derived from OVCAR-8 ovarian cancer cells overexpress Pglycoprotein. ${ }^{10-13} \mathrm{NCl} / \mathrm{Adr}-\mathrm{Res}$ cells were obtained from $\mathrm{NCl}$ and cultured in MEM media containing $10 \%$ fetal bovine serum. Cells were cultured to $\sim 50-70 \%$ confluency and harvested using $0.25 \%$ trypsin, and cells were seeded at $1 \times 10^{3}$ cells/well in 96 -well plates for $3 \mathrm{~h}$ for ATP CellTiter-Glo ${ }^{\circledR}$ assays. Serial dilutions (1:3) of compounds were added to the wells. Plates were allowed to incubate for $72 \mathrm{~h}$. A CellTiter-Glo ${ }^{\circledR}$ cell viability kit from Promega was used to measure ATP content of cells treated with compounds following manufacturer's instruction. After 15 minutes of incubation with CellTiter-Glo ${ }^{\circledR}$ at ambient temperature, the plates were read on GloMax ${ }^{\circledR} 96$ Microplate Luminometer (Promega, Madison, $\mathrm{WI}$ ) within 30 minutes. A decrease in the ATP content is a measure of decrease in cellular viability. The $\mathrm{IC}_{50}$ value - the concentration at which an agent reduces cell viability by $50 \%$ of the maximum effect - was determined using PRISM ${ }^{\mathrm{TM}}$ software, version 5.0 (GraphPad Software, La Jolla, CA, USA). 


\section{II. $\quad{ }^{1} \mathrm{H}$ and ${ }^{13} \mathrm{C}$ NMR Spectra of Compounds}
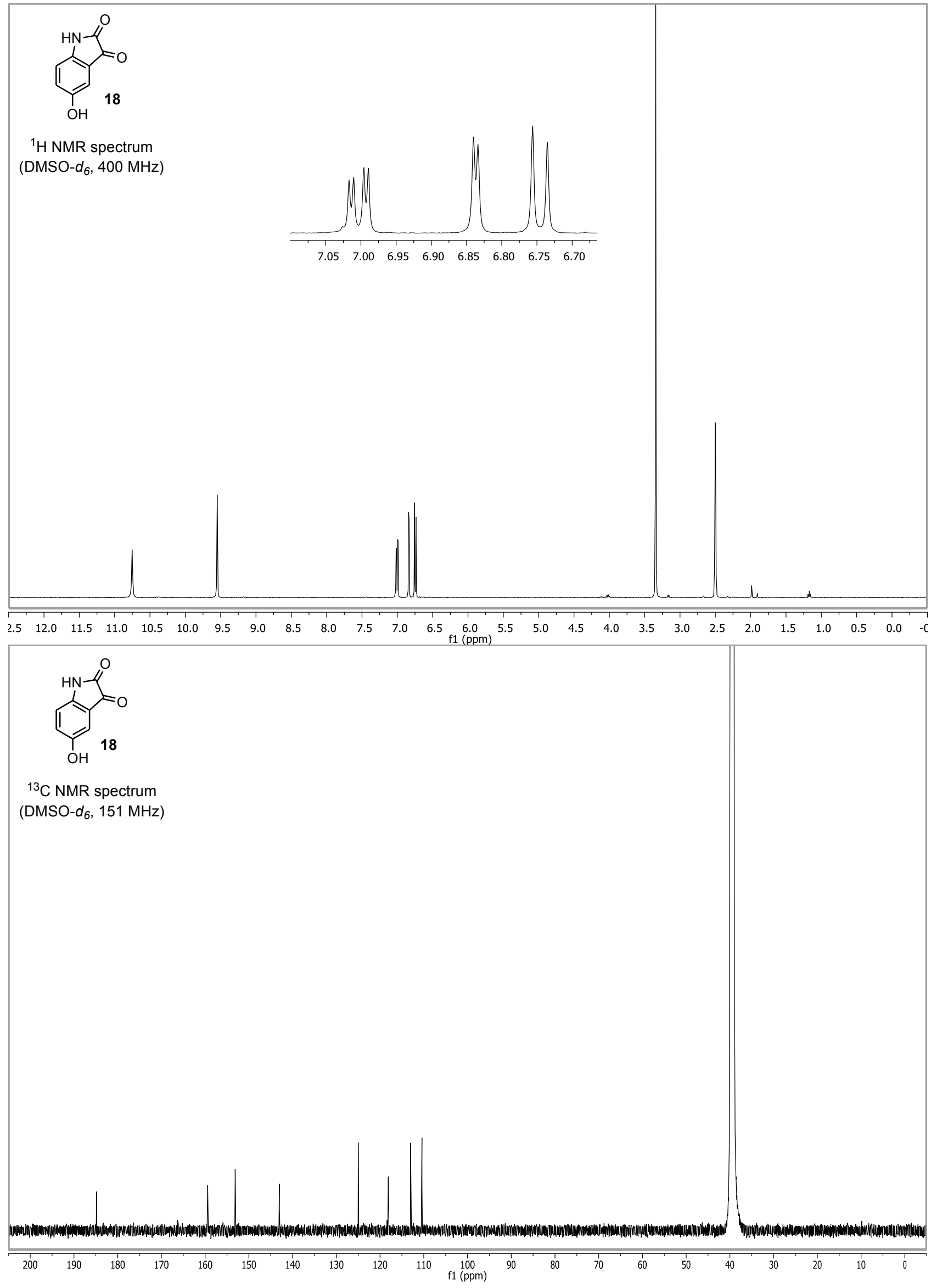

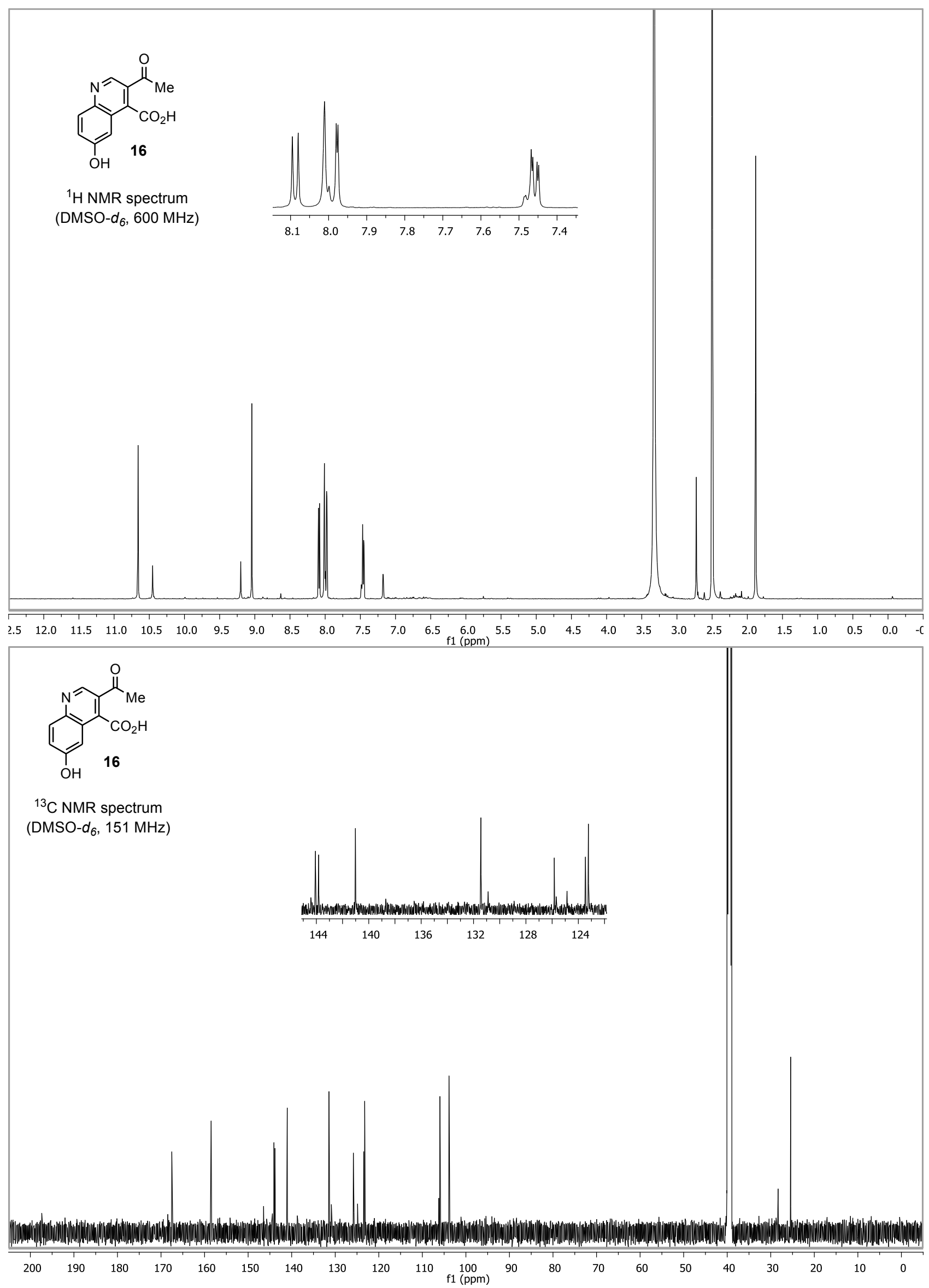

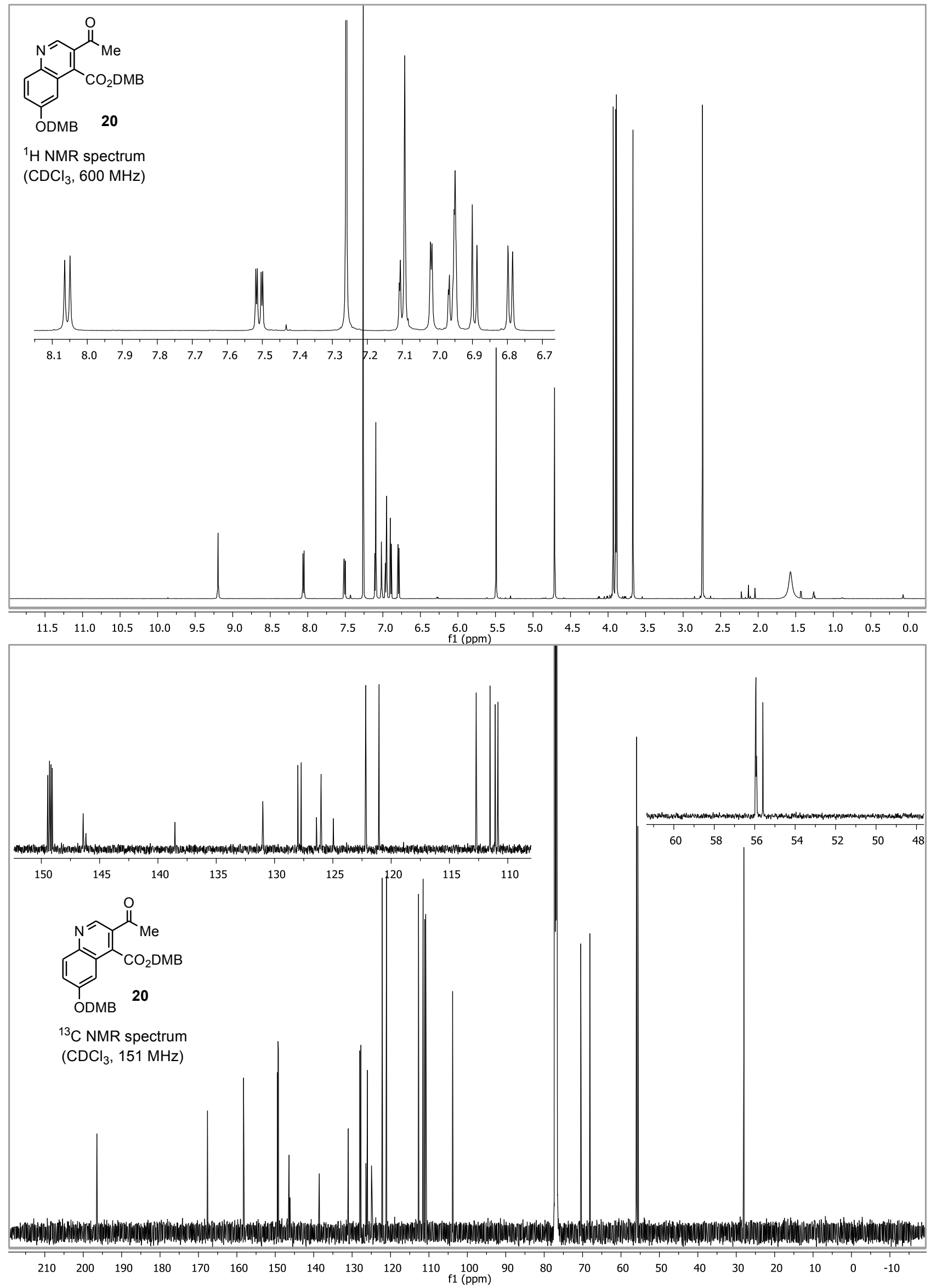

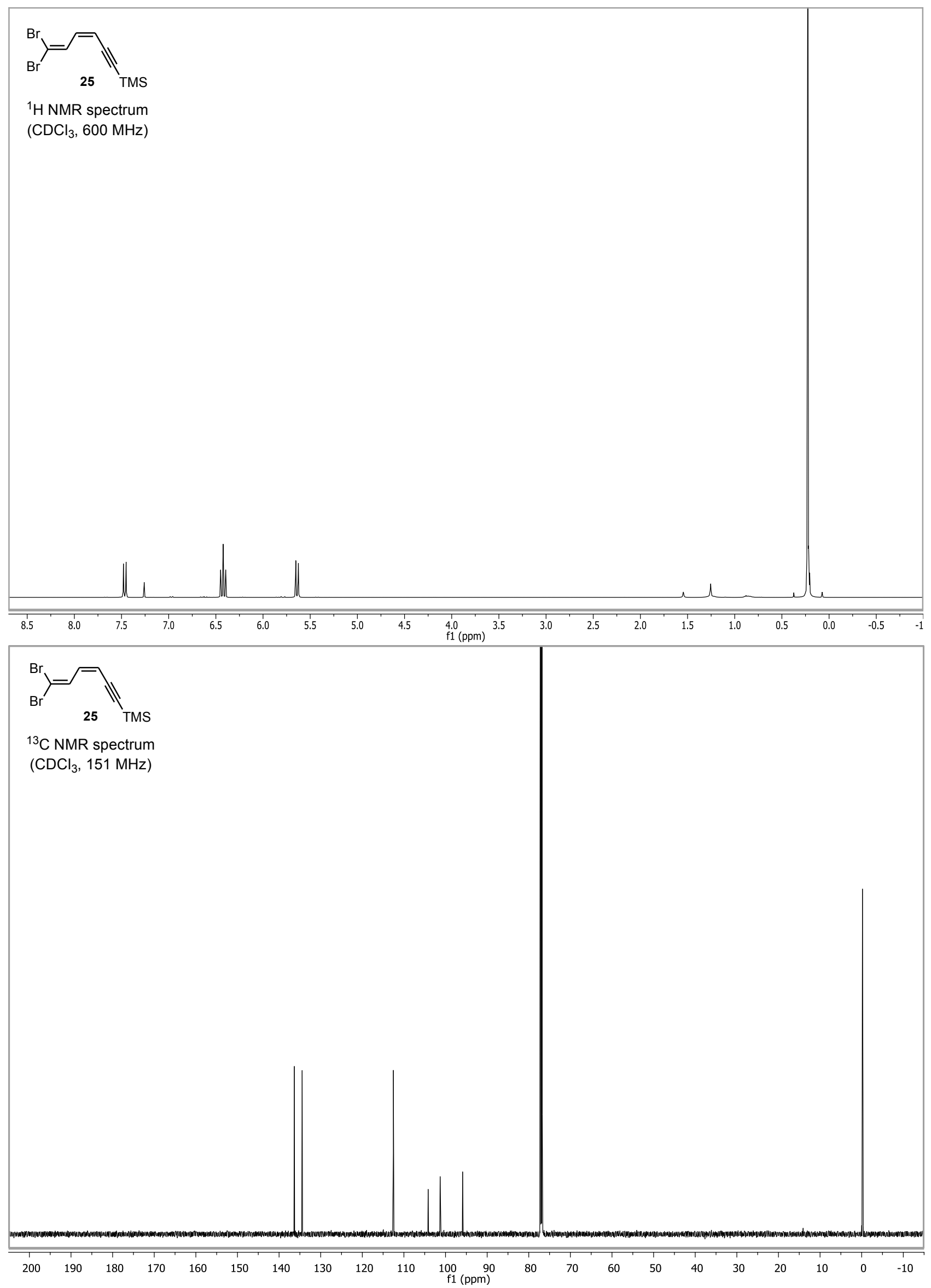

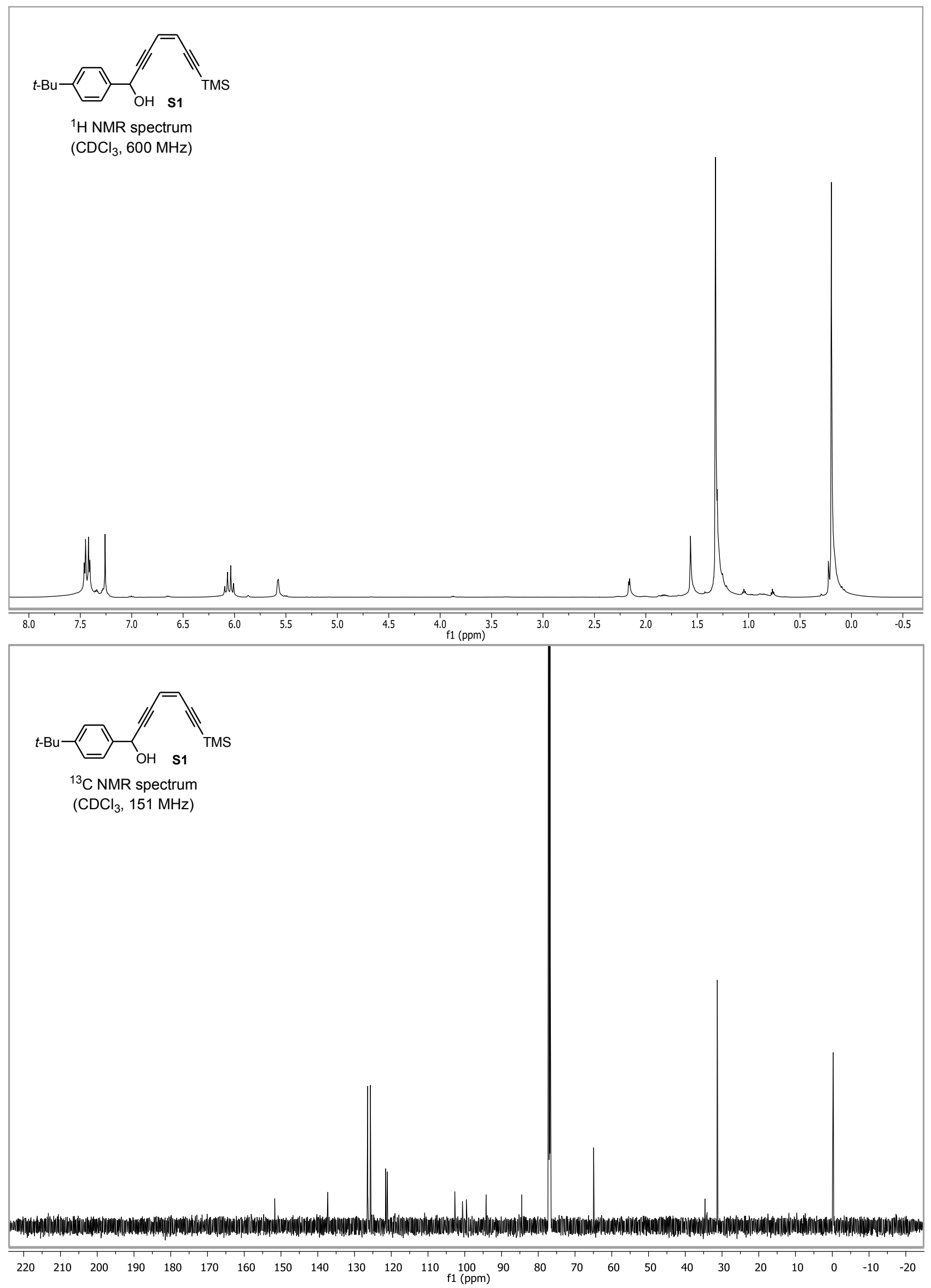

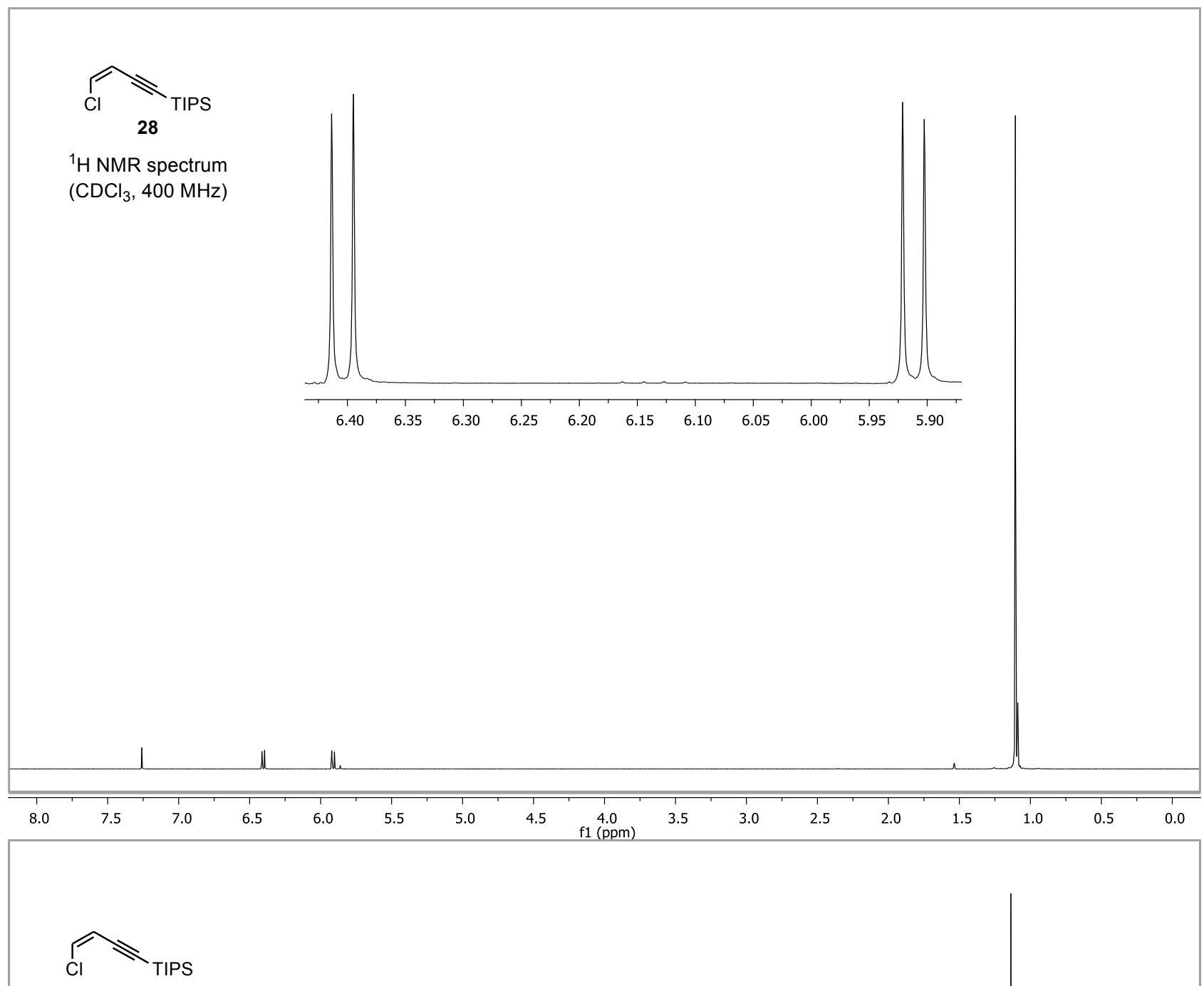

28

${ }^{13} \mathrm{C}$ NMR spectrum $\left(\mathrm{CDCl}_{3}, 100 \mathrm{MHz}\right)$
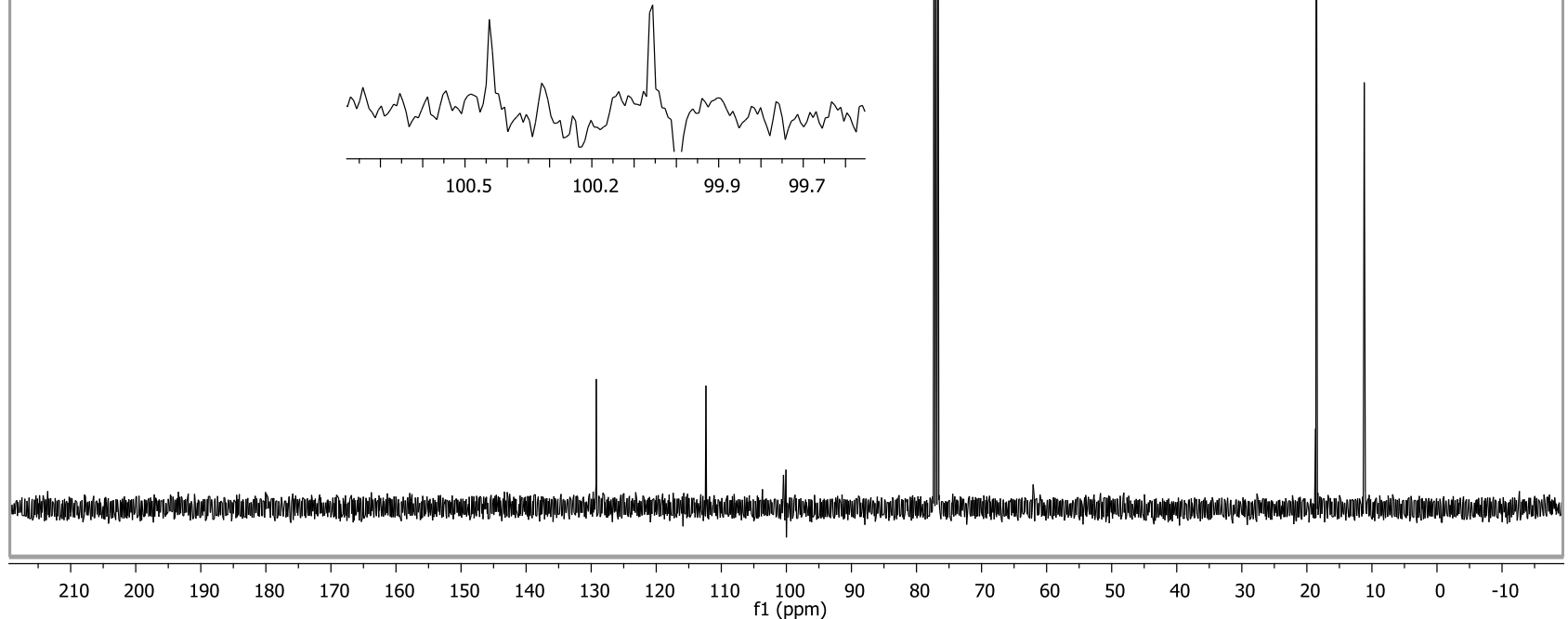


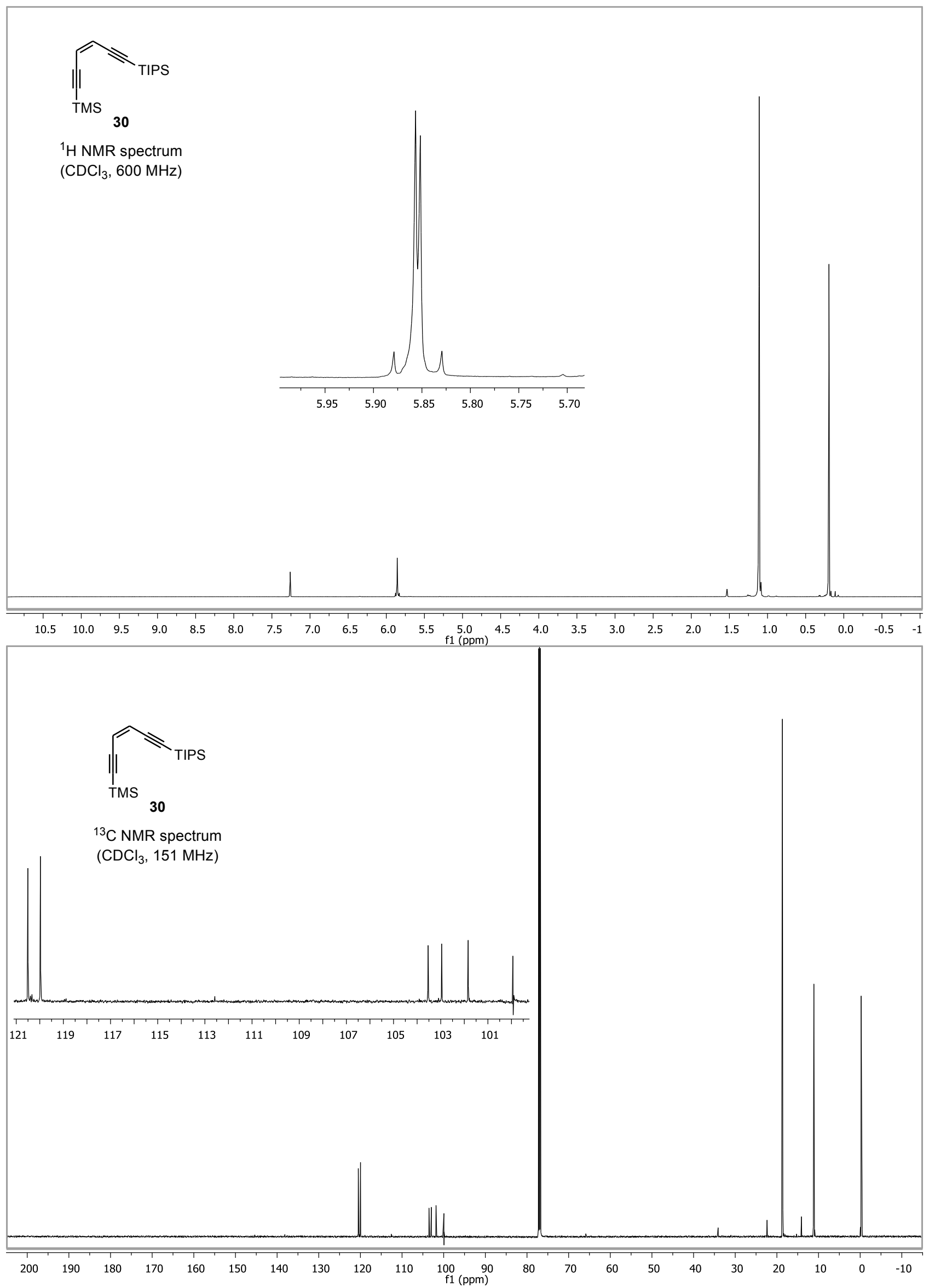



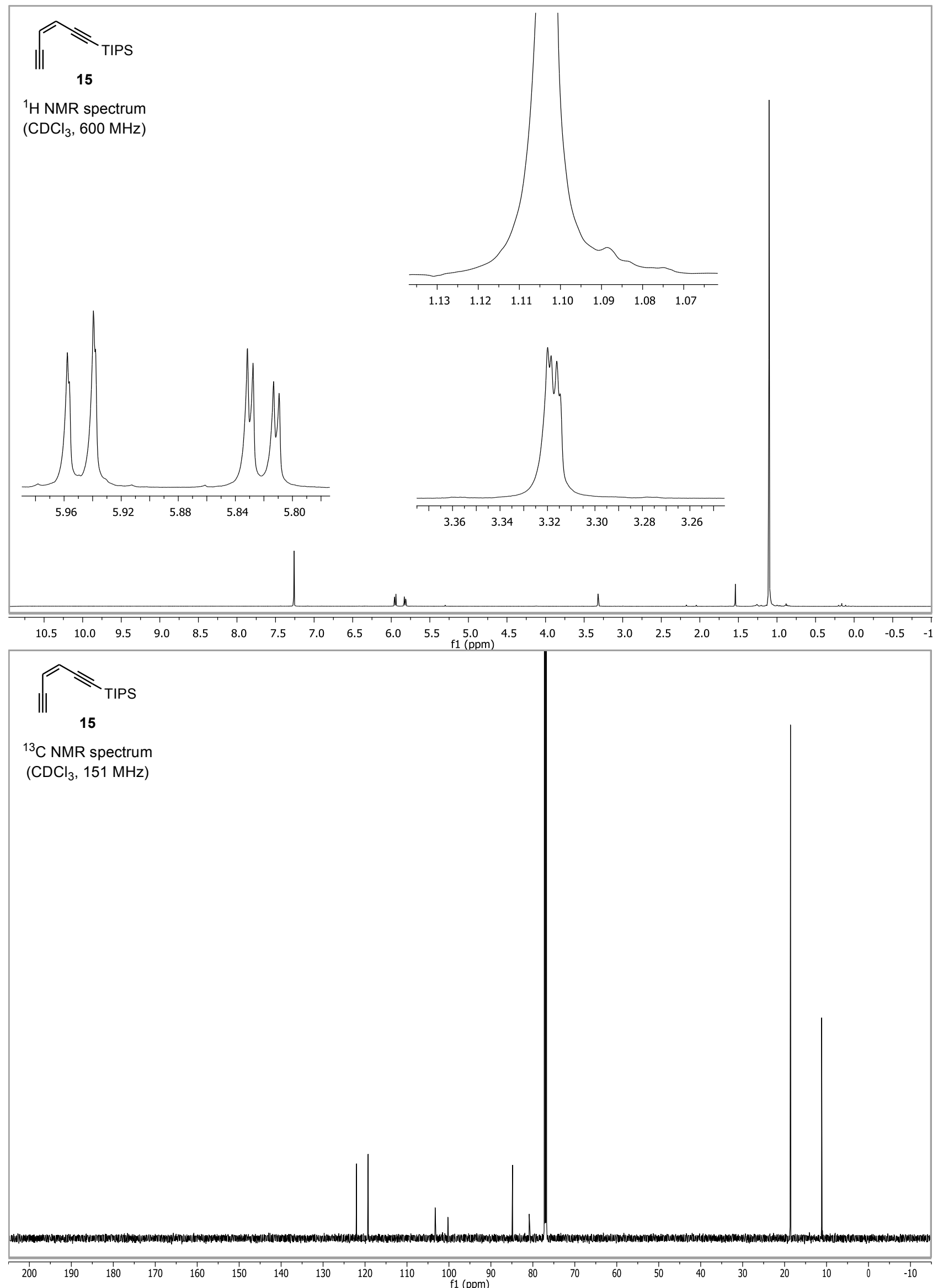

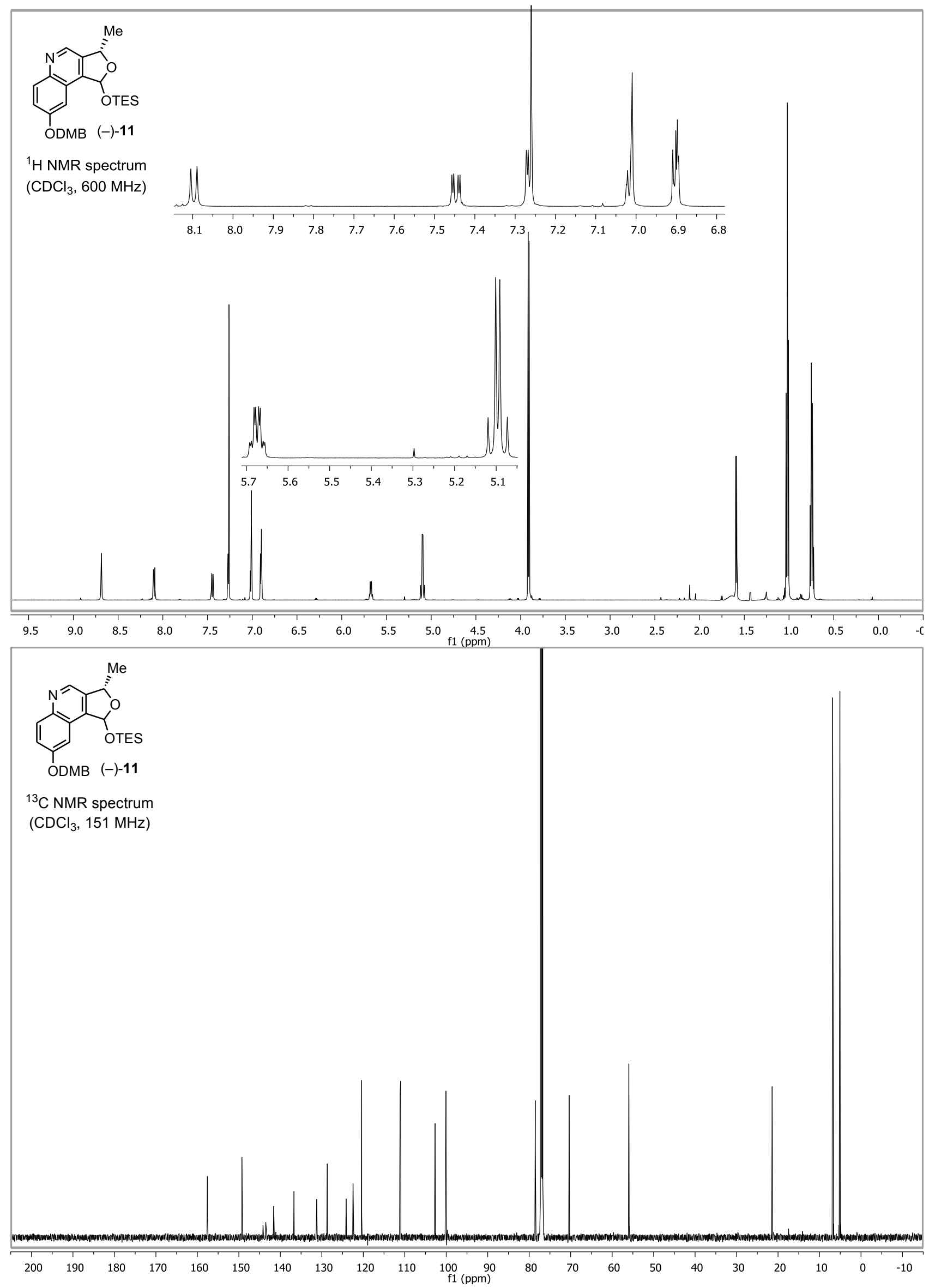

S83 

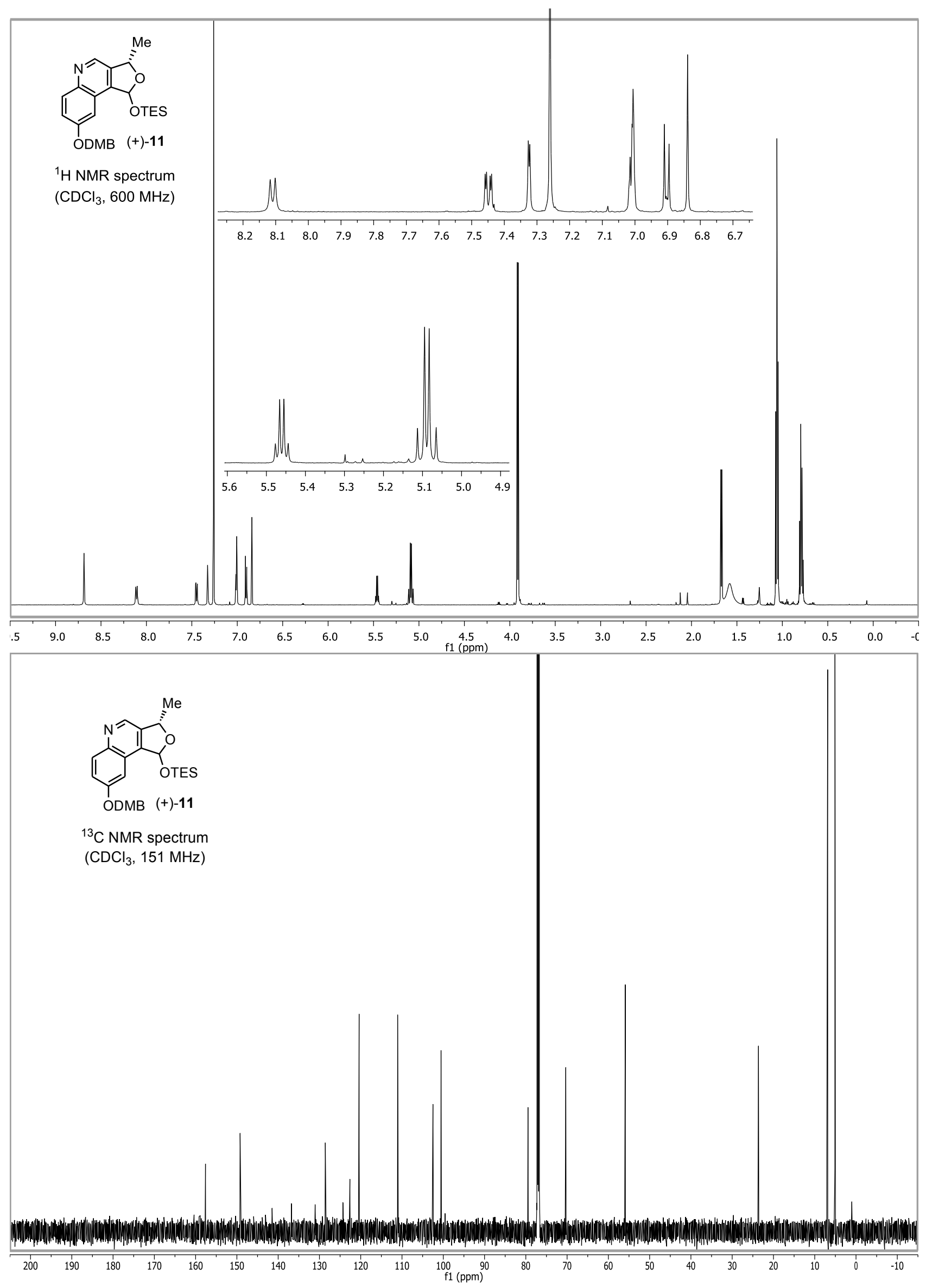

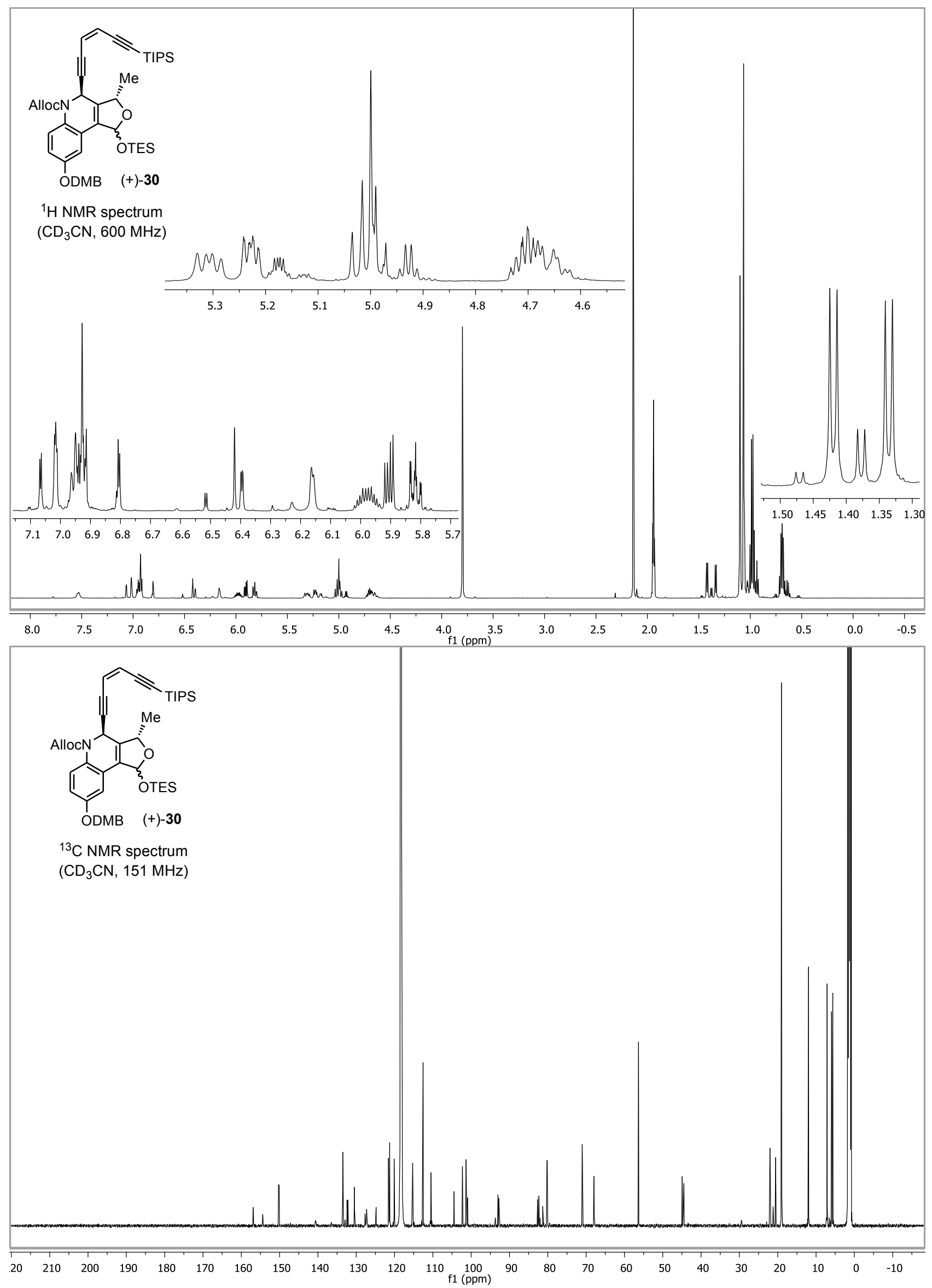

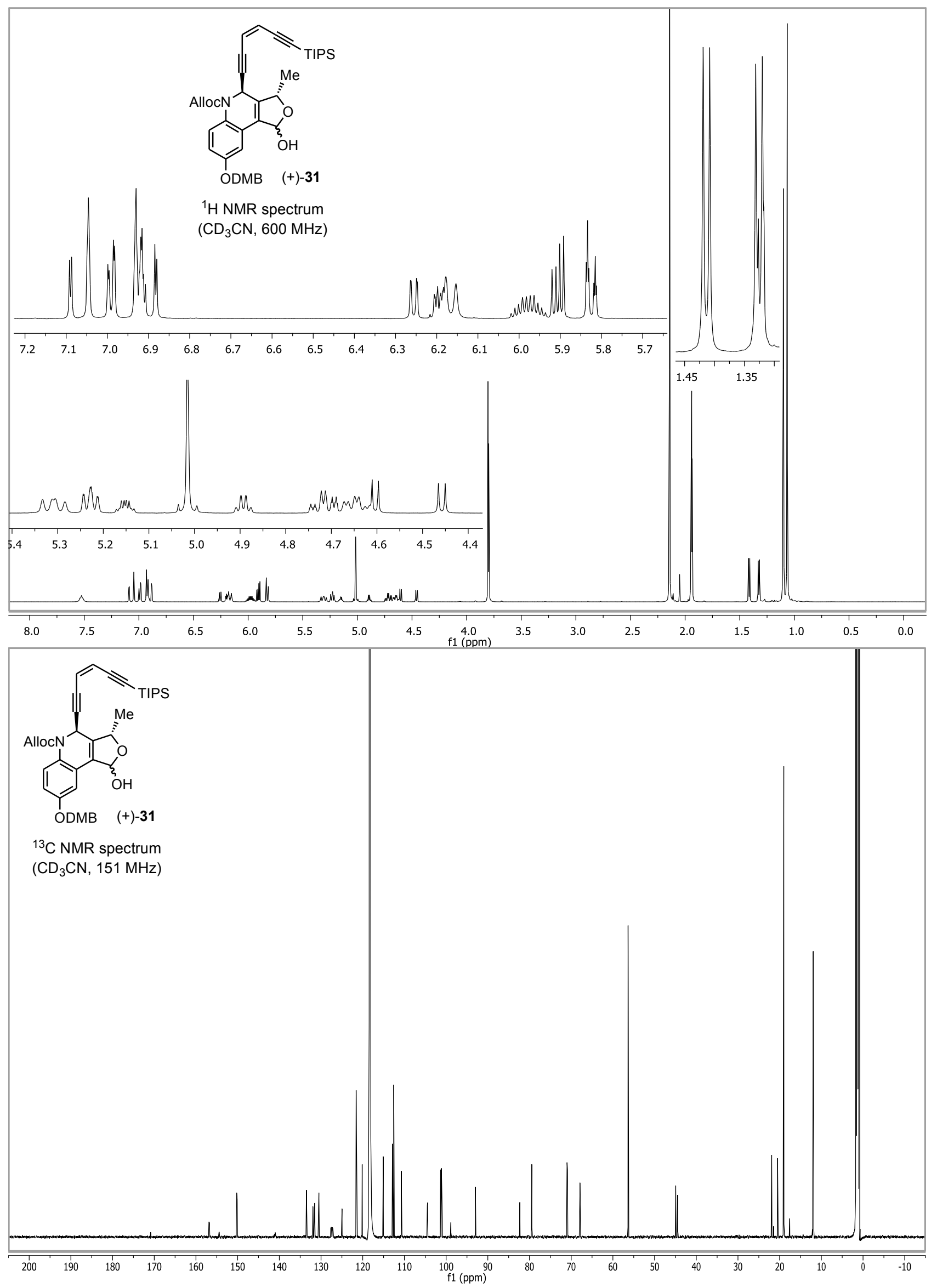

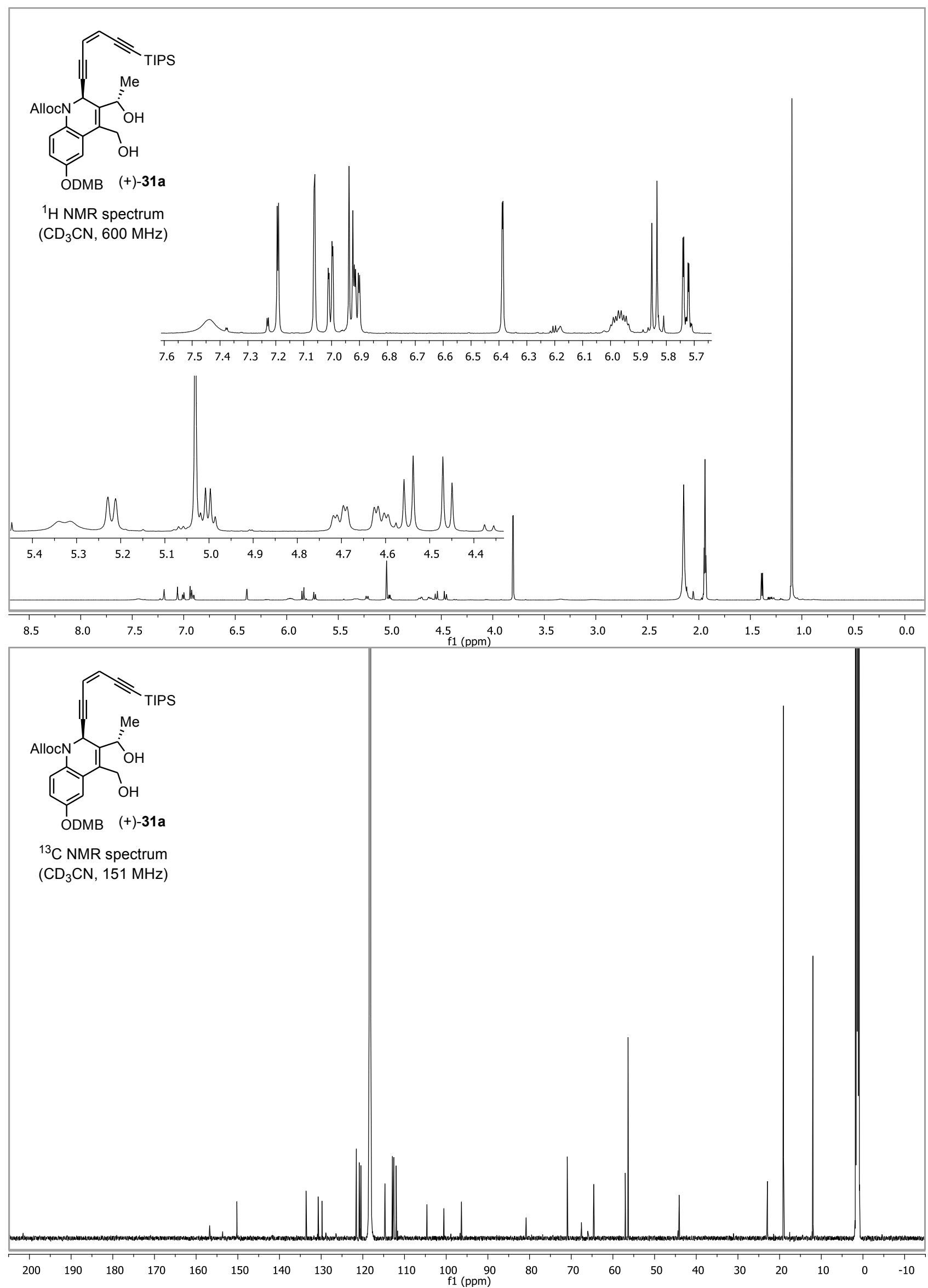

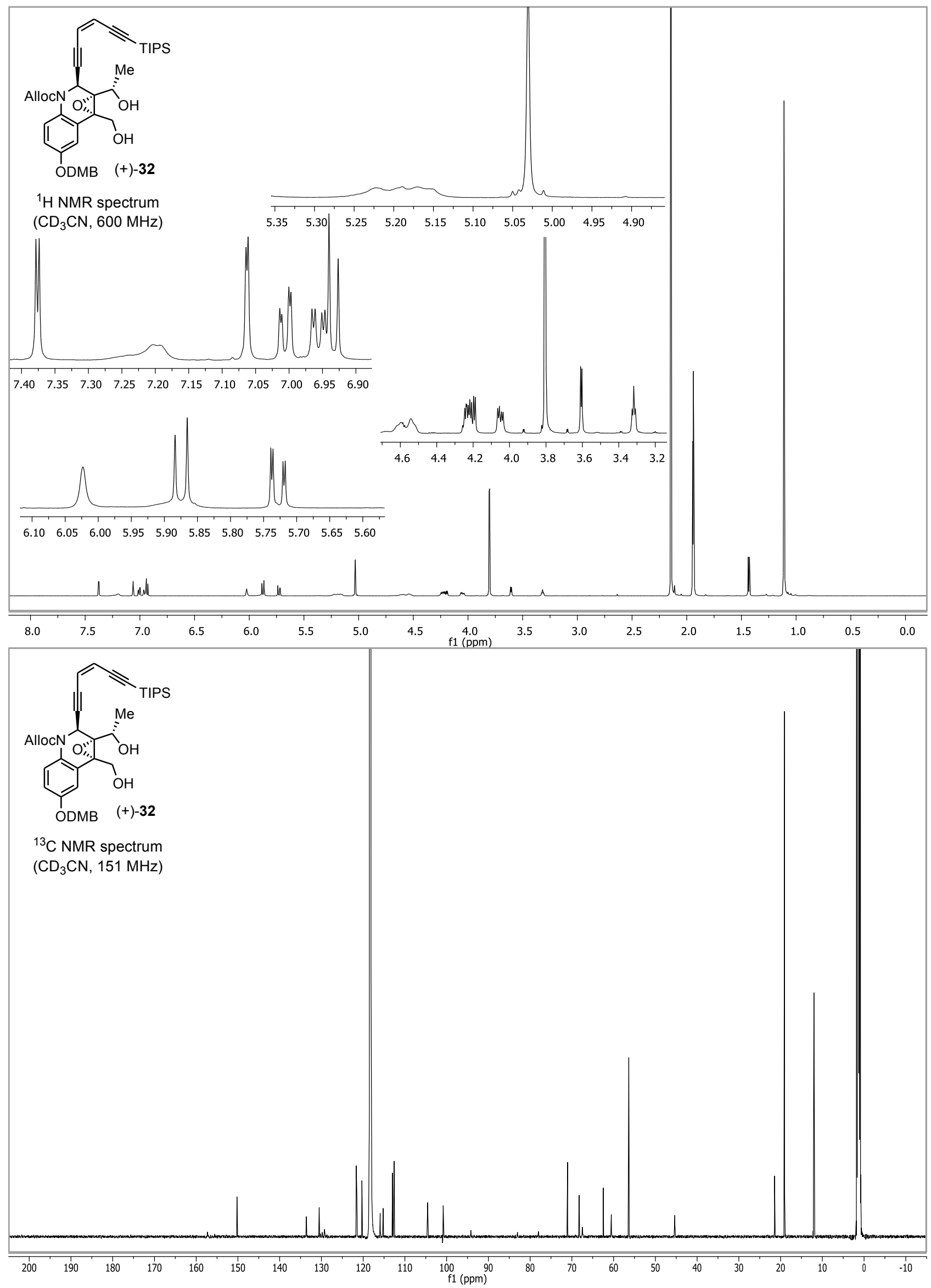

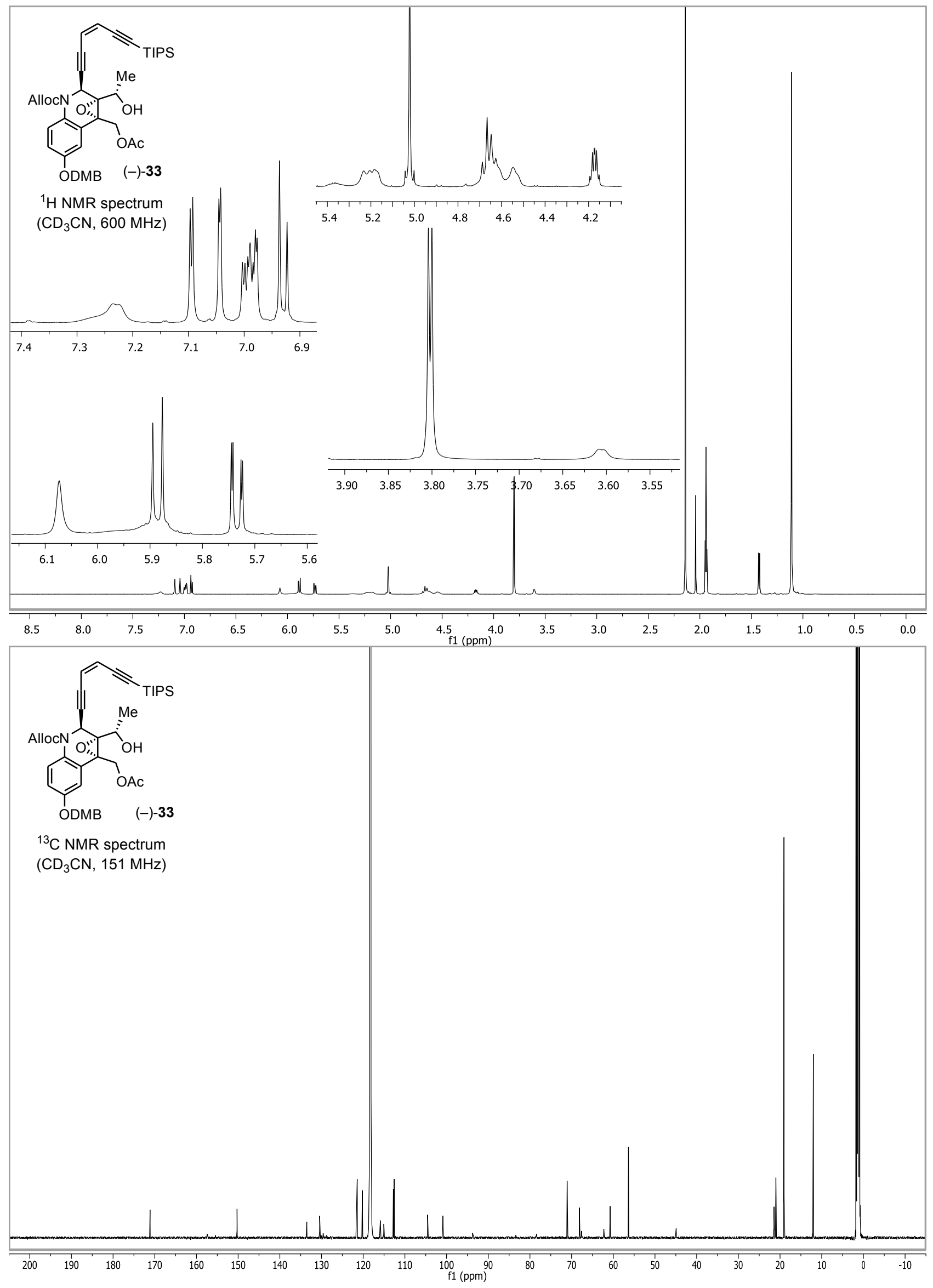

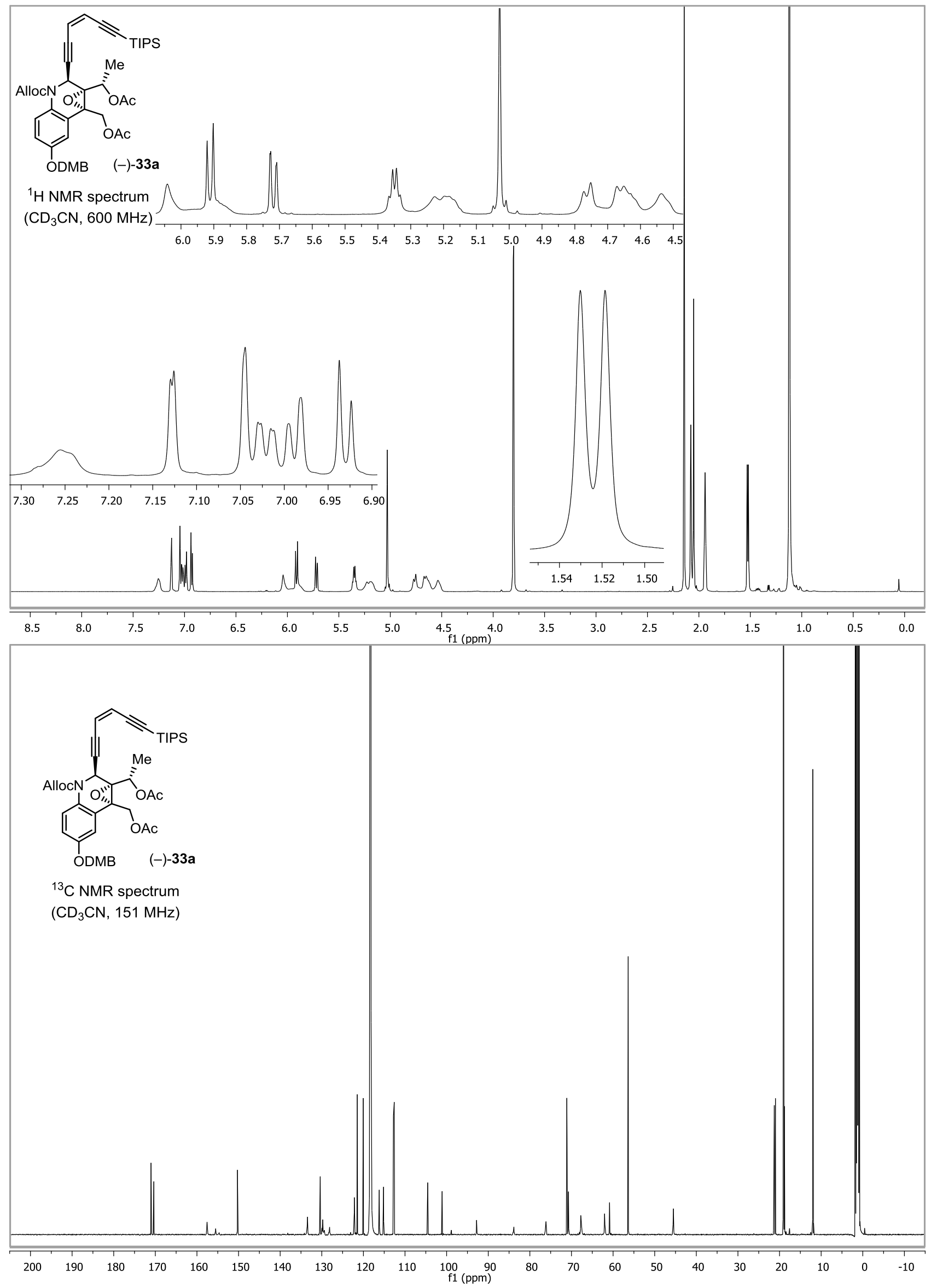

S90 

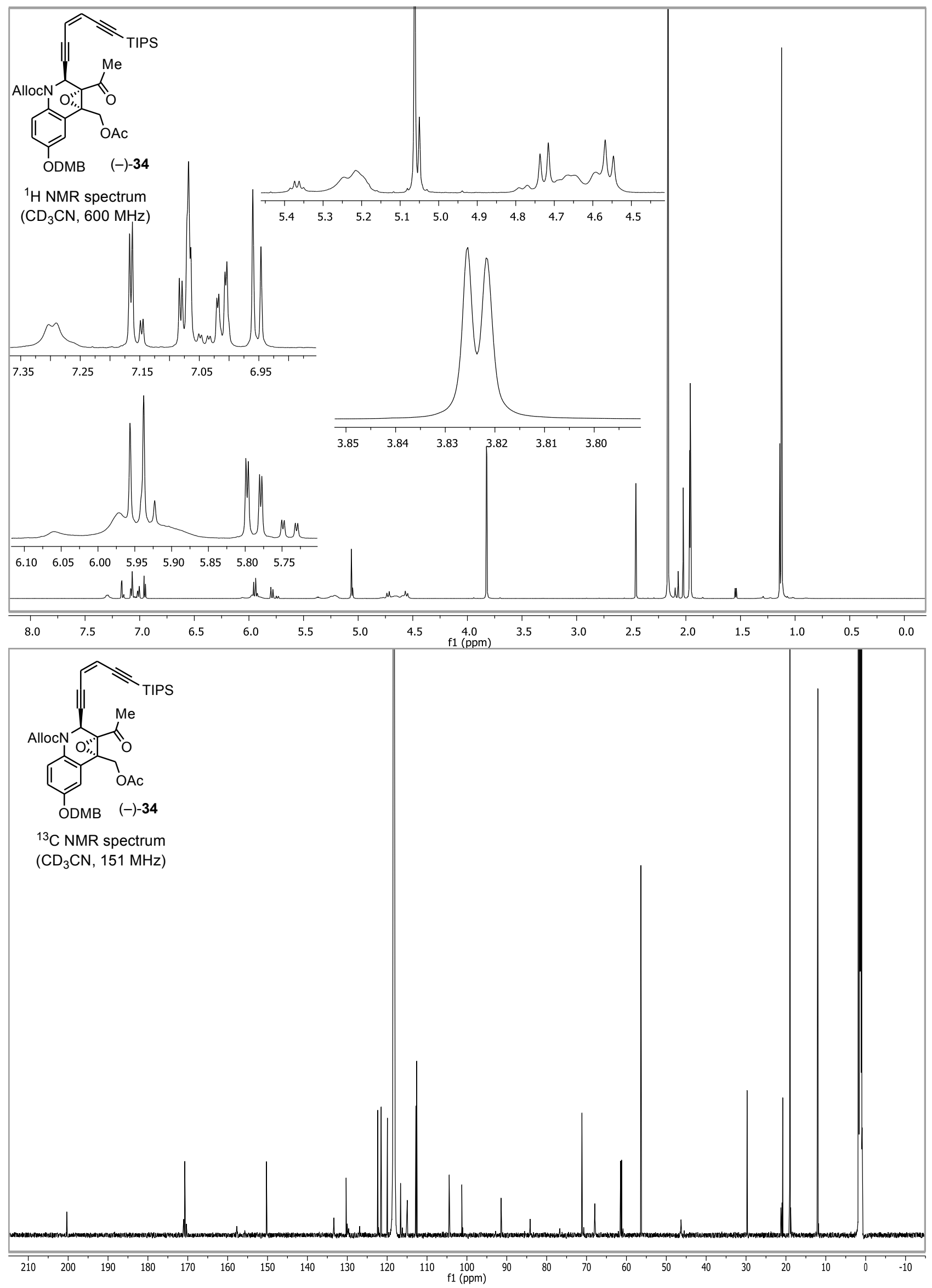



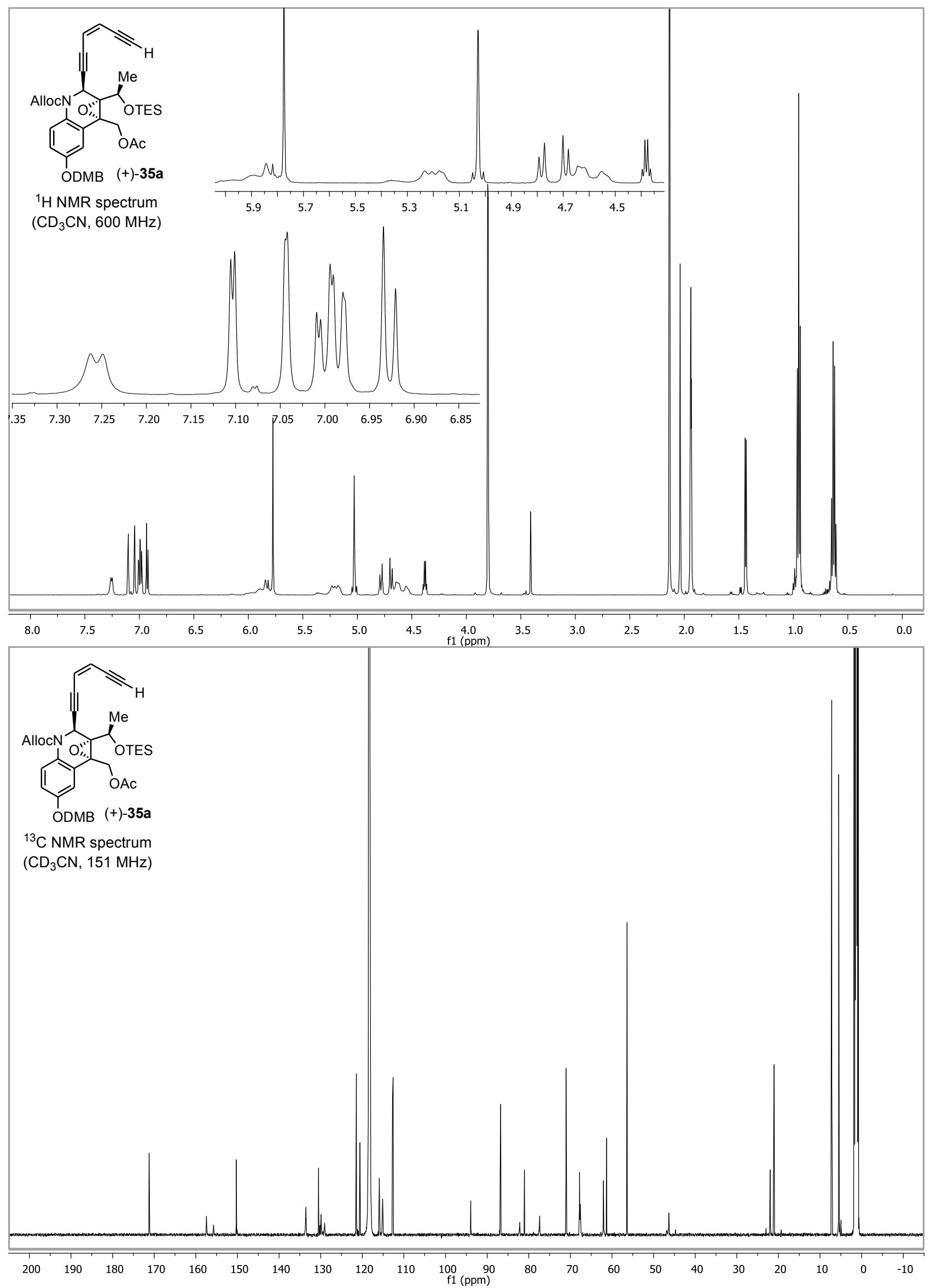

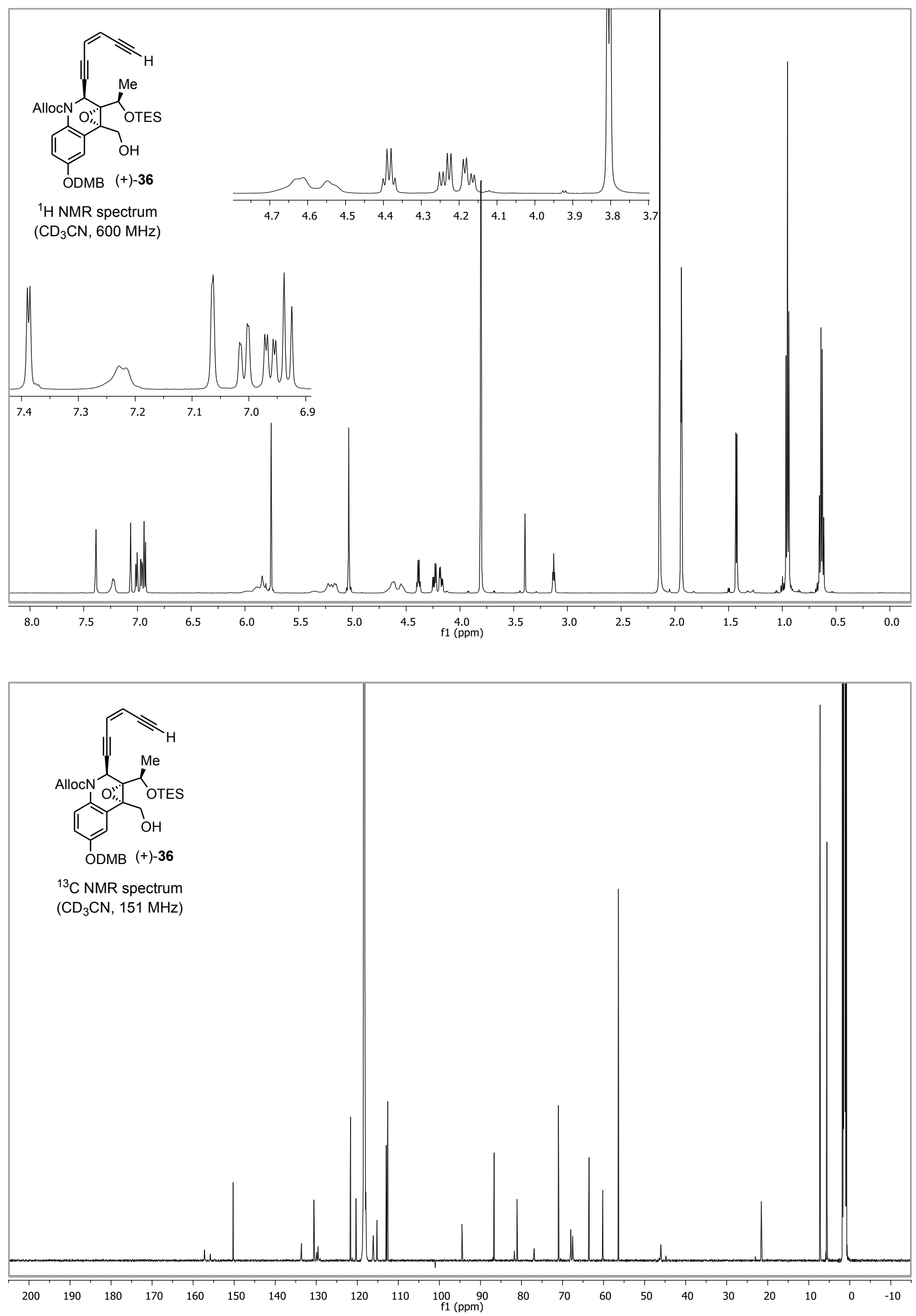

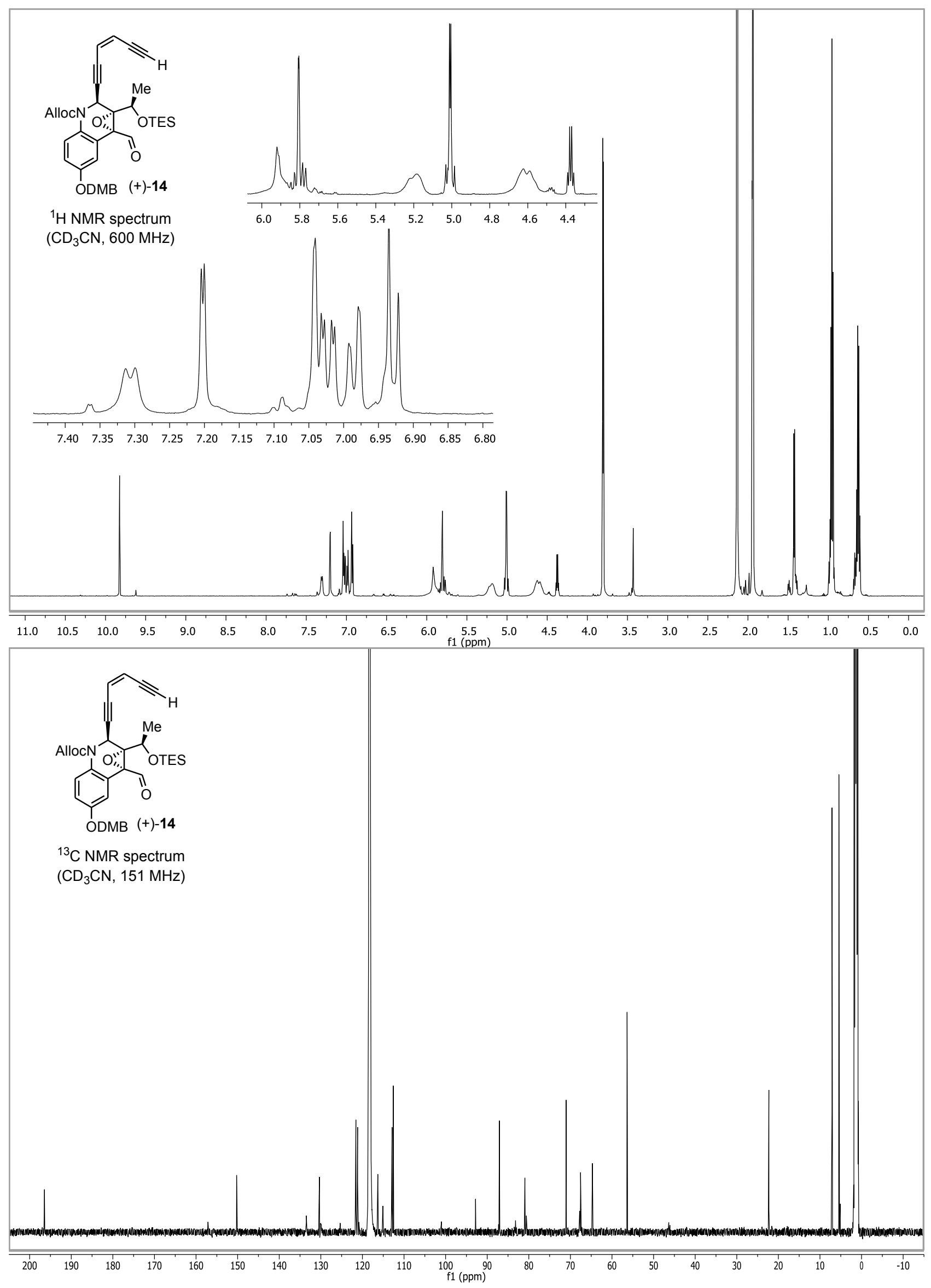

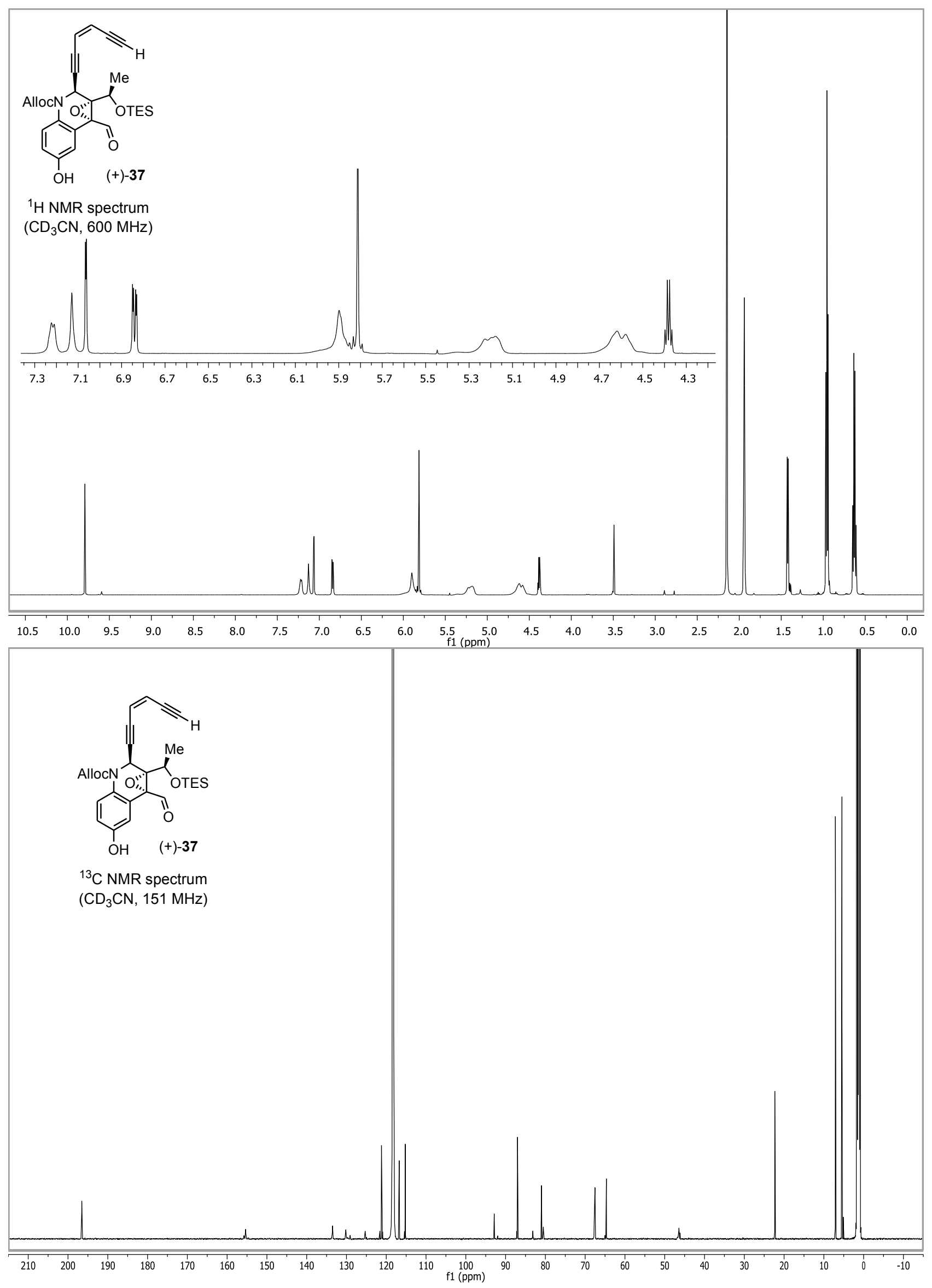

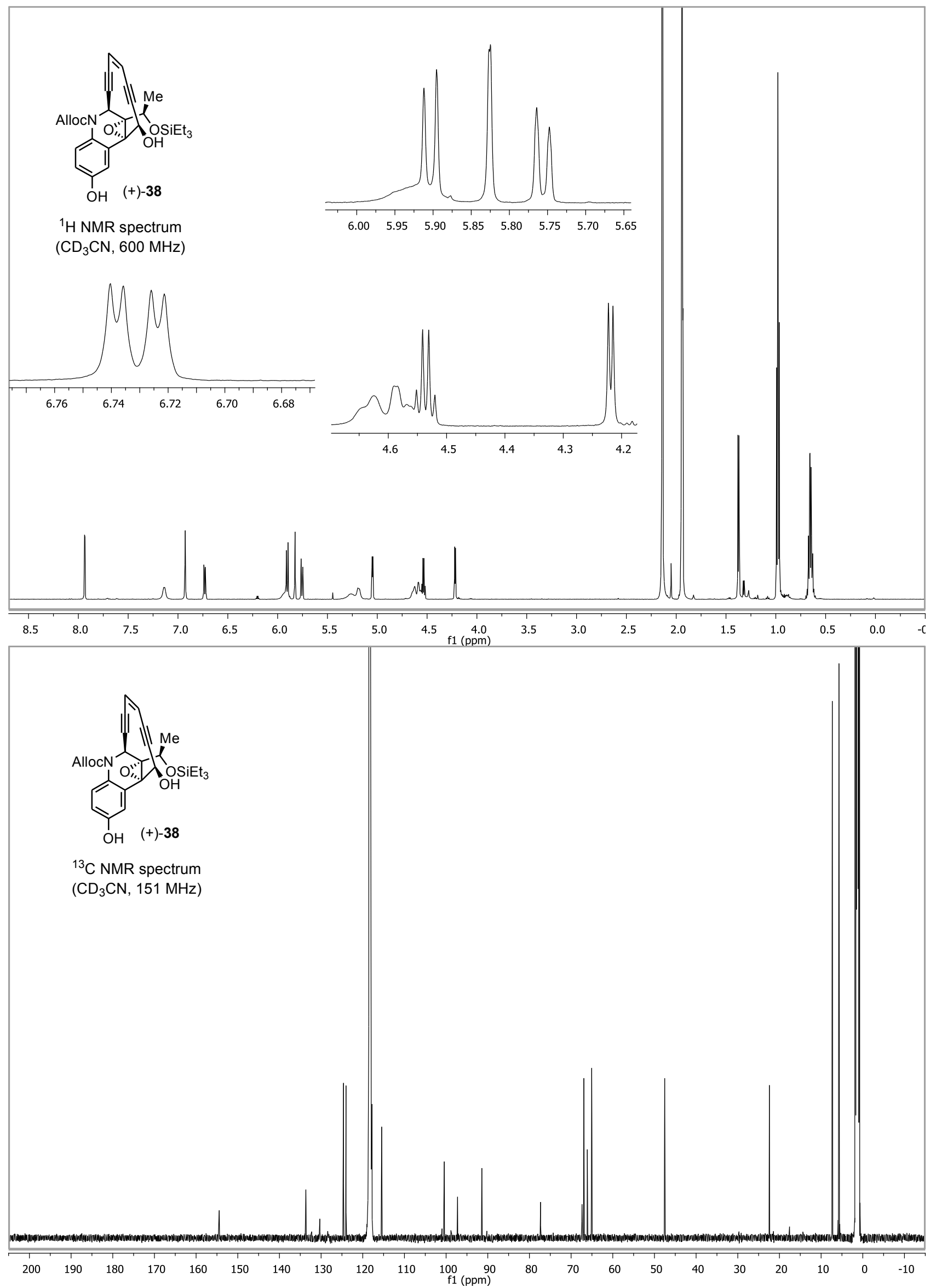

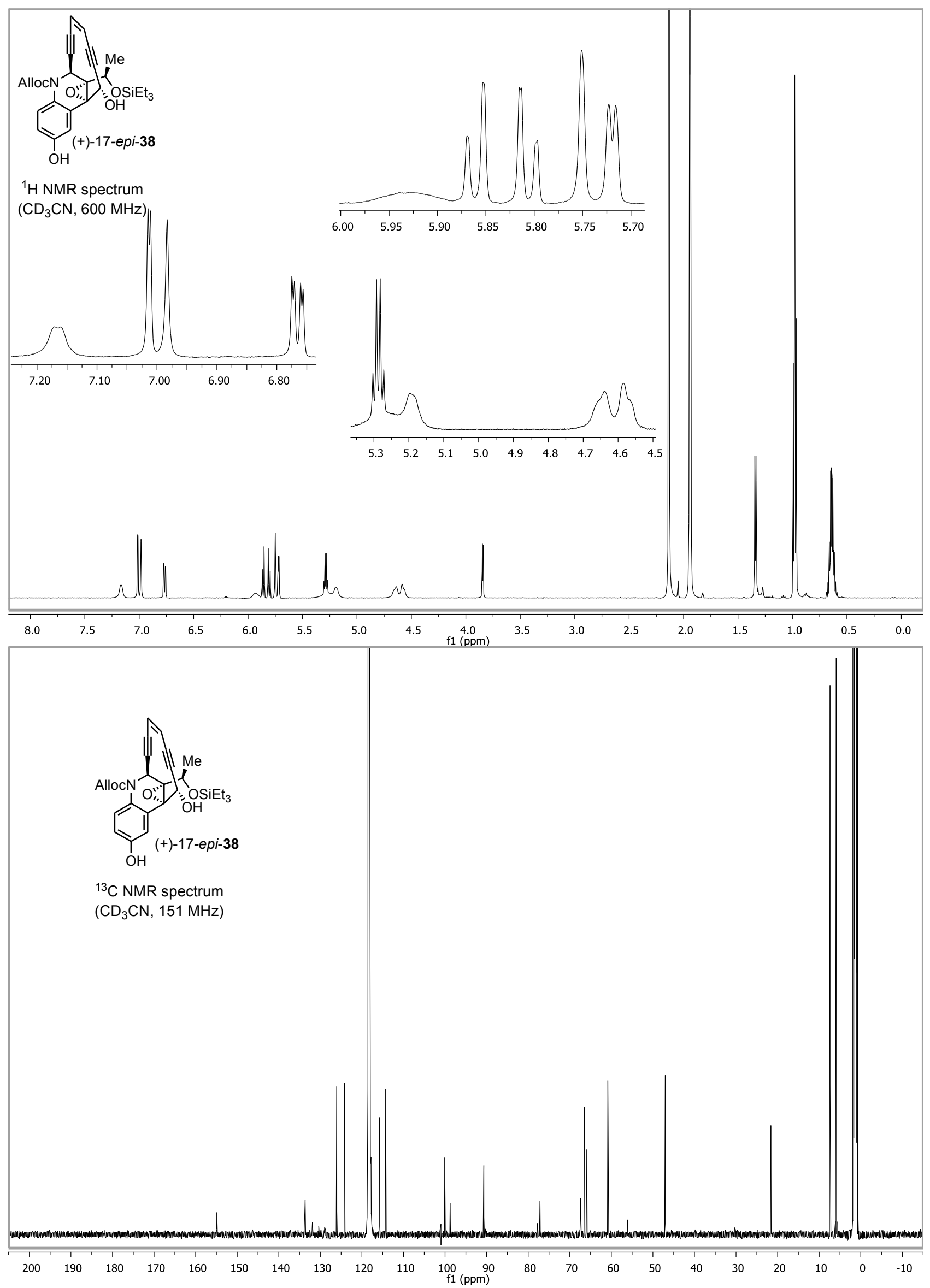

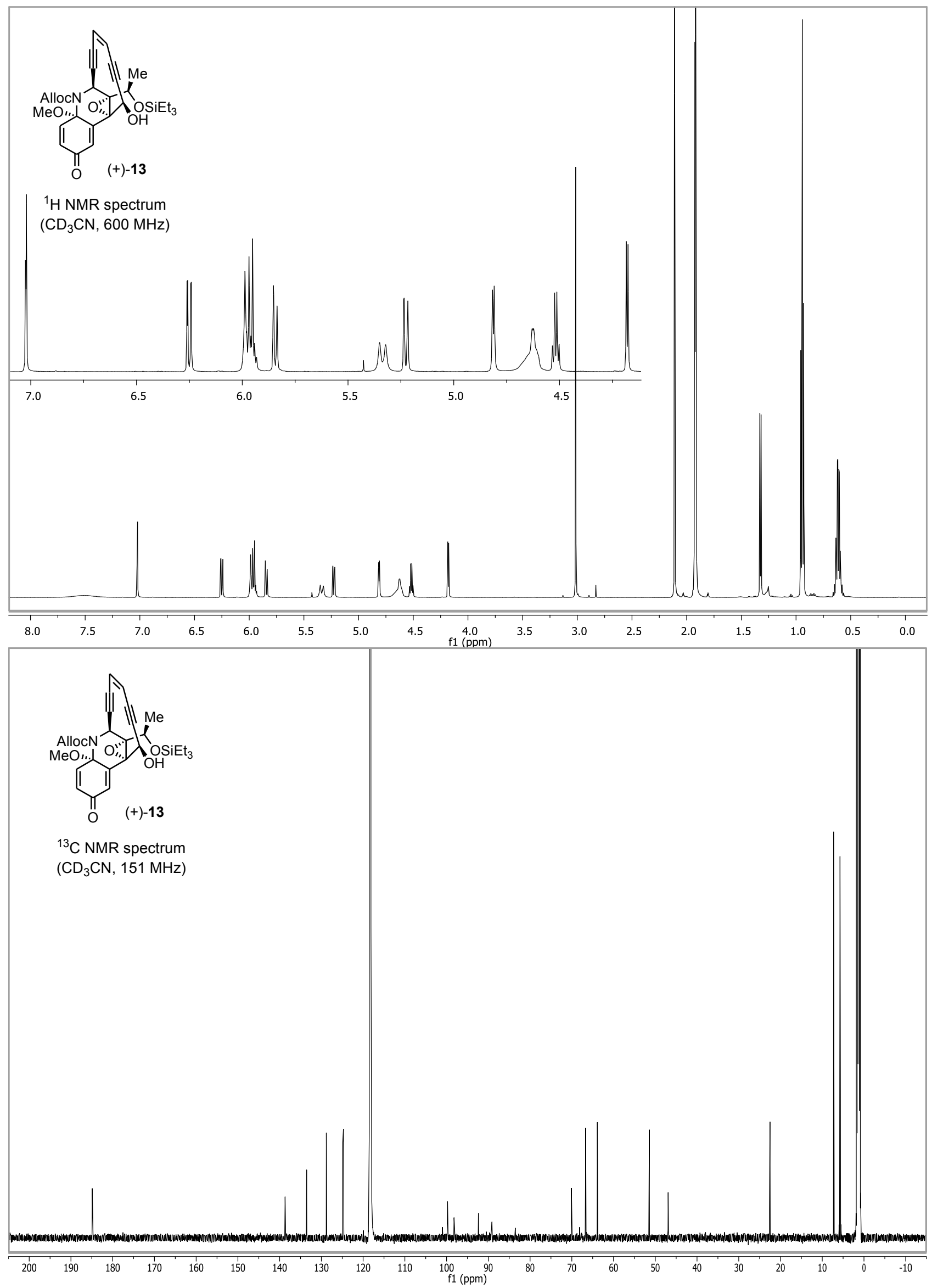


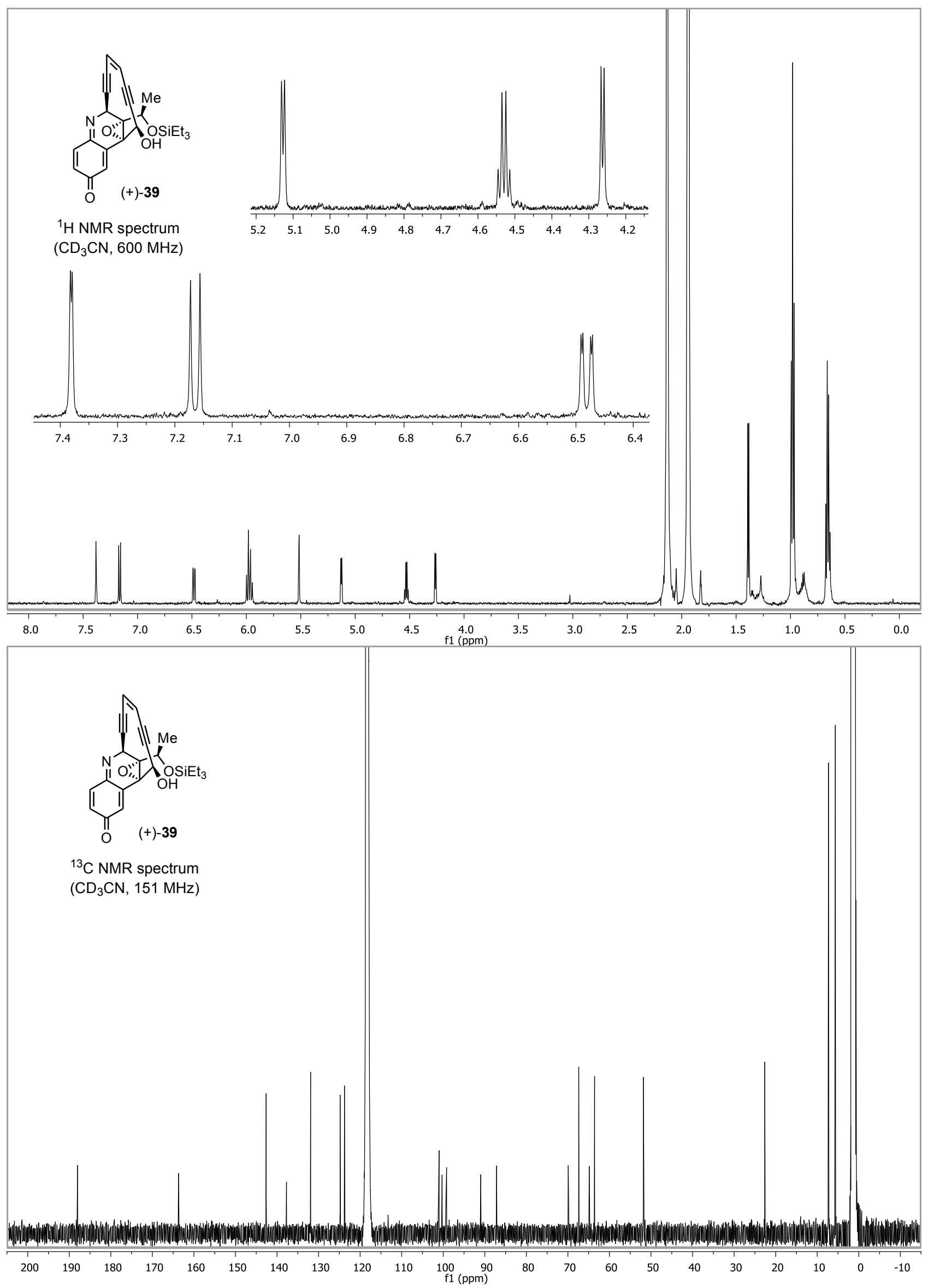



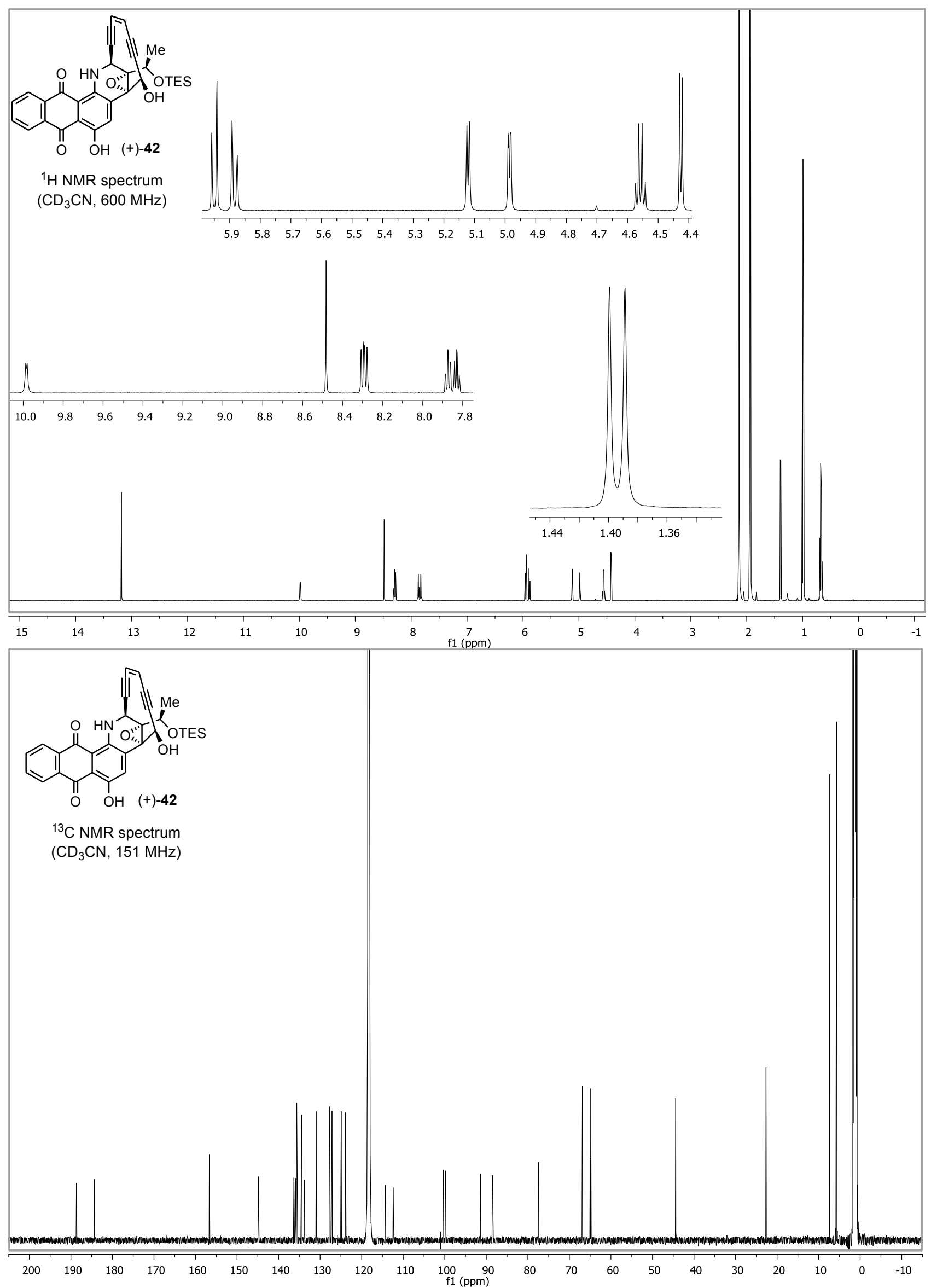

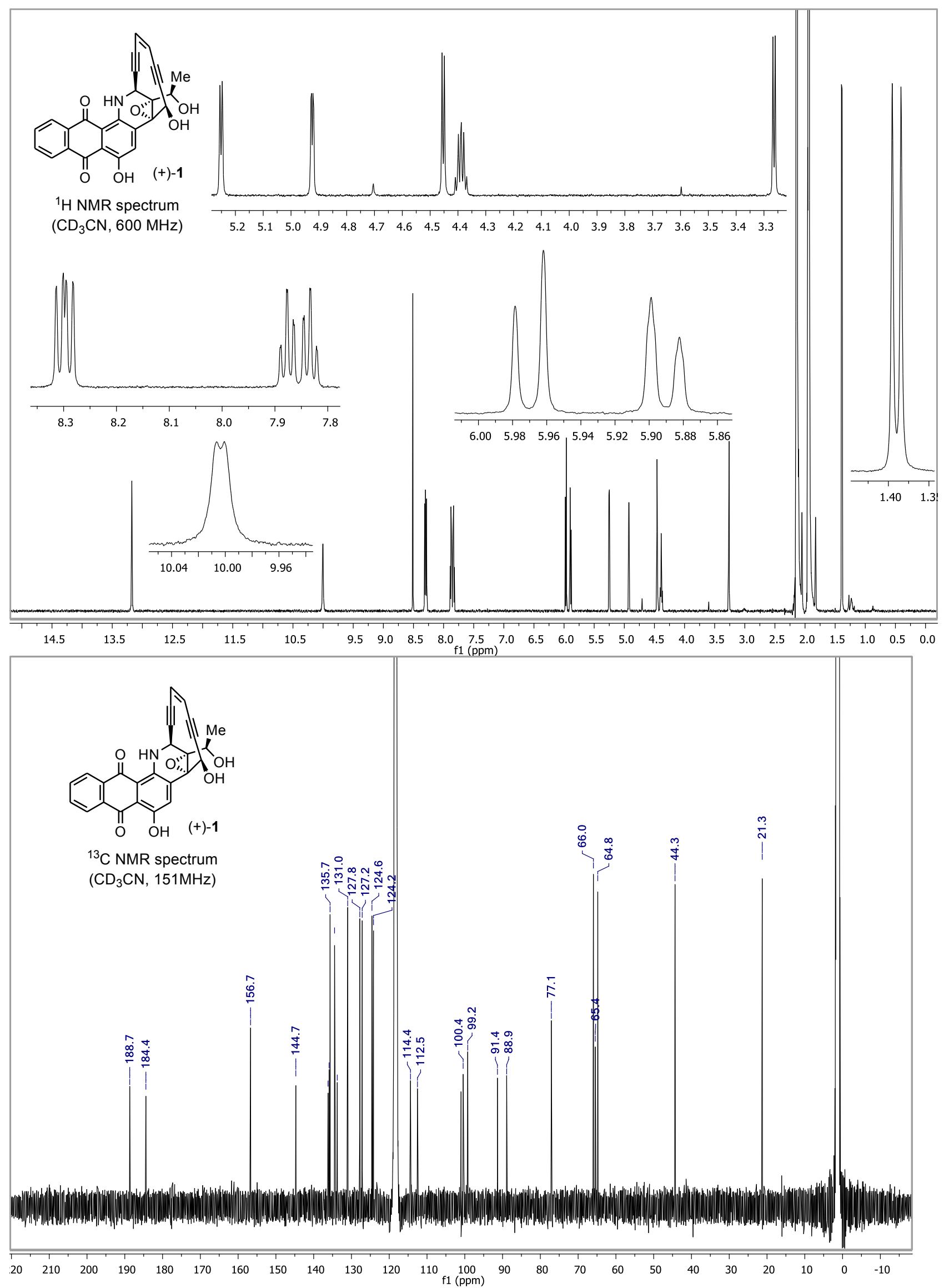

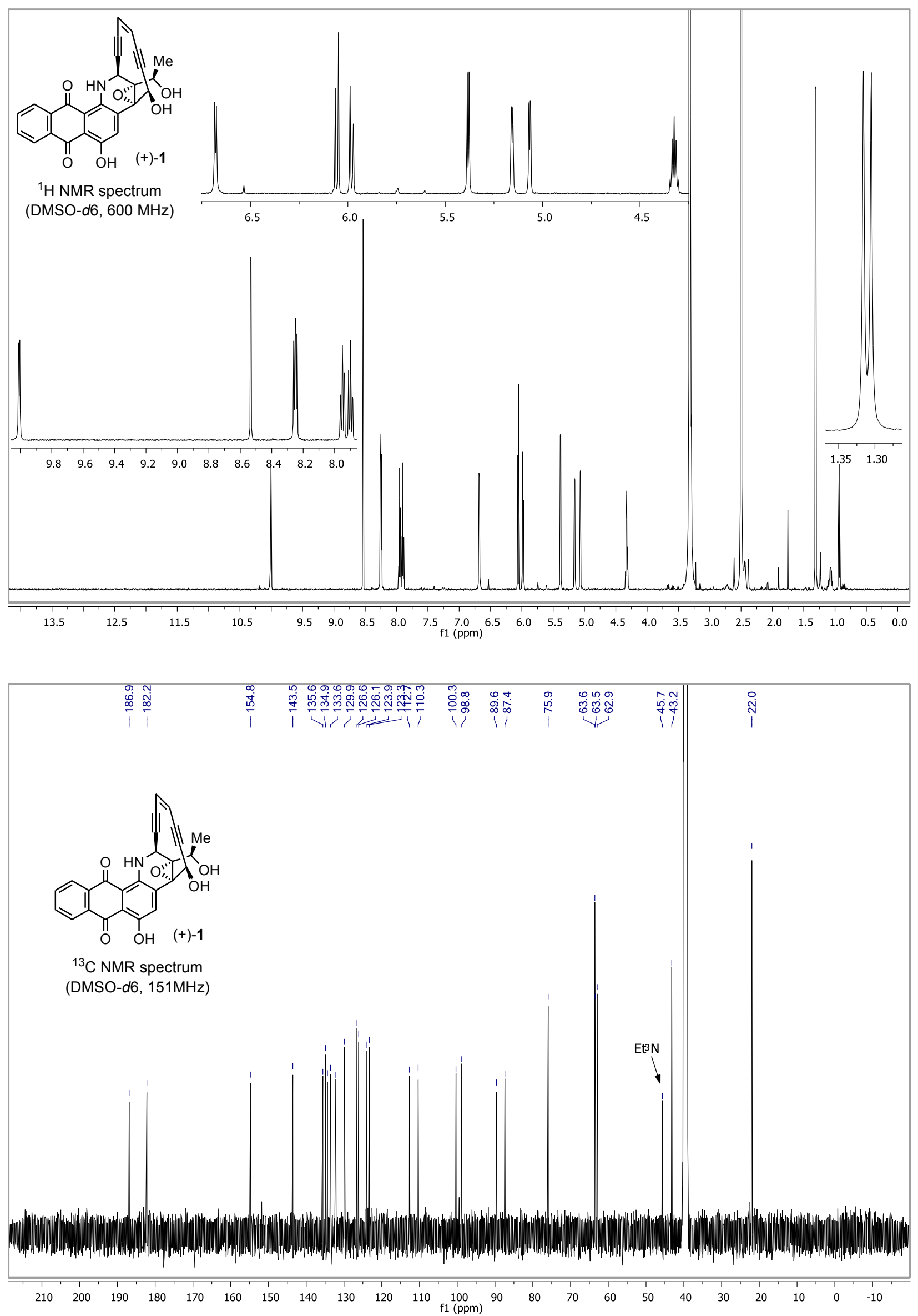

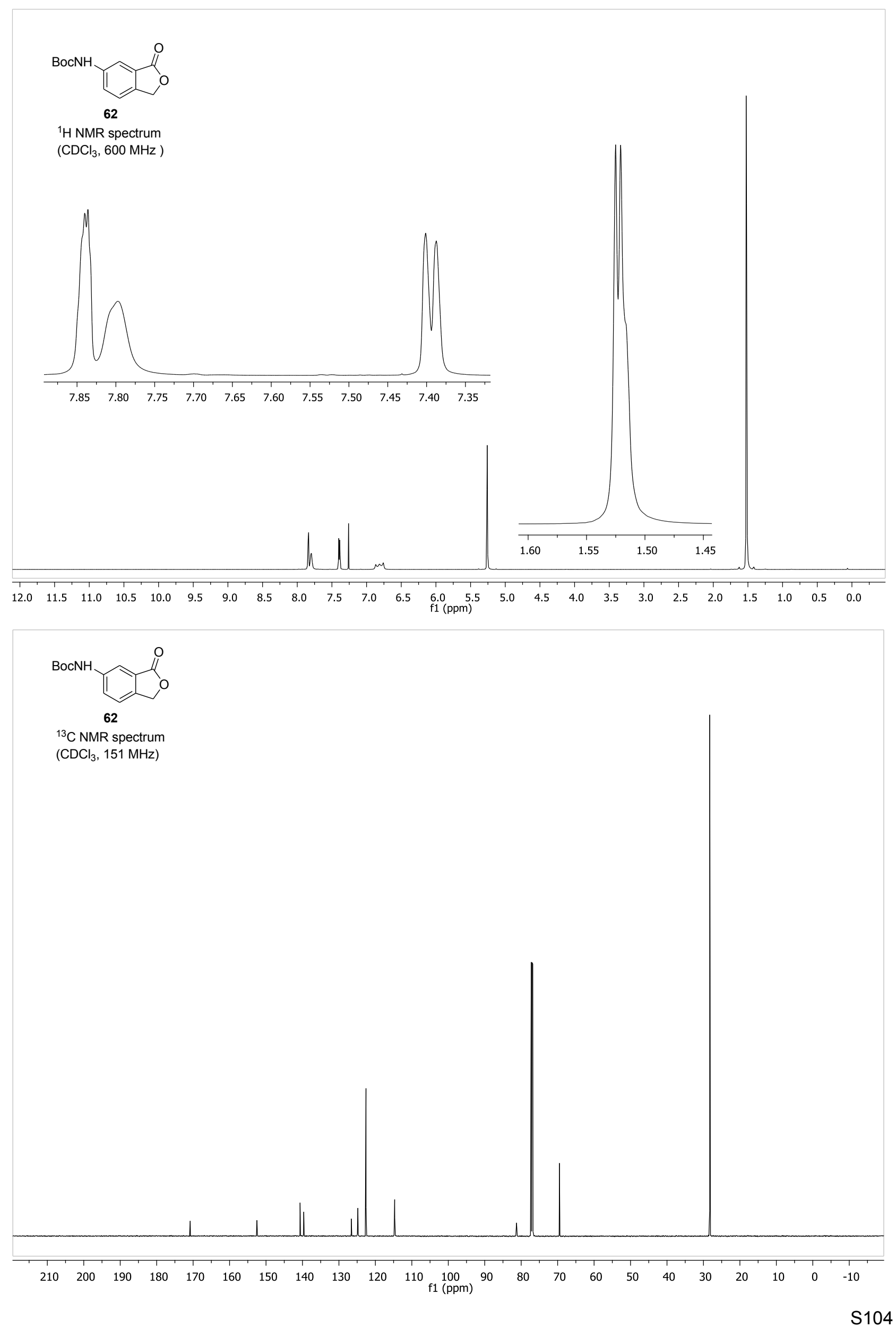

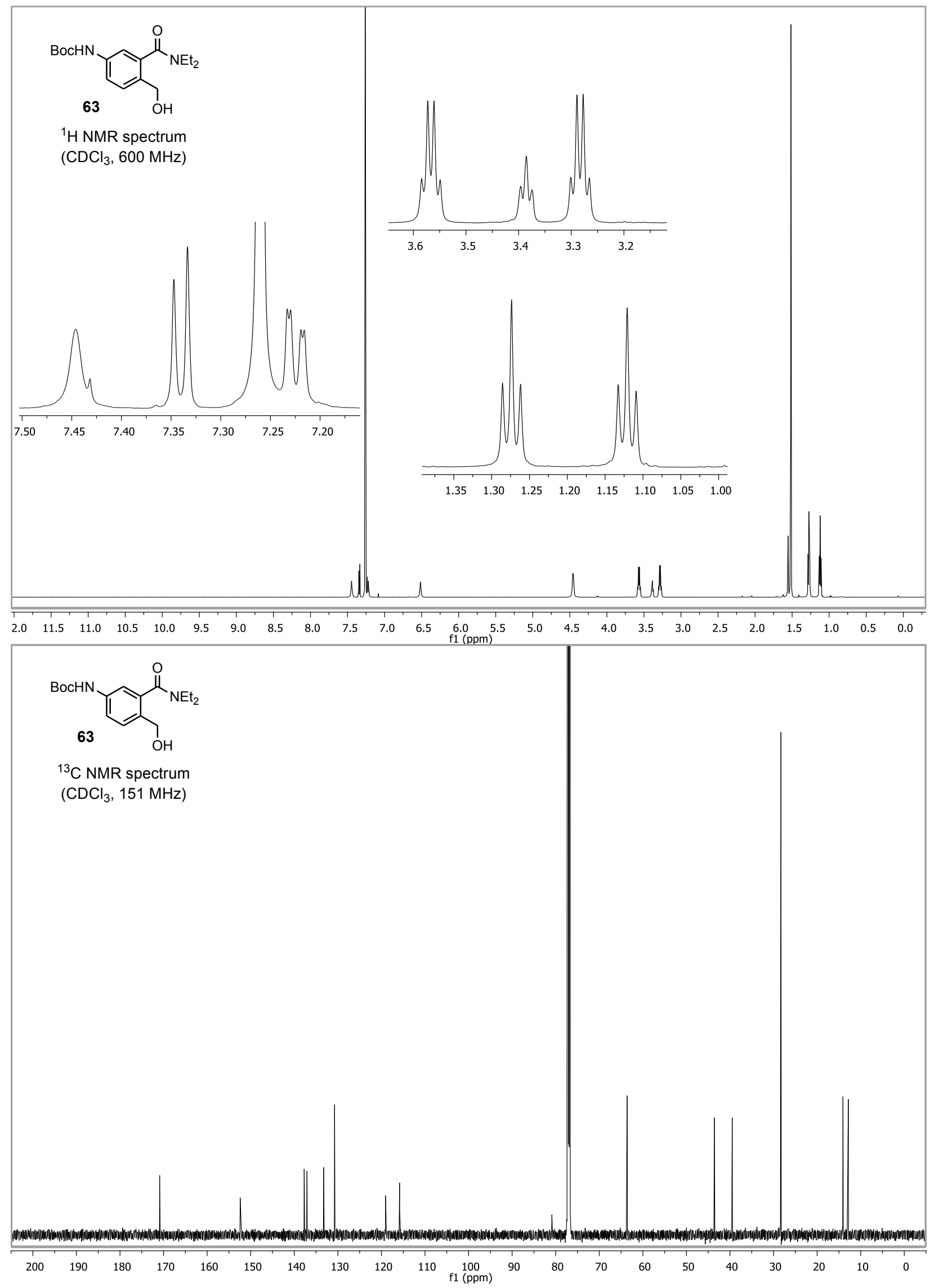

S105 

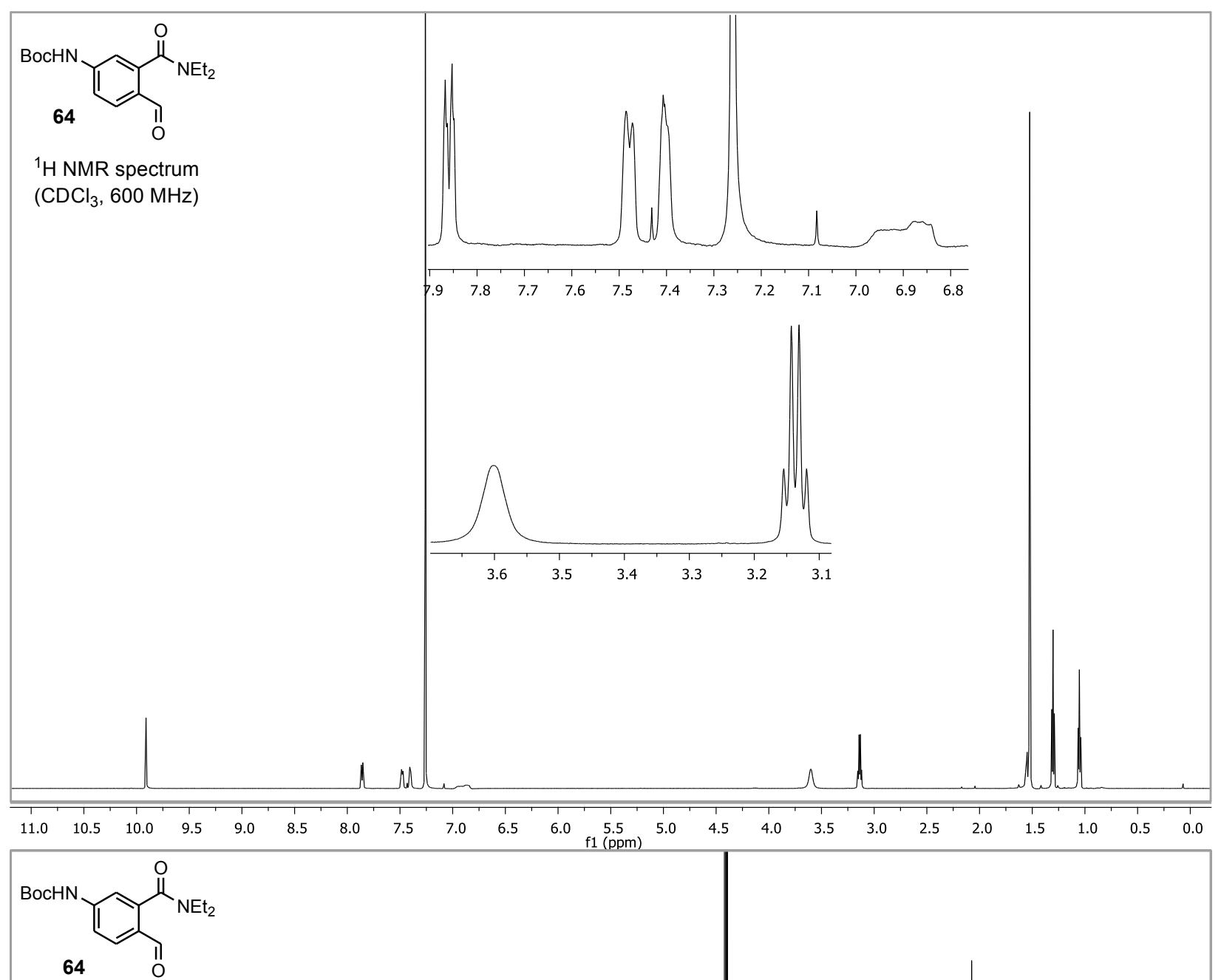

${ }^{13} \mathrm{C}$ NMR spectrum $\left(\mathrm{CDCl}_{3}, 151 \mathrm{MHz}\right)$ 

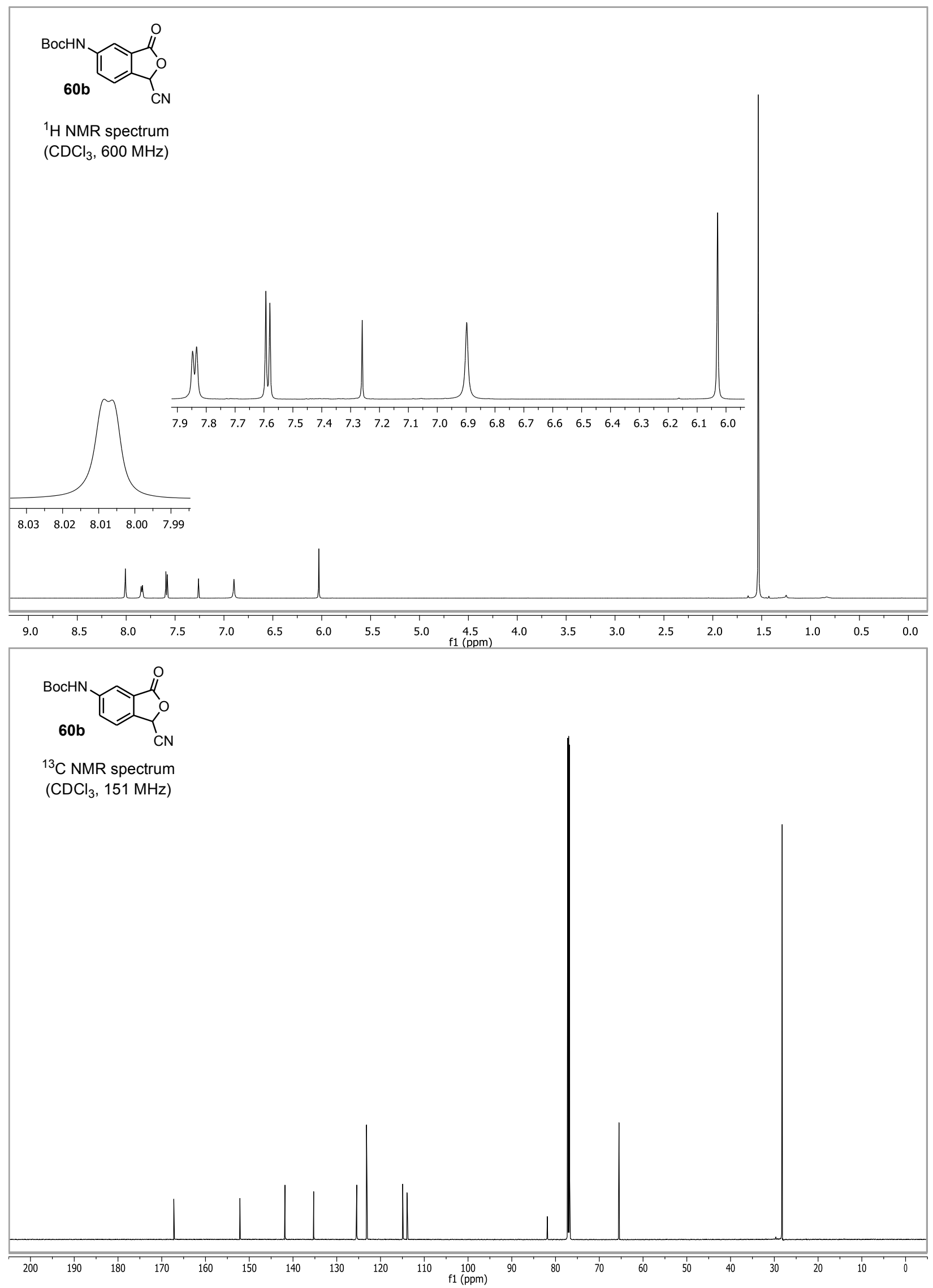

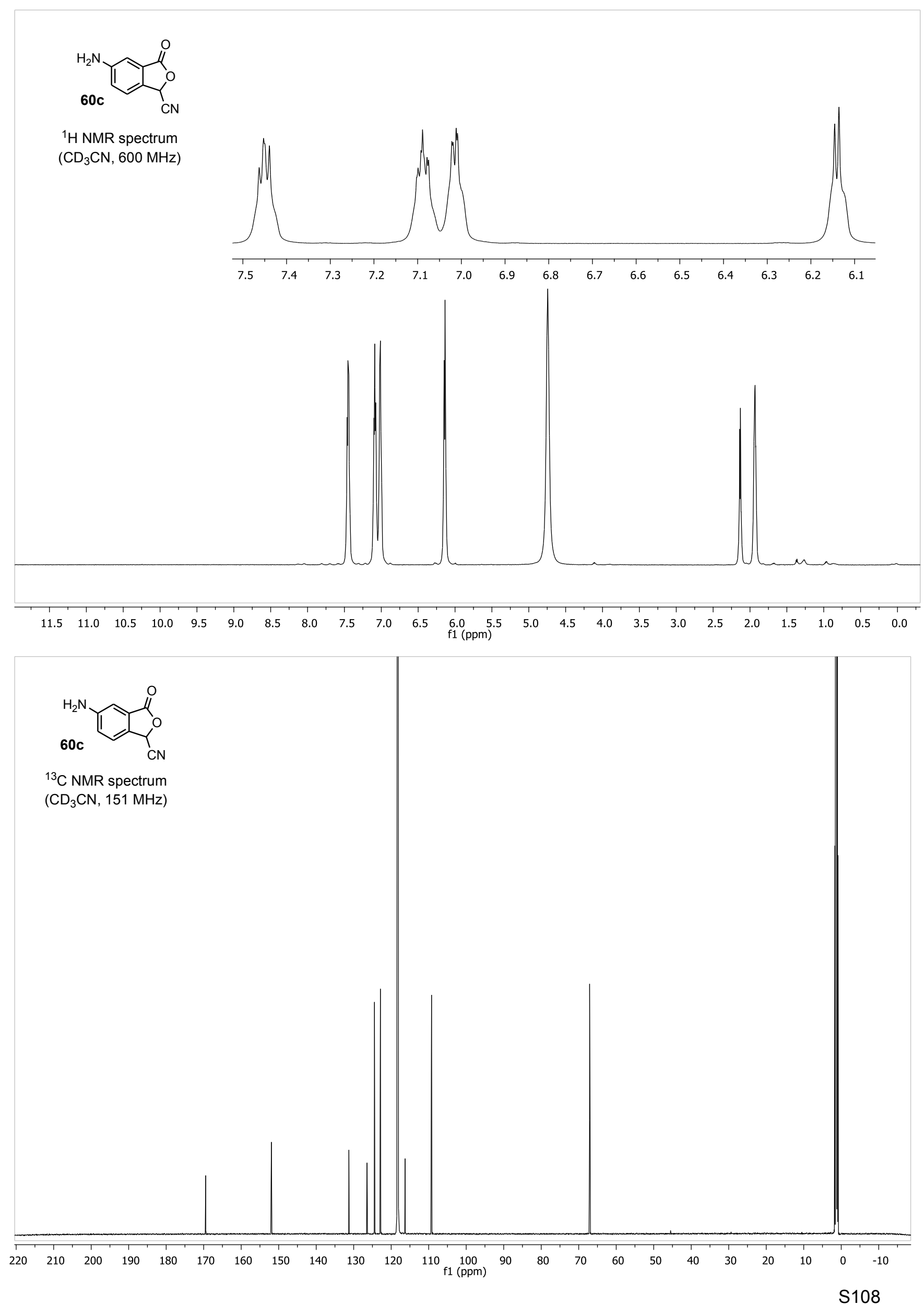

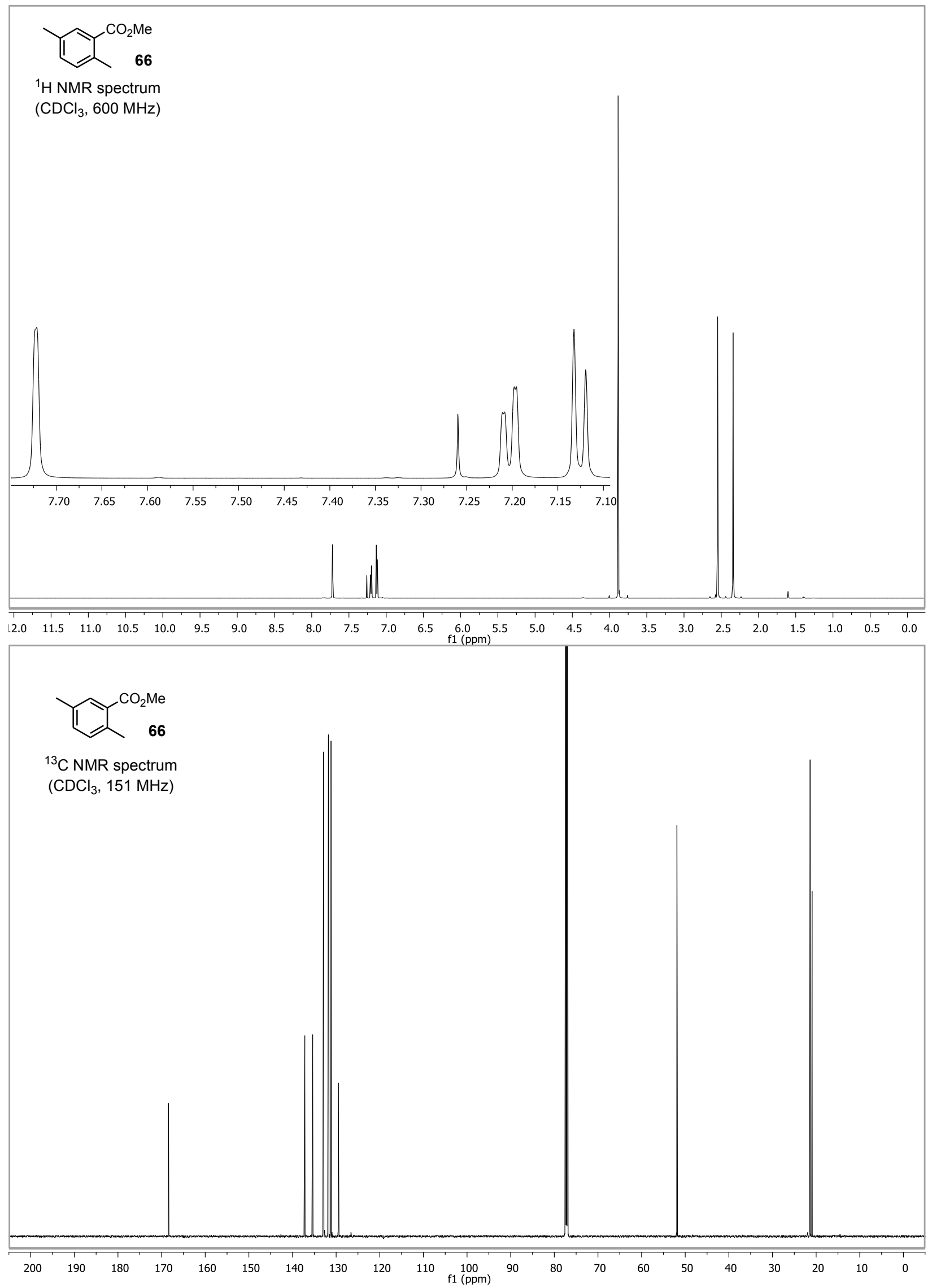

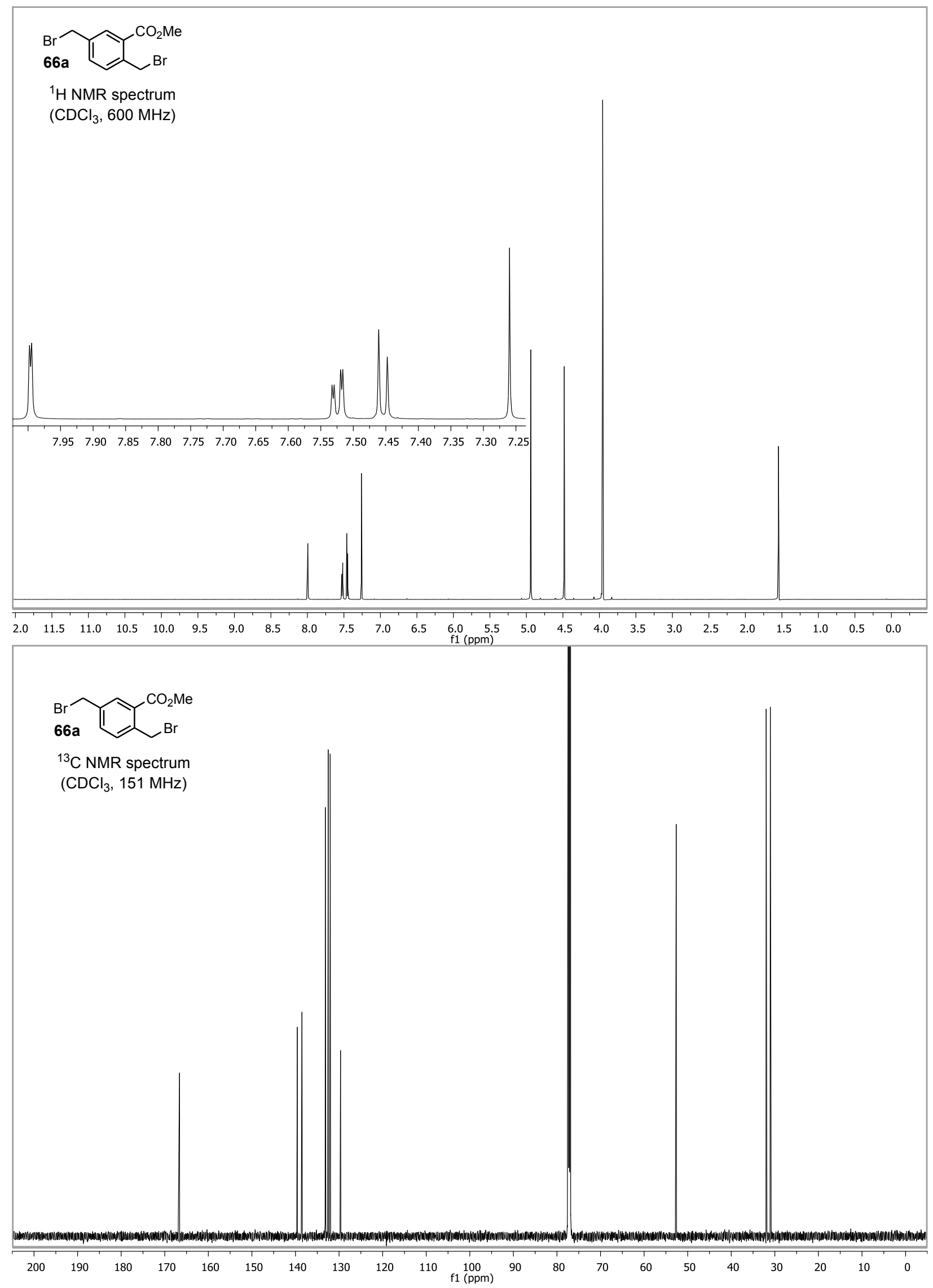

S110 

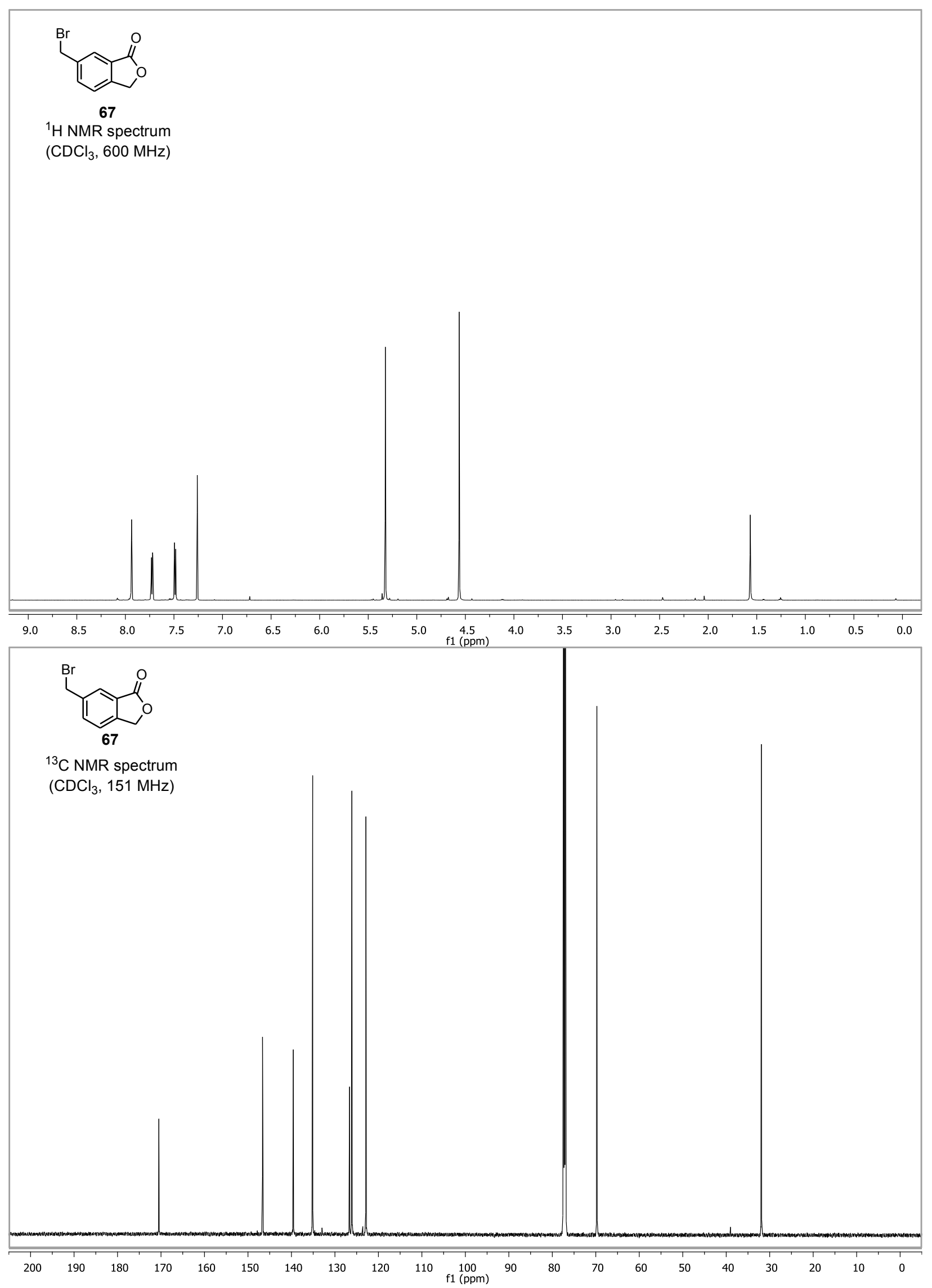

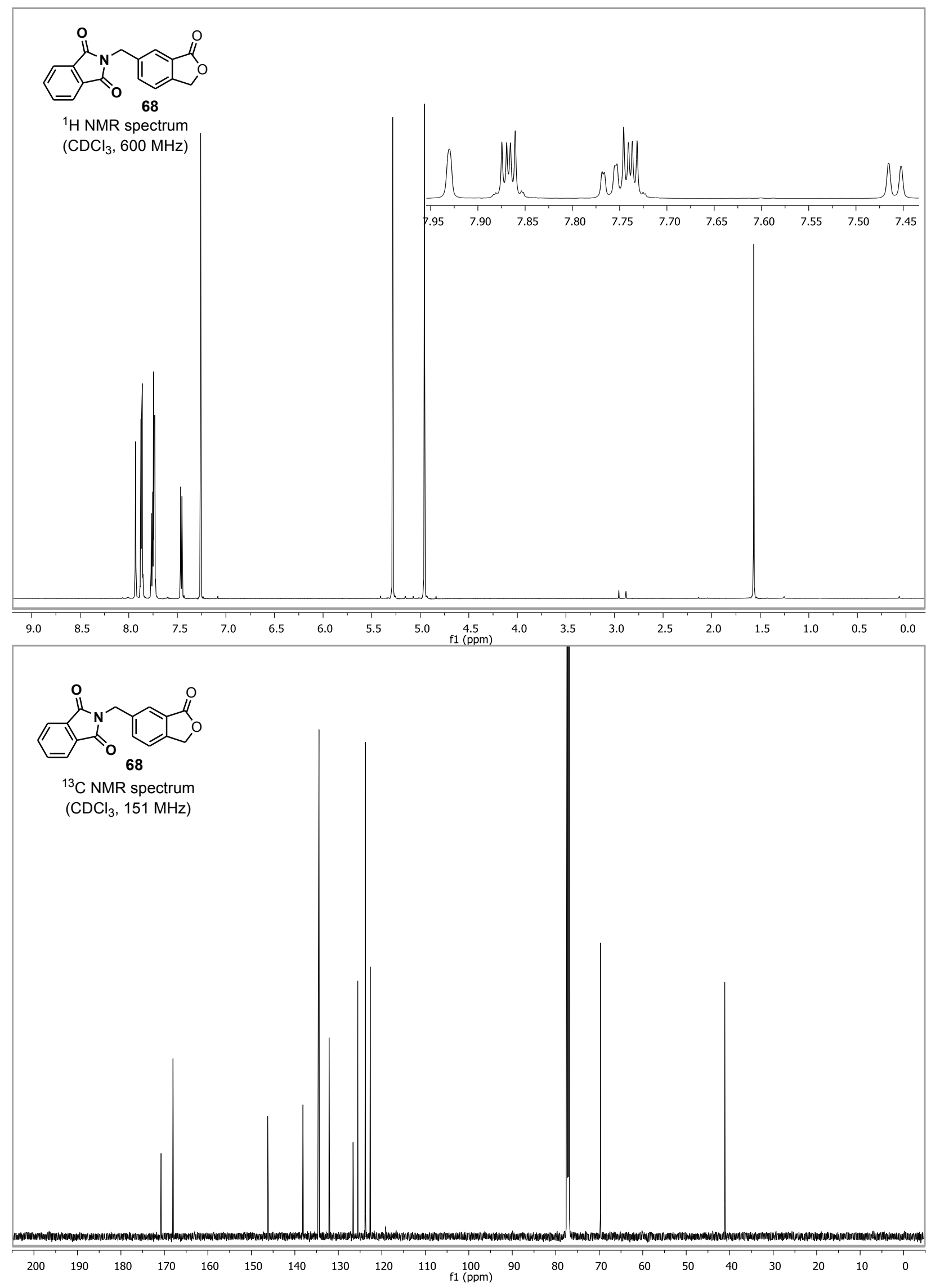

S112 

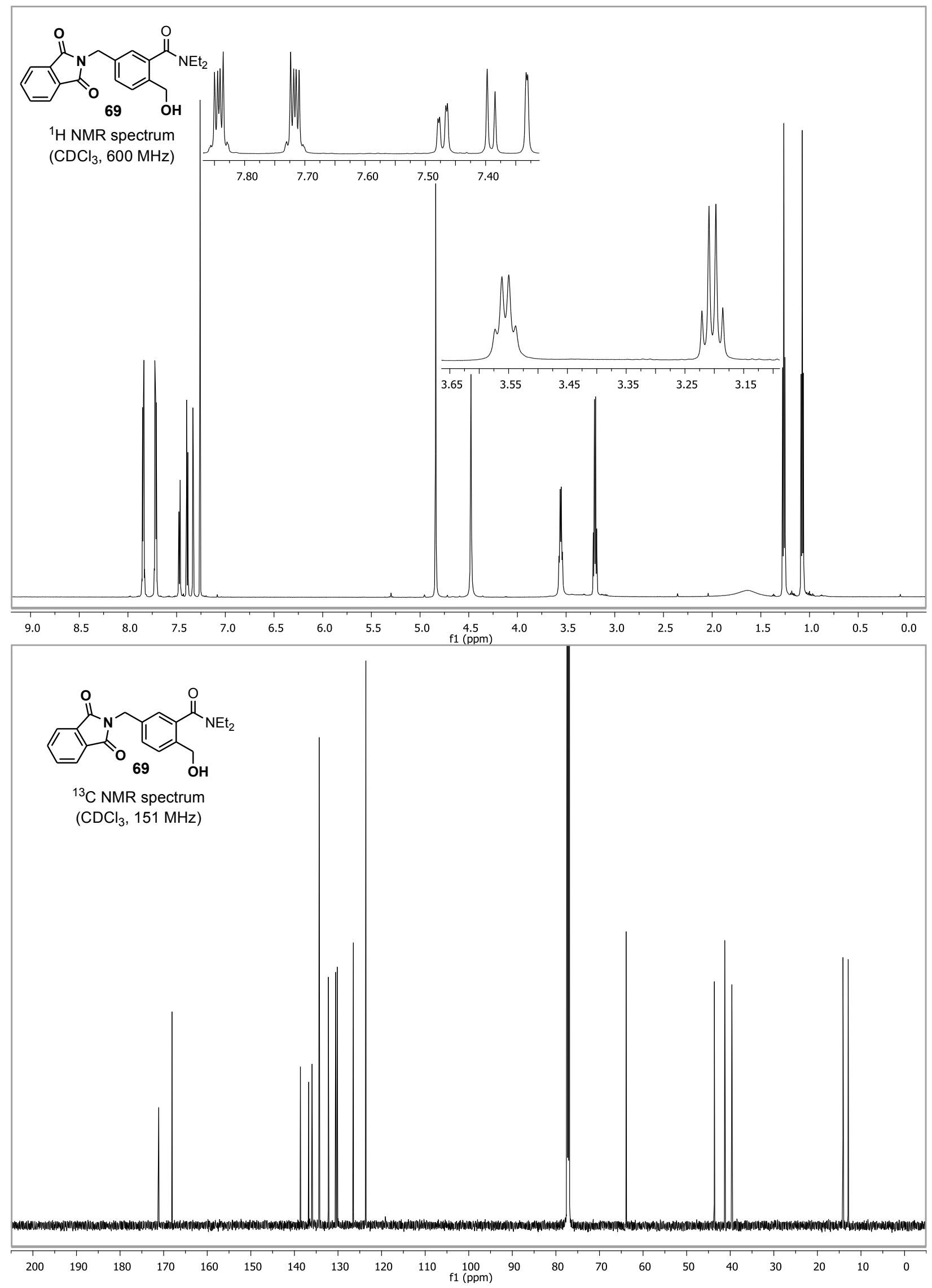

S113 

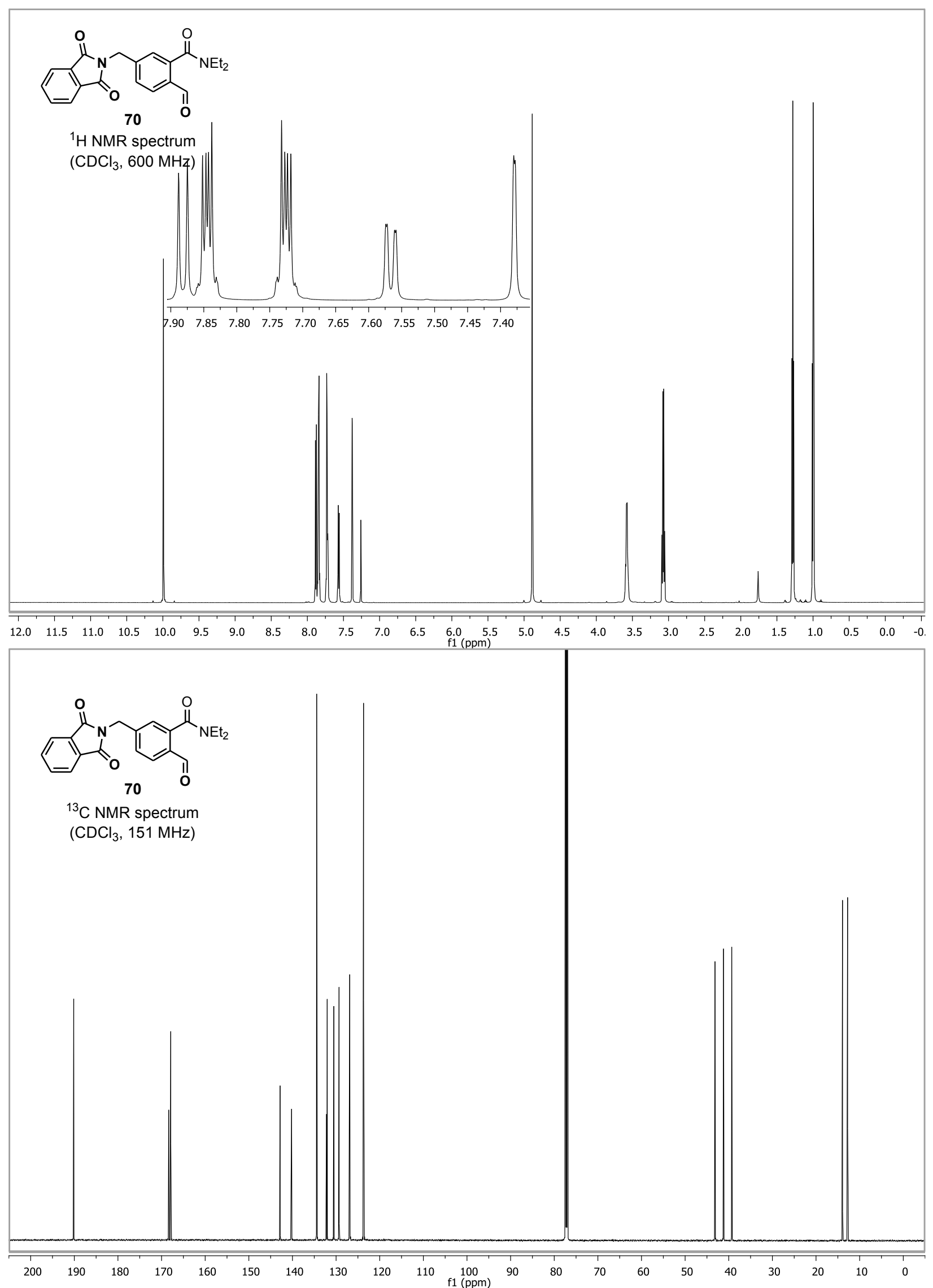

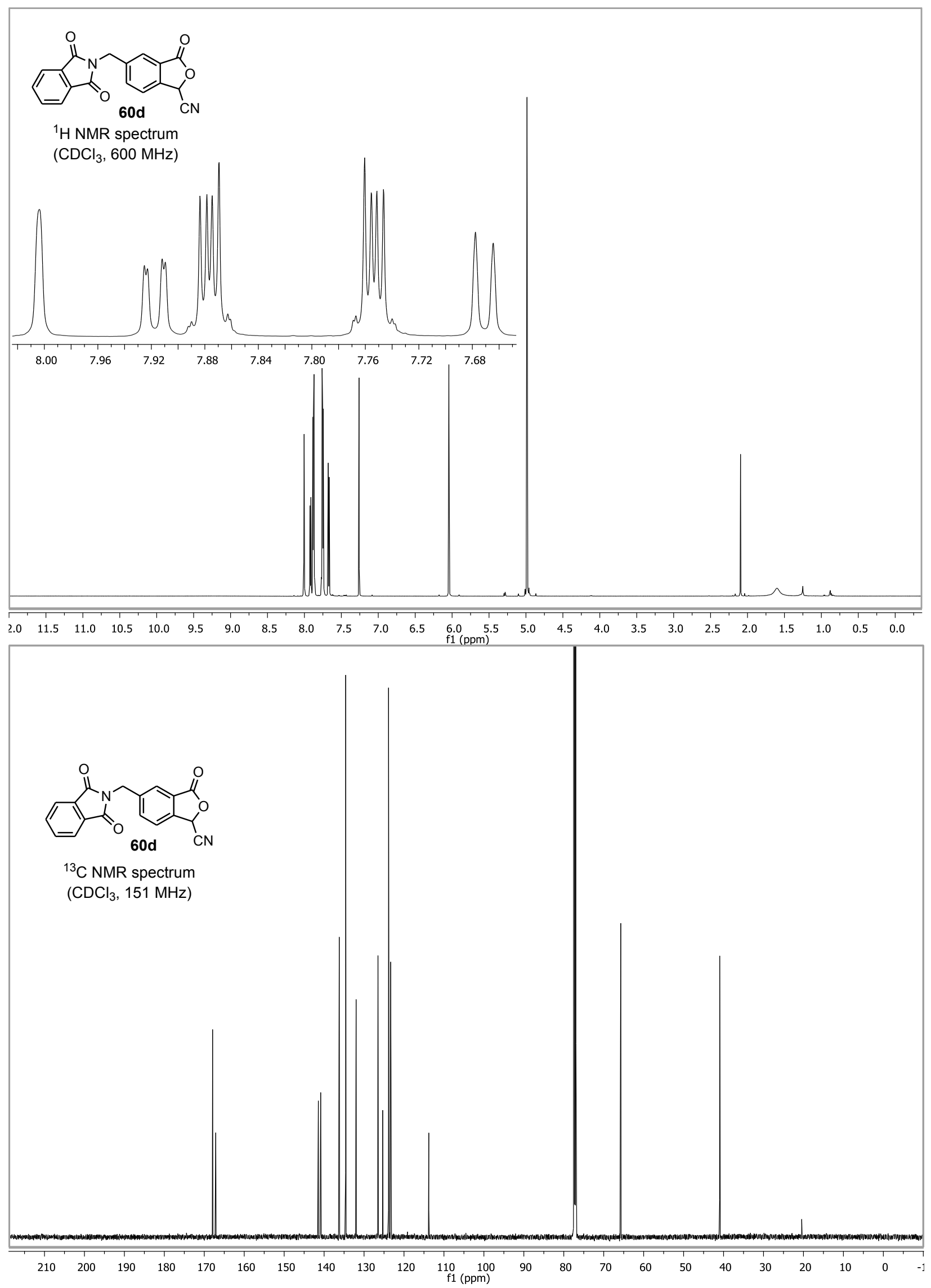

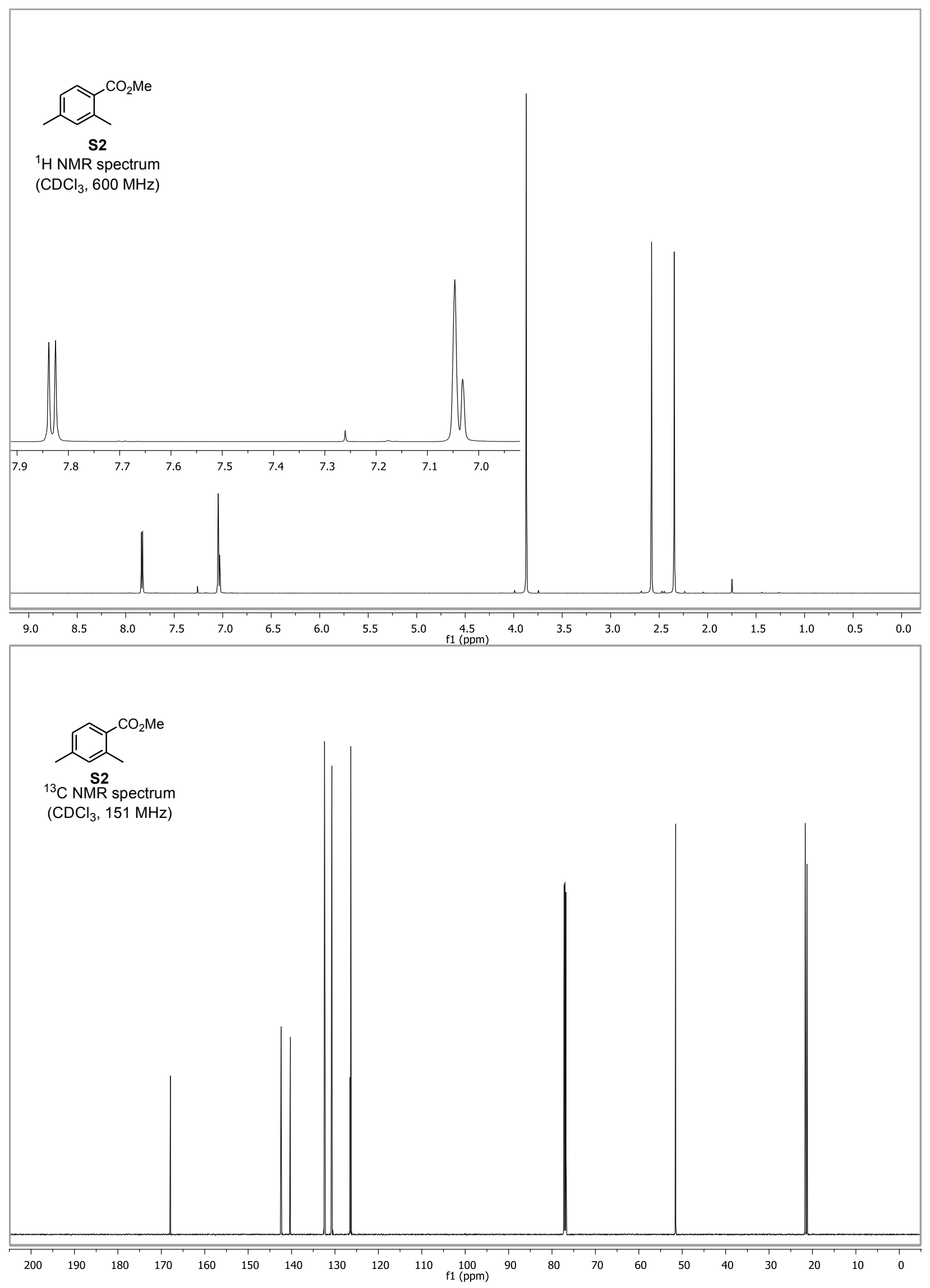


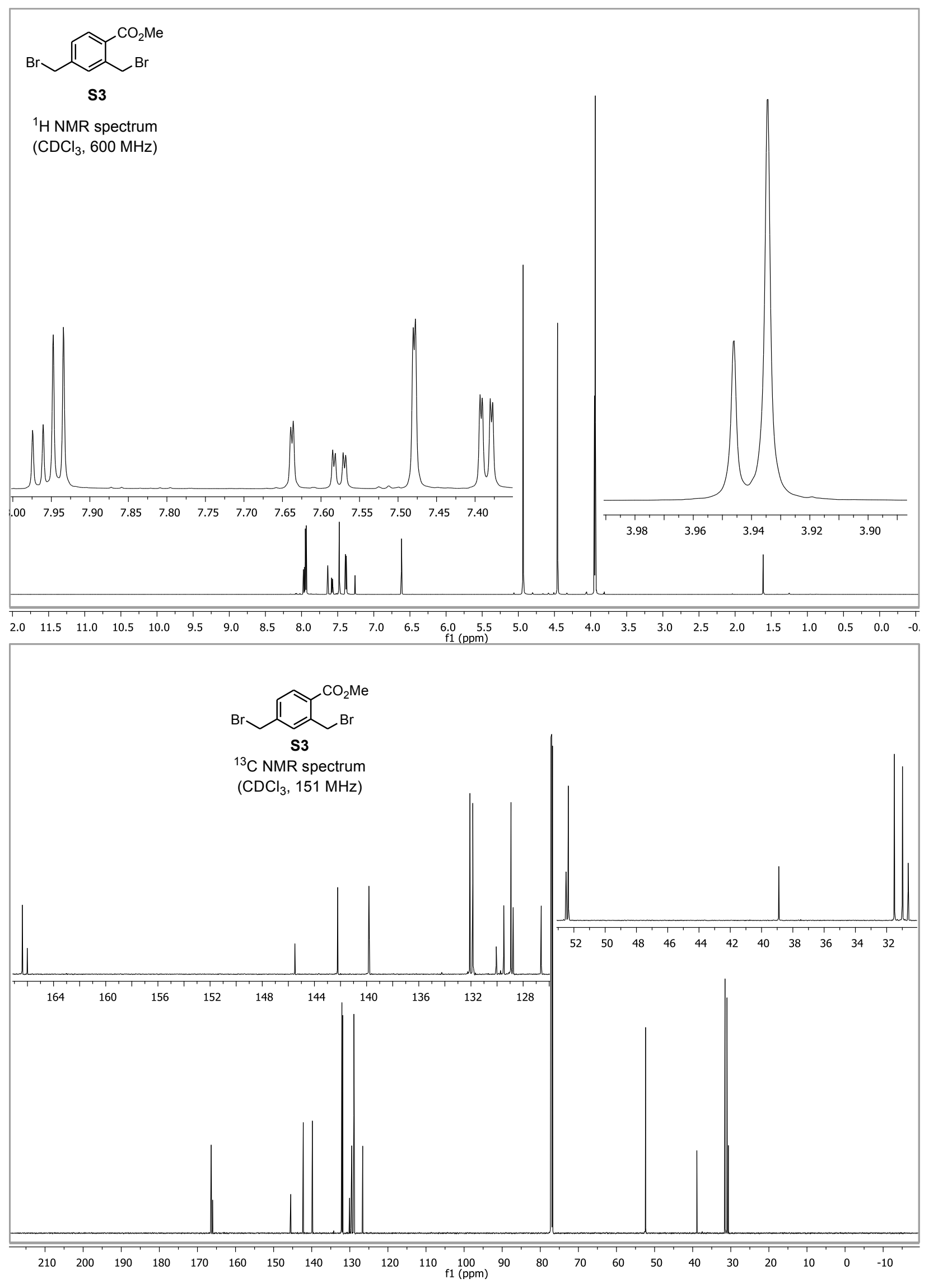




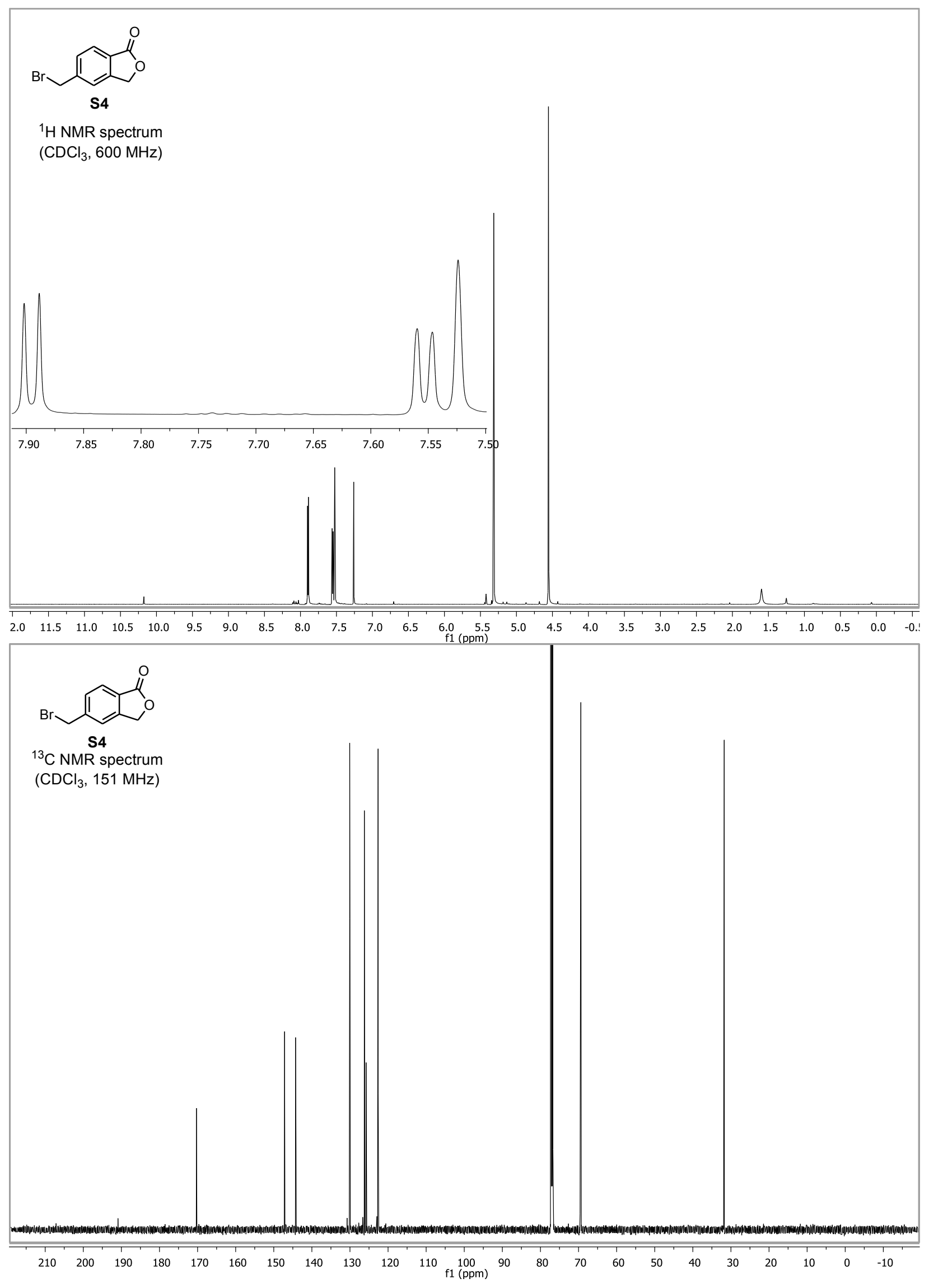



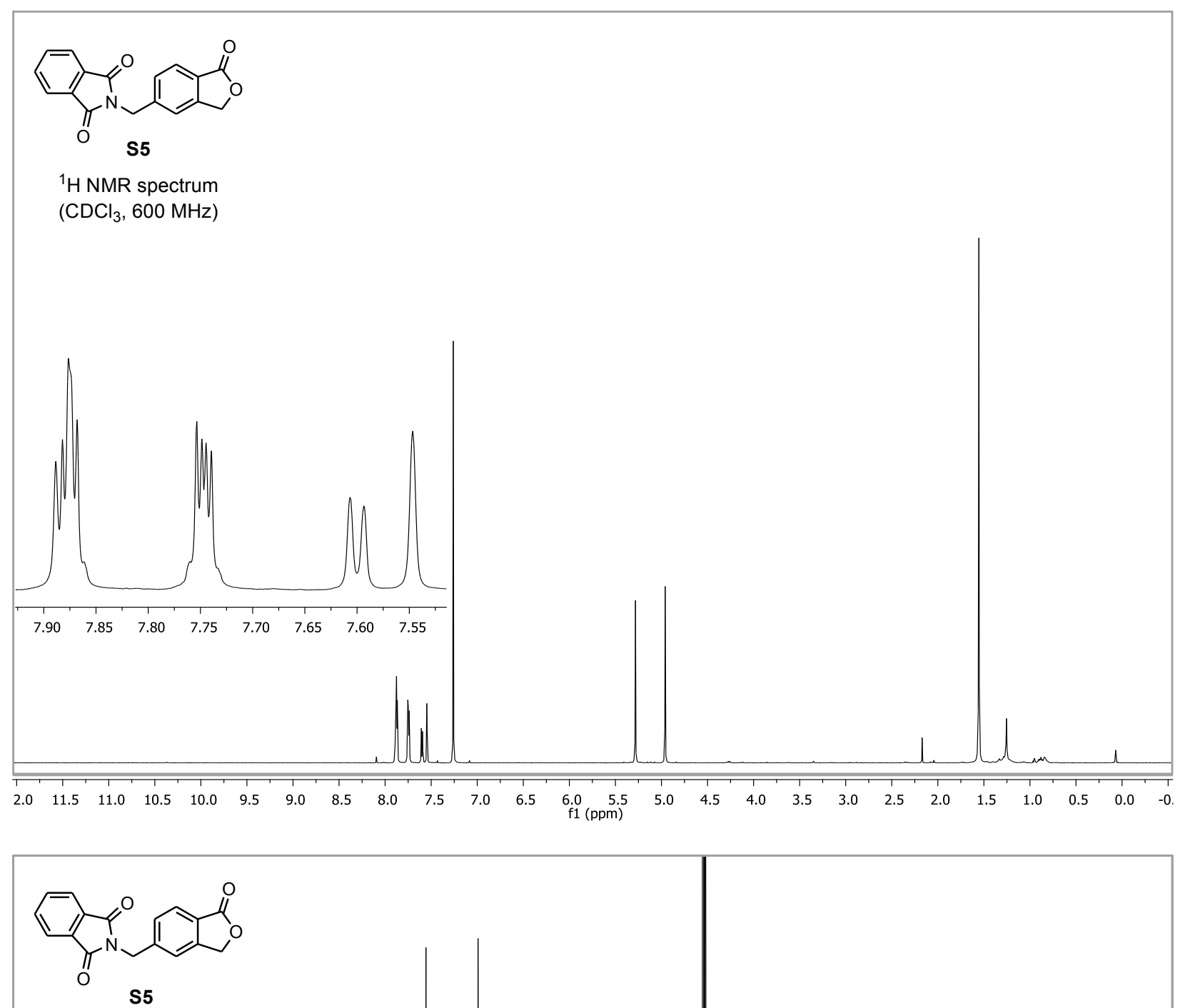

${ }^{13} \mathrm{C}$ NMR spectrum $\left(\mathrm{CDCl}_{3}, 151 \mathrm{MHz}\right)$

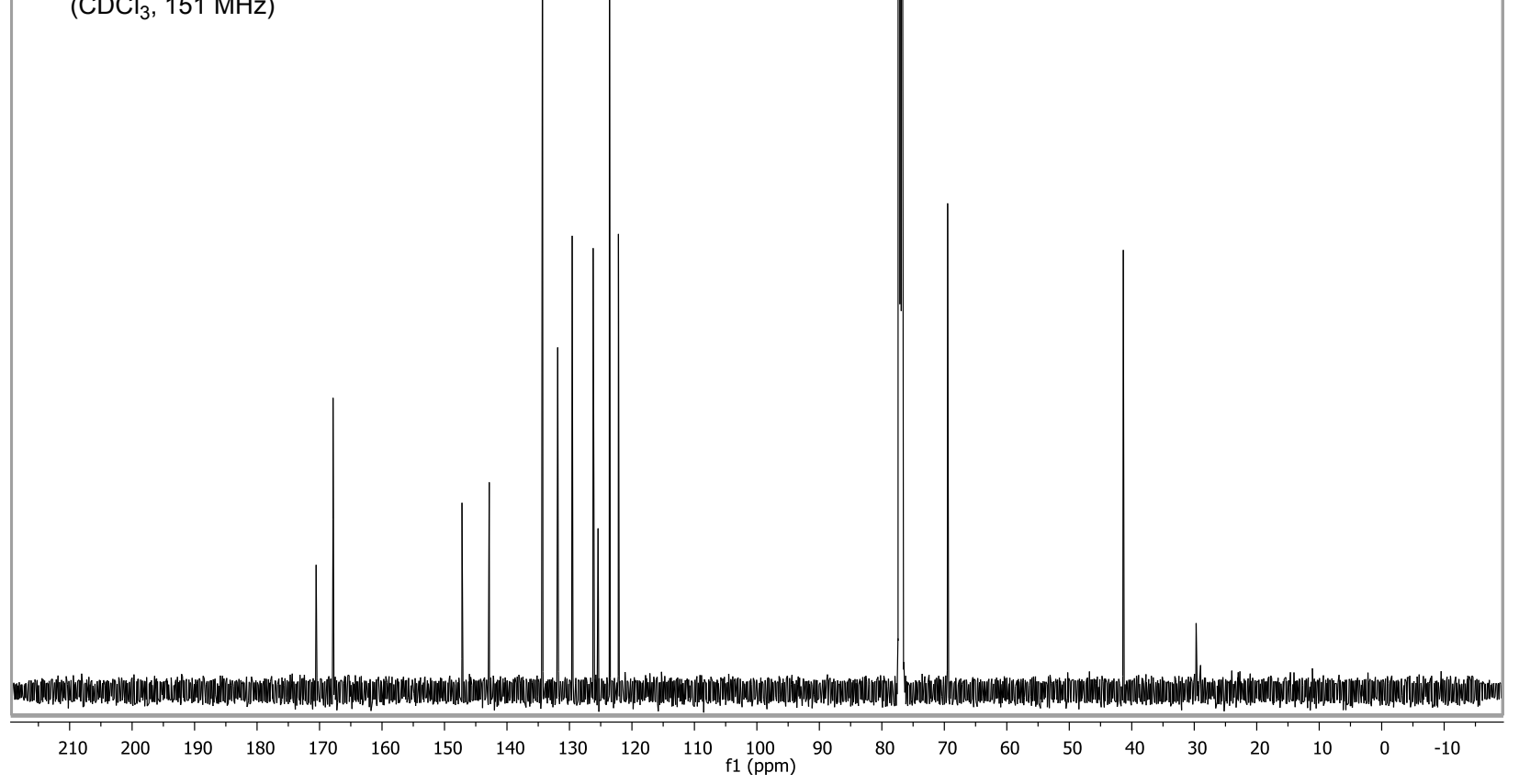



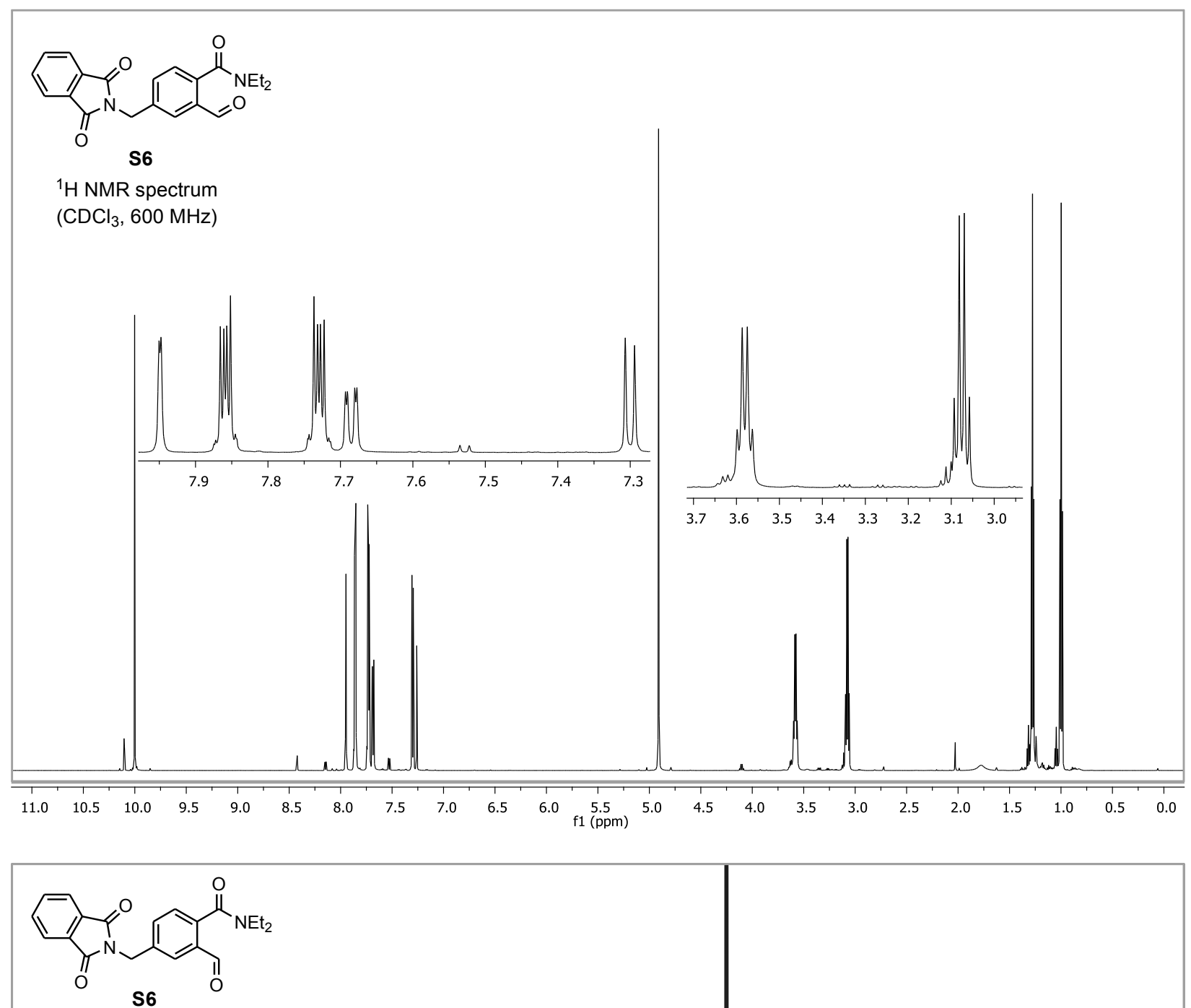

${ }^{13} \mathrm{C}$ NMR spectrum $\left(\mathrm{CDCl}_{3}, 151 \mathrm{MHz}\right)$
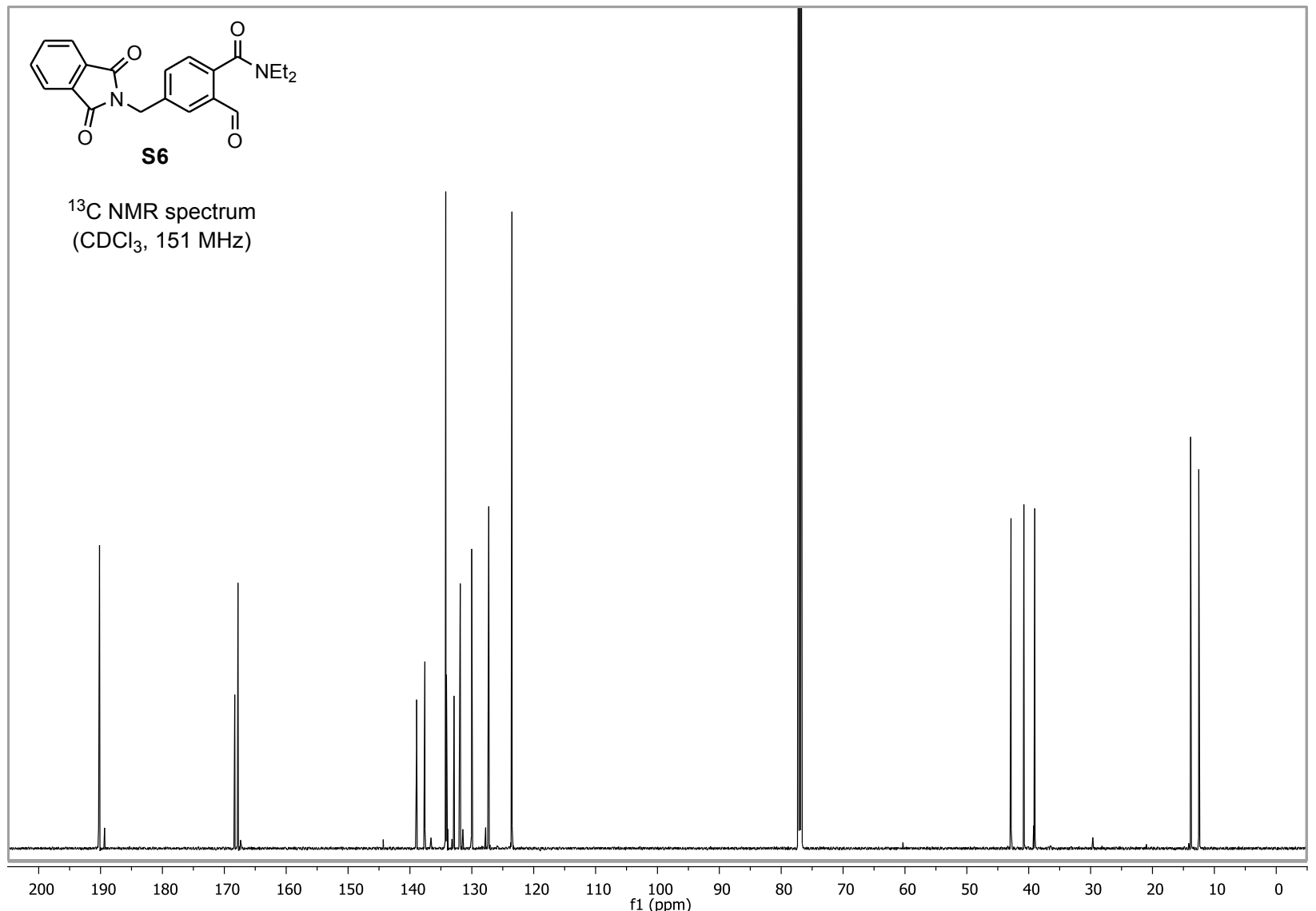

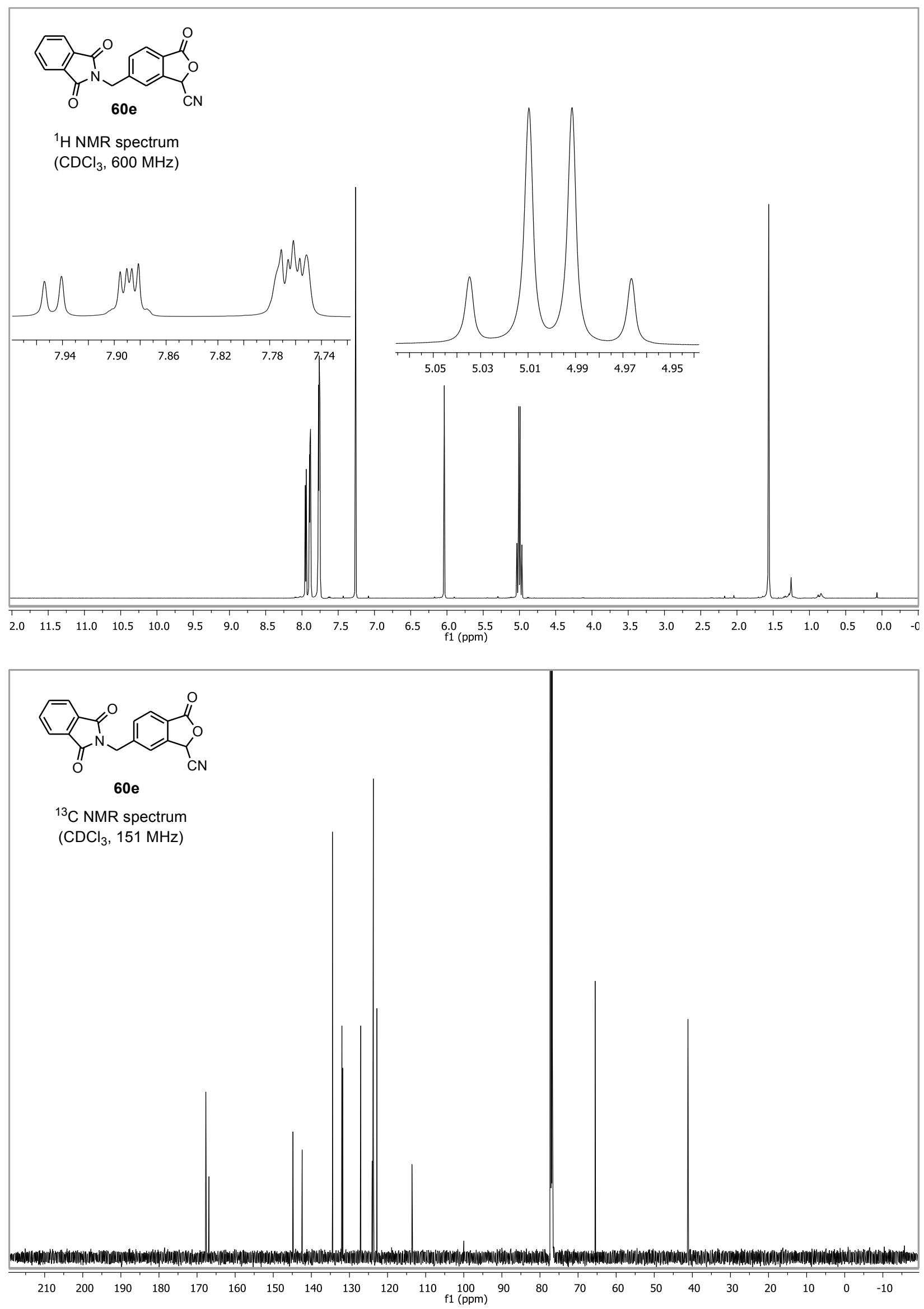

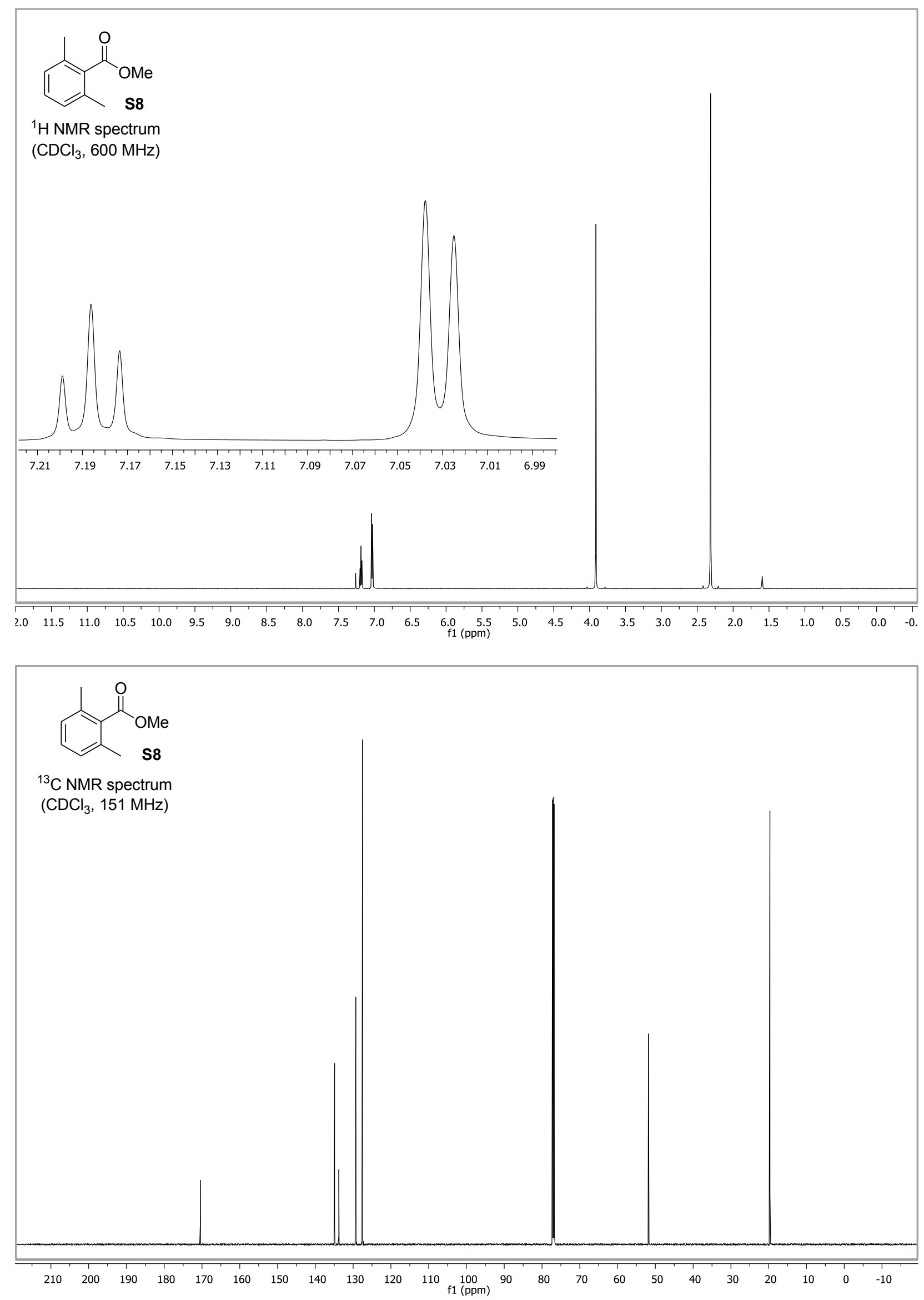

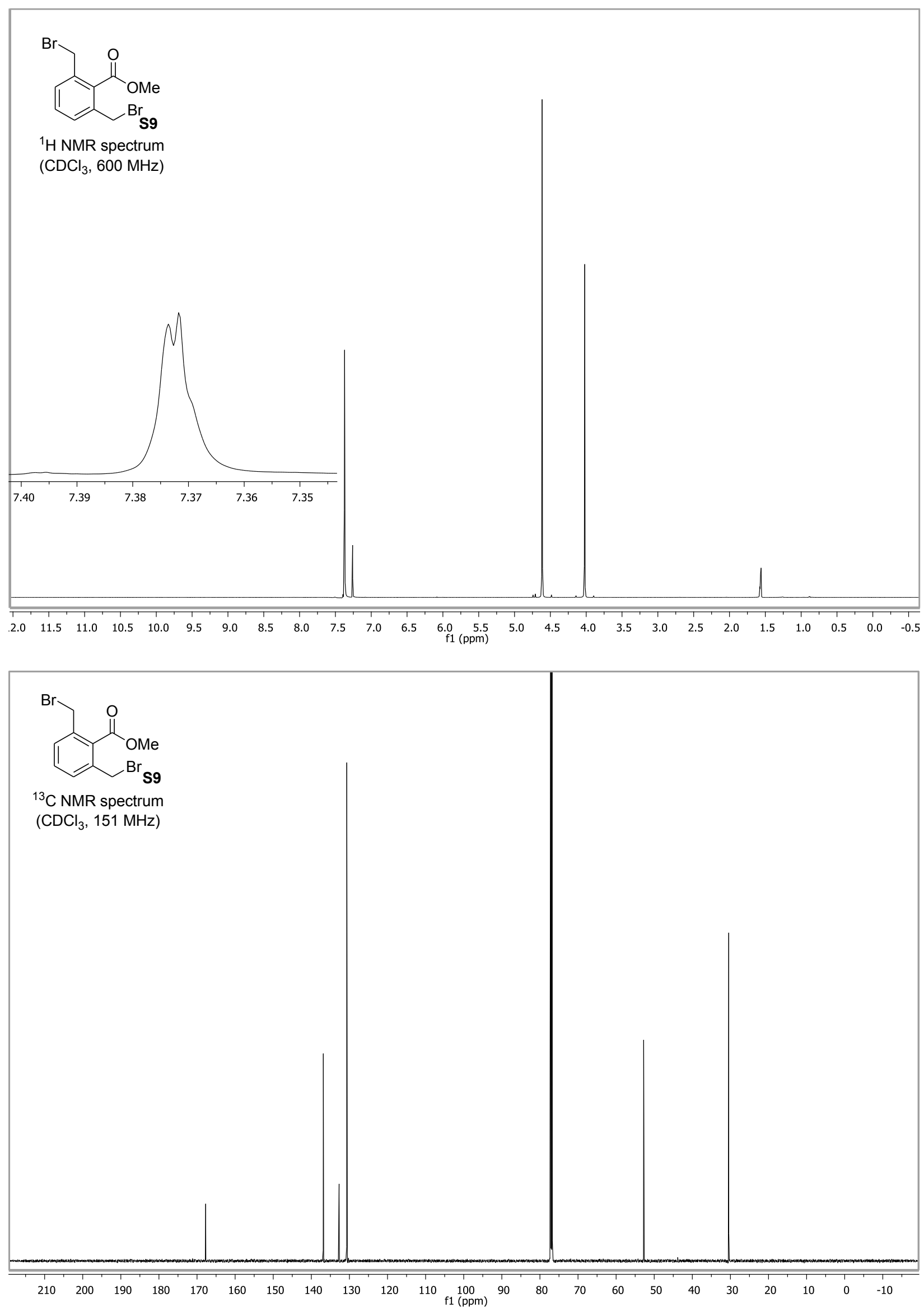

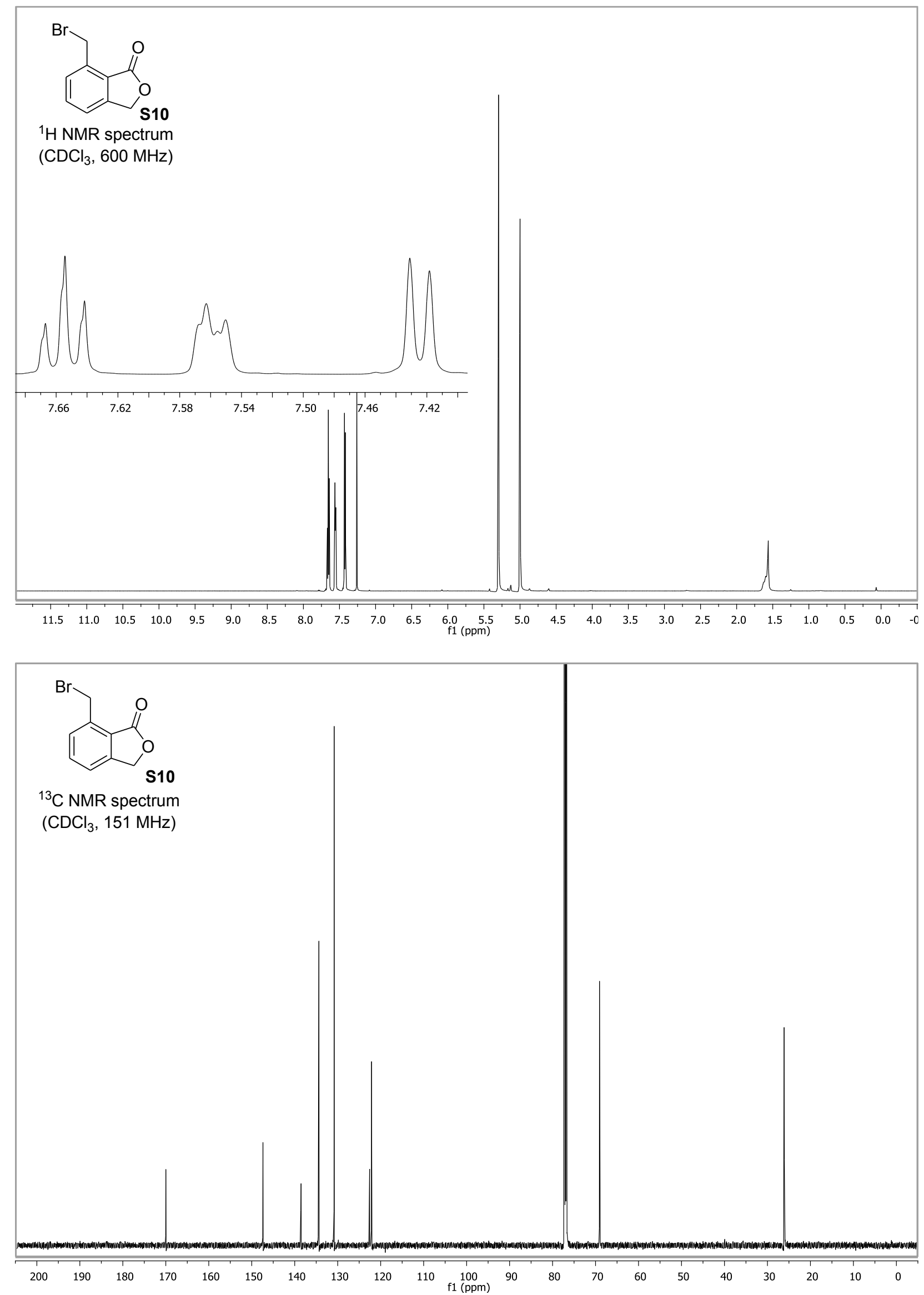

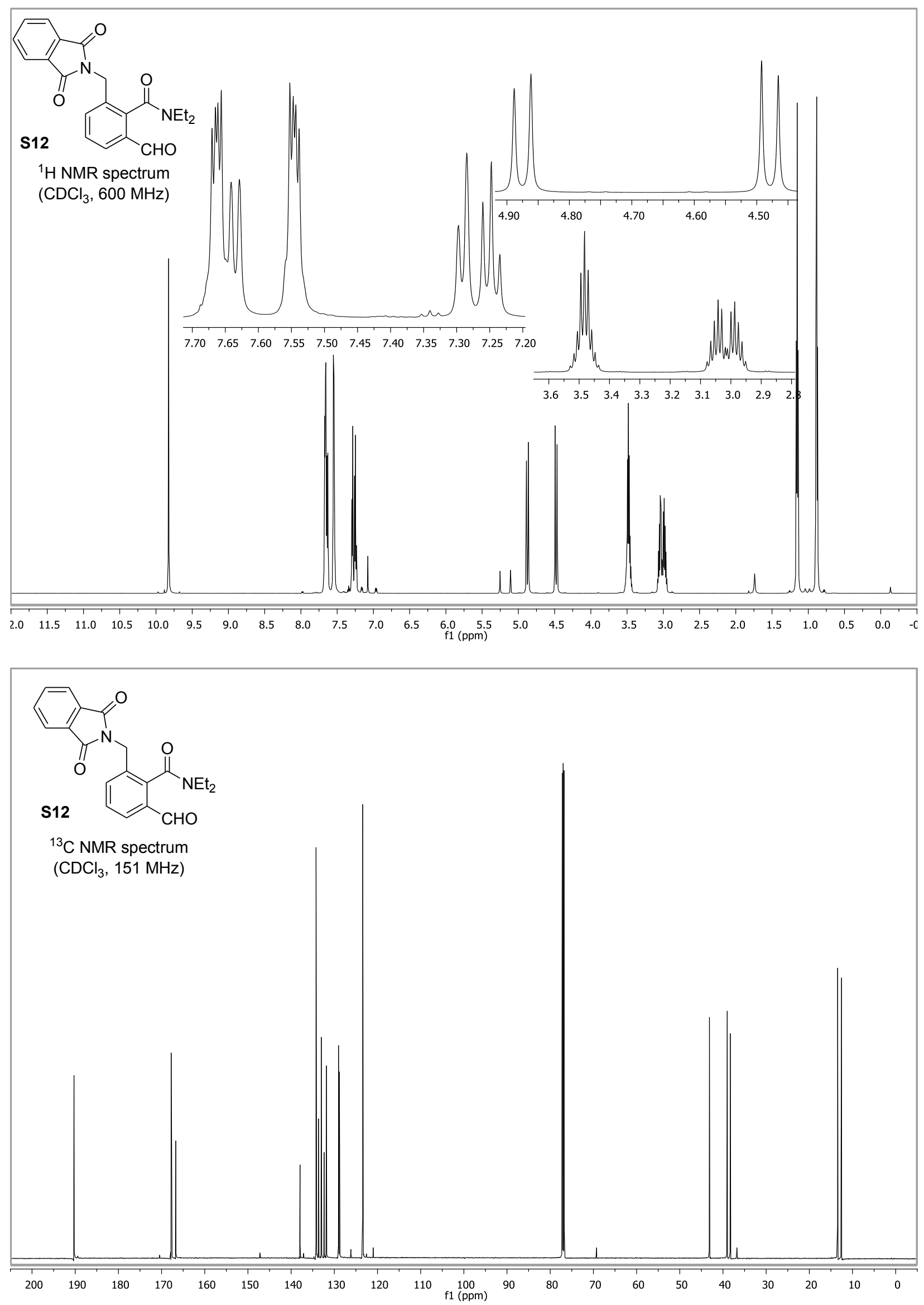

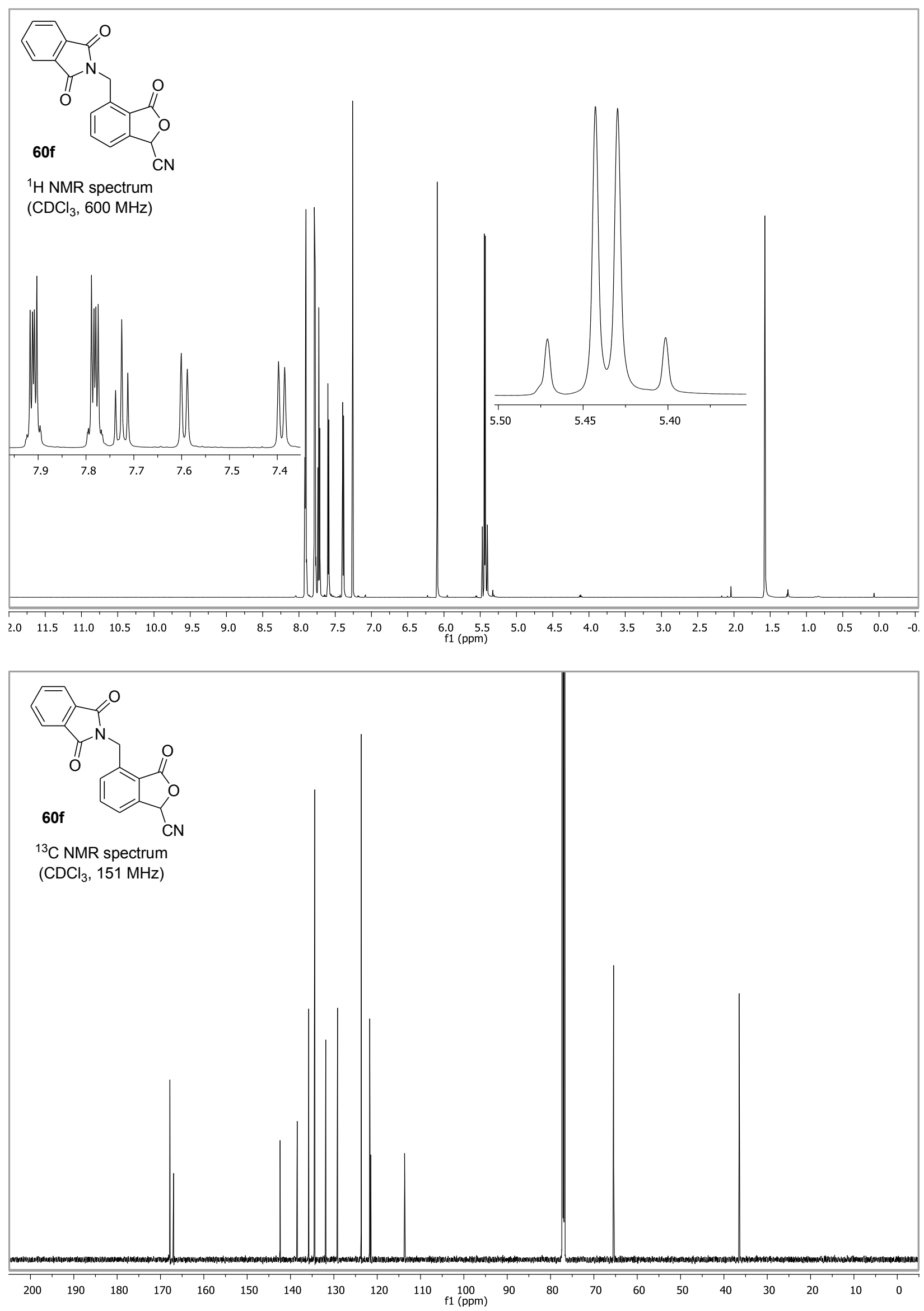

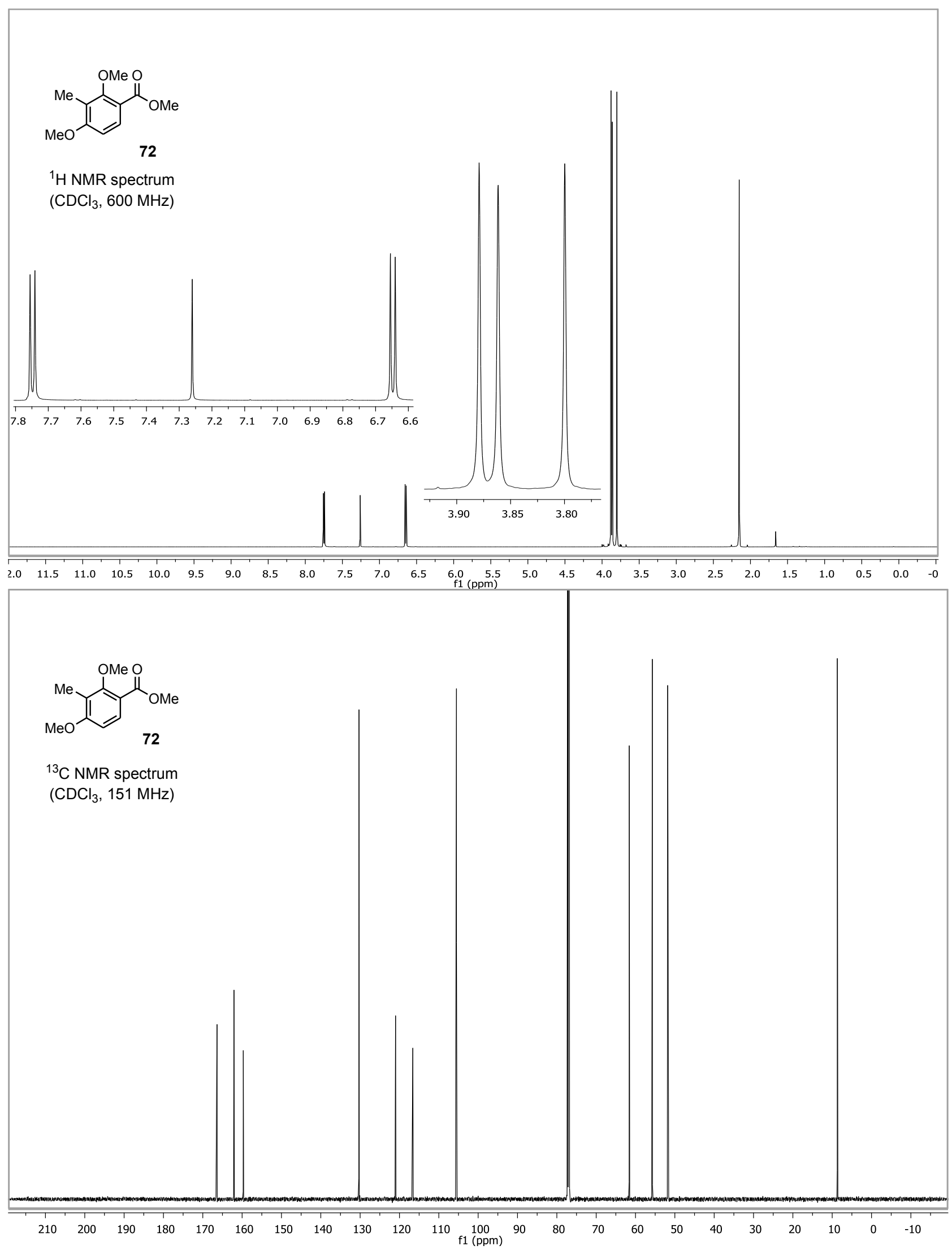

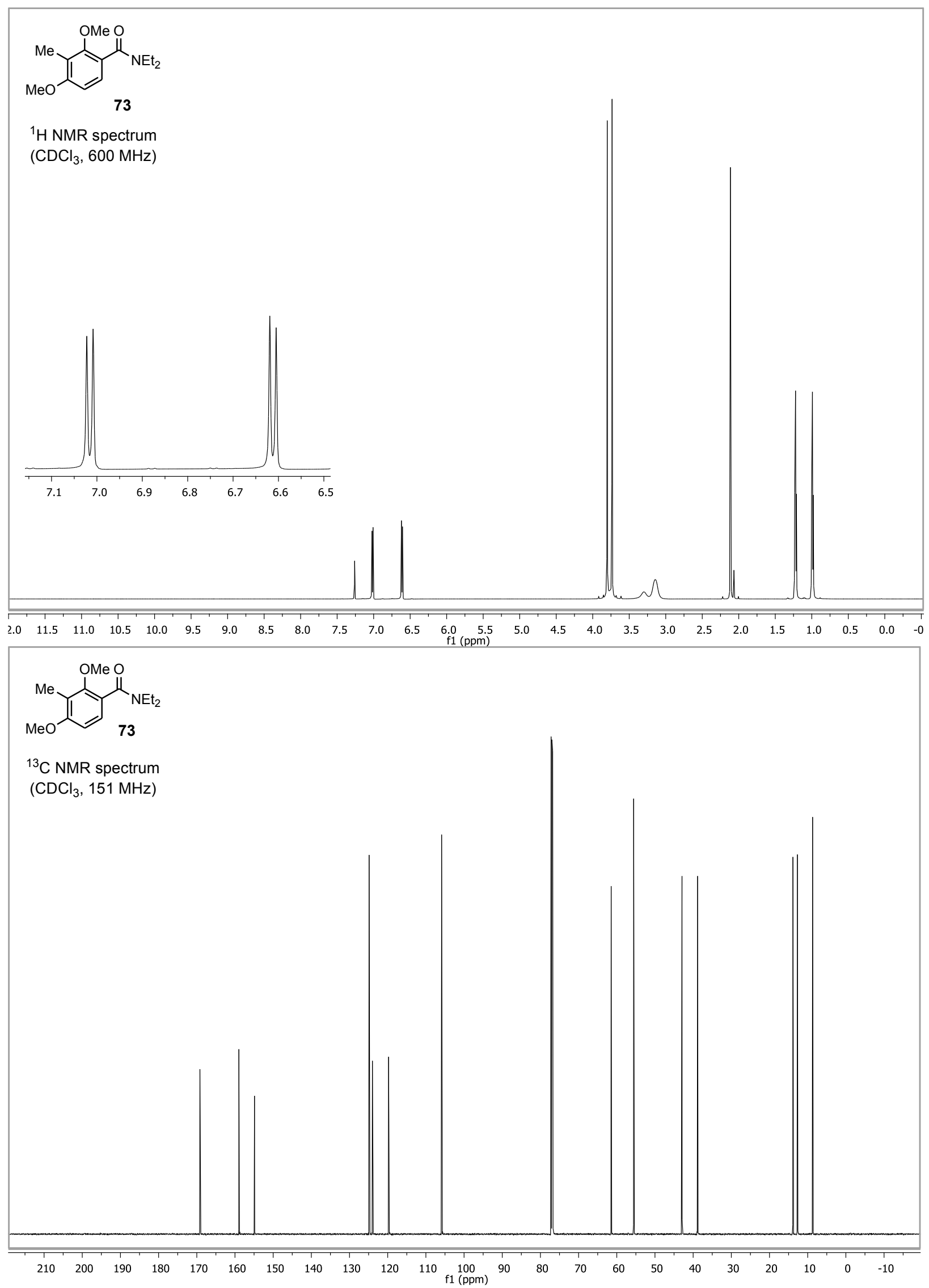

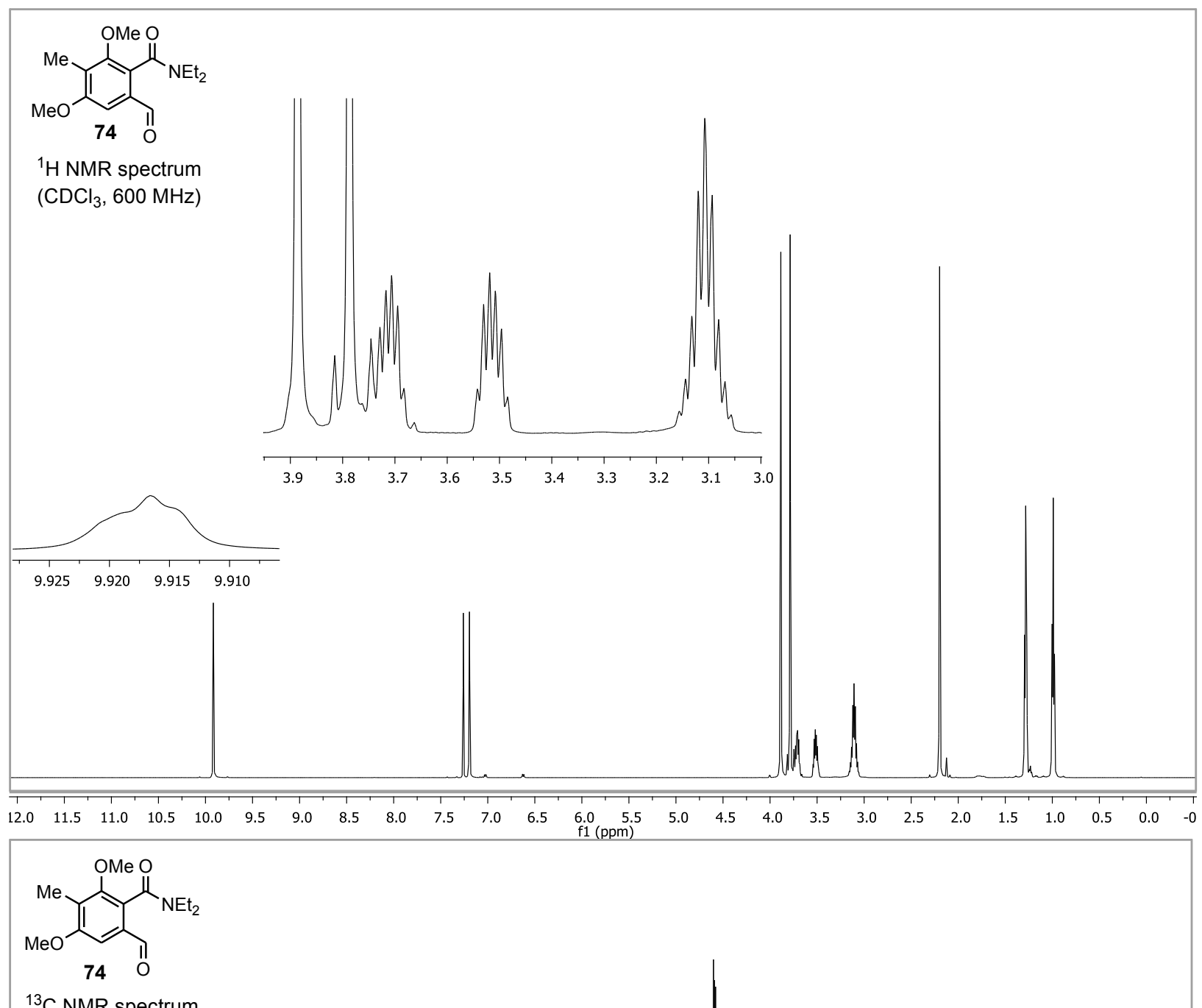

$\left(\mathrm{CDCl}_{3}, 151 \mathrm{MHz}\right)$

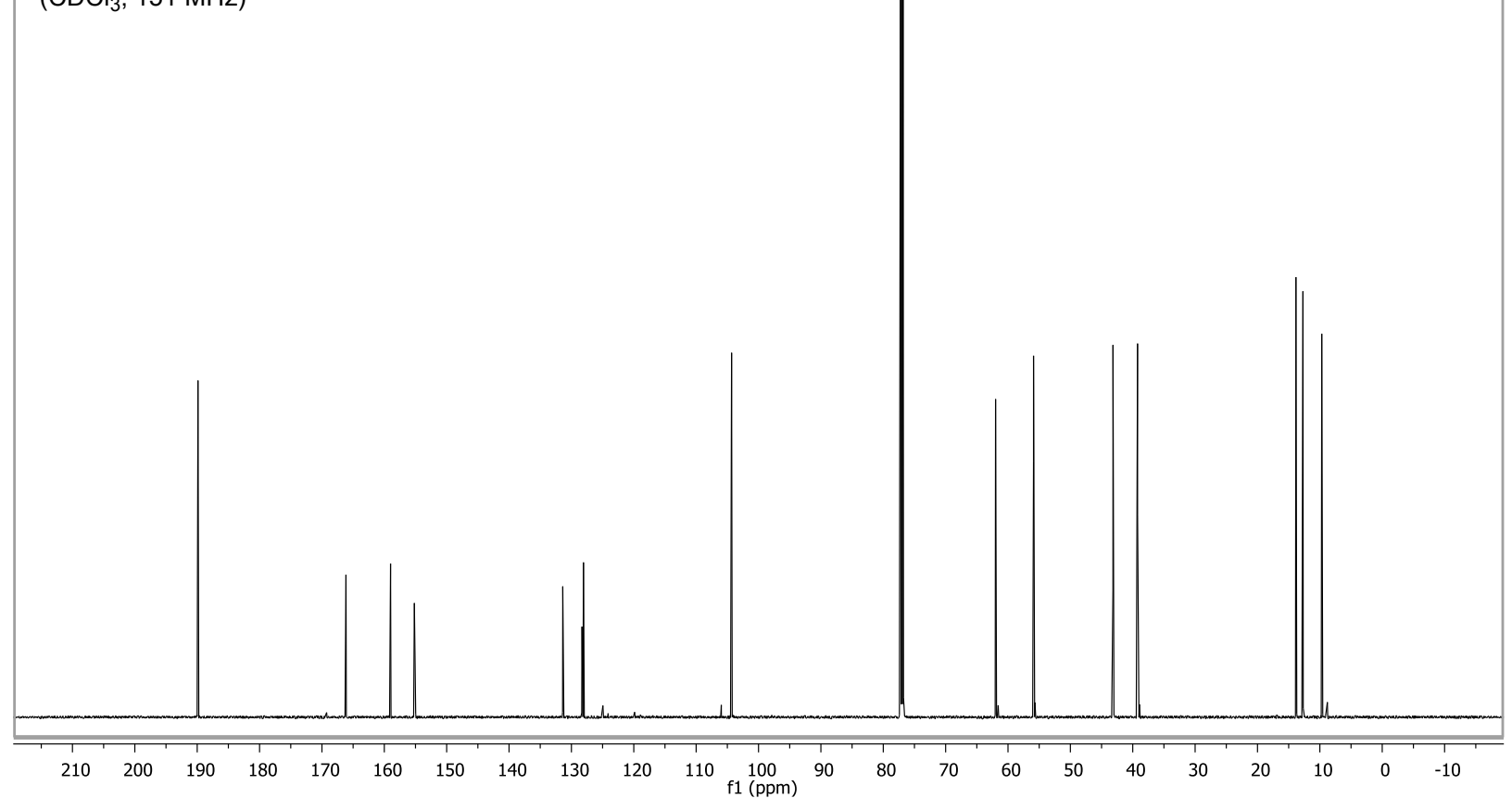



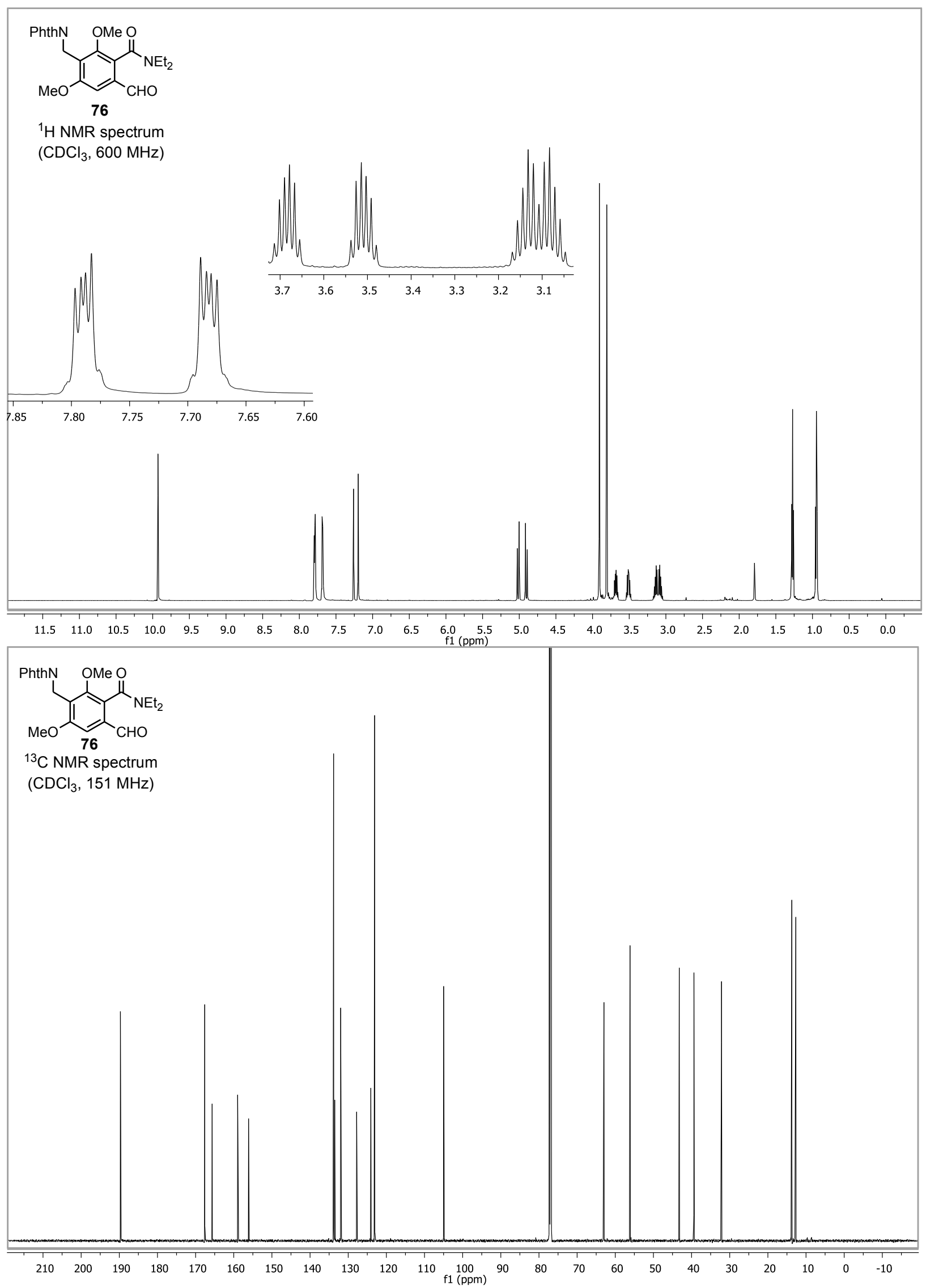

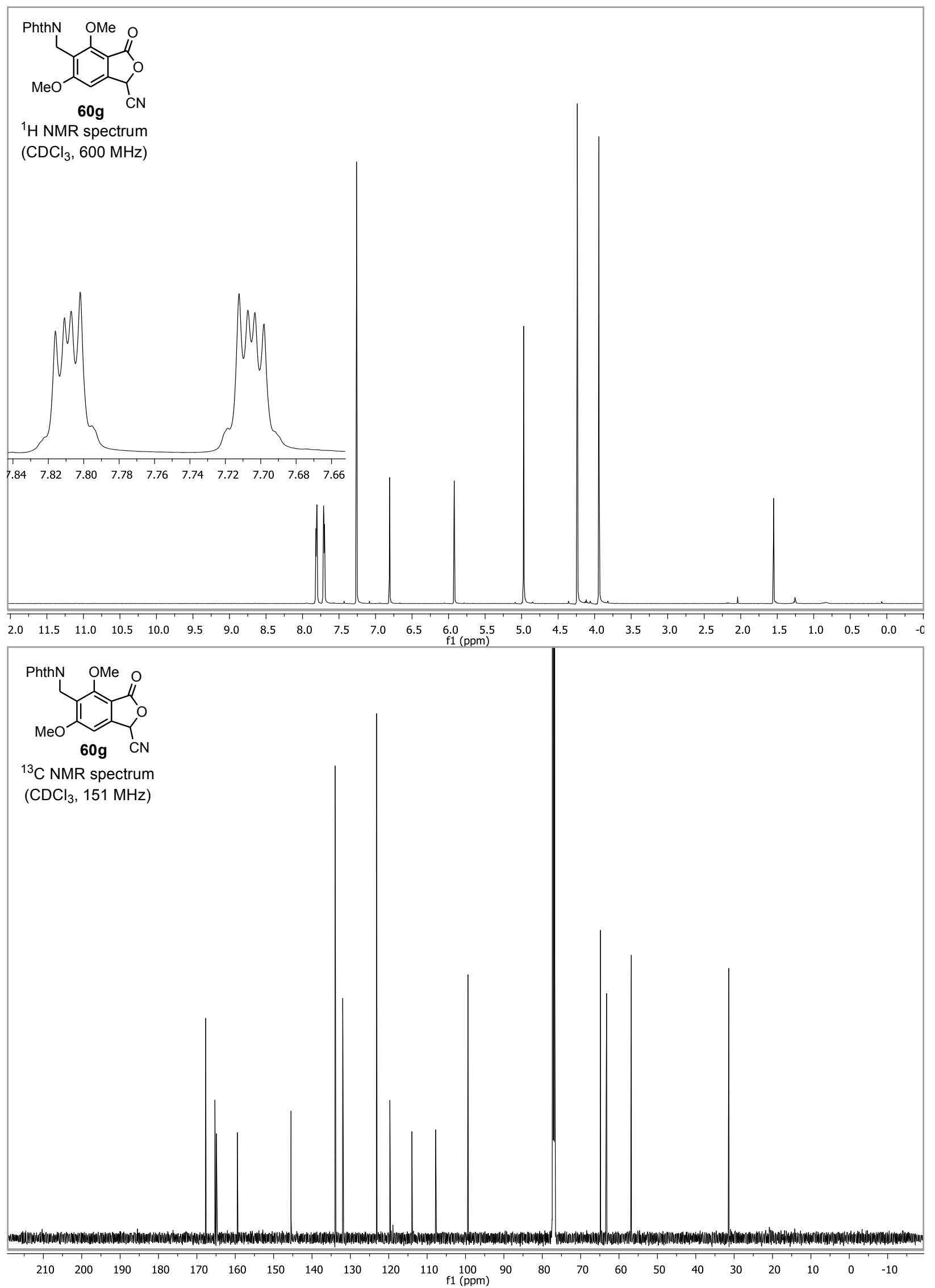


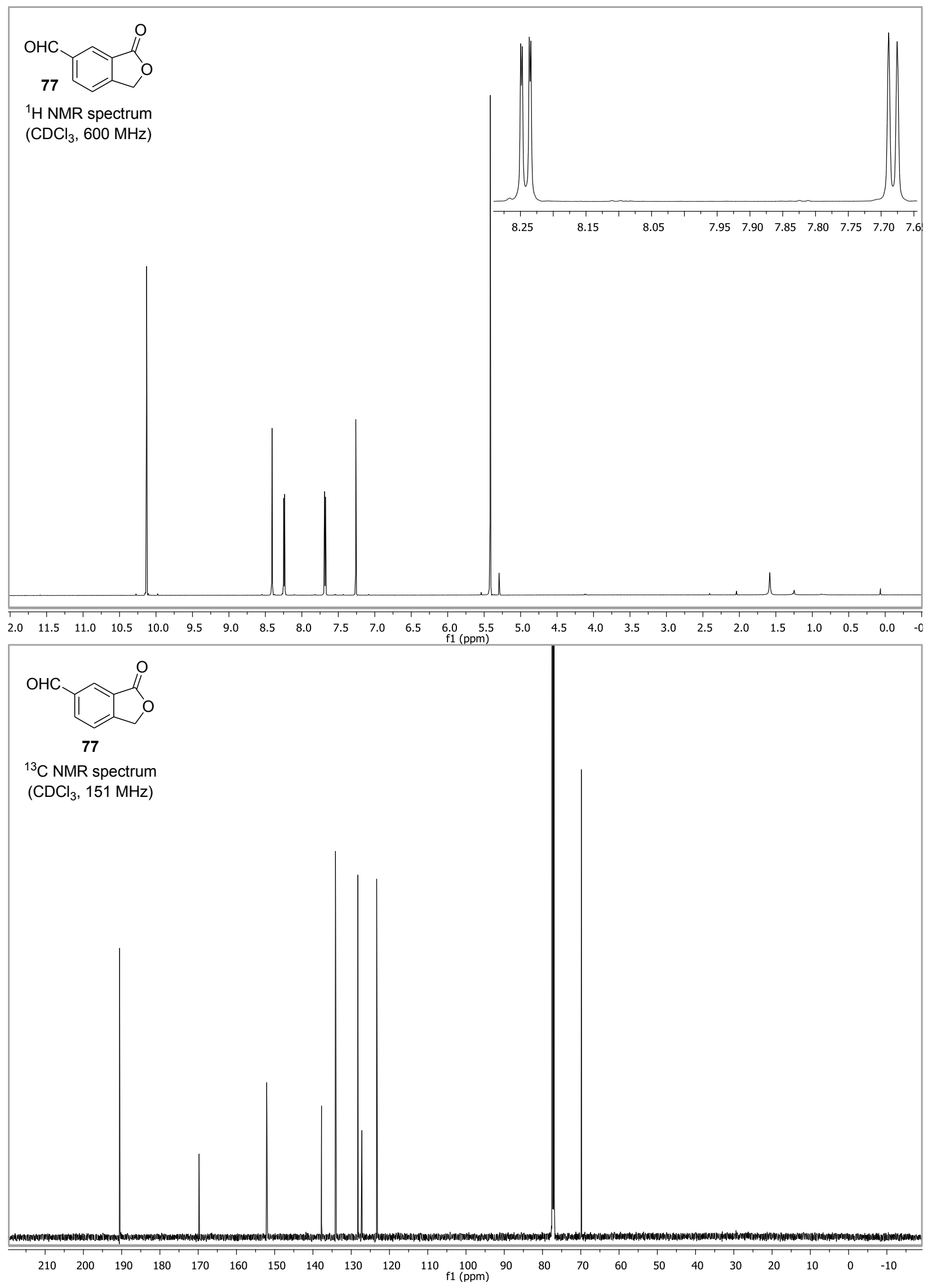




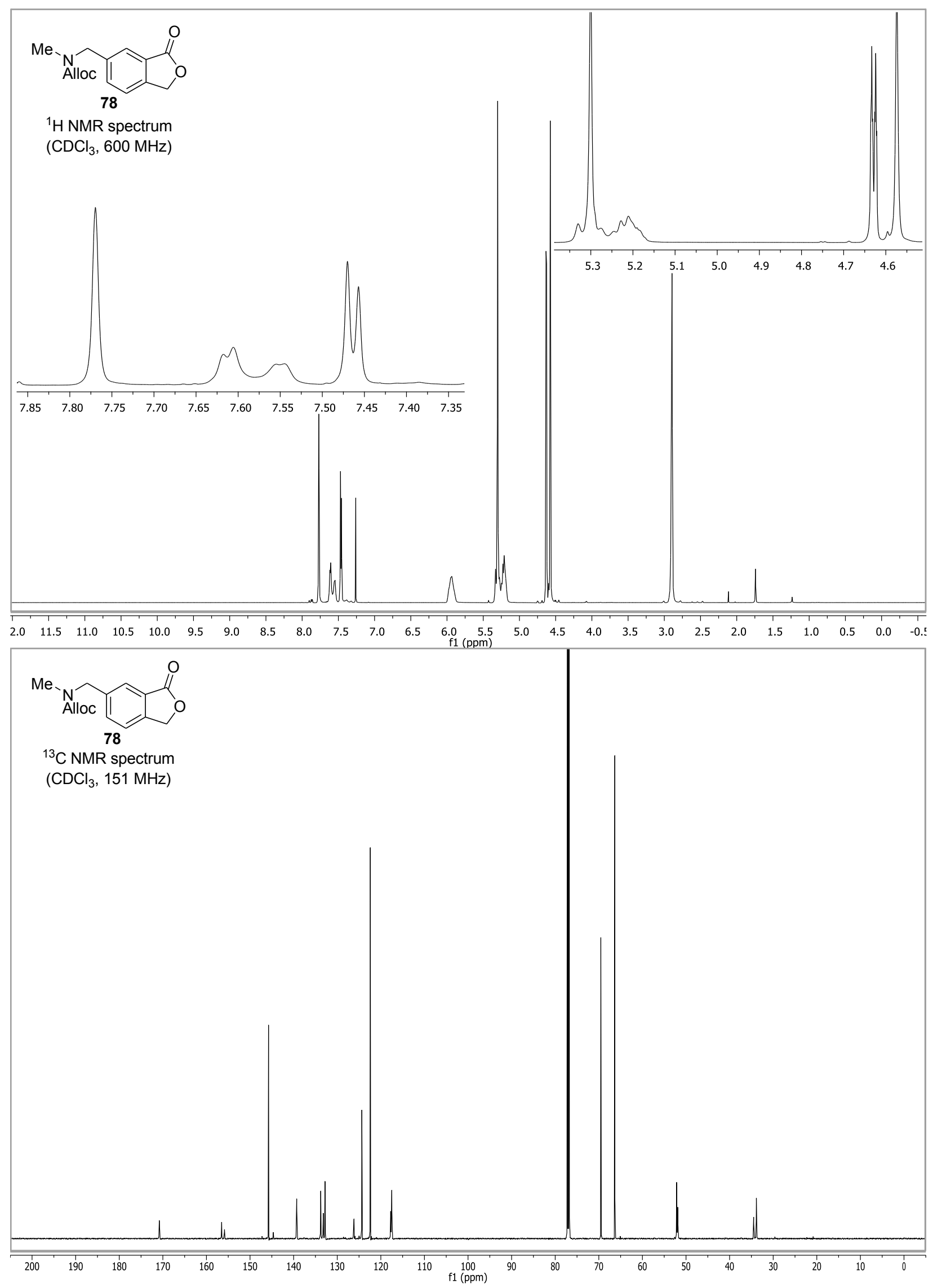



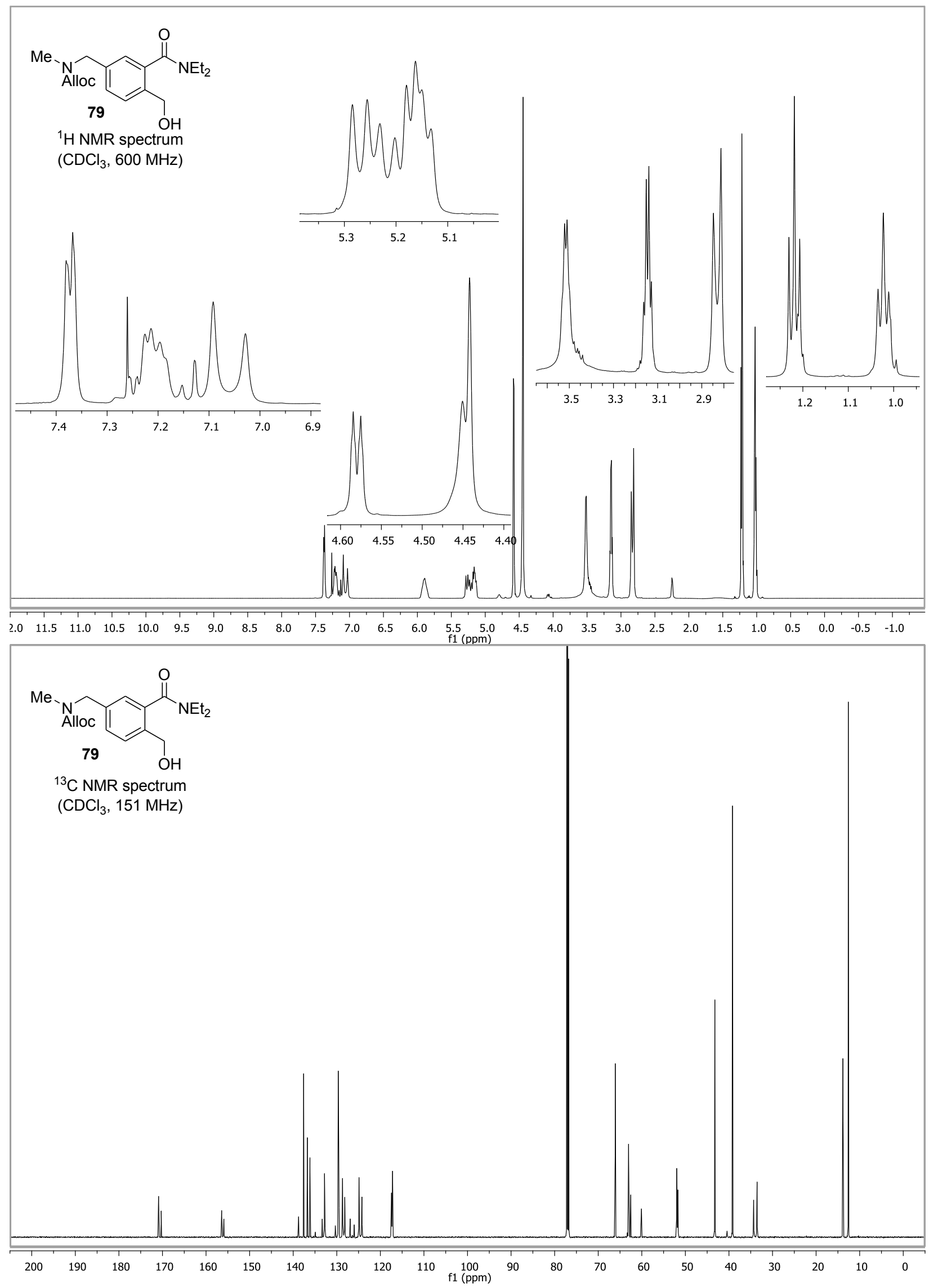

S134 


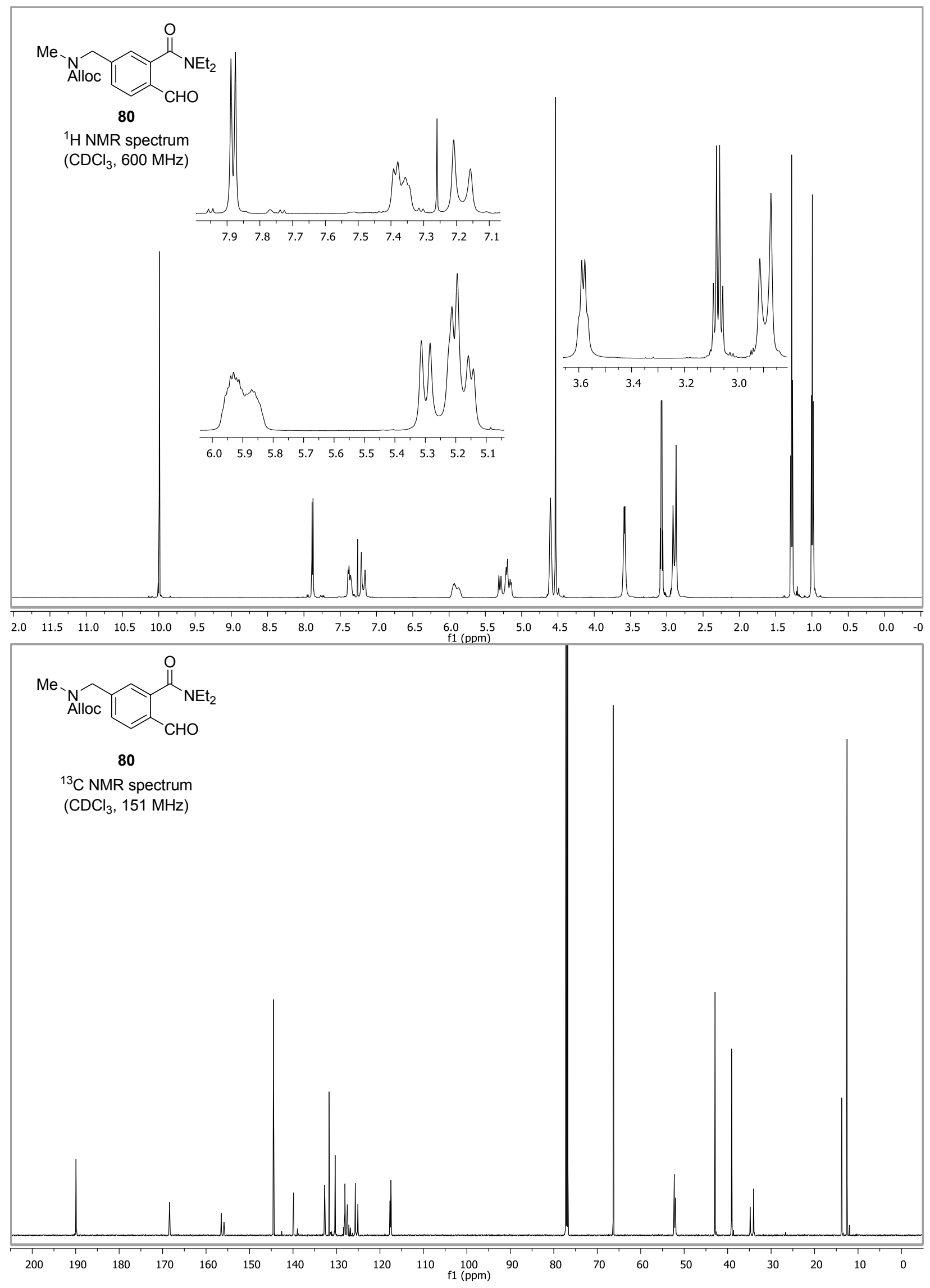



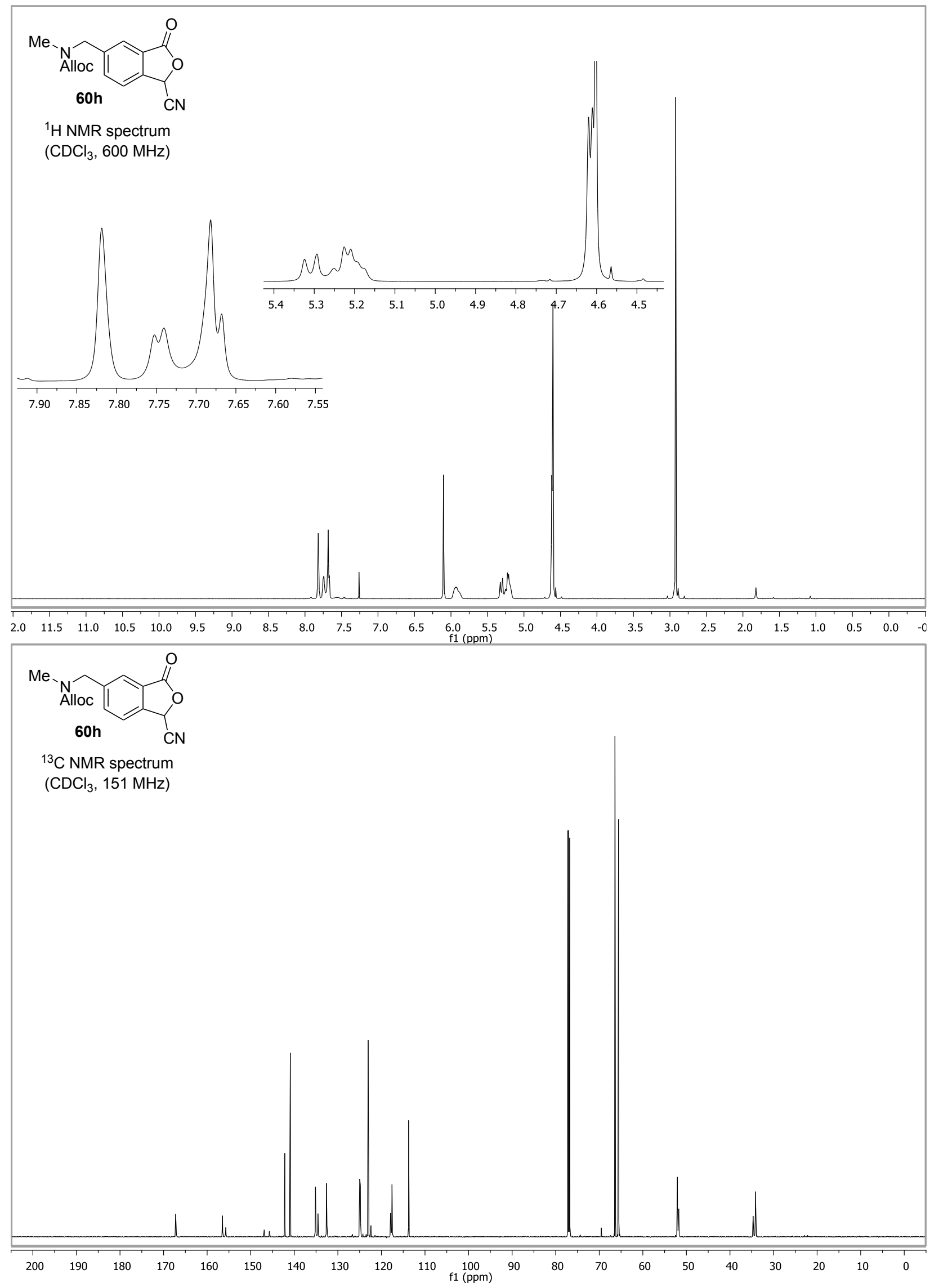

S136 

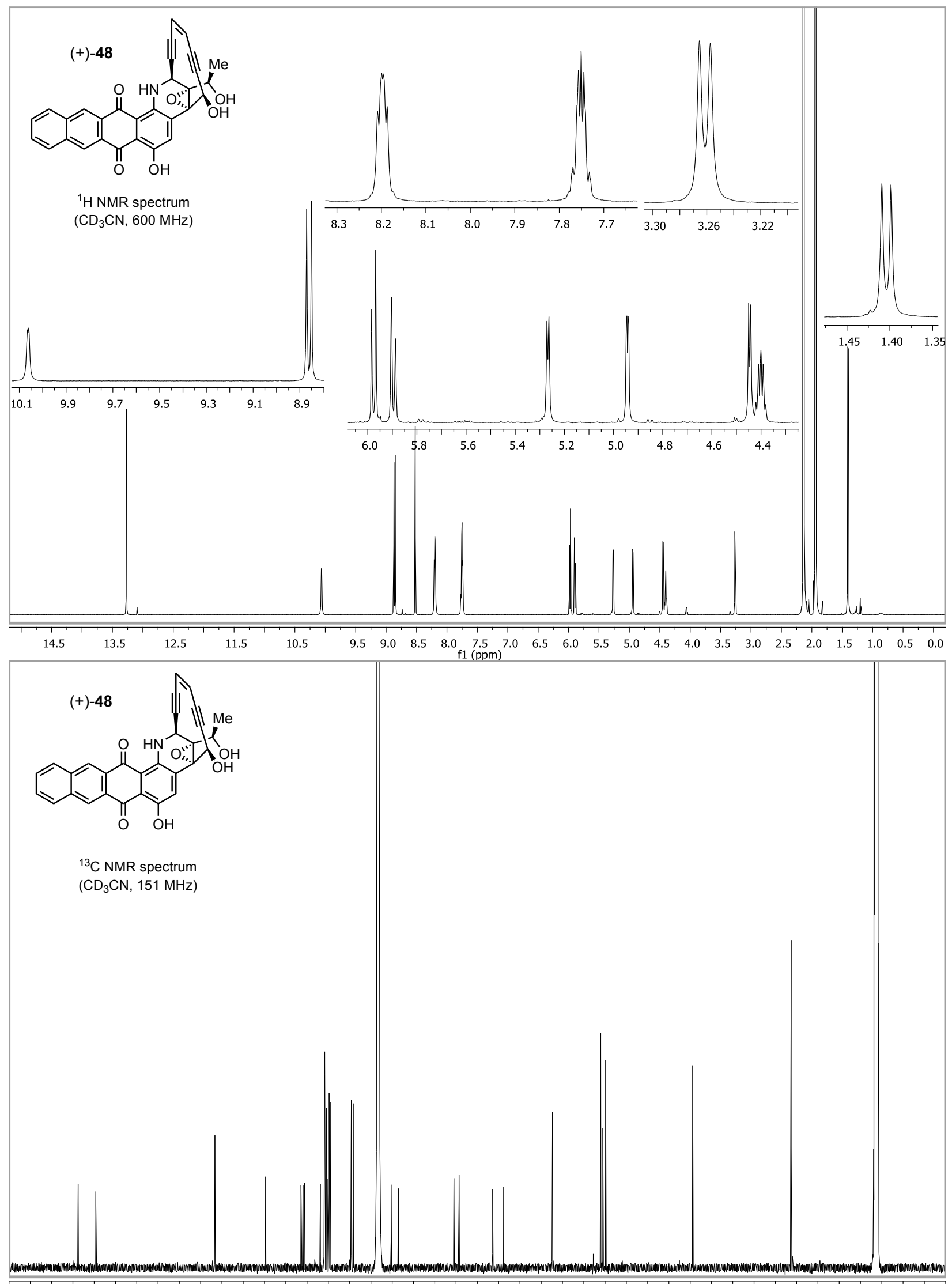

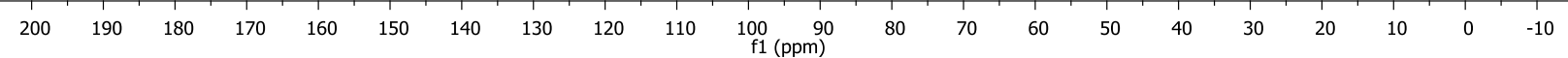



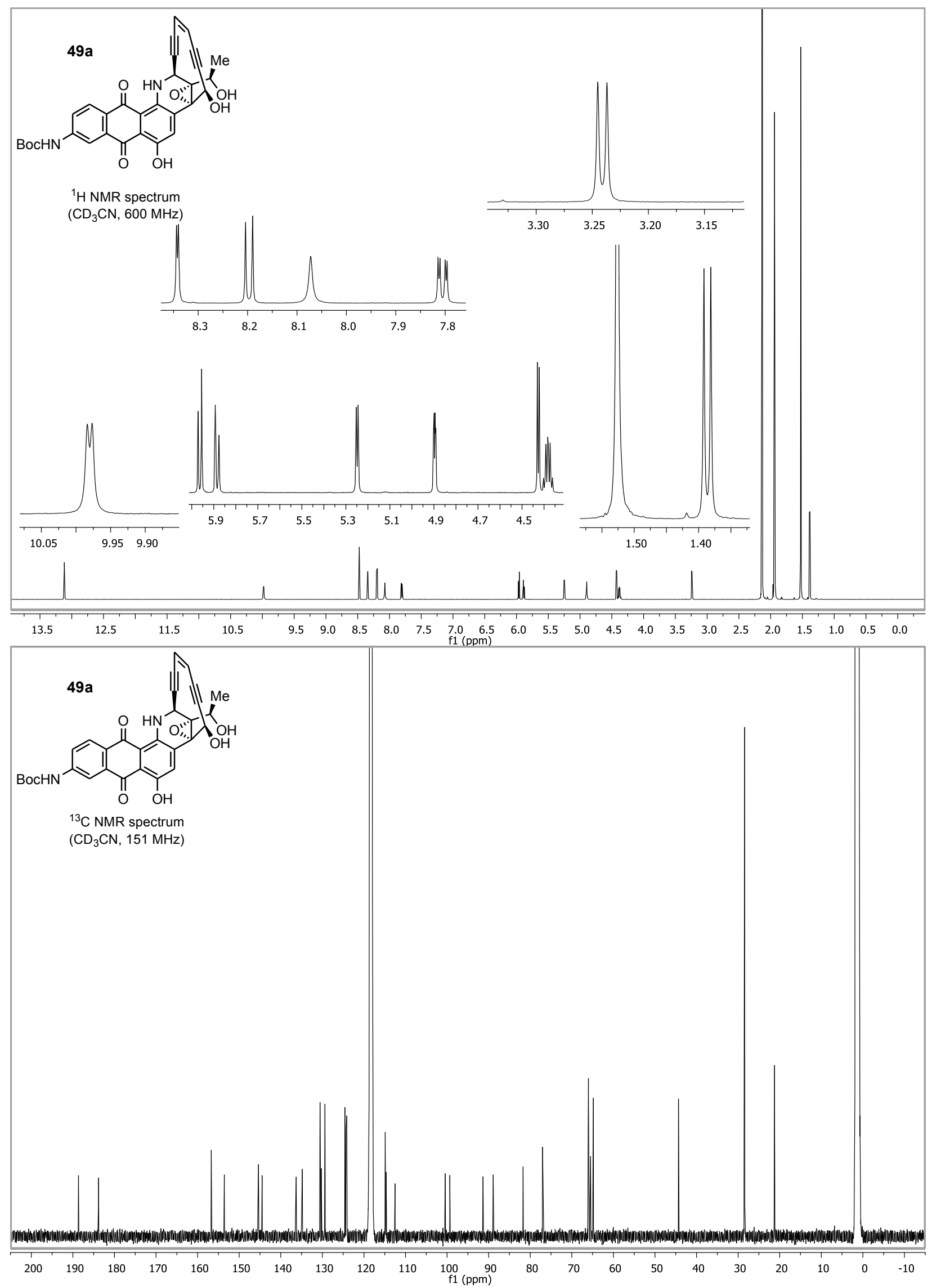

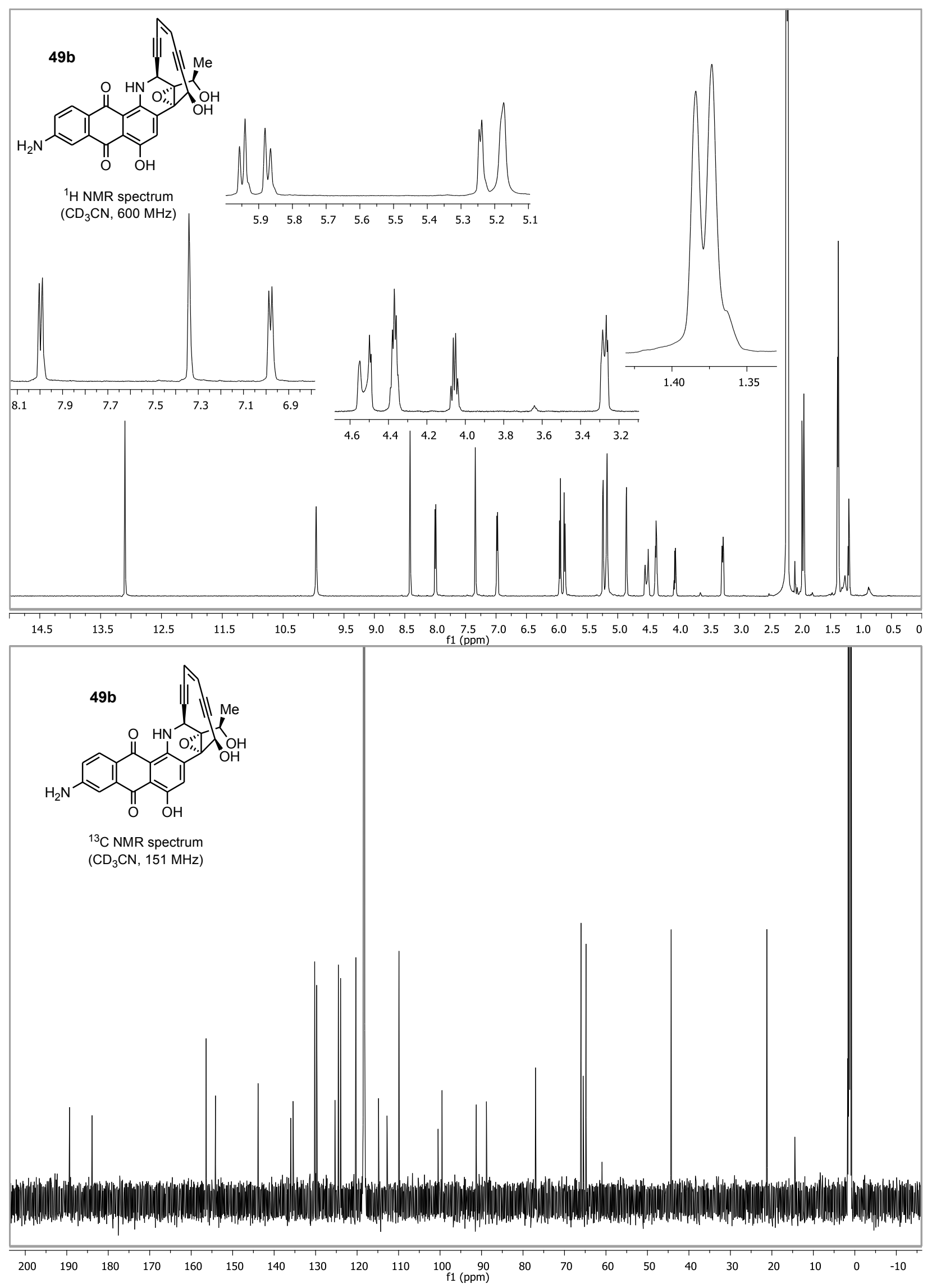

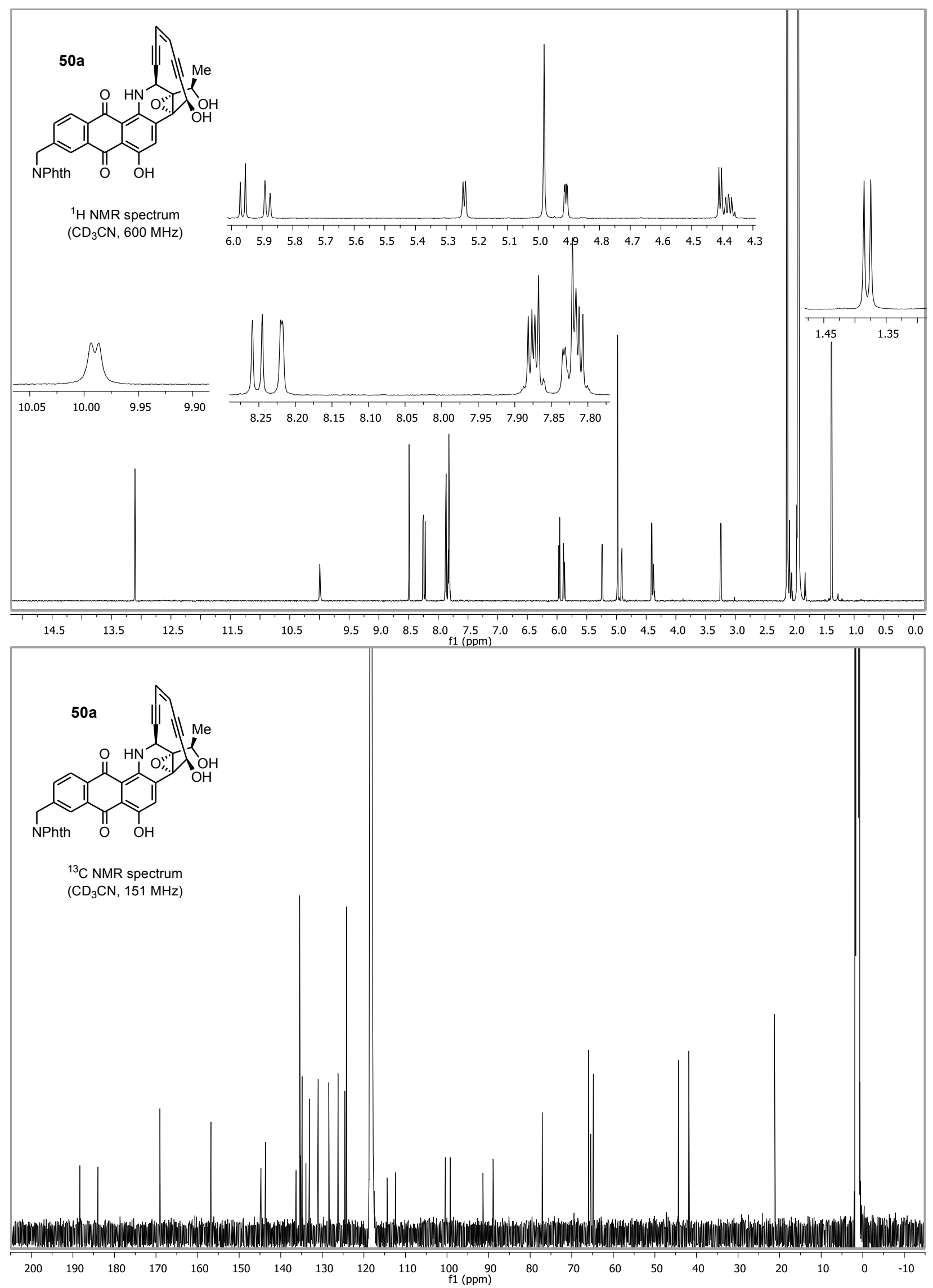

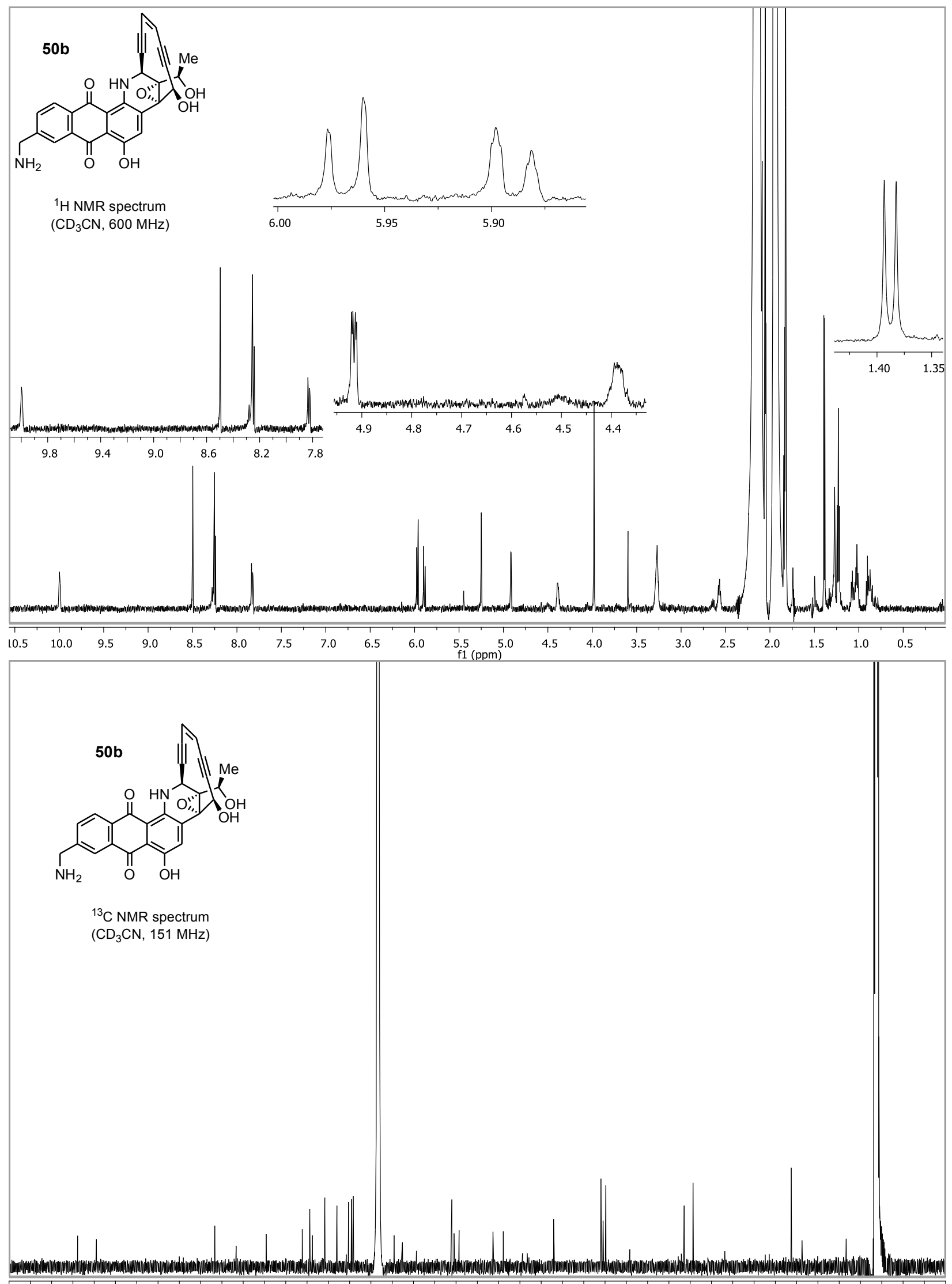

$\begin{array}{llllllllllllllllllllll}200 & 190 & 180 & 170 & 160 & 150 & 140 & 130 & 120 & 110 & \begin{array}{c}100 \\ \mathrm{f} 1(\mathrm{ppm})\end{array} & 80 & 70 & 60 & 50 & 40 & 30 & 20 & 10 & 0 & -10\end{array}$ 

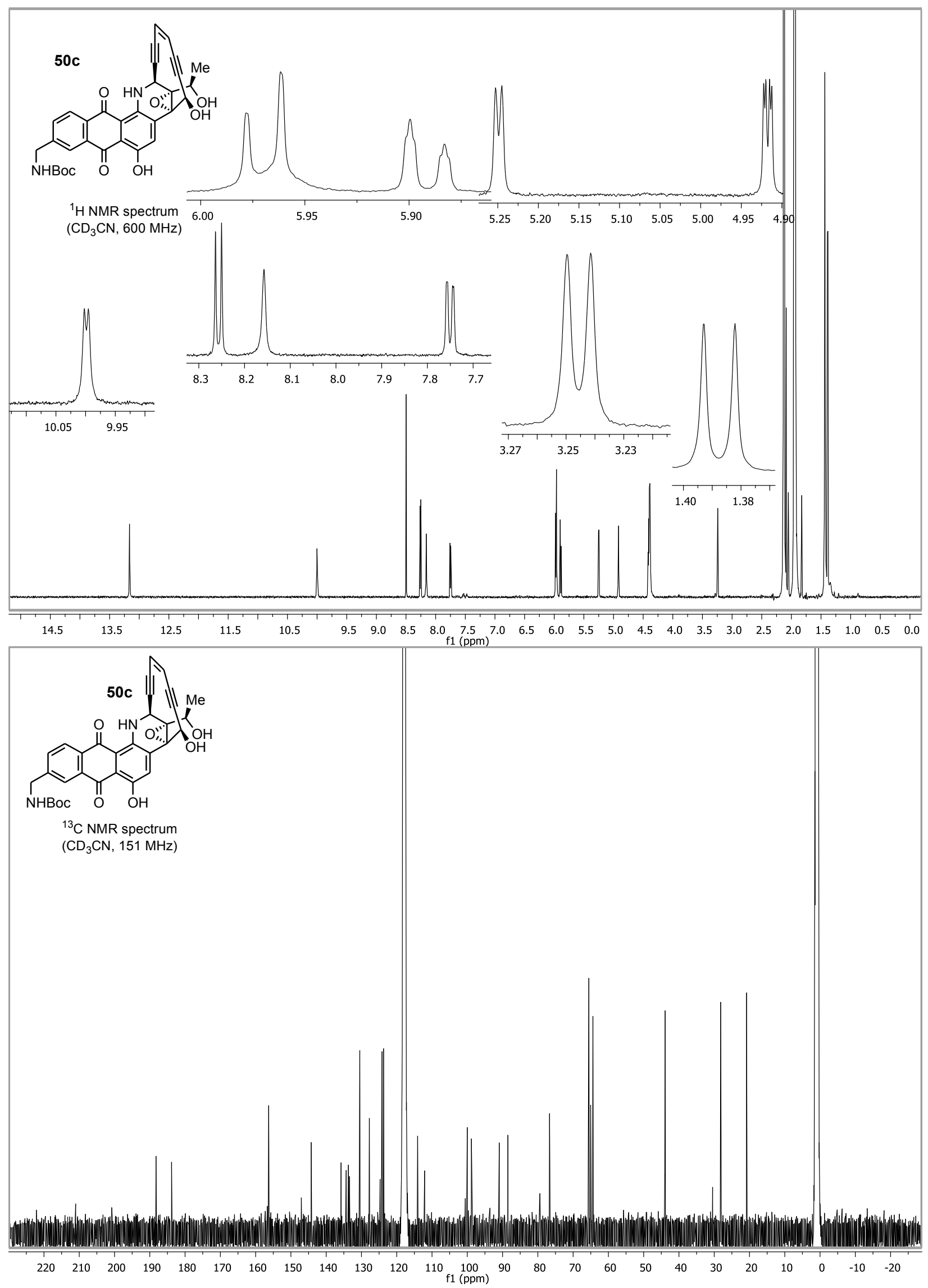

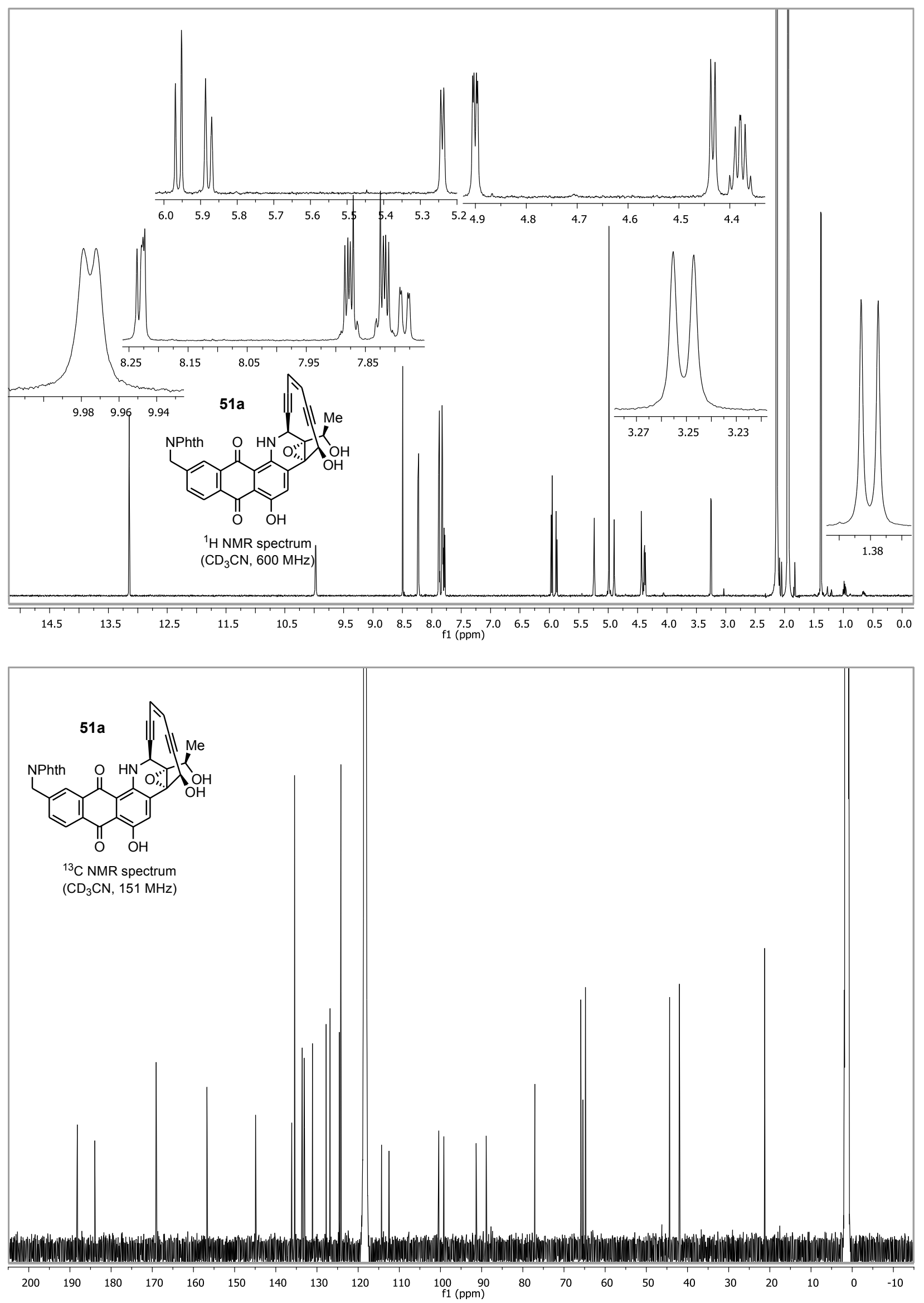

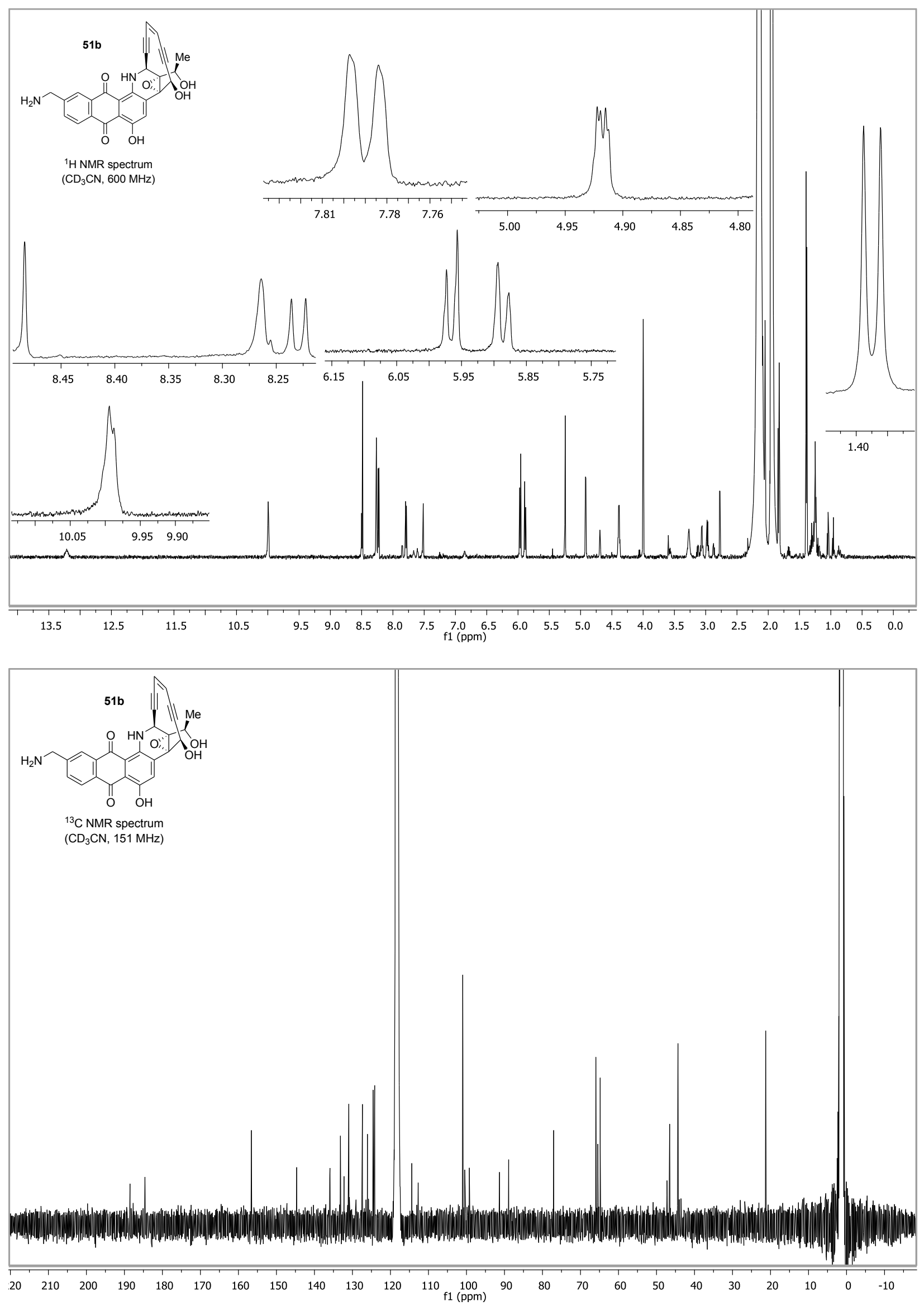

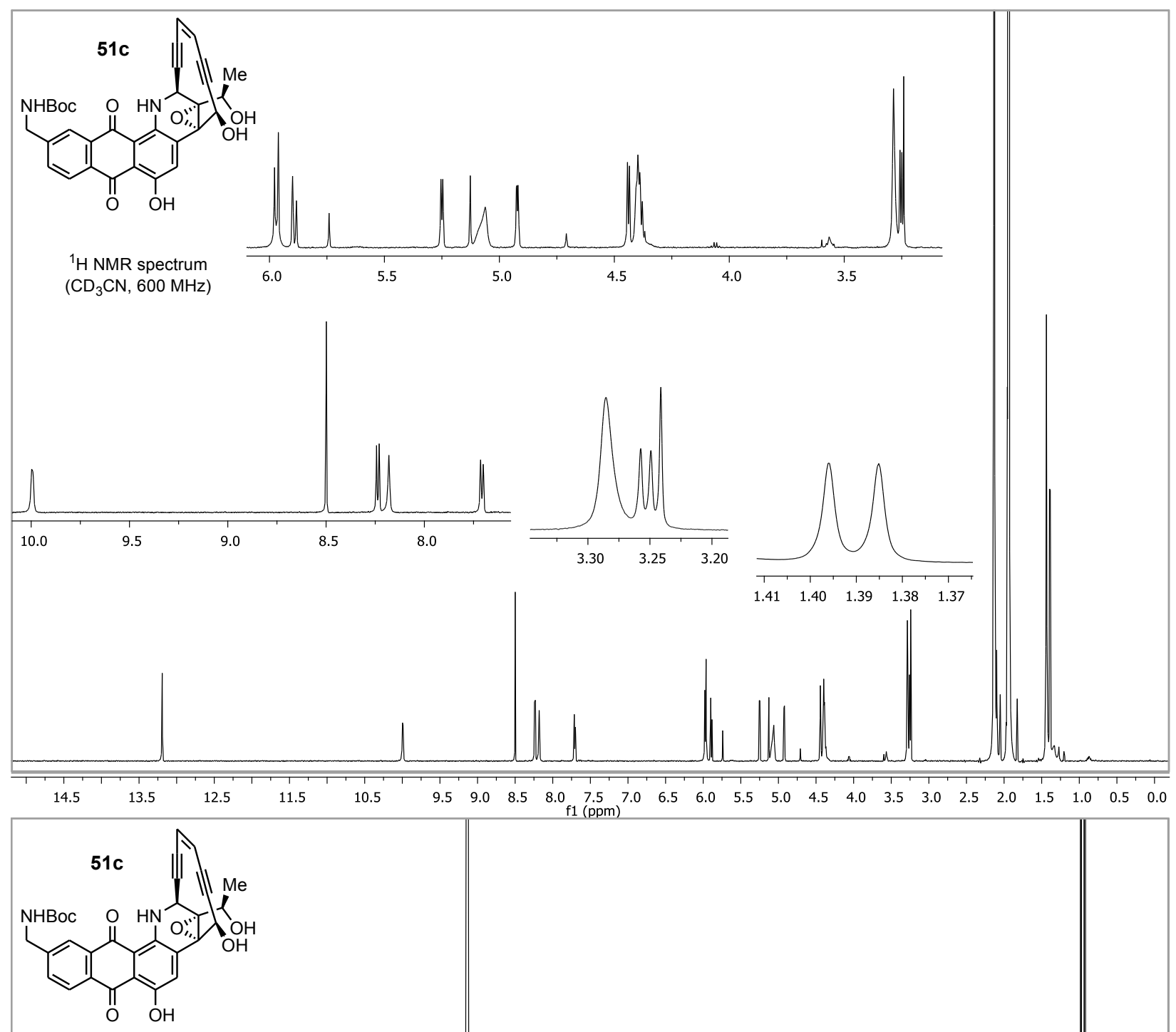

${ }^{13} \mathrm{C}$ NMR spectrum $\left(\mathrm{CD}_{3} \mathrm{CN}, 151 \mathrm{MHz}\right)$

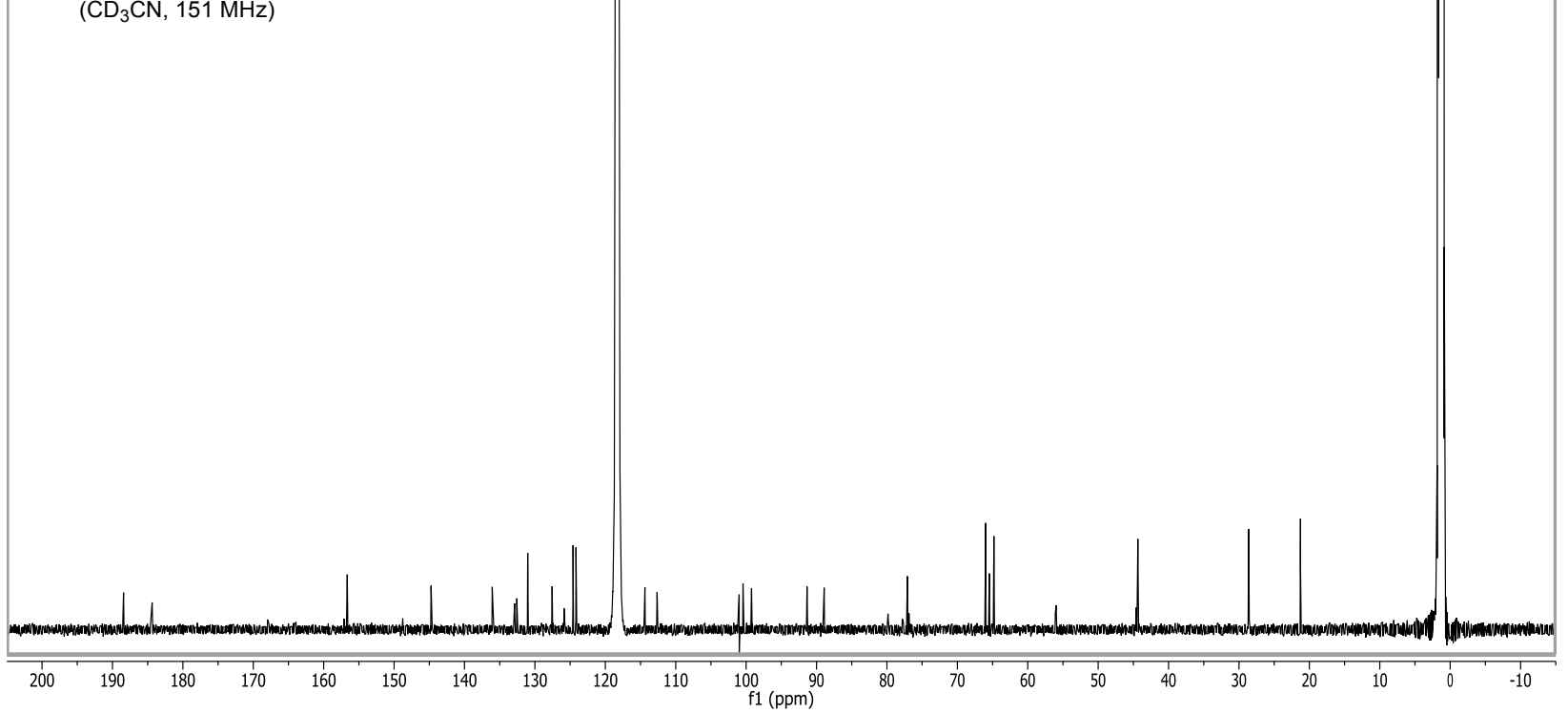






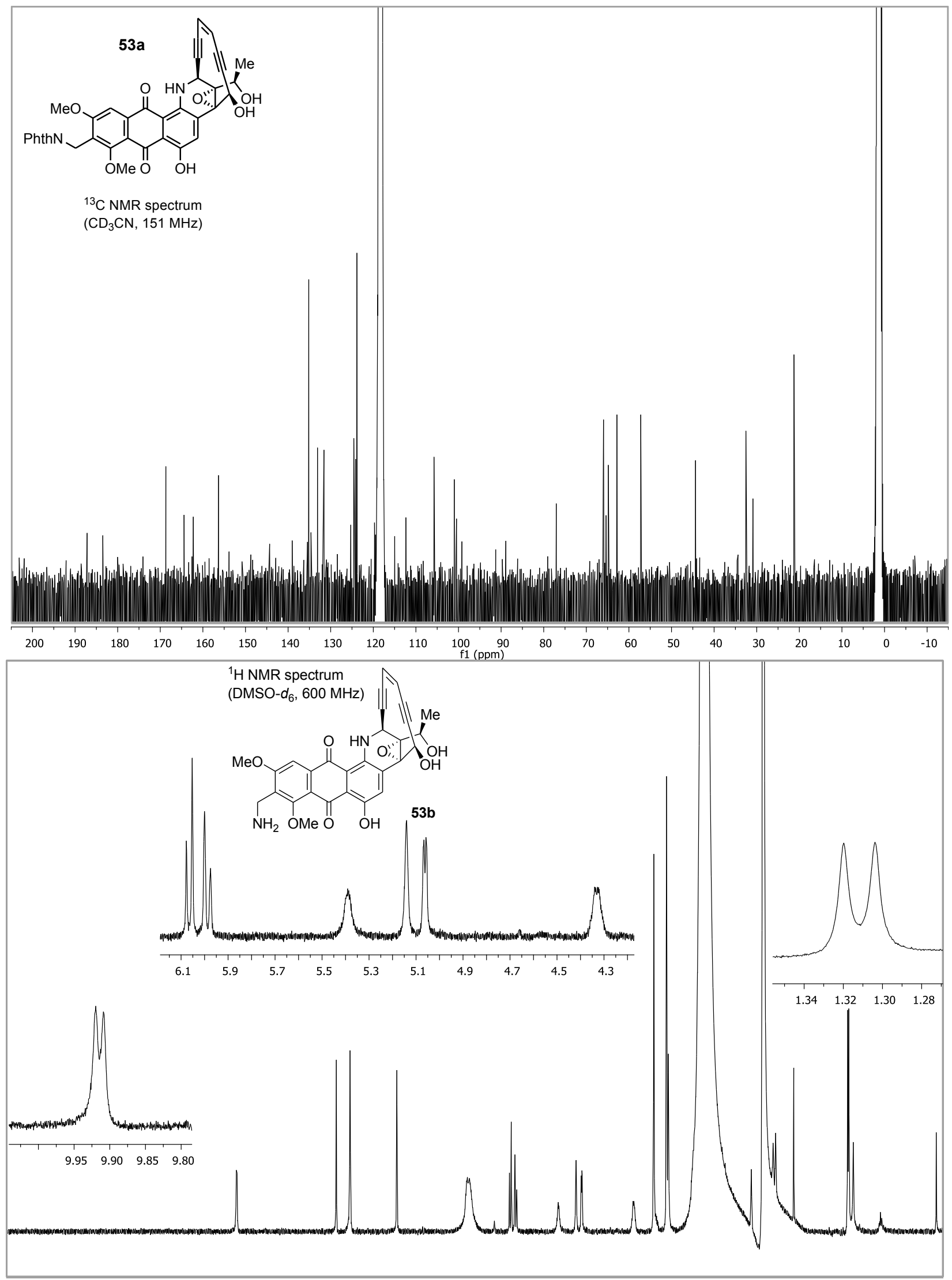

\begin{tabular}{llllllllllllllllllllllllllllllll}
\hline 13.0 & 12.5 & 12.0 & 11.5 & 11.0 & 10.5 & 10.0 & 9.5 & 9.0 & 8.5 & 8.0 & 7.5 & 7.0 & 6.5 & 6.0 & 5.5 & 5.0 & 4.5 & 4.0 & 3.5 & 3.0 & 2.5 & 2.0 & 1.5 & 1.0 & 0.5 & 0.
\end{tabular} 

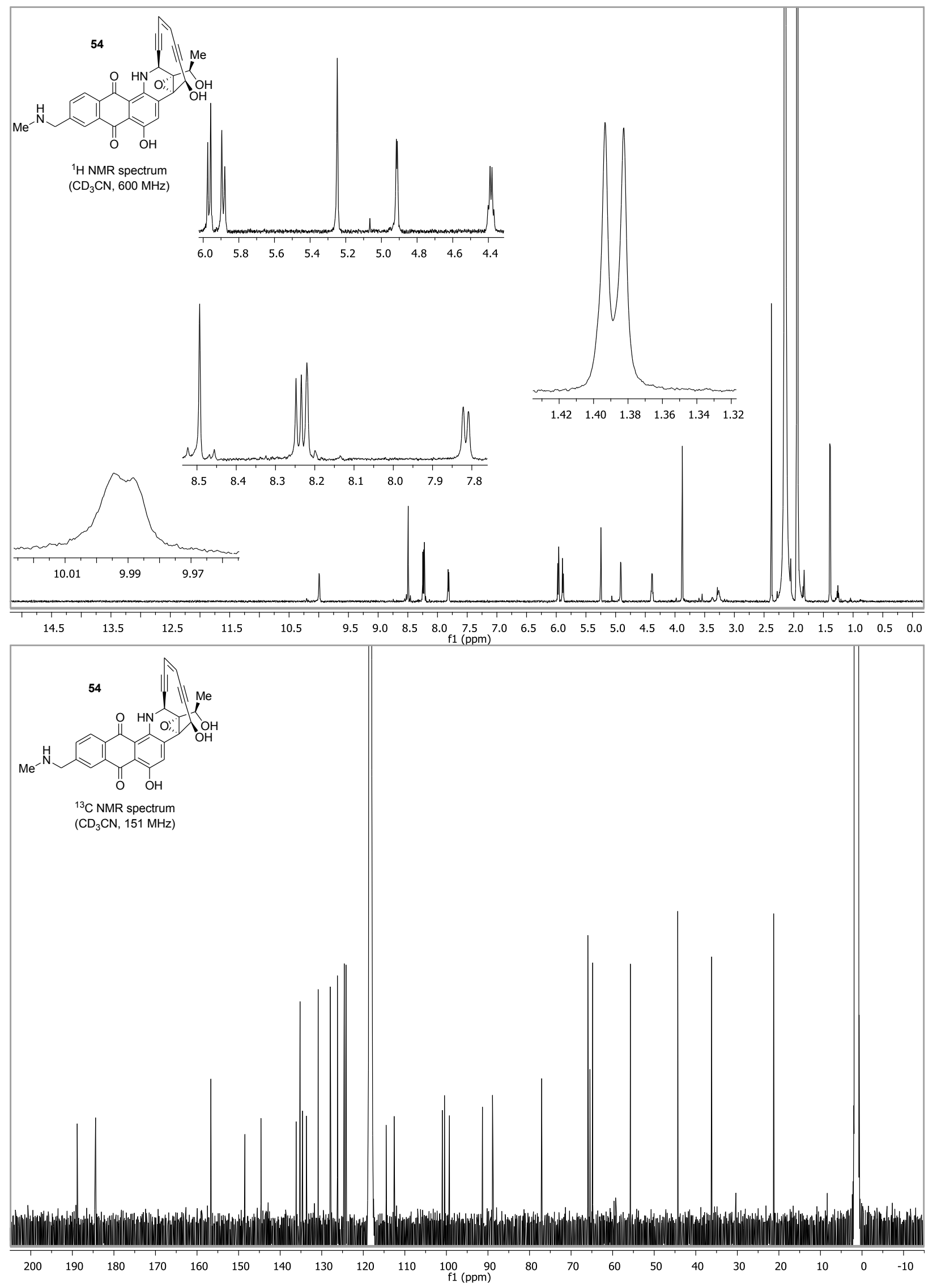

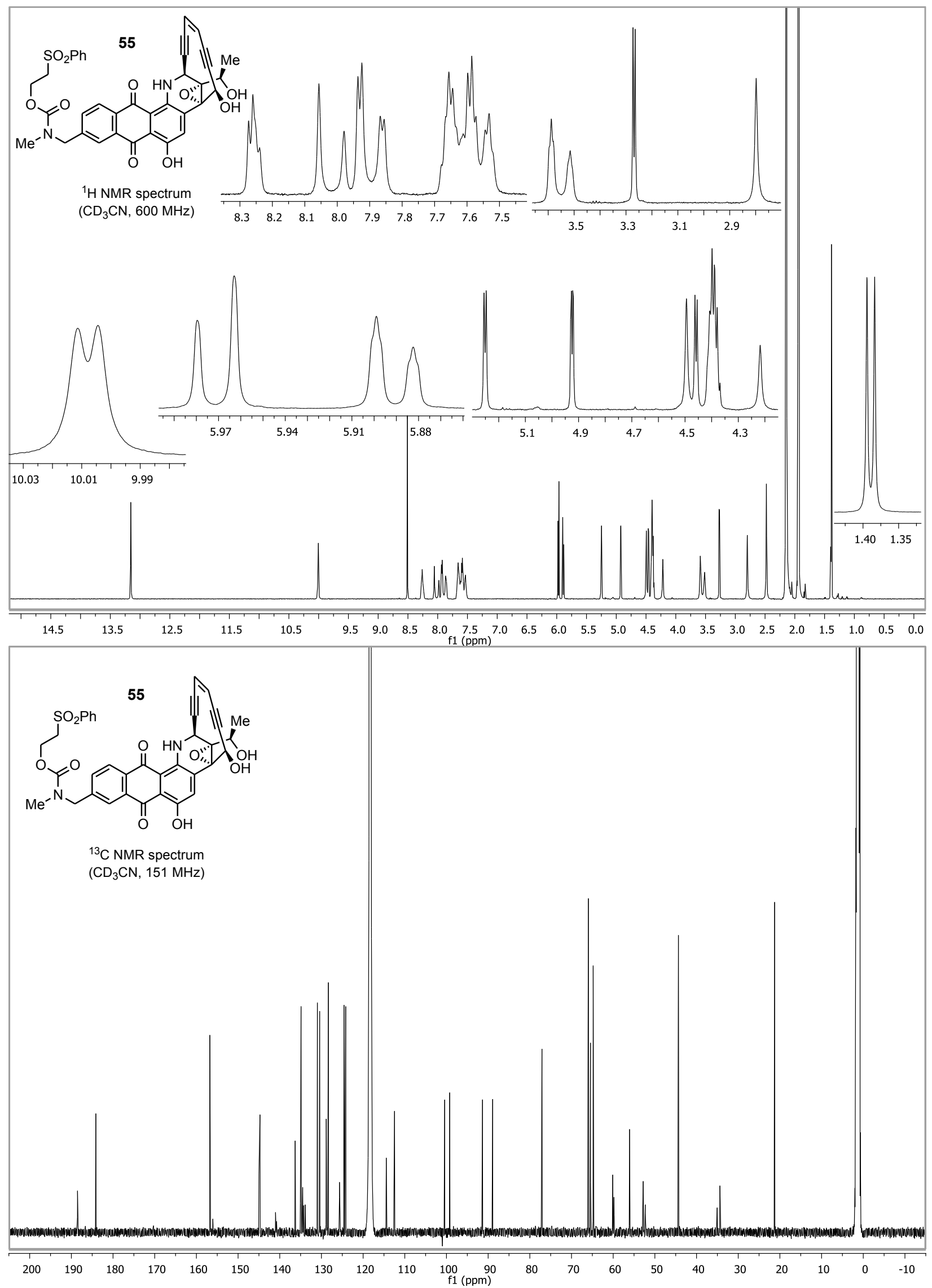

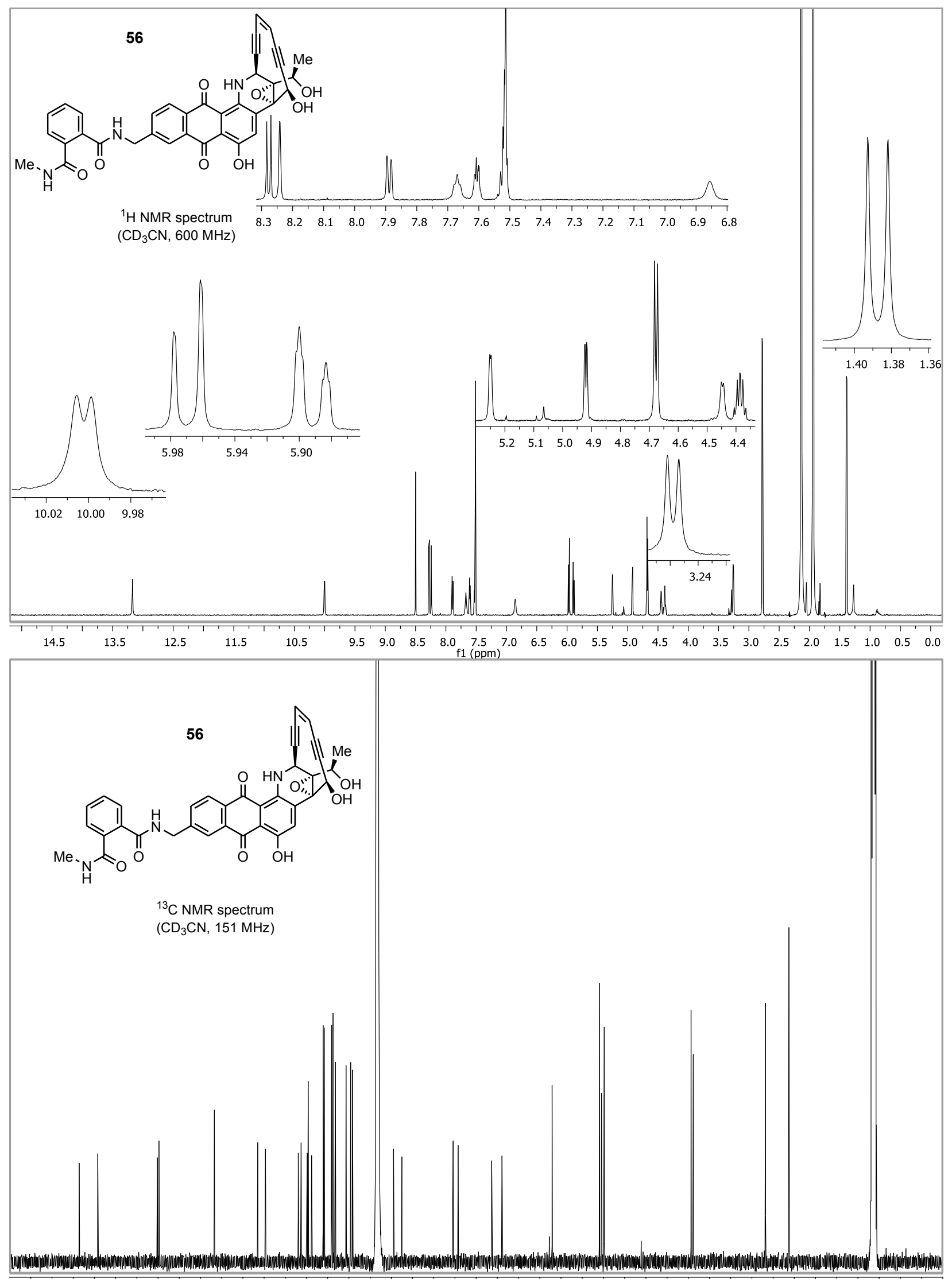

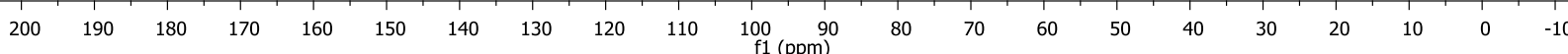



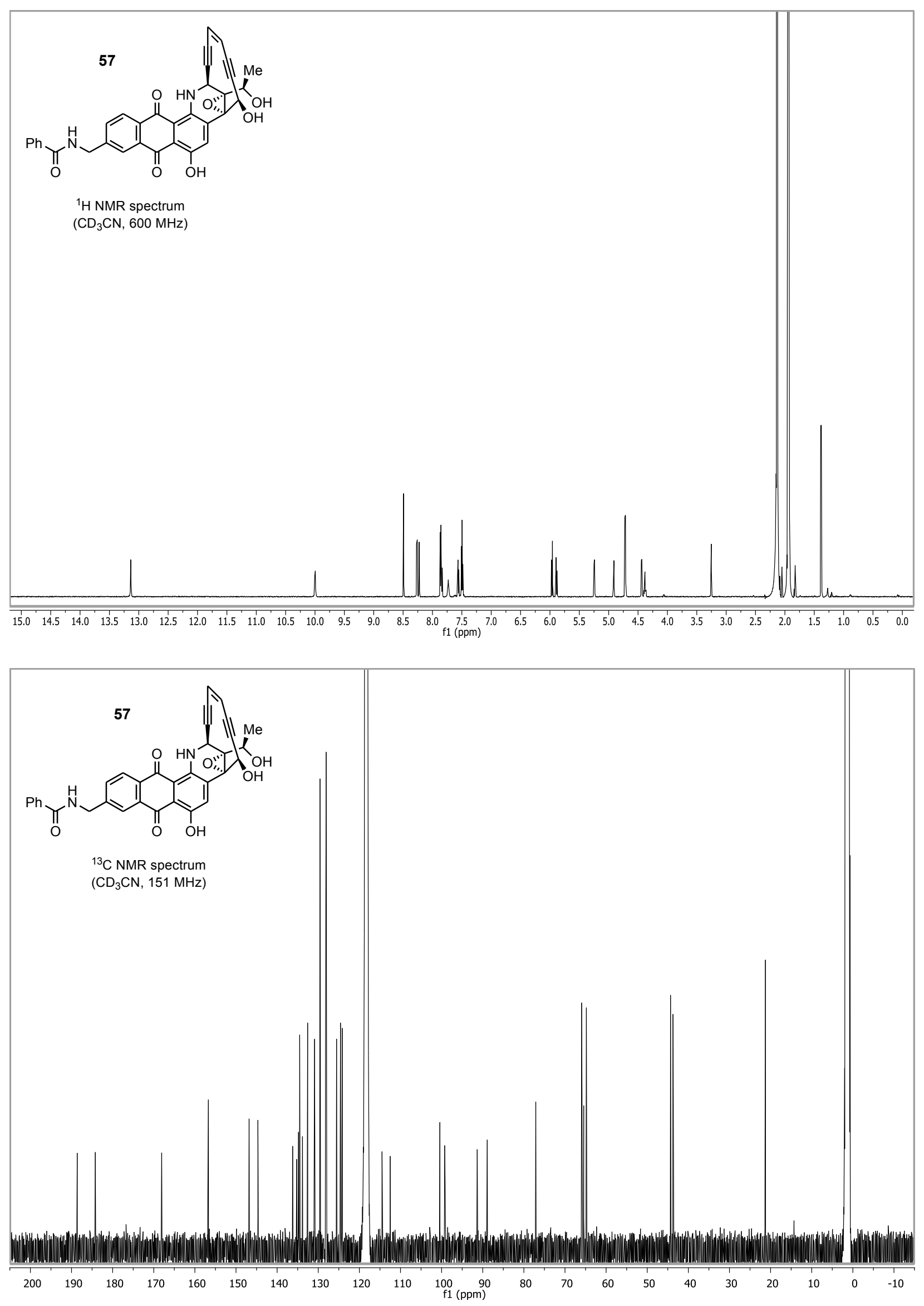

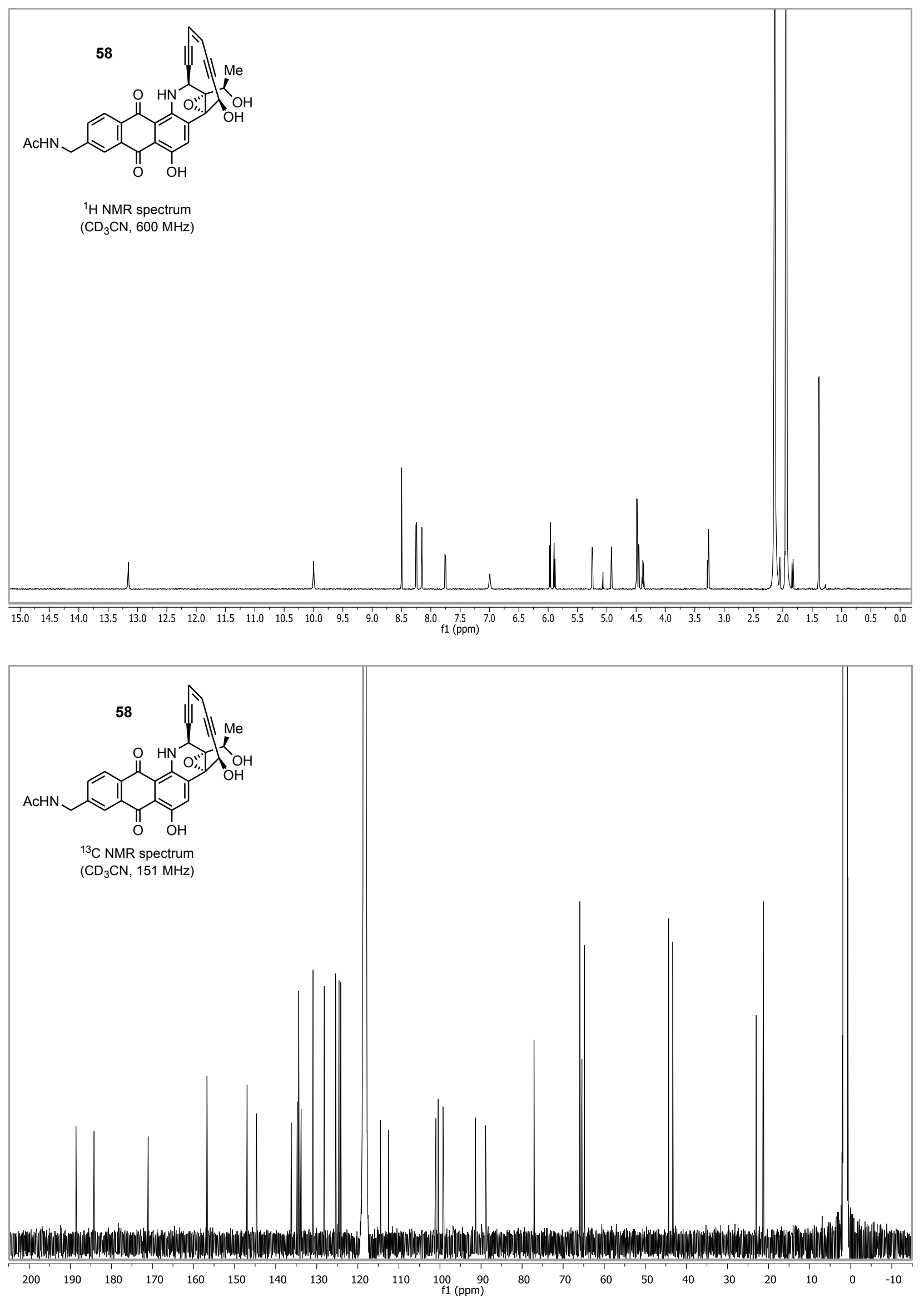

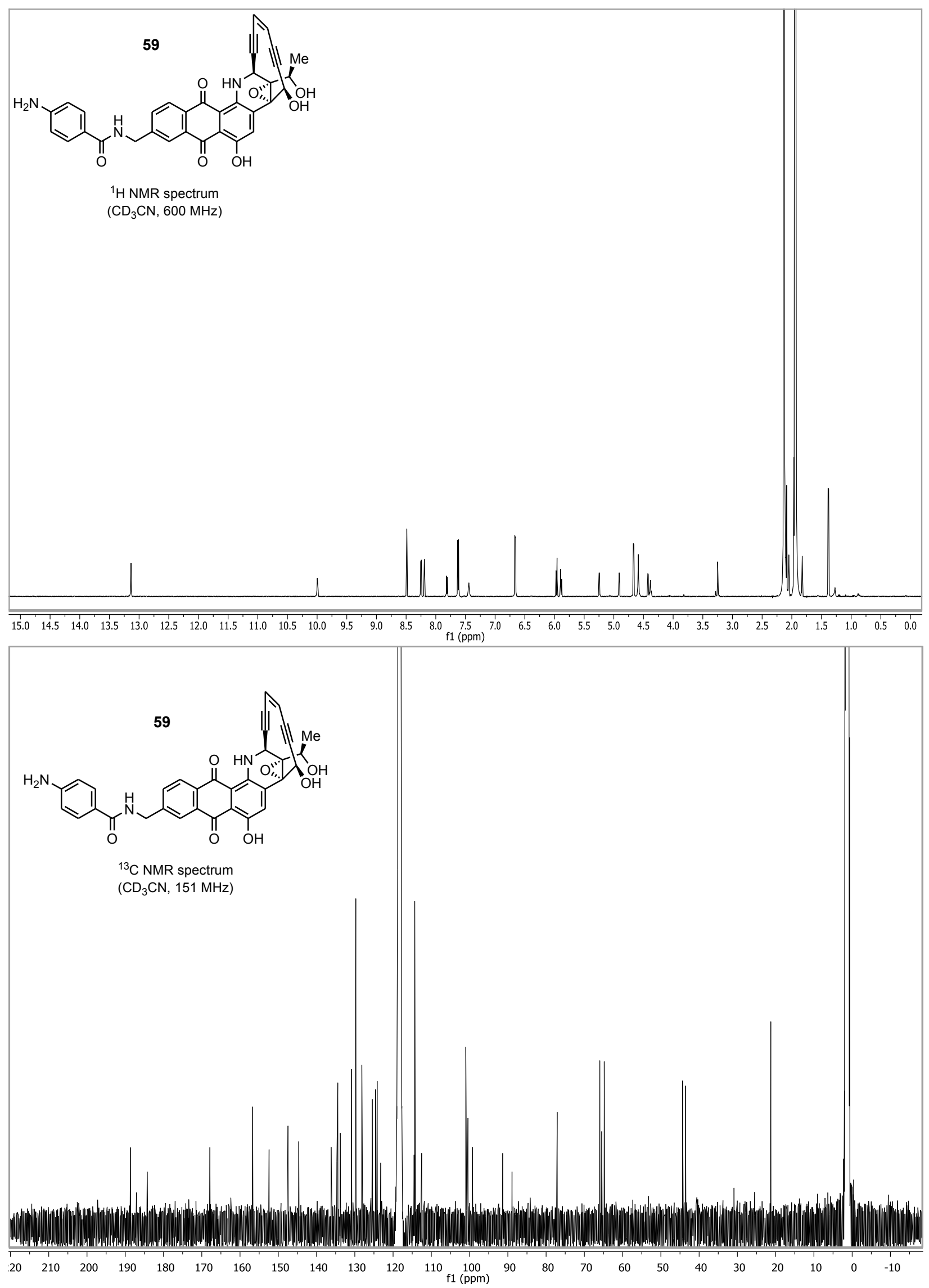


\section{References}

1. Pangborn, A. B.; Giardello, M. A.; Grubbs, R. H.; Rosen, R. K.; Timmers, F. J. Organometallics 1996, 15, 1518-1520.

2. Still, W. C.; Kahn, M.; Mitra, A. J. Org. Chem. 1978, 43, 2923-2925.

3. a) Nicolaou, K. C.; Zhang, H.; Chen, J. S.; Crawford, J. J.; Pasunoori, L. Angew. Chem. Int. Ed. 2007, 46, 4704-4707; b) Nicolaou, K. C.; Chen, J. S.; Zhang, H.; Montero, A. Angew. Chem. Int. Ed. 2008, 47, 185-189. c) Chen, J. S. PhD Thesis, The Scripps Research Institute, 2008.

4. (a) Hartung, I. V.; Eggert, U.; Haustedt, L. O.; Niess, B.; Schaefer, P. M.; Hoffmann, H. M. R. Synthesis 2003, 1844-1850. (b) Waser, J.; González-Gómez, J. C.; Nambu, H.; Huber, P.; Carreira, E. M. J. Org. Lett. 2005, 7, 4249-4252.

5. (a) Lu, Y.-F.; Harwig, C. W.; Fallis, A. G. J. Org. Chem. 1993, 58, 4202-4204. (b) Lu, Y.-F.; Harwig, C. W.; Fallis, A. G. Can. J. Chem. 1995, 73, 2253-2262.

6. Davies, J.; Wang, H.; Taylor, T.; Warabi, K.; Huang, X.-H.; Andersen, R. J. Org. Lett. 2005, 7, 5233-5236.

7. Neudeck, H. K. Monatsh. Chem. 1996, 127, 201-217.

8. Newcomb, M.; Moore, S. S.; Cram, D. J. J. Am. Chem. Soc. 1977, 99, 6405-6410.

9. Nicolaou, K. C.; Dai, W.-M.; Tsay, S.-C.; Estevez, V. A.; Wrasidlo, W. Science 1992, 256, 1172-1178.

10. Liscovitch M.; Ravid D. Cancer Lett. 2007, 245, 350-352.

11. Batist, G.; Tulpule, A.; Sinha, B. K.; Katki, A. G.; Myers, C. E.; Cowan, K. H. J. Biol. Chem. 1986, 261, 15544-15549.

12. Alvarez M.; Paull K.; Monks A.; Hose C.; Lee J. S.; Weinstein J.; Grever M.; Bates S.; Fojo T. J. Clin. Invest. 1995, 95, 2205-2214.

13. Lee J. S.; Paull K.; Alvarez M.; Hose C.; Monks A.; Grever M.; Fojo A. T.; Bates S. E. Mol. Pharmacol. 1994, 46, 627-638. 